
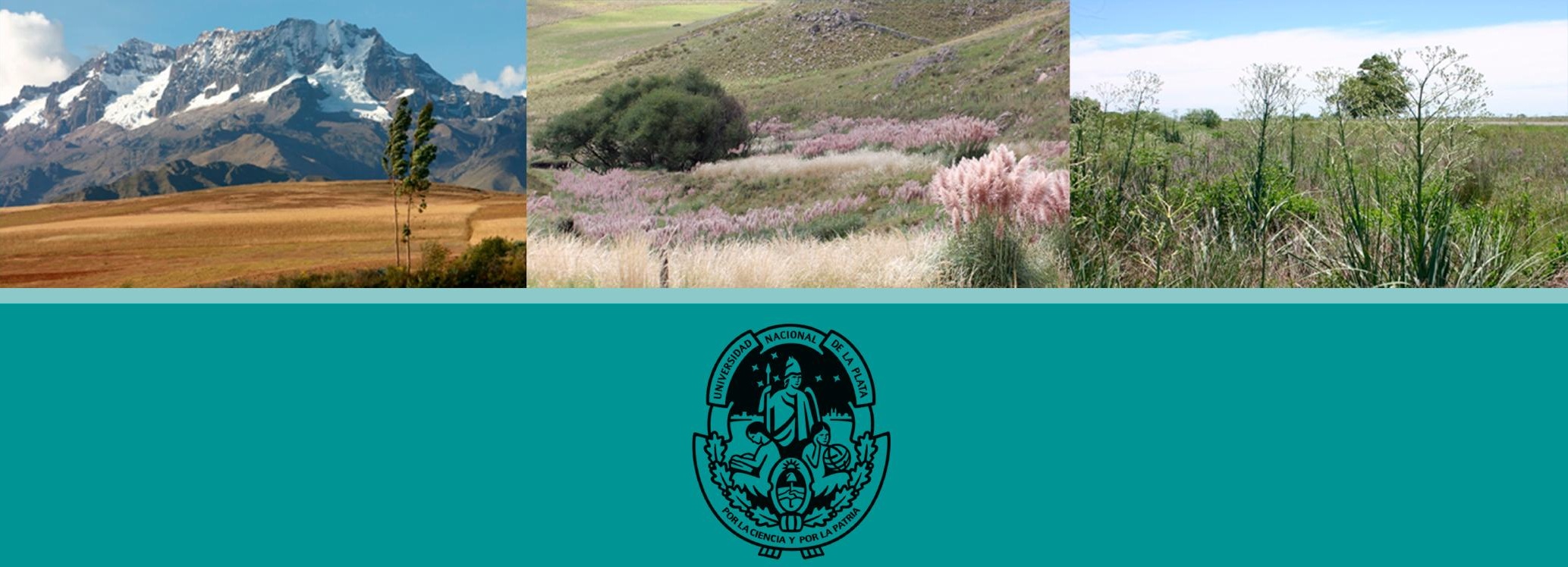

\title{
Diversificación ecológica y evolutiva en la tribu Dichroplini (Acrididae: Melanoplinae) y su correspondencia con patrones de distribución
}

Tesista: Scattolini, María Celeste

Directoras: Cigliano, María Marta

Confalonieri, Viviana Andrea.

(19) MUSEO DE LA PLATA

UNLP | Facultad de Ciencias Naturales y Museo

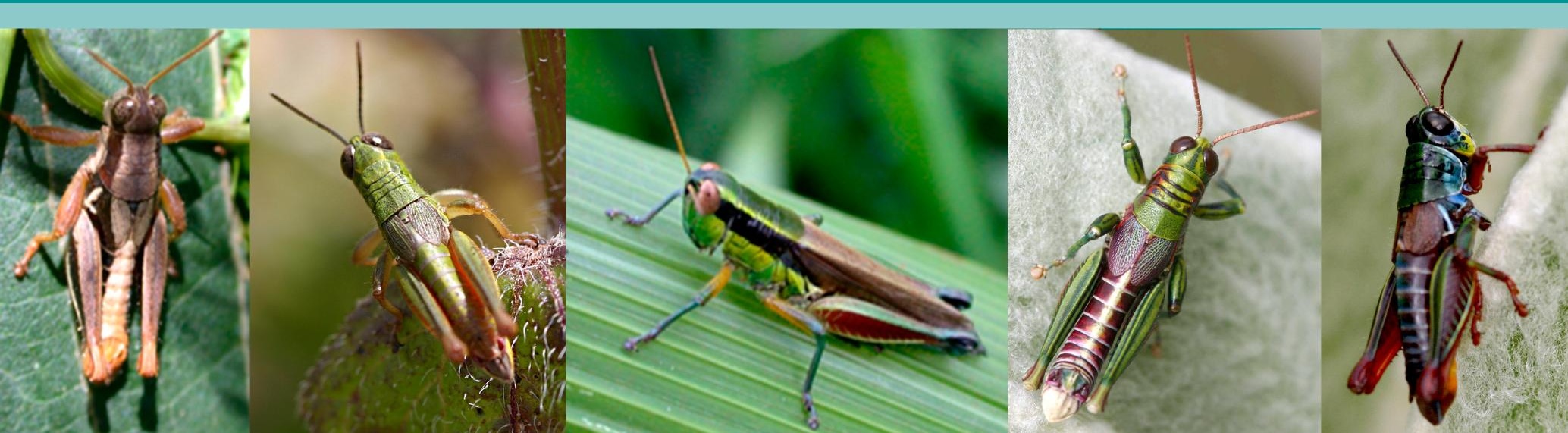


Trabajo de Tesis Doctoral

\title{
Diversificación ecológica y evolutiva en la tribu Dichroplini (Acrididae:
}

Melanoplinae) y su correspondencia con patrones de distribución

Scattolini, María Celeste

\author{
Directoras: \\ Cigliano, María Marta \\ Confalonieri, Viviana Andrea
}




\section{ÍNDICE}

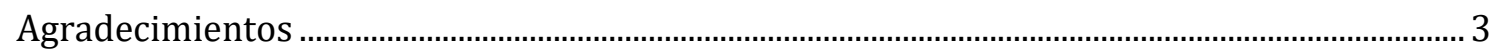

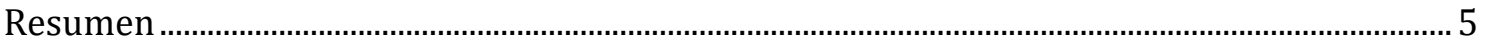

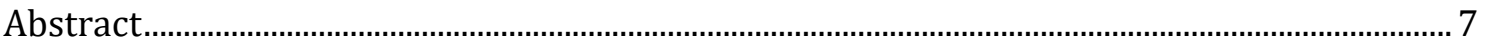

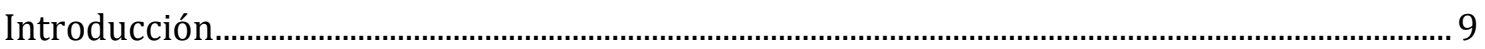

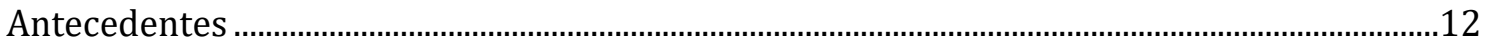

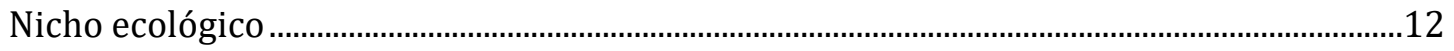

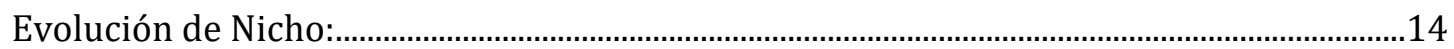

Señal filogenética, conservadurismo, divergencia .....................................................................14

Procesos geohistóricos de Sudamérica......................................................................................15

Biomas considerados: delimitación de las áreas de estudio ......................................................18

Grupo de estudio: Tribu Dichroplini .............................................................................................23

Capítulo 1: Diversificación del Género Orotettix (Orthoptera: Acrididae)..................................26

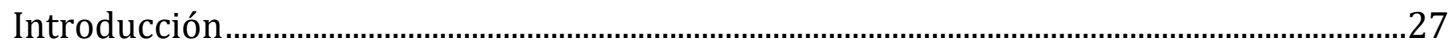

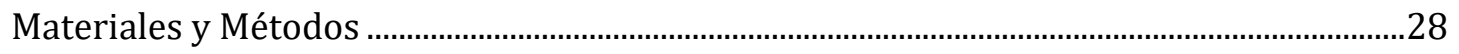

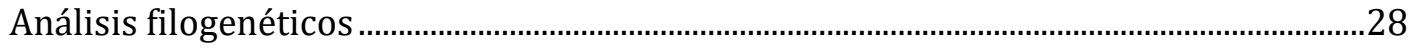

Registros de ejemplares y distribución geográfica ……………………………………….....29

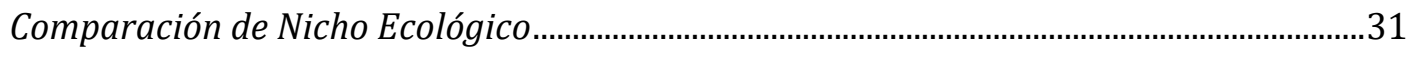

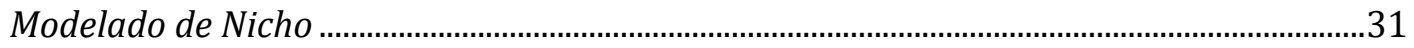

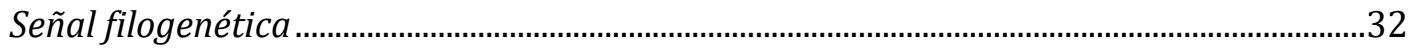

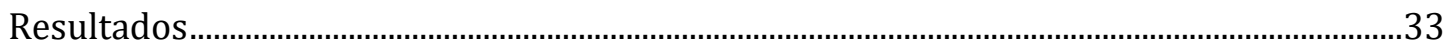

Análisis filogenético ...................................................................................................................33

Variables Bioclimáticas ..........................................................................................................33

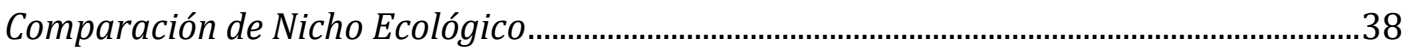

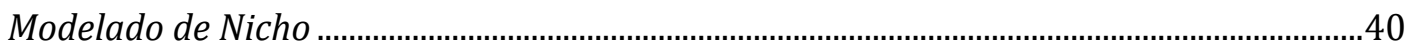

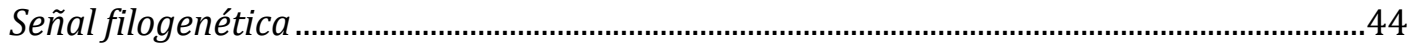

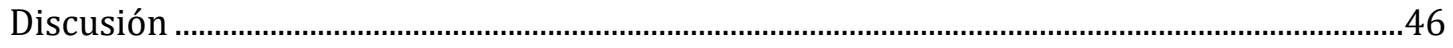


Relaciones filogenéticas y diversificación de especies.

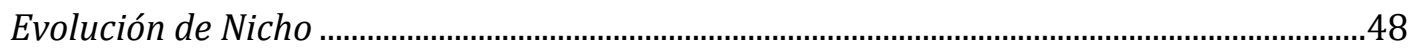

Capítulo 2: Diversificación del grupo de géneros Scotussae (Orthoptera: Acrididae)............50

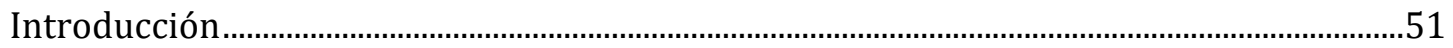

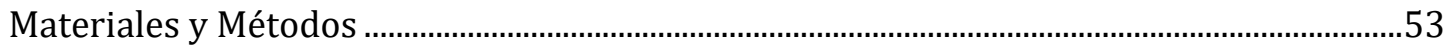

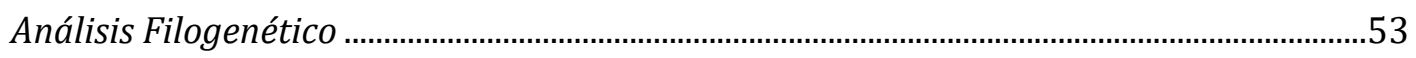

Registros de Ejemplares y Distribución Geográfica................................................................59

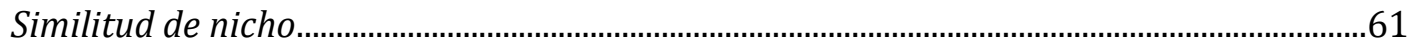

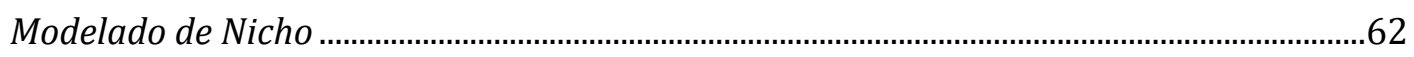

Biogeografía histórica del grupo Scotussae ..........................................................................64

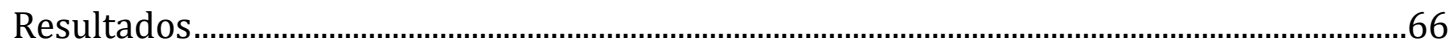

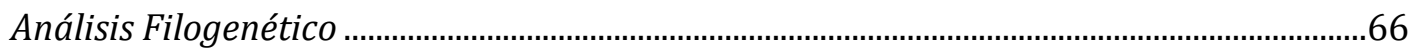

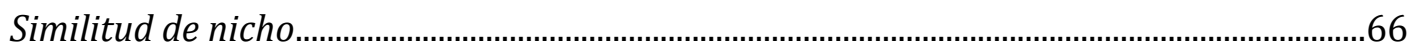

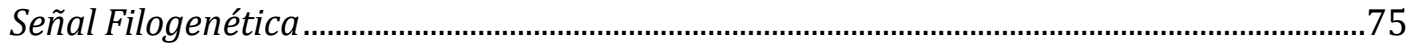

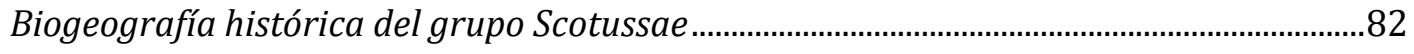

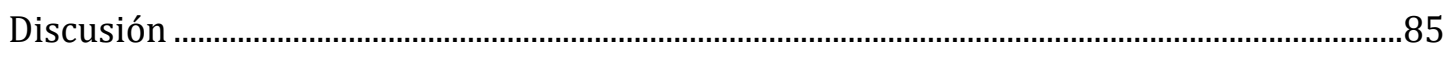

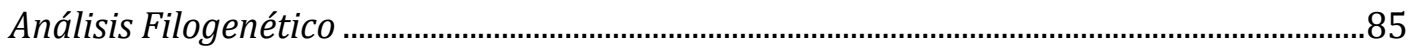

Patrones de diversificación del grupo Scotussae …………………………………...............85

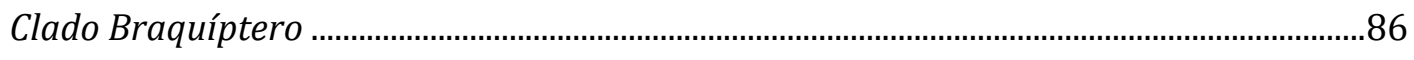

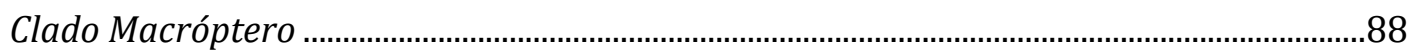

Capítulo 3: Diversificación de la tribu Dichroplini.............................................................................92

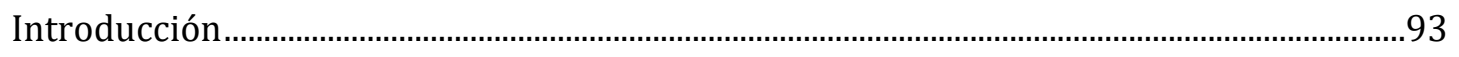

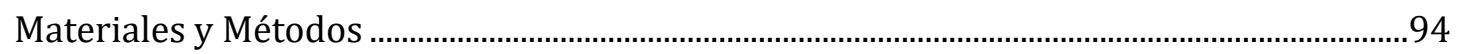

Registros de ejemplares; Distribución Geográfica y registro de desarrollo alar ................94

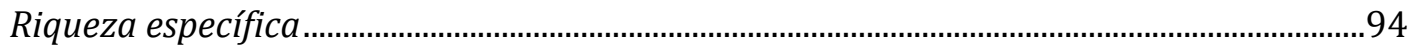

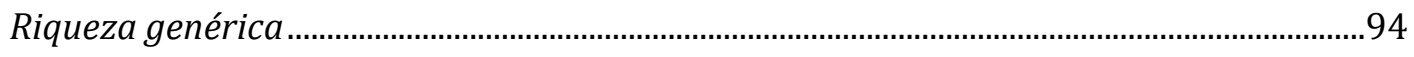

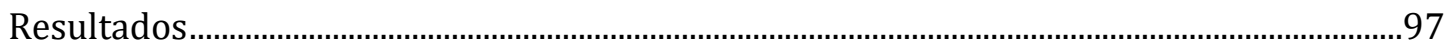

Registros de ejemplares y Distribución Geográfica ..................................................................97

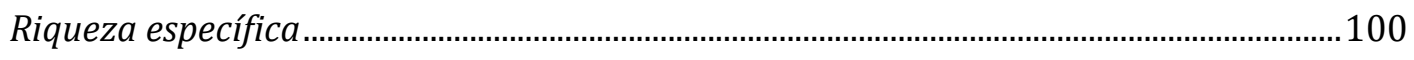




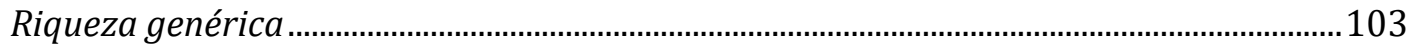

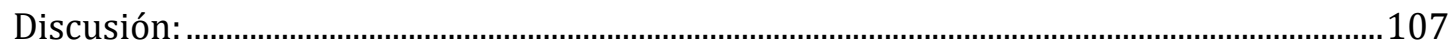

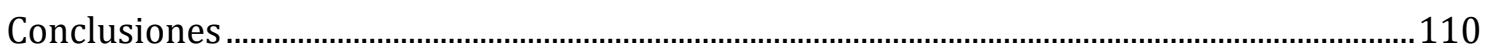

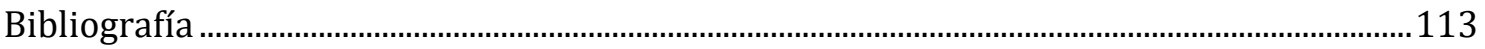

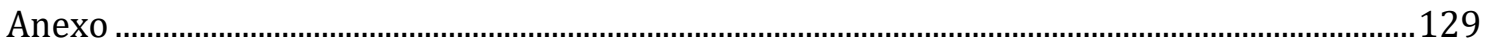




\section{Agradecimientos}

Siento que mi primer agradecimiento debe ser a la educación pública, gratuita y de calidad. Sin ella mis padres no hubiesen podido, aun así con muchísimo esfuerzo, estudiar y recibirse en la UNLP. Yo también tuve el placer de estudiar en una escuela pública e ingresar posteriormente a la FCNyM, a la cual le debo mi título de licenciada en Biología y donde hoy me encuentro finalizando mi Doctorado.

Es imposible agradecer a todas las personas que han tocado mi vida en estos últimos años, pero como dice mi compañero, las cosas se muestran con hechos. Voy a decir unas palabras, pero lo que espero es poder estar con toda la gente que me ayudo, de la misma manera que ellos estuvieron cuando los necesité.

A María José Apodaca y Jorge Crisci por guiarme hacia el hermoso grupo de trabajo del cuál hoy formo parte.

Un particular agradecimiento a mis directores, María Marta, Viviana y Carlos, que aceptaron acompañarme en este arduo pero fascinante camino que es la tesis doctoral, y lo hicieron siempre con todo su cariño y sabiduría. Particularmente quiero agradecerle a María Marta que decidió aceptarme dentro de su excelente grupo de trabajo, dándome un lugar hermoso donde poder trabajar de la mejor manera. Me ayudó a encontrar mi voz dentro de la ciencia y cuando la encontré me acompaño en mis proyectos, apoyándome en todo y guiándome con muchísimo respeto y afecto.

A mis compañeros de laboratorio, Holger Braun y Hernán Pereira, que me han ayudado siempre, compartiendo discusiones sobre conceptos, revisiones de redacción, ideas sobre trabajos, scripts de R e infinitas cosas más hacen que se disfrute el día a día.

A Nélida Caligaris, Julián Lange y Silvia Pietrokovsky, por la indispensable ayuda técnica y su infinita paciencia, en la preparación de materiales, planillas y enseñarme a realizar la extracción y amplificación de las secuencias genéticas.

A Estrellita Lorier y Klaus Riede, por brindarme materiales necesarios para mi trabajo de tesis.

A la Orthoptera Species File (OSF), que me otorgó una beca para realizar muestreos dentro del marco de mi tesis. 
A Andrés Lira-Noriega, con quien tuve el placer de realizar una pasantía y aprender muchísimo, lo cual me permitió reevaluar muchos de los aspectos de mi tesis y reorientarme hacia nuevos horizontes.

A los Risso, que apostaron por mí, me invitaron a formar parte de su cátedra y su vida, con su maravillosa forma de ser. A Miguel por ser mi maestro en la bioestadística, la relación docentes-alumnos (principalmente humana) pero especialmente por mostrarme que hay otra forma de tomarse la vida.

A María José Iglesias quien me ayudó a escucharme, conocerme y aceptarme, lo que me permitió cambiar el rumbo de mi vida y llegar al hermoso lugar que llegue hoy.

A Elio y Yani, grandes compañeros y amigos, con quienes tuve la buena ventura de compartir trabajos y viajes y espero seguir compartiendo muchos más.

A mis amigas y amigos del alma, (Naza, Grego, Belu, Jupi, Beto, Guada, Sara y Matu). Todos me ayudaron y enseñaron a cada paso de la tesis, desde los ratos en la terraza resolviendo dudas, un almuerzo compartido o una llamada telefónica.

A mi hermosa familia, pero mucho más particularmente a mamá y papá, que me acompañaron en todo, brindándome todo lo que tenían para dar y muchas veces más. Me hicieron sentir muy acompañada y amada, también en mi elección del camino que amo, la Biología y la Investigación. A mis hermanas, mis compañeras de camino de siempre y hasta siempre, mis faros en la neblina, mis pilares.

A mi familia política, que más que política ha sido adoptiva, me abrieron las puertas de su hogar y desde el primer día me hicieron sentir una más de la familia. Me escucharon, ayudaron y acompañaron siempre, haciéndome sentir su comprensión y afecto.

Y por último, a mi mejor amigo y compañero, Facu. Es muy difícil agradecer las miles de cosas que hace día a día para acompañarme en el desarrollo en mi pasión. Es mi roca, mi cable a tierra, cada día más juntos y más compañeros. 


\section{Resumen}

En este trabajo de tesis, se aplica un enfoque biogeográfico integrativo al estudio de la diversificación de la tribu Dichroplini, en el cual se analizan simultáneamente tres fuentes de evidencia (tiempos de diversificación, relaciones filogenéticas y evolución geográfica), incorporando la información ecológica en la reconstrucción biogeográfica. El estudio se realiza a distintos niveles jerárquicos (específico, dentro del género Orotettix; genérico, dentro del grupo Scotussae y a nivel tribal) y en diferentes áreas geomorfológicas de Sudamérica.

En el primer capítulo se desarrolla el estudio del género andino Orotettix para el cual se realizó un análisis filogenético molecular, basado en tres fragmentos genéticos (COI, ND2, H3) y 28 ejemplares que representaron nueve de las diez especies del género, más tres especies de Dichroplini elegidas como outgroup. Se evaluó la similitud y el grado de superposición de nicho realizado entre sus especies. También se generaron modelos de nicho ecológico para determinar el nicho ambiental y las distribuciones potenciales. Se analizó la asociación entre las relaciones filogenéticas y la superposición de nicho, las distancias ambientales y las distancias geográficas. Debido a la falta de señal filogenética y la evidencia obtenida a partir de los patrones biogeográficos y ecológicos encontrados en este estudio, se considera que la diversificación en Orotettix pudo haber sido consecuencia del aislamiento geográfico, combinado con oportunidades ecológicas dadas por los hábitats emergentes resultado del surgimiento de los Andes. La topografía compleja del paisaje, unido a las fluctuaciones del Cuaternario desencadenadas por las glaciaciones, podrían haber llevado a la diferenciación de las especies braquípteras, altamente endémicas de Orotettix.

El segundo capítulo trata sobre la diversificación del grupo de géneros Scotussae. Es un grupo diverso, habitante de la cuenca Parano-Platense que presenta especies tanto braquípteras como macrópteras, con variación en la forma del ovipositor y re-arreglos cromosómicos complejos. En este grupo se realizó un análisis filogenético combinado de 50 ejemplares que representaron 24 especies de las 48 especies del grupo, considerando los mismos fragmentos genéticos que en el capítulo anterior y añadiendo la evidencia morfológica. Se realizaron los mismos análisis de similitud y modelado de nicho ecológico que en el estudio del género Orotettix, complementándolos con el estudio de la señal filogenética de las variables ambientales y un análisis de estimación del rango ancestral. Los resultados de estos estudios revelaron que la ecología habría tenido un rol principal 
en la diversificación del grupo Scotussae, ya que las relaciones filogenéticas presentan una mayor asociación con las variables ambientales que con las distancias geográficas. Dentro del grupo se recuperaron dos clados principales (clado Braquíptero/clado Macróptero) con patrones de diversificación diferentes, que podrían estar, al menos en parte, relacionados con el desarrollo alar. La diversificación del grupo de géneros Scotussae habría ocurrido durante el Plioceno en el bioma abierto del Bosque Tropical Seco Estacional (BTSE). Se considera que los procesos geohistóricos ocurridos en el BTSE durante las últimas glaciaciones podrían haber jugado un papel predominante en la especiación alopátrida que habría sufrido el clado Braquíptero. Sin embargo y en función de los resultados obtenidos se considera que el principal evento de diversificación del clado Macróptero podría haber sido la especiación simpátrida, encontrándose principalmente indicios de especiación ecológica y barreras citogenéticas determinantes para la diversificación del clado.

En el tercer capítulo se analiza la diversificación a nivel de la tribu en todo su ámbito de distribución, donde se evaluaron los patrones de diversidad de las especies (163) y géneros (28), analizando su riqueza, amplitud de rango y amplitud de nicho ecológico. Los resultados sugieren que los centros de diversificación de la tribu Dichroplini coincidirían con aquellos mencionados para el grupo (Andes Septentrionales y cuenca Parano-Platense), sumándose un tercer centro evolutivo en la región de los Andes Centrales. Los Andes se caracterizan por presentar especies braquípteras, con amplitudes de nicho y rangos de distribución reducidos, con un alto grado de endemismo y elevada riqueza regional. El centro evolutivo de la cuenca Parano-Platense presenta la mayor diversificación de la tribu, encontrándose la mayor riqueza en el Bosque Atlántico Paranense y Chaco Húmedo del Bosque Tropical Seco Estacional (BTSE) y el Bosque de Araucarias de Bosque Lluvioso Tropical (BLT), contando esta región con especies tanto braquípteras como macrópteras con rangos de distribución variables. 


\section{Abstract}

In this thesis, an integrative biogeographic approach is applied to study the diversification of the Dichroplini tribe, analyzing simultaneously three sources of evidence (diversification time, phylogenetic relations and geographic evolution), adding the ecological information to the biogeographic reconstruction. The study is performed considering three hierarchical levels (specific, within Orotettix genus; generic, within de Scotussae genus group and tribal) in different geomorphological areas of South America.

The first chapter deals with the study of Andean genus Orotettix. A multilocus molecular phylogeny was generated based on three genetic regions (COI, ND2, H3) considering 28 specimens that represent nine of the ten species of the genus, plus three Dichroplini species selected as outgroups. Niche similarity tests and the degree of niche overlap were estimated between its species. Ecological niche models were generated assessing the realized ecological niche and the potential distribution. Phylogenetic signal between the phylogenetic relatedness and the niche overlap, the geographic and the environmental distances were analyzed. Based on the lack of phylogenetic signal and the evidence obtained from the biogeographic and ecological patterns found in this study we consider that diversification in Orotettix may have been mainly driven by geographic isolation combined with ecological opportunities afforded by the emergence of island-like habitats after the Andean uplift. The complex landscape topography enhanced by Quaternary fluctuations driven by glaciations could have led to the differentiation in narrowly restricted endemisms in Orotettix species.

The second chapter deals with the diversification of the Scotussae genus group. It is a diverse group that inhabits the Parano-Platense basin, presenting both brachypterous and macropterous species, with variation in the ovipositor morphology and with complex chromosomal rearrangements. A combined phylogenetic analysis of 50 specimens, representing 24 species of the 48 species of the group, was performed considering the same genetic fragments as in the previous chapter combined with the morphological evidence. Niche similarity tests and ecological niche models were performed as mentioned for the Orotettix chapter, complementing them with the study of phylogenetic signal in the environmental variables and an analysis of the ancestral range. Our findings suggest that ecology would have played a major role in the Scotussae group diversification, since phylogenetic relationships have a greater association with environmental variables than with geographical distances. Within the group, two main clades (Brachypterous clade / 
Macropterous clade) were recovered showing evidence of different diversification patterns, which might be related to wing development. The diversification of the Scotussae genus group would have occurred during the Pliocene in the Seasonally Dry Tropical Forests (SDTF) open vegetation biome. The geo-historical events that occurred during the last glacial-interglacial cycles in the SDTF could have played a predominant role in the allopatric speciation that had suffered the Brachypterous clade. On the other hand, it is considered that the main diversification event within the Macropterous clade could have been sympatric speciation, finding evidence of ecological speciation and cytogenetic barriers.

The third chapter comprises the diversification at the tribal level. The diversity patterns of the species (163) and genera (28) were analysed considering the richness, range size and niche breadth. The results suggest that the diversification centers of the Dichroplini tribe would coincide with those mentioned for the group (Northern Andes and Parano-Platense basin), adding a third evolutionary center in the Central Andes region. The Andes are characterized by brachypterous species, with reduced niche breadths and ranges, with a high degree of endemisms and high regional richness. The evolutionary center of the Parano-Platense basin presents the greatest diversification of the tribe, finding the greatest richness in the Paranense Atlantic Forest and Humid Chaco of the Seasonally Dry Tropical Forests (SDTF) and in the Araucaria Forest of Tropical Rain Forest, characterized by brachypterous and macropterous species with variable distribution ranges. 


\section{Introducción}

La tribu Dichroplini Rehn \& Randell es la que presenta la mayor diversificación de los Melanoplinae sudamericanos, compuesta actualmente por 28 géneros y 163 especies válidas (Cigliano et al., 2018). Los miembros de esta tribu constituyen, en general, el grupo dominante tanto en número de especies como en número de individuos en la mayoría de las comunidades de tucuras de pastizal de Sudamérica (Cigliano et al., 2000) y sus especies pueden presentar distribuciones extremadamente restringidas o abarcar casi la totalidad de Sudamérica. La tribu ha sido motivo de estudios sistemáticos recientes y aunque sus relaciones filogenéticas no han sido analizadas en su totalidad, existen análisis a nivel molecular que dan cuenta de su monofilia (Amédégnato et al., 2003; Chintauan-Marquier et al., 2011). Asimismo, se considera, sobre la base de estudios filogenético moleculares, que la distribución de los Melanoplinae en Sudamérica responde, en parte, a eventos climáticos que permitieron el aumento de ecosistemas abiertos de tipo sabana durante el Eoceno temprano y geológicos, como el surgimiento de los Andes, que deben haber afectado la diversificación y dispersión de Melanoplianae Neotropicales, incluyendo los Dichroplini (Amédégnato et al., 2003; Chintauan-Marquier et al., 2011). Con respecto a los centros de diversificación, Ronderos (1981) considera que habrían existido dos centros de diversificación de Dichroplini, uno constituido en los Andes Septentrionales de Colombia y Venezuela y el otro en la zona central-sur del continente, a nivel de la cuenca ParanoPlatense donde se habría llevado a cabo la mayor diversificación del grupo. Dentro de estos centros de diversificación cada género de Dichroplini habría ocupado sectores específicos del continente con características florísticas y climáticas propias (Ronderos, 1981).

La biogeografía es el estudio de la distribución de las especies y ecosistemas en el espacio geográfico y a través del tiempo geológico. El objetivo de la biogeografía no es solo analizar los patrones de distribución de las especies, sino también descubrir los factores responsables de las variaciones de dicha distribución. La biogeografía integra los conceptos e información provenientes de la ecología, la biología evolutiva, la geología y la geografía (Sanmartín, 2012). Las distribuciones de especies y su dinámica en el tiempo resultan de las propiedades de las especies, la variación ambiental y las interacciones entre especies, y las capacidades de las especies para modificar sus entornos y alterar la dinámica de otras especies. Tradicionalmente, la biogeografía ha sido dividida en biogeografía ecológica e histórica (Morrone \& Crisci, 1995) pero esta distinción se ha 
vuelto borrosa en los últimos años (Sanmartín, 2012). Debido a la revolución de la genética molecular en la sistemática, a la mayor disponibilidad de datos de ocurrencia de las especies (Soberón et al., 1996; Graham et al., 2004; Soberón \& Peterson, 2005; Sanmartín, 2012) y a las nuevas técnicas y nuevos métodos estadísticos de modelado de nicho ecológico (Stigall \& Lieberman, 2006; Ronquist \& Sanmartín, 2011; Sanmartín, 2012), la biogeografía ha experimentado un "Renacimiento" (Riddle et al., 2008; Werneck, 2011). La biogeografía actual integra varias disciplinas, reuniendo información acerca de las limitaciones fisiológicas y ecológicas a la dispersión de los organismos hasta los fenómenos geológicos y climatológicos que operan a escalas globales y dentro de un marco evolutivo.

En este trabajo de tesis, se aplica un enfoque biogeográfico integrativo al estudio de la diversificación de la tribu Dichroplini, en el cual las tres fuentes de evidencia (tiempos de diversificación, relaciones filogenéticas y evolución geográfica) son analizadas simultáneamente, incorporando la información ecológica en la reconstrucción biogeográfica a través de técnicas del modelado de nicho ecológico (Stigall \& Lieberman, 2006), aplicando aproximaciones paramétricas (ej. Análisis Bayesianos) así como nuevos métodos estadísticos (Ronquist \& Sanmartín, 2011; Sanmartín, 2012). El estudio se realiza a distintos niveles jerárquicos (específico, genérico y tribal) y en diferentes áreas geomorfológicas de Sudamérica.

Para alcanzar el estudio de diversificación de la tribu Dichroplini, se plantearon las siguientes hipótesis de trabajo y objetivos específicos:

Hipótesis de trabajo

1. Los patrones de diversificación de la tribu diferirían según las diferentes regiones geomorfológicas que habitan sus integrantes.

2. La variabilidad en la estructura del ovipositor y el desarrollo alar estarían relacionados con los patrones de diversificación de los miembros de la tribu Dichroplini.

3. Los patrones filogenéticos, en conjunto con la diversificación geográfica y de nicho ecológico brindarían evidencia sobre los procesos de diversificación ocurridos en la tribu

4. La diversificación de la tribu Dichroplini habría ocurrido, principalmente, en dos regiones: Parano-Platense y Andes Septentrionales. 
Objetivos:

1. Realizar un análisis filogenético molecular del género Orotettix Ronderos \& Carbonell y uno combinado, incluyendo datos morfológicos, del grupo de géneros Scotussae Dinghi, Confalonieri \& Cigliano.

2. Inferir la diversificación ambiental y geográfica de las especies mediante el uso de modelos y grado de superposición de nicho ecológico

3. Relacionar los patrones filogenéticos, la variación morfológica (ovipositor y desarrollo alar) y la diversificación ambiental y geográfica con los cambios climáticos y geológicos ocurridos en las áreas de distribución del grupo.

4. Analizar los mecanismos de diversificación de la tribu Dichroplini en dos regiones geomorfológicas diferentes, los Andes y la región Parano-Platense, a partir del estudio del género Orotettix y del grupo de géneros Scotussae.

5. Relevar la diversidad y distribución geográfica de las especies y géneros de la tribu Dichroplini.

6. Comparar los patrones de diversidad y distribución geográfica con los patrones biogeográficos e hipótesis de diversificación propuestos para la tribu. 


\section{Antecedentes}

\section{NICHO ECOLÓGICO}

El término "nicho" abarca varios conceptos bajo una misma palabra (Whittaker et al., 1973; Colwell, 1992; Leibold, 1995; Chase \& Leibold, 2003; Odling-Smee et al., 2003). Posiblemente una de las razones por las cuales el término ha adquirido tantos significados es debido a que, desde la primera vez que fue utilizado, los ecólogos lo han aplicado para analizar una pregunta muy compleja: ¿qué combinaciones de factores ambientales permiten que una especie exista en una determinada región geográfica o en una comunidad biótica dada, y qué efectos tiene dicha especie sobre la comunidad/ecosistema? Esta pregunta puede ser contestada de diversas maneras, y a distintas escalas geográficas. Hutchinson (1957) definió al nicho como el hipervolumen n dimensional de variables en donde cada punto del hipervolumen corresponde a un estado de cada una de las variables que permitiría que una determinada especie exista indefinidamente. Holt (2009) lo define como el conjunto de condiciones abióticas y bióticas, en las que una especie es capaz de persistir, a diferentes escalas (por ejemplo microhábitats), incluyendo los recursos e interacciones con otras especies. Fuera del nicho, no se espera que los individuos de la especie dejen descendencia, ni que sus poblaciones persistan. Soberón (2007) definió dos clases de nicho: los nichos Grinnelliano y Eltoniano. El nicho Grinnelliano se refiere a las variables ambientales que determinan las distribuciones de especies a escala geográfica, mientras que el nicho Eltoniano se refiere a la dinámica de recursos y consumidores y las interacciones bióticas que determinan las distribuciones a escala local. Dada la estructura espacial amplia de las variables

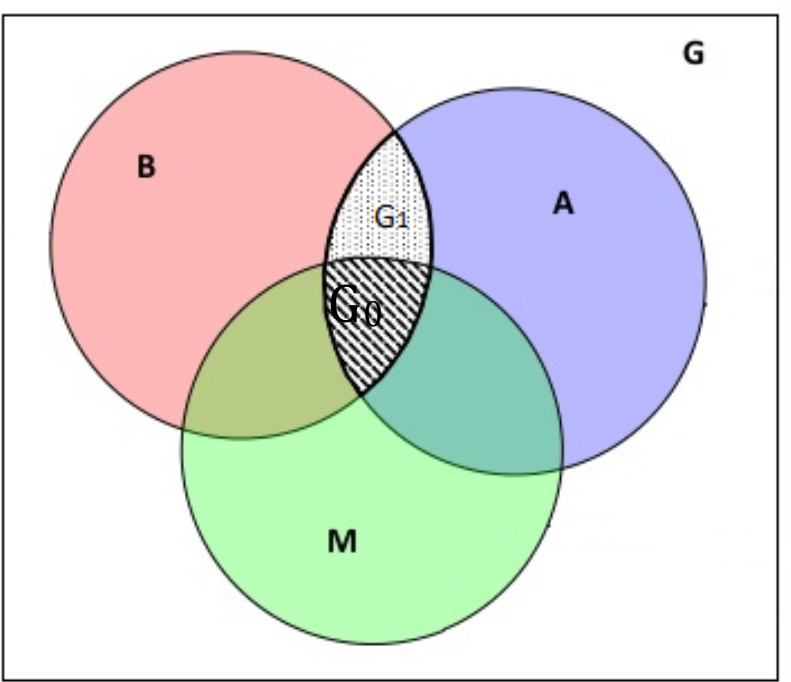

Figura 1: Diagrama BAM ambientales que definen el nicho Grinnelliano comparado con la dinámica local y compleja del nicho Eltoniano (Soberón, 2007), el estudio del primer tipo es más fácil de abordar y es así que se ha estudiado más extensamente (Peterson, 2011; Pyron et al., 2015; Olalla-Tárraga et al., 2017). El denominado diagrama de BAM (Fig. 1) (Soberón \& Peterson, 2005) ha sido ampliamente utilizado para describir la 
influencia simultánea de las condiciones ambientales, las interacciones bióticas y la dispersión. Se denomina "nicho fundamental" (representado en el diagrama por A) al conjunto de condiciones ambientales del entorno que permitirían la supervivencia y reproducción de la especie. Se denota con la letra B, la región del entorno que contiene interacciones bióticas adecuadas para la permanencia de la especie. El área accesible o región donde puede dispersarse naturalmente la especie, considerando sus tiempos evolutivos, se representa con la letra $\mathrm{M}$. El área de superposición entre A y B determina el "nicho realizado" (coloreado con gris en el diagrama), que es el subconjunto de condiciones ambientales del nicho fundamental en el cual la especie S es un competidor superior y puede persistir (Hutchinson, 1957) en el entorno que interactúa (Peterson et al., 2011). Dentro del nicho realizado, se pueden definir dos regiones importantes: el área ocupada (Go), que es la parte del entorno que cuenta con condiciones ambientales y bióticas favorables y que ha estado accesible a la especie; y el área accesible (GI) que correspondería a regiones con condiciones ambientales y bióticas favorables, pero no accesibles a la especie.

La caracterización completa del nicho ecológico es extremadamente difícil, ya que se necesita información precisa sobre los límites fisiológicos (escenopoéticos) y sobre las interacciones del uso de los recursos (bionómicas). Asimismo, si consideramos exclusivamente las condiciones ambientales, puede ser que parte del nicho fundamental de la especie no se encuentre representado en el espacio geográfico. Dada la dificultad de obtener estos datos, la mayoría de los estudios se basan en la medición de variables climáticas a partir de observaciones del espacio de nicho ocupado (Peterson \& Vieglais, 2001; Peterson, 2003; Pearson \& Dawson, 2003; Soberon \& Nakamura, 2009), y por este medio se trata de estimar el nicho fundamental. Trabajos recientes han utilizado algoritmos de estimación de nichos para tratar de obtener una aproximación al nicho fundamental (medido como «idoneidad de hábitat») y se ha empezado a asociar la abundancia de una población en relación al espacio que ocupa dentro del nicho ecológico de la especie (de Moraes \& Viveiros, 2012; Escalante \& Martínez-Meyer, 2013; MartínezMeyer et al., 2013; Siqueira et al., 2009; Torres et al., 2012; VanDerWal, 2009; YáñezArenas et al., 2012; Yáñez-Arenas et al., 2014). Este concepto ha derivado en la hipótesis del «centroide del nicho», la cual plantea que la mayor abundancia se alcanza en el centroide del nicho (región "óptima”) y conforme una población esté más alejada de éste, tenderá a presentar menor abundancia, ya que las condiciones se vuelven menos favorables hacia la periferia (Hutchinson, 1957; Martínez-Meyer et al., 2013; Blonder et al., 2014). 


\section{EVOLUCIÓN DE NICHO:}

\section{SEÑAL FILOGENÉTICA, CONSERVADURISMO, DIVERGENCIA}

La señal filogenética (SF) es una propiedad estocástica de la evolución y ha sido definida como la tendencia de aquellas especies filogenéticamente cercanas a parecerse más entre sí de lo que se asemejan especies extraídas del árbol al azar (Blomberg \& Garland, 2002). La señal filogenética existe cuando los caracteres evolucionan de manera similar al movimiento browniano, donde la cantidad y dirección de cambio, en cualquier intervalo dado, es reducida y aleatoria. Dicho patrón de evolución podría resultar de la deriva genética o de la selección natural que fluctúa aleatoriamente en tiempo, dirección y magnitud. En consecuencia, se esperaría una relación entre el grado de parentesco, cuantificado como el tiempo de divergencia entre pares de especies, y el grado de similitud entre ellas; cuanto menor sea el tiempo de divergencia entre dos especies y su ancestro, menor será la diferencia esperada entre ellas (Blomberg \& Garland, 2002). El estudio de la SF requiere la construcción de un árbol filogenético y evaluar la modificación de los caracteres bajo el modelo de Movimiento Browniano (MB) (Felsenstein, 1985). Debido a que la SF es una propiedad estocástica del árbol, muchos estudios la dan por sentada, y por lo tanto, erróneamente, no la evalúan (Webb et al., 2002; Edwards \& Donoghue, 2006). Algunos trabajos han sugerido que la falta de señal filogenética puede deberse a un fenómeno semejante a la diversificación en islas (Carlquist, 1974); donde las altas tasas de diversificación evolutiva (radiación adaptativa) junto a una cladogénesis casi simultánea (Simpson, 1953; Schluter, 2000), pueden determinar que no se detecte SF (Harvey \& Pagel 1991; Losos, 2008). En caso de que la SF sea significativa, se pueden aplicar métodos estadísticos basados en la filogenia (Blomberg et al., 2003) para determinar si los caracteres están evolucionando de una forma más lenta (lo que indicaría que existe algún tipo de restricción al cambio de dicho carácter) o más rápida de lo esperado bajo MB. Para este tipo de estudios es necesario combinar enfoques filogenéticos, geográficos y ambientales (Wiens et al., 2010) y así evaluar el cambio evolutivo (Diniz-Filho et al., 2010).

El conservadurismo de nicho ha sido definido de formas diferentes según distintos autores (Duncan \& Williams, 2002; Anderson et al., 2004; Peres-Neto, 2004; Wiens \& Graham, 2005; .Mouillot et al., 2006; Swenson et al., 2006; Johnson \& Stinchcombe, 2007). En este trabajo de tesis se aplica la definición de Losos (2008), el cual define que el conservadurismo filogenético de nicho (CFN) existe cuando las especies estrechamente relacionadas son más similares ecológicamente de lo esperado en función de sus relaciones filogenéticas; su ocurrencia sugiere que algún proceso restringe la divergencia entre especies estrechamente relacionadas. Asimismo, si especies estrechamente 
relacionadas tienden a diferir más de lo esperado por el azar, se considera que se trataría de divergencia filogenética de nicho (DFN) (Pyron et al., 2015). La mayoría de los estudios bajo esta temática se han centrado en el análisis de nichos climáticos realizados, caracterizados por la distribución geográfica de las especies (Colwell \& Rangel, 2009) y sugieren que el CFN podría ser un patrón biogeográfico generalizado (Wiens \& Graham, 2005; Wiens et al., 2010; Peterson, 2011). Sin embargo, varios estudios indican que las similitudes ecológicas y filogenéticas pueden no estar relacionadas entre sí, por lo que es importante examinar empíricamente el grado de ocurrencia. Para el estudio de la CFN y el DFN debe primero evaluarse la superposición de nicho, en función a las distribuciones geográficas (Warren et al., 2008; Broennimann et al., 2012), y complementar el estudio con un análisis de correlación entre el grado de superposición ambiental y la distancia filogenética (Knouft et al., 2006; Cardillo \& Warren, 2016)

El CFN (Peterson et al., 1999; Losos et al., 2003; Wiens, 2004; Hamlin et al., 2016) estaría implícito en la especiación alopátrica (Kozak \& Wiens, 2006; Evans et al., 2009; Couvreur et al., 2011). Sin embargo, se han citado casos donde se infiere especiación simpátrica en situaciones de CFN (Ackerly, 2003; Kozak \& Wiens, 2006) donde, complementado con otros estudios, se puede inferir un desplazamiento del nicho en algún eje no considerado en el análisis ambiental, pudiendo éste ser temporal, altitudinal o debido a algún carácter adaptativo. Asimismo, la DFN ha sido asociada a casos de especiación parapátrica o peripátrica (Graham et al., 2004; Pyron et al., 2015; Nunes \& Pearson, 2017). Sin embargo, otros estudios realizados sobre una amplia variedad de taxones han demostrado que la divergencia ecológica ha tenido un papel importante en la especiación simpátrica (Feder, 1998; Lu \& Bernatchez, 1999; Rundle et al., 2000; Schliewen et al., 2001; Vía, 2001).

En función a lo aquí planteado se considera que resulta indispensable identificar la concordancia entre los patrones evolutivos (topología, cronología, filogenia) con los cambios geológicos y ambientales, para poder determinar aquellos mecanismos/procesos que actúan en la especiación de la tribu (Knowles et al., 2007; Lacey Knowles \& AlvaradoSerrano, 2010; Chan, 2011; Loera et al., 2012).

\section{PROCESOS GEOHISTÓRICOS DE SUDAMÉRICA}

Las razones de la hiperdiversidad en Sudamérica han inspirado e intrigado a los biogeógrafos, biólogos evolutivos y sistemáticos desde hace casi 200 años (Humboldt, 1820). Sudamérica ha experimentado un conjunto de eventos tectónicos y geohistóricos 
importantes (Burnham \& Graham, 1999; Potter \& Szatmari, 2009; Hoorn et al., 2010) que ha generado corredores de dispersión y/o barreras geográficas tanto a escala continental como a escala regional (Hoorn et al., 2010; Antonelli \& Sanmartín, 2011; Sanmartín, 2012). Dichos eventos han resultado en una heterogeneidad topográfica (Fig. 2) y de hábitat excepcional generando una disparidad muy marcada en la distribución de la diversidad dentro de Sudamérica, con varias regiones hiperdiversas (Myers et al., 2000). Esto ha planteado numerosos interrogantes que llevaron a abordar cuestiones claves en la evolución y la biogeografía de la región.

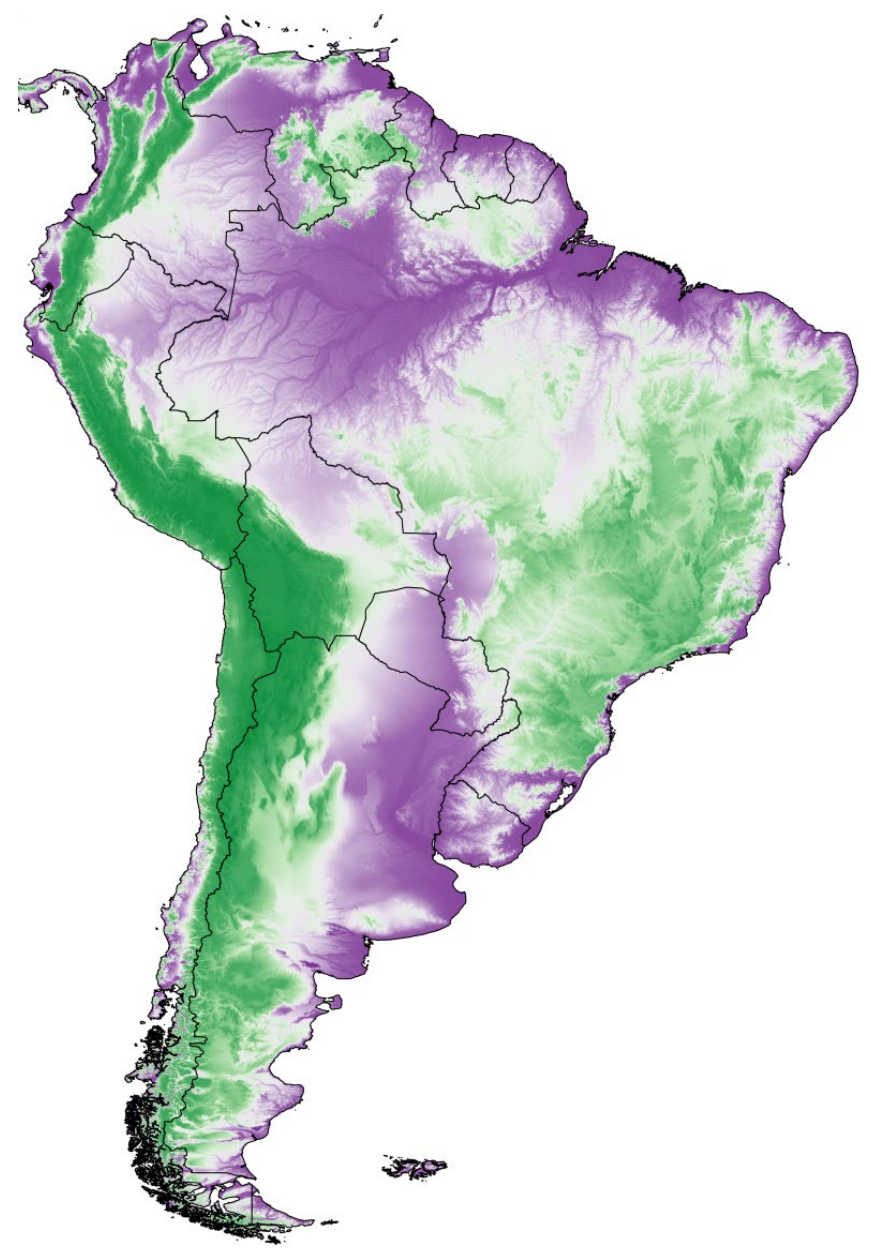

Figura 2: Mapa topográfico de Sudamérica

Durante los últimos 50 millones de años Sudamérica sufrió diversos eventos tectónicos, tanto a escala continental, con la separación y convergencia de placas tectónicas (Simpson, 1980; Stehli \& Webb, 1985; Cody et al., 2010) como a escala regional, con el comienzo del surgimiento de los Andes ( $\sim 40 \mathrm{Ma}$.) y las ingresiones marinas en el oeste de la Amazonía (Hoorn et al., 2010; Antonelli \& Sanmartín, 2011; Sanmartín, 2012). El continente Sudamericano se separó de la Antártida hace aprox. 32 Ma., dando origen al Pasaje de Drake y posteriormente colisionó con la Placa de Nazca ( 23 Ma.), resultando 
en una segunda elevación de los Andes del Norte y Centrales (Gregory-Wodzicki, 2000; Garzione et al., 2008; Hoorn et al., 2010; Graham, 2012; Le Roux, 2012). Ambos eventos, junto con la glaciación antártica occidental, determinaron un aumento del gradiente térmico desde el ecuador hacia los polos, reforzado por el anticiclón subtropical del Pacífico sur y el surgimiento de la corriente fría de Humboldt (Hinojosa \& Villagran, 1997;.Gregory-Wodzicki, 2000; Zachos et al., 2001; Hughes et al., 2013). Posteriormente, durante la mayor parte del Neógeno, se infieren largos períodos de condiciones ambientales uniformes, interrumpidos esporádicamente por períodos de cambio geológicamente cortos pero altamente disruptivos.

Es sabido que el Neógeno tardío fue un tiempo de diastrofismo y cambios globales frecuentes relativos al nivel del mar (Haq et al., 1987). Durante el Mioceno TardíoPlioceno Inferior (11 - 3 Ma. aproximadamente) se registra en el sur de Argentina, la primera evidencia de un avance glacial (Moerner \& Sylwan, 1989; Rabassa, 1999), con climas más fríos y con una estacionalidad más marcada que la ocurrida durante el Mioceno medio. Durante el Mioceno Medio y Tardío ocurrió la ingresión marina más importante de la región, originando el mar Paranaense, que ocupó casi la totalidad de la llanura chacopampeana hasta Paraguay, Bolivia y Brasil (Aceñolaza, 2004; Ortiz-Jaureguizar \& Cladera, 2006). La ingresión fue posible cuando la planicie descendió como respuesta a las fuerzas tensionales causadas por la elevación de los Andes en el Mioceno y regresionó hace aproximadamente unos 7 Ma. cuando se produjo la elevación de las Sierras Bonaerenses por las fuerzas compresivas generadas por la elevación de los Andes y el movimiento de la placa Sudamericana hacia el oeste (Magnussen Saffer, 2005; Matteucci, 2012). Se piensa que la regresión dejó al descubierto gran parte del estuario del río de La Plata y a la plataforma submarina (Aceñolaza, 2004; Matteucci, 2012). Los eventos mencionados dieron inicio a "La Era de las Llanuras del Sur" (ASP) (Pascual \& Bondesio, 1982; Pascual et al., 1996; Ortiz-Jaureguizar \& Cladera, 2006), conocida de esta forma debido a que la extensa superficie previamente inundada por el "Mar Paraneano" fue reemplazada por planicies igualmente extendidas. Dicha región abarcaba desde el norte de la Patagonia, el centro y norte de Argentina, Uruguay, las laderas orientales de los Andes al norte de Bolivia, el sur de Perú y Venezuela, y la cuenca alta del Amazonas (Marshall et al., 1983; Pascual et al., 1996). Estos eventos produjeron un cambio en la flora de Sudamérica, con el surgimiento de nuevas familias más modernas que se hicieron abundantes (Romero, 1993). Asimismo, se registró una explosión en la diversidad de los mamíferos, principalmente de los ungulados herbívoros y omnívoros siendo los más numerosos en la historia de Sudamérica (Steinbauer et al., 2016). El final de la ASP, durante el Plioceno 
Superior - Pleistoceno temprano ( 4 - 2 Ma.), se correlaciona con una nueva fase diastrófica andina (Yrigoyen, 1979; Pascual et al., 1996; Ortiz-Jaureguizar \& Cladera, 2006; Ortiz-Jaureguizar, 1998) desencadenando la elevación de la Cordillera Central de Argentina y Chile y los sistemas orográficos orientales de Argentina (ej. Puna y Cordillera Pampeana) con el consecuente hundimiento del Chaco y Pantanal (Colli, 2005; Porzecanski \& Cracraft, 2005). Asimismo se elevan la meseta brasileña al sudeste de dicho país y la región Mesopotámica en el noreste Argentino. Los levantamientos finales desencadenados en este período tuvieron marcadas consecuencias ecológicas, produciendo un efecto de sombra pluviométrica que resultó en condiciones extremadamente xéricas que persisten actualmente en el Chaco Seco (Pascual et al., 1996; Alberdi et al., 1997).

Durante el Cuaternario, los cambios climáticos tuvieron mayor amplitud y frecuencia. Los avances y retrocesos cíclicos de los glaciares produjeron una expansión y retracción marcada de los biomas áridos y húmedos, brindando nuevas oportunidades para la biota de la región (Marshall \& Cifelli, 1990). Durante los climas secos y fríos hubo una contracción de las áreas ocupadas por biomas tropicales y subtropicales, lo que resultó en la expansión e interconexión concomitante de biomas abiertos (Kalin-Arroyo et al., 1988). A lo largo del flanco oriental de los Andes, se formó un corredor de sabana durante períodos de climas fríos y secos, proporcionando un corredor norte-sur para animales y plantas (Webb, 1978, 1991; Webb \& Rancy, 1996). Este corredor abierto unía las estepas y pastizales del sur de Argentina con las praderas de Colombia (Webb, 1978, 1991, Marshall, 1985, Webb \& Rancy, 1996). Por el contrario, cuando las áreas abiertas se retiraron durante los períodos interglaciales de climas cálidos y húmedos, la selva tropical se expandió.

\section{BIOMAS CONSIDERADOS: DELIMITACIÓN DE LAS ÁREAS DE ESTUDIO}

La tribu Dichroplini se caracteriza por presentar especies adaptadas particularmente a biomas abiertos, principalmente de pastizal. La integración entre la biogeografía histórica y la filogeografía en estudios sobre la diversificación de los biomas abiertos en Sudamérica (Riddle et al., 2008; Nogueira et al., 2011; Werneck, 2011; Guarnizo et al., 2016) ha sugerido procesos históricos y evolutivos ocurridos en estos biomas que permitieron delimitar nuevos refugios, distintas áreas biogeográficas y las relaciones entre ellas no develados hasta el momento por las metodologías de la biogeografía clásica (Cabrera \& Willink, 1973; Hughes et al., 2013; Morrone, 2014). Sin embargo dichos estudios no abarcan el área total de distribución de la tribu, por lo que, en 
este trabajo de tesis se realizó una combinación de las diversas propuestas. Se utiliza la definición de Werneck (2011) del Cerrado, Chaco y el Bosque Tropical Seco Estacional (BTSE), a las cuales se agrega la Pampa, los Bosque Lluviosos Tropicales (BLT) y los Pastizales Andinos de Altura (Cabrera \& Willink, 1973; Hughes et al., 2013; Morrone, 2014) (Fig. 3).

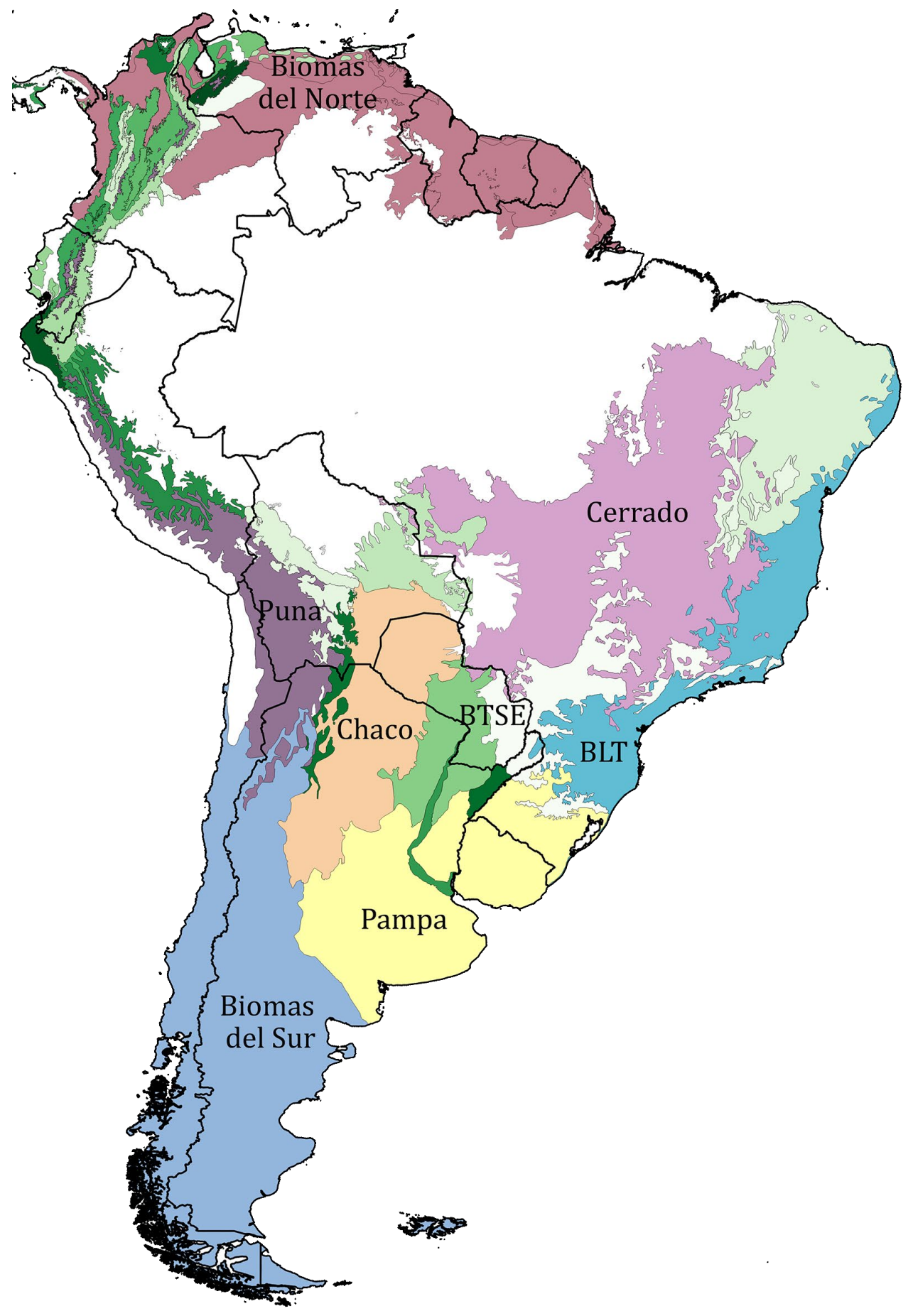

Figura 3: Biomas de la región de estudio, en la gama del verde se encuentran las diferentes regiones del BTSE. 
La distribución actual del Bosque Tropical Seco Estacional (BTSE), uno de los biomas abiertos de Sudamérica, es discontinua, con grandes áreas que se extienden desde el noreste de Brasil hasta la cuenca del río Uruguay, y áreas más pequeñas rodeando la cuenca del Amazonas alcanzando Centroamérica, México y el Caribe (Pennington et al., 2006; Werneck, 2011) (Fig. 3). Las áreas más grandes se encuentran en el noreste de Brasil, la ecorregión de Caatinga, a lo largo del sistema de ríos Paraguay-Paraná en el Bosque Atlántico Paranense (de aquí en más como Paranense) y Chaco Húmedo; y en el sudoeste de Bolivia y el noroeste de Argentina en el Chiquitano, el Bosque Seco de Montaña Boliviano y las Yungas. Partes significativas de BTSE también ocurren en la costa caribeña de Colombia y Venezuela, mientras que fragmentos más pequeños ocurren en valles secos en los Andes de Bolivia, Perú, Ecuador, Colombia, y también en áreas costeras de Ecuador y norte de Perú. También aparecen diseminados en áreas de condiciones edáficas favorables en todo el bioma de sabana Cerrado, en la meseta central de Brasil (Werneck et al., 2011). Los BTSEs se distribuyen en regiones tropicales, libre de heladas, con estacionalidad de lluvias marcada y con un período de al menos cinco meses de sequía severa (Mooney et al., 1995). Se encuentran restringidos biofísicamente a suelos con alto contenido de nutrientes, $\mathrm{pH}$ moderado a alto y precipitaciones inferiores a $1600 \mathrm{~mm} /$ año Hasta la década de 1990, las consideraciones biogeográficas del BTSE estaban desarticuladas, considerando la Caatinga por un lado, y los bosques secos de Sudamérica por otro. El origen y diversificación de BTSE son complejos y la literatura más temprana sugirió que la flora de Caatinga se derivaba del Chaco (Andrade-Lima, 1982) o del Chaco y de la Mata Atlántica (Rizzini, 1979). Ha habido debates biogeográficos con respecto a que los BTSE específicamente, y los biomas abiertos en general, deberían considerarse biomas relictuales debido a su distribución disyunta. En función a modelos de paleodistribución de los BTSE se ha propuesto que este bioma se habría expandido durante el Pleistoceno inferior o el Neógeno, seguido por una fragmentación en el último máximo glacial y una expansión secundaria en el Holoceno (Werneck, 2011; Werneck et al., 2011).

El Chaco es otro bioma de vegetación abierta, de llanuras aluviales de tierras bajas del centro de Sudamérica, ubicado en el norte de Argentina, el oeste de Paraguay, el sudeste de Bolivia y el extremo occidental del estado de Mato Grosso do Sul en Brasil (Fig. 3). El clima de esta región está marcado por una fuerte estacionalidad, presentando veranos muy cálidos y heladas invernales. El bioma del Chaco no debe confundirse con la región geográfica que lo contiene, el Gran Chaco que, de hecho, incluye tres subregiones distintas: Chaco Húmedo, Chaco Seco y Chaco Montano (TNC et al., 2005). Es probable que la flora del Chaco sea un relicto del Plioceno o del Pleistoceno temprano, establecida 
posteriormente a las incursiones marinas del Mioceno tardío, las cuales cubrieron la mayor parte de la depresión de la cuenca del Chaco-Paraná y probablemente inundaron gran parte del bioma chaqueño. La provincia biogeográfica del Chaco corresponde a una unidad distintiva con una biota compleja que representa elementos de muchos otros biomas (Morrone, 2001, 2004), subdividida en dos conjuntos principales con frecuencia definidas como Chaco Seco y Chaco Húmedo (Spichiger et al., 1995, 2004). El carácter de la fauna del Chaco a menudo se describe como ampliamente distribuido en otras regiones de Sudamérica, con diversidad y niveles de endemismo moderados, como consecuencia de su ubicación central y accesibilidad (Myers \& Wetzel, 1983; Short, 1975; Willig et al., 2000).

El Cerrado (Fig. 3) es el segundo bioma abierto más grande de Sudamérica y ha sido identificado como uno de los 25 principales "hotspots" de biodiversidad y centros de endemismo del mundo (Myers et al., 2000; Pennington et al., 2006; Nogueira et al., 2011). Se distribuye en condiciones similares (o ligeramente más húmedas) que los BTSE, pero tiende a asociarse con suelos más pobres, lo que determina que el Cerrrado presente grandes extensiones de pastizales, mientras que los BTSE están dominados por árboles, presentando sólo pequeños parches de pastizales (Pennington et al., 2006). Es un paisaje dominado por vastas mesetas, producto de ciclos tectónicos de elevación, erosión y empobrecimiento del suelo, separadas por una red de drenajes recientes que forman jóvenes valles (Ab'Sáber, 1983; Cole, 1986; da Silva, 1997, Werneck, 2011; Nogueira et al., 2011). El levantamiento final de las mesetas a sus altitudes actuales (500-1700 m) tuvo lugar desde el Neógeno Tardío al Cuaternario Temprano, con la posterior erosión de las depresiones periféricas (100-500 m) (da Silva, 1997). La vegetación tipo sabana y praderas herbáceas abiertas es dominante en las mesetas antiguas, mientras que en las depresiones la biota es más compleja, con una matriz de sabanas cruzadas por amplias extensiones de bosques de galería, presentando parches de bosques secos y semicaducifolios (Eiten, 1972; Cole, 1986; da Silva, 1997; Oliveira-Filho \& Ratter, 2002; Da Silva \& Bates, 2002). Las superficies geomorfológicas del Cerrado y la marcada estratificación del hábitat horizontal generan un paisaje complejo, en mosaico que puede promover y mantener una alta diversidad a pesar de su simplicidad vertical (Colli et al., 2002). Se ha propuesto que los grupos de especies de vegetación abierta asociados a las mesetas más antiguas se caracterizan por una alta estructura genealógica y diversidad genética, en consonancia con sus antiguas edades de diversificación. Otros estudios dan evidencia de una gran riqueza y número de endemismos de organismos pequeños y de poca vagilidad asociados a los hábitats abiertos de mesetas (Nogueira et al., 2009). 
La Pampa (Fig. 3), otro de los destacados biomas abiertos de Sudamérica, se encuentra ubicada en el centro este de la Argentina, Uruguay y la mitad austral del estado de Río Grande, presentando un relieve principalmente llano o ligeramente ondulado, con algunas montañas de poca altura ( $<1200$ mts) (Cabrera \& Willink, 1973). Esta región es una de las áreas de pastizales templados más grandes del mundo y constituye el más importante ecosistema de praderas de la Argentina. Las especies vegetales dominantes de la provincia pampeana son gramíneas, la mayoría de los elementos florísticos pertenecen al dominio chaqueño y al espinal. El clima puede clasificarse como subtropical húmedo o como templado oceánico, con precipitaciones todo el año que disminuyen de norte a sur; presentando veranos cálidos y sin una estación seca marcada (Cabrera \& Willink, 1973; Matteucci, 2012). La ecorregión Pampa ha sido subdividida en dos subregiones sobre la base de las condiciones climática, la Pampa Húmeda y la Pampa Subhúmeda, y a su vez estas dos han sido subdivididas según relieve, topografía y tipos de suelo (Matteucci, 2012). El uso antrópico de la tierra ha tenido un profundo impacto en la estructura natural de las comunidades mediante la introducción de especies de hierbas exóticas, la conversión de áreas nativas a tierras agrícolas y áreas de pastoreo (Fregonezi et al., 2013). Las consecuencias bióticas del cambio climático en el hemisferio sur se han discutido en relación con la contracción y expansión de varios biomas, sin embargo, hay pocos estudios sobre la biogeografía y los patrones de diversificación en este contexto en los pastizales templados y tropicales del sur de Sudamérica, específicamente la Pampa (Speranza et al., 2007; Solis-Neffa, 2009; Fregonezi et al., 2013).

Los Bosque Lluviosos Tropicales (BLT; Fig. 3) se encuentran en regiones con precipitación anual mayor a $1500 \mathrm{~mm}$ y poca estacionalidad de las precipitaciones (Malhi et al., 2009). Incluyen el Amazonas, la Mata Atlántica y el Bosque Húmedo de Araucaria (de aquí en más como Bosque de Araucaria), presentando una distribución mucho más continua que los BTSE, especialmente en el Amazonas y las Guyanas. Sin embargo, es importante señalar que estas grandes áreas de bosque lluvioso rara vez son homogéneas y abarcan una gran variedad de tipos de suelo y vegetación, incluido un bosque elevado, vegetación de matorral y bosque a lo largo de las llanuras aluviales de ríos inundados estacionalmente (Hughes et al., 2013). Los bosques lluviosos sudamericanos están ocupados por linajes que a menudo muestran niveles moderados o altos de simpatría, con menor estructuración filogenética que los taxa pertenecientes al BTSE (Lavin, 2006; Pennington et al., 2009; Pennington \& Dick, 2010). Asimismo, se ha sugerido que la diversificación de taxa de los pastizales de altura del Bosque de Araucaria podría haberse debido al aislamiento por barreras geográficas (especiación alopátrica) durante los 
períodos glaciales e interglaciales (Behling \& Pillar, 2007; Lorenz-Lemke et al., 2010; Fregonezi et al., 2013).

Los Pastizales Andinos de altura incluyen el Páramo, la Puna y la Jalca, se encuentran por encima de c. 3000 m en los Andes tropicales (Luteyn, 1999; Hughes \& Eastwood, 2006; Pennington et al., 2010; Sklenár et al., 2011; Hughes et al., 2013). Solo el páramo comprende unas 3500 especies de plantas vasculares (Luteyn, 1999; Sklenár et al., 2011). Estos pastizales se encuentran generalmente como extensos bolsones, aparentemente llanos, separados por cadenas montañosas (Cabrera \& Willink, 1973). El clima es seco y frío, con grandes variaciones de temperatura diarias durante todo el año, y lluvias estivales (Cabrera \& Willink, 1973). Tal vez uno de los patrones más consistentes de este bioma es la edad reciente de los grupos y la gran diversificación presente en los pastizales andinos de alta elevación (Hughes et al., 2013). Estudios recientes revelan que en estos hábitats andinos existe una alta proporción de la flora endémica que se ha diversificado en los últimos millones de años (Hoorn et al., 2010; Jabaily \& Sytsma, 2012; Drew \& Sytsma, 2012; Särkinen et al., 2012). Estos resultados son concordantes con las reconstrucciones geológicas que indican que un levantamiento mayor de los Andes centrales y del norte tuvo lugar en los últimos $10 \mathrm{Ma}$, y en otras regiones (como la Cordillera nororiental) considerablemente más tarde (Garzione et al., 2008; Hoorn et al., 2010). Esta evidencia refuerza la idea de la existencia de una radiación explosiva temprana, con tasas excepcionalmente altas de diversificación neta de especies y poca evidencia de extinción, en hábitats geológicamente jóvenes (Hughes \& Eastwood, 2006; Drummond et al., 2012; Hughes et al., 2013).

\section{GRUPO DE ESTUDIO: TRIBU DICHROPLINI}

La familia Acrididae se habría originado hace aproximadamente $65 \mathrm{Ma}$. (Song et al., 2018) y hoy incluye más de 6700 especies válidas de tucuras (Cigliano et al., 2018). Constituye uno de los grupos de herbívoros dominantes en los pastizales del mundo (Uvarov, 1966; Mitchell \& Pfadt, 1974; Gangwere et al., 1997; Cigliano et al., 2000; Guo et al., 2006), contribuyendo a más de la mitad de la biomasa total de artrópodos (Gillon 1983) y representan un gran aporte al ciclado de nutrientes (Mitchell \& Pfadt, 1974; Belovsky \& Slade, 1993; Gangwere et al., 1997). Las tucuras pueden ser excelentes indicadores del uso del suelo, ya que son ecológicamente sensibles y, sin embargo, suficientemente móviles y abundantes como para servir como excelentes bioindicadores (Samways \& Sergeev, 1997; Gebeyehu \& Samways, 2002; Bazelet \& Samways, 2014). Por otro lado, varias especies de tucuras y langostas pueden generar periódicamente 
brotes/explosiones poblacionales locales y/o a gran escala, causando un enorme daño económico al agro (COPR, 1982).

Según una reciente filogenia de Acrididae propuesta por Song et al. (2018) se considera que la subfamilia Melanoplinae se habría originado en Sudamérica durante el Eoceno temprano ( $43 \mathrm{Ma}$.), dando lugar posteriormente al surgimiento de la tribu Dichropini hace aproximadamente 20 Ma. (Rowell \& Flook, 2007; Song et al., 2018). Esta tribu exhibe la mayor diversificación de melanoplinos sudamericanos, presentando 28 géneros y 163 especies válidas (Cigliano et al., 2018), las cuales pueden presentar distribuciones extremadamente restringidas o abarcar casi la totalidad de Sudamérica. Asimismo, constituye el grupo dominante tanto en número de especies como en número de individuos en la mayoría de las comunidades de pastizal de Sudamérica (Cigliano et al., 2000). La tribu ha sido motivo de estudios sistemáticos recientes y aunque sus relaciones filogenéticas no han sido analizadas en su totalidad, existen análisis parciales a nivel molecular que dan cuenta de su monofilia (Amédégnato et al., 2003; Chintauan-Marquier et al., 2011). Sobre la base de estudios filogenético moleculares, se considera que la diversificación de la subfamilia Melanoplinae en Sudamérica respondería, en parte, a eventos climáticos que habrían permitido el aumento de ecosistemas abiertos de tipo sabana durante el Eoceno temprano y geológicos, como el surgimiento de los Andes, que deben haber contribuido a su diversificación y dispersión hacia Norteamérica (Amédégnato et al., 2003; Chintauan-Marquier et al., 2011; Song et al., 2018).

Con respecto a la diversificación de la tribu Dichroplini, Ronderos (1981) considera que habrían existido dos centros de diversificación, uno constituido en los Andes Septentrionales de Colombia y Venezuela, y el otro en la zona central-sur del continente, a nivel de la cuenca Parano-Platense donde se habría llevado a cabo la mayor diversificación del grupo. Dentro de estos centros de diversificación cada género de Dichroplini habría ocupado sectores específicos del continente, con características florísticas y climáticas propias (Ronderos, 1981).

Desde el punto de vista de las variaciones morfológicas existen dos características intrínsecas de la tribu Dichroplini que podrían estar estrechamente relacionadas con los patrones de diversidad y biogeográficos observados en el grupo: el braquipterismo/macropterismo y la variabilidad en la estructura del ovipositor (desarrollado en capítulo 2) y serán puestas a prueba en este trabajo de tesis. 
El desarrollo de alas y la capacidad de vuelo son rasgos característicos de todos los órdenes de insectos superiores. Las alas bien desarrolladas permiten la dispersión, con importantes consecuencias para el flujo de genes, la especiación y la evolución, no obstante, gran número de insectos ha perdido secundariamente la capacidad de vuelo (Roff, 1986, 1990; Wagner \& Liebherr, 1992). La tendencia de los insectos a reducir sus alas es un fenómeno ampliamente conocido, que se interpreta como una adaptación evolutiva a factores ambientales (Roff, 1994; Hodkinson, 2005) atribuido principalmente a tres fenómenos: hábitats insulares, entornos estables y clima (Chopard, 1938; Mani, 1968; Rolf, 1986, 1990; Braun, 2002, 2011; Maveety et al., 2011). Darwin (1859) atribuye la ausencia de vuelo en insectos de las pequeñas islas oceánicas al peligro de ser arrastrados por los aires, explicación que también se aplica a los ambientes montañosos. Cuando la dispersión no trae beneficios ecológicos (como la posibilidad de terminar en lugares poco favorables después de la migración) la ausencia de vuelo es la consecuencia natural, ya que los peligros contrarrestan los efectos positivos (Roff, 1990; Wagner \& Liebherr, 1992; Grzywacz et al., 2018). Asimismo varios autores sostienen que los entornos estables favorecerían la evolución de la ausencia de vuelo. Southwood (1962) considera que "se debería encontrar un mayor nivel de movimiento migratorio en aquellas especies asociadas con hábitats temporales o transitorios que en aquellas con hábitats estables". La ausencia de alas en regiones de climas adversos parece explicarse mejor por los costos energéticos, donde perder la capacidad de vuelo sería una adaptación de ahorro de energía en zonas menos favorables. Dicho patrón se observa en las zonas templadas y en las altas montañas de los trópicos, donde se encuentra una mayor proporción de especies de alas cortas (Roff, 1990; Grzywacz et al., 2018). Dentro de los ortópteros, diversos estudios han demostrado una alta concordancia con dichos patrones. Rolf (1990) determinó que las especies aladas de ortópteros predominan en los pastizales, regiones desérticas y zonas transicionales, mientras que las especies no voladoras habitan mayoritariamente en bosques, regiones montañosas, tundras y cuevas. Asimismo, los Phaneropterinae de alas cortas se encuentran en las montañas tropicales (Braun, 2010; Massa, 2015), donde el braquipterismo aumenta con la altitud (Braun, 2011; Grzywacz et al., 2018). Independientemente de las razones ecológicas, la ausencia de vuelo en los ortópteros es frecuente y ha sido mencionada como promotor de una mayor diversidad (Ikeda et al., 2012; Grzywacz et al., 2018). 


\section{Capítulo 1: Diversificación del Género}

\section{Orotettix (Orthoptera: Acrididae)}

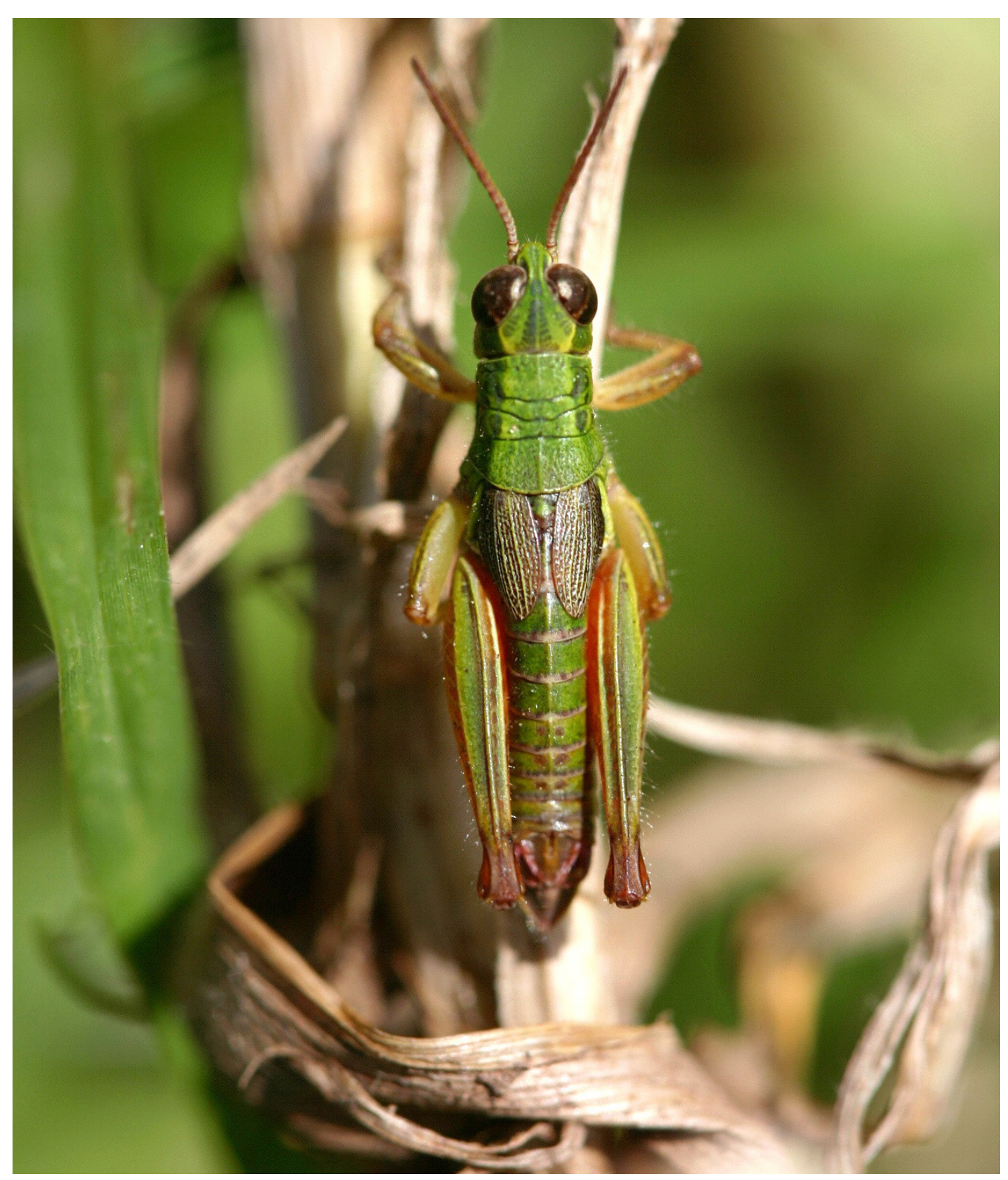

Publicado en: Scattolini, M.C., Confalonieri, V.A., Lira-Noriega, A., Pietrokovsky, S., \& Cigliano, M.M. 2018. Diversification mechanisms in the Andean grasshopper genus Orotettix (Orthoptera: Acrididae): ecological niches and evolutionary history. Biological Journal of the Linnean Society, 123 (4): 697-711, https://doi.org/10.1093/biolinnean/bly008 


\section{INTRODUCCIÓN}

Los Andes constituyen la cadena montañosa más larga del mundo, albergando una diversidad ecológica y taxonómica excepcional (Young et al., 2002; Graham, 2009). En Perú y Bolivia conforman los Andes Centrales, con aproximadamente $4.000 \mathrm{mts}$ de elevación, constituidos por las Cordilleras Oriental y Occidental, (Garzione et al., 2008; Sempere et al., 2008; Gonzalez \& Pfiffner, 2012). La orogénesis andina y los ciclos glaciales (Imbrie et al., 2011) son mecanismos que se considera han sido fundamentales en el proceso de especiación de numerosos grupos de plantas y animales(Ribas et al., 2007; Koscinski et al., 2008; Picard et al., 2008; Antonelly et al., 2009; Elias et al., 2009; Chaves et al., 2011; Ceccarelli et al., 2016; Guarnizo et al., 2016). La especiación vertical, a través de gradientes de elevación y ecológicos (Moritz et al., 2000; Willmott et al., 2001; Hughes \& Eastwood, 2006; Brumfield \& Edwards, 2007), y la especiación alopátrica en los valles de áreas geográficas adyacentes (Willmott et al., 2001; Brumfield \& Edwards, 2007; Cigliano \& Amedegnato, 2010; Särkinen et al., 2012; Pocco et al., 2013; Benham \& Witt, 2016) son dos de las principales hipótesis que intentan explicar la diversidad que se encuentra hoy en día en los Andes.

El género Orotettix Ronderos \& Carbonell pertenece a la tribu Dichroplini y es endémico de los Andes de Perú, extendiéndose hacia el altiplano Boliviano, entre los 1950 y 4500 m s.n.m (Pocco et al., 2015; Cigliano et al., 2018). Este género de tucuras braquíptero está representado por especies morfológicamente muy similares, que se diferencian principalmente por características de su genitalia masculina y tegminas. Los melanoplinos se caracterizan por una gran divergencia en su genitalia masculina, diagnóstica a nivel de especie (Cigliano \& Lange, 2007), coincidente con el patrón observado en Orotettix. Un estudio reciente, en donde se aplicó taxonomía integrativa para la delimitación de especies del género Orotettix, mostró una alta congruencia entre la información brindada por los datos moleculares (COI) y la evidencia morfológica (Pocco et al., 2015). El género Orotettix incluye diez especies que son, en su mayoría raras, con distribuciones muy restringidas en diferentes ambientes de las ecoregiones de la Puna Central Andina, la Puna Central Andina Húmeda y las Yungas Peruanas (Olson et al., 2001). Tres de estas especies, O. colcaensis Cigliano, Pocco \& Lange, O. hortensis Ronderos \& Carbonell y 0 . ceballosi Ronderos \& Carbonell, muestran una distribución claramente alopátrica en la Cordillera Occidental, el Altiplano y la Cordillera Oriental respectivamente (Pocco et al., 2015). Las especies de Orotettix son un grupo interesante para llevar a cabo 
estudios sobre los mecanismos de diversificación específica debido a su similitud morfológica, baja vagilidad y el alto nivel de endemismo local en una topografía compleja.

Dados los cambios en el paisaje a través de la historia del surgimiento de los Andes Centrales, las glaciaciones cíclicas del Pleistoceno y considerando los patrones de distribución observados en el género Orotettix, la especiación en este género pudo haber sido consecuencia de la orogenia y/ó ocurrido luego de la elevación de los Andes, como resultado de los subsecuentes cambios climáticos. En este capítulo se ponen a prueba estas hipótesis, y a través de la reconstrucción filogenética y el modelado de nicho ecológico se trata de dilucidar los posibles mecanismos de diversificación ocurridos en Orotettix.

\section{MATERIALES Y MÉTODOS}

\section{Análisis filogenéticos}

Para el análisis filogenético se utilizaron 28 ejemplares de la tribu Dichroplini. Los ejemplares/especímenes representan todas las especies de Orotettix excepto O. laevis Ronderos \& Carbonell que sólo se conoce a partir de su material tipo (Pocco et al., 2015), y tres especies seleccionadas como grupo externo (Atrachelacris unicolor Giglio-Tos, Leiotettix pulcher Rehn y Dichromatos lilloanus (Liebermann)). Los protocolos de extracción y amplificación de los dos genes mitocondriales [Subunidad 2 de la Deshidrogenasa NADH (ND2) y Citocromo C oxidasa, subunidad I (COI)] y el fragmento de gen nuclear [Histona 3 (H3)] fueron implementados según Husemann et al., (2013). Estudios previos han demostrado que estos marcadores son informativos para establecer la relación entre especies de acridios (Husemann et al., 2012, 2013, 2015; Guzman et al., 2017). Las secuencias de las tres regiones de los genes fueron examinadas, recortadas y alineadas usando Geneious 6.1.6 (http://www.geneious.com, Kearse et al., 2012). Para evitar la posibilidad de analizar amplificaciones de pseudogenes de COI (Bensansson et al., 2000), las secuencias fueron traducidas de acuerdo al código genético mitocondrial de invertebrados y examinadas usando como referencia la secuencia de aminoácidos obtenida de varios órdenes de insectos (Lunt et al., 1996). Se asume que las copias son mitocondriales si no contienen desplazamientos del cambio de lectura ("frameshifts") o del codón de parada ("stop codón") (Sorenson \& Fleischer, 1996; Zhang \& Hewitt, 1996). Se utilizó el JModelTest v. 2.1.7 (Posada, 2008), aplicando el criterio de información de Akaike (AIC) (Akaike, 1973) para inferir los modelos de evolución molecular más apropiados para cada conjunto de datos (COI: GTR+I+G; ND2: HKI+I+G, HIS: HKY+I). 
La distribución posterior de los árboles filogenéticos se exploró usando el algoritmo de cadenas de Monte Carlo implementado en BEAST v2.4.7 (Bouckaert et al., 2014). El archivo ingresado en BEAST fue generado usando el programa BEAUti v2.4.7 (Bouckaert et al., 2014). Las tres regiones genéticas fueron analizadas independientemente, y luego combinadas para la obtención del árbol y la estimación del modelo de reloj molecular. Se utilizó el proceso de especiación de "Yule" como prior de especiación para el árbol, y el tamaño poblacional se dejó como constante. El análisis se corrió con 50.000.000 generaciones, muestreando los árboles cada 1.000 generaciones. Se consideró que se había alcanzado la convergencia cuando todos los parámetros de árbol alcanzaron un valor de tamaño de muestras efectivo ("effective sample sizes: ESS") superior a 200. Una vez alcanzada la estabilidad en los valores de verosimilitud, evaluado a través del programa Tracer 1.6 (Rambaut et al., 2014), se descartaron como "burn-in" los primeros 5.000.000 árboles (10\%). Se generó el árbol de máxima credibilidad de clado ("maximum clade credibility: MCC") con el programa TreeAnnotator v1.7.5 (Drummond \& Rambaut, 2007) y se visualizó y editó el árbol con el programa FigTree 1.4.2 (http://tree.bio.ed.ac.uk/software/figtree/) mostrando las probabilidades posteriores como soporte de las ramas. La edad de los nodos se estimó considerando solo un individuo por especie, usando la tasa de sustitución generalizada del COI de 1,6 \% sustituciones/sitio/linaje/Ma. (Allegrucci et al., 2011).

\section{Registros de ejemplares y distribución geográfica}

Los registros de ejemplares usados en este estudio se basan en los datos publicados en Pocco et al., (2015). También se incluyen registros de materiales depositados en la Colección de Entomología del Museo de La Plata, Argentina. En total se registraron más de 580 ejemplares que cubren la totalidad de la distribución conocida para el género, abarcando las regiones de la Puna Central Andina, la Puna Central Andina Húmeda y las Yungas Peruanas. (Fig. 4) (Olson et al., 2001).

Para cada especie solo se consideraron como ocurrencias únicas, aquellas localidades que se encontraban dentro de un rango de 0.1 arc-minutos. Como resultado, solo se incluyeron 61 registros para el total de las especies (Tabla S1): O. lunatus Cigliano, Pocco \& Lange (1), O. astreptos Cigliano, Pocco \& Lange (2), O. andeanus (Bruner) (19), 0. carrascoi Ronderos \& Carbonell (5), O. ceballosi (12), O. colcaensis (6), O. dichrous Cigliano, Pocco \& Lange (5), O. hortensis (6), O. paucartambensis Cigliano, Pocco \& Lange (5). A pesar de que el número de ocurrencias es bajo comparado con otros grupos taxonómicos, 
este se corresponde con el esfuerzo de muestreo y con la distribución conocida para todas estas especies raras y de distribuciones sumamente restringidas.

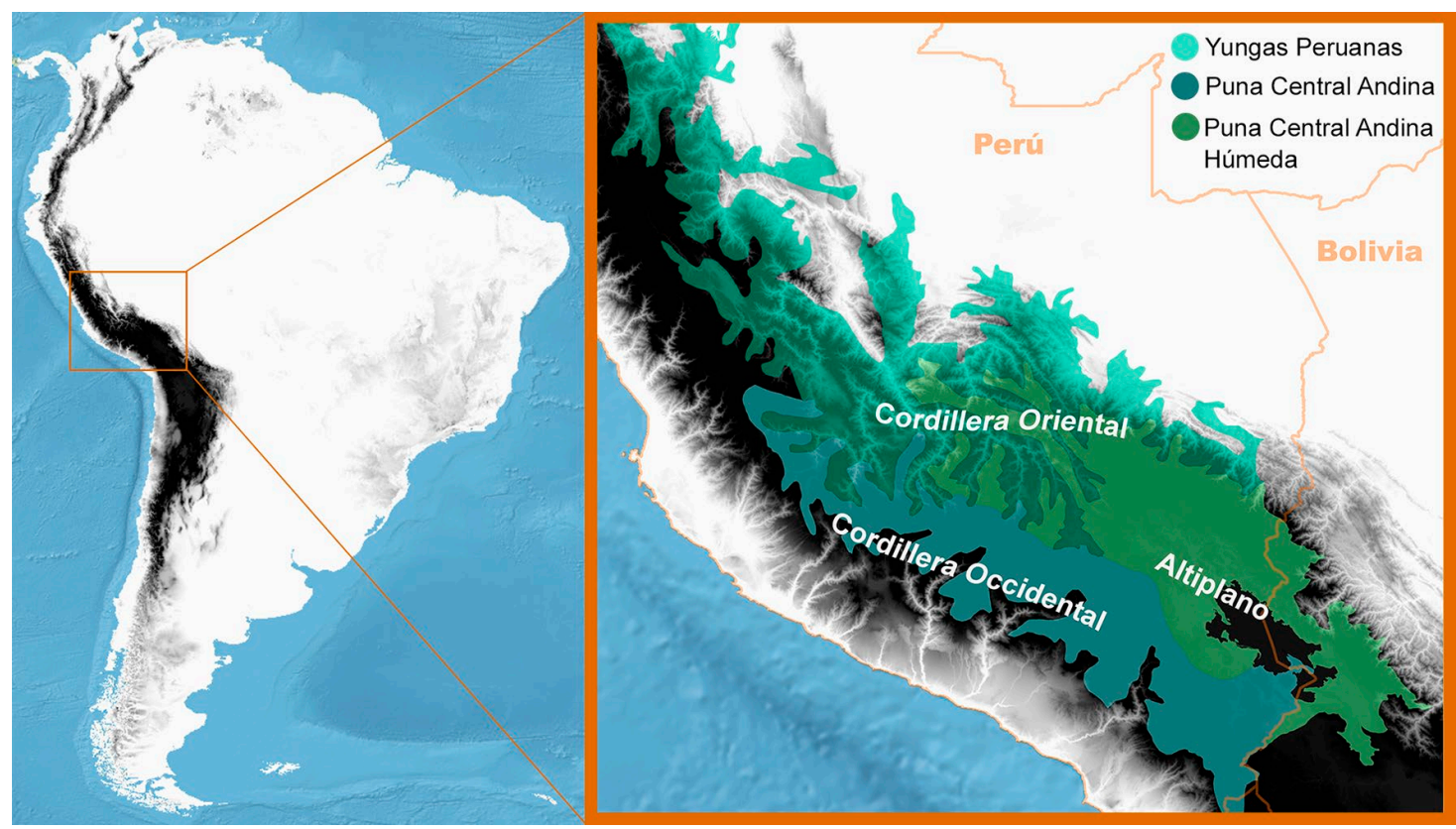

Figura 4: Mapa de la región de estudio, ilustrando las características geomorfologicas (Garzione et al., 2008) y las ecorregiones (Olson et al., 2001)

Para visualizar la variabilidad climática de cada especie, se extrajeron los valores de las 19 variables bioclimáticas (http://www.worldclim.org; Hijmans et al., 2005) para cada registro de especie. Los valores fueron representados en gráficos de caja.

Previo a la estimación de las áreas potenciales de distribución, se restringió el área accesible ("background area") para cada especie, siguiendo la metodología de Barve et al., (2011). Las áreas accesibles se estimaron basándose en las ecoregiones donde se distribuía cada especie, añadiendo un radio de $20 \mathrm{~km}$ alrededor del área determinada, utilizando el programa QGIS 2.18.11 (http://qgis.osgeo.org).

Para evitar problemas de la multi-colinearidad (Dormann et al., 2013) de las variables climáticas, se realizó un Análisis de Componentes Principales (ACP) de las 19 variables bioclimáticas a una resolución de 30 arc-seg ( $\sim 1 \mathrm{~km}^{2}$ en el ecuador). El ACP se calculó para el total de las ecorregiones que habita el género, más un radio de $20 \mathrm{~km}$, pero los modelos se calibraron teniendo en cuenta el área accesible de cada especie. Se utilizaron los primeros tres componentes principales, que en conjunto explicaron el 93,4\% de la variabilidad total. El componente principal (CP) 1 se correspondió principalmente con la temperatura, el CP 2 con la precipitación y el CP 3 representó la variación de temperatura diurna, estacional y anual. 
Similitud de nicho. Se utilizó el CP1 y el CP2 (que en conjunto explican el 88,4\% de la varianza total de variables ambientales) para evaluar las diferencias en el nicho realizado, siguiendo a Broennimann et al., (2012).

Los datos de presencia (registros) fueron usados para realizar el test de similitud de nicho entre las especies de Orotettix usando el paquete de R 'ecospat' (Broennimann et al., 2012). Se utilizaron los estadísticos de "Schoener's D" (Schoener, 1968) y “Hellinger's I Distances" (van der Vaart, 1998) para evaluar la superposición de nicho (Warren et al., 2008). El análisis permite evaluar el conservadurismo o divergencia de nicho entre cada par de especies de Orotettix. Estos análisis evalúan el grado de superposición de nicho entre dos especies, considerando la distribución de una especie en relación al área accesible de la otra especie.

Análisis de Componentes Principales. El nicho realizado de las especies también se comparó siguiendo la topología de árbol filogenético según Smith \& Donoghue, (2010). Para ello se realizaron ACPs con los valores extraídos de las 19 variables bioclimáticas de los registros de aquellas especies que constituyen cada uno de los clados del árbol. Para estos análisis se utilizó el programa PAST (Hammer et al., 2009). Los distintos gráficos de ACPs se representaron sobre cada nodo del árbol de consenso obtenido en BEAST.

Las especies hermanas fueron comparadas mediante un ANOVA del primer y segundo CP realizado en R (Graham, 2009; Smith \& Donoghue, 2010).

\section{Modelado de Nicho}

Los modelos de nicho ecológico (MNE) se realizaron para todas las especies del género, excepto para 0 . astreptos y 0 . lunatus que presentan, cada una, menos de 5 registros (Pearson et al., 2007; Schwallier et al., 2016). Los modelos se realizaron usando los primeros tres CP (que explicaban el 93,4\% de la variabilidad climática, como se mencionó más arriba). Seguimos dos metodologías para generar los modelados de nicho, la ampliamente utilizada metodología de Maxent (Phillips et al., 2006), que aplica la máxima entropía para computar una medida relacionada a la probabilidad de presencia, usando la distribución de probabilidades de Gibbs; y una metodología nueva, basada en elipsoides que aplica el criterio de representar el hipervolumen n-dimensional, como fue originariamente propuesto por Hutchinson (1957) y recientemente aplicado por OsorioOlvera, Falconi \& Soberón, (2016),. Este enfoque considera que las condiciones 
ambientales donde habita una especie pueden esquematizarse a través de un hipervolumen. Si consideramos exclusivamente tres dimensiones sería un elipsoide. Dentro de este elipsoide, las condiciones más favorables para una especie determinada se encuentran en el centro y hacia la periferia las condiciones se hacen menos favorables.

Se generaron modelos en Maxent (versión 3.4.1) analizados bajo las opciones lineal y cuadrática en formato logístico, con un máximo de 500 generaciones. Se analizó la complejidad de los modelos para tratar de reducir la sobre-parametrización, se generaron modelos con valores de "beta-regularization multiplier" de 0,01, 0,05, 0,1, 0,5, 1, 2, y 3. Este parámetro afecta el ajuste de la distribución posterior, a valores mayores se generan predicciones más generalizadas (Razgour et al., 2011; Shcheglovitova \& Anderson, 2013). El desempeño de los modelos fue evaluado a través de su proyección en el espacio geográfica considerando exclusivamente aquellos modelos con valores de AUC mayores a 0,75 (Pearce \& Ferrier, 2000; Elith et al., 2006).

Los modelos de elipsoides se realizaron con el paquete de $\mathrm{R}$ 'nichetoolbox' que genera el elipsoide de volumen mínimo (Osorio-Olvera et al., 2016). Esta metodología brinda parámetros útiles como el centroide de nicho (óptimo del nicho) y el volumen de la elipse (amplitud del nicho). Como se cuenta con muy pocos registros, el análisis se generó usando la matriz de covarianza de los datos entrantes.

Los modelos obtenidos bajo ambas metodologías se evaluaron con la optimización "Delete-one jackknife optimization approach" (Peterson et al., 2011) usando el programa "pValueCompute" (Pearson et al., 2007), que se ha demostrado tener buen desempeño en estudios con tamaño muestreal reducido (Pearson et al., 2007; Shcheglovitova \& Anderson, 2013).

\section{Señal filogenética}

La señal filogenética se analizó comparando la cercanía filogenética con la diversificación ecológica y geográfica.

La distancia filogenética entre pares de especies se calculó utilizando el paquete 'ape' versión 4.1 (Paradis et al., 2004).

La distancia geográfica entre las especies se calculó a partir del centro geográfico (promedios de latitud y longitud) del rango de cada especie estimado a partir de los registros (las ocurrencias únicas). El óptimo de nicho se calculó a partir del centroide de nicho ecológico, obtenido de los modelos de elipsoides. 
Las distancias entre los centros geográficos y los óptimos ecológicos se calcularon usando distancias Euclideanas entre cada par de especies con la función 'dist2'.

Asimismo, se generaron matrices de superposición de nicho con los valores de D y de I extraídos del test de superposición, descripto previamente. Para evaluar el grado de correlación entre la distancia filogenética (distancia patrística entre las especies) y el centro geográfico, el óptimo de nicho y la superposición de nicho, se realizaron análisis de Mantel (Sokal, 1979; Borcard \& Legendre, 2012) con el paquete de R 'vegan' (Oksanen et al., 2017).

\section{RESULTADOS}

\section{Análisis filogenético}

La amplificación y secuenciación de los tres fragmentos de genes (COI, ND2, H3) resultaron en un total de 1180 pares de bases de genes mitocondriales y un total de 306 pares de bases nucleares. La Tabla 1 muestra los códigos de acceso al GenBank de estas secuencias junto con las publicadas previamente. El análisis filogenético basado en los tres marcadores recuperó al género Orotetix como grupo monofilético con dos grupos principales: uno incluyendo las especies hermanas 0 . paucartambensis y 0 . ceballosi, y el otro incluyendo al resto de las especies (Fig. 5). Dentro de este clado, $O$. hortensis se separa basalmente. Luego se identifican dos clados, uno constituido por 0 . lunatus, agrupado a las especies hermanas 0 . astreptos y 0 . dichrous, y el otro contiene a $O$. colcaensis relacionado con 0 . andeanus y 0 . carrascoi. Todas las relaciones del árbol se encuentran soportadas por probabilidades posteriores mayores a 0,65 . El análisis del reloj molecular indica que la diversificación del género habría ocurrido aproximadamente durante el Pleistoceno medio a tardío, y que el ancestro de estas especies habría existido hace alrededor de uno 3,25 millones de años.

\section{Variables Bioclimáticas}

Orotettix ceballosi y 0 . hortensis muestran las distribuciones más amplias del género en la mayoría de las variables bioclimáticas; y la última especie tolera las temperaturas más frías y estaría expuesta a los rangos más amplios de temperatura (diurna, estacional y anual) (Figs. 6, 7); mientras que las restantes especies del género (incluido 0 . ceballosi) se caracterizaron por tolerar un rango más restringido en estas variables bioclimáticas. Orotettix colcaensis soporta mayores valores de temperatura (diurna, estacional y anual) que el resto de las especies, excepto 0 . hortensis, y tolera los valores menores de 
precipitación del mes más seco (variable bioclimática 14) cuarto más seco (variable bioclimática 17), y cuarto más frío (variable bioclimática 19) del género.

\begin{tabular}{|c|c|c|c|}
\hline Ejemplar & COI & ND2 & H3 \\
\hline O.andeanus_SC10 & MG948531 & MG948475 & MG948503 \\
\hline O.andeanus_SC11 & KP099693.1 & MG948476 & MG948504 \\
\hline O.andeanus_SC22 & KP099705.1 & MG948477 & MG948505 \\
\hline O.astreptos_C86 & KP099656.1 & MG948478 & MG948506 \\
\hline O.astreptos_SC17 & KP099655.1 & MG948479 & MG948507 \\
\hline O.carrascoi_SC108 & MG948532 & MG948480 & MG948508 \\
\hline O.carrascoi_SC110 & MG948533 & MG948481 & MG948509 \\
\hline O.ceballosi_SC33 & KP099680.1 & MG948482 & MG948510 \\
\hline O.ceballosi_SC48 & KP099688.1 & MG948483 & MG948511 \\
\hline O.ceballosi_SC51 & KР099686.1 & MG948484 & MG948512 \\
\hline O.colcaensis_S79-4 & KP099657.1 & MG948485 & MG948513 \\
\hline O.colcaensis_S81-5 & KP099658.1 & MG948486 & MG948514 \\
\hline O.colcaensis_SC154 & MG948534 & MG948487 & MG948515 \\
\hline O.dichrous_C18 & KP099664.1 & MG948488 & MG948516 \\
\hline O.dichrous_SC9 & KP099663.1 & MG948489 & MG948517 \\
\hline O.hortensis_SC131 & MG948535 & MG948490 & MG948518 \\
\hline O.hortensis_SC123 & KP099675.1 & MG948491 & MG948519 \\
\hline O.hortensis_SC142 & MG948536 & MG948492 & MG948520 \\
\hline O.lunatus_C96 & KP099652.1 & MG948493 & MG948521 \\
\hline O.lunatus_C98 & KP099653.1 & MG948494 & MG948522 \\
\hline O.lunatus_C99 & KP099654.1 & MG948495 & MG948523 \\
\hline O.paucartambensis_C57 & KP099660.1 & MG948496 & MG948524 \\
\hline O.paucartambensis_C58 & KР099661.1 & MG948497 & MG948525 \\
\hline O.paucartambensis_SC2 & MG948537 & MG948498 & MG948526 \\
\hline O.paucartambensis_SC3O & MG948538 & MG948499 & MG948527 \\
\hline A.unicolor_75 & MG948528 & MG948472 & MG948500 \\
\hline D.Iilloanus_E3 & MG948529 & MG948473 & MG948501 \\
\hline L.pulcher_105.2 & MG948530 & MG948474 & MG948502 \\
\hline
\end{tabular}

Tabla 1: Códigos de acceso de secuencias de Genbank. En negrita se indican las secuencias descargadas. 

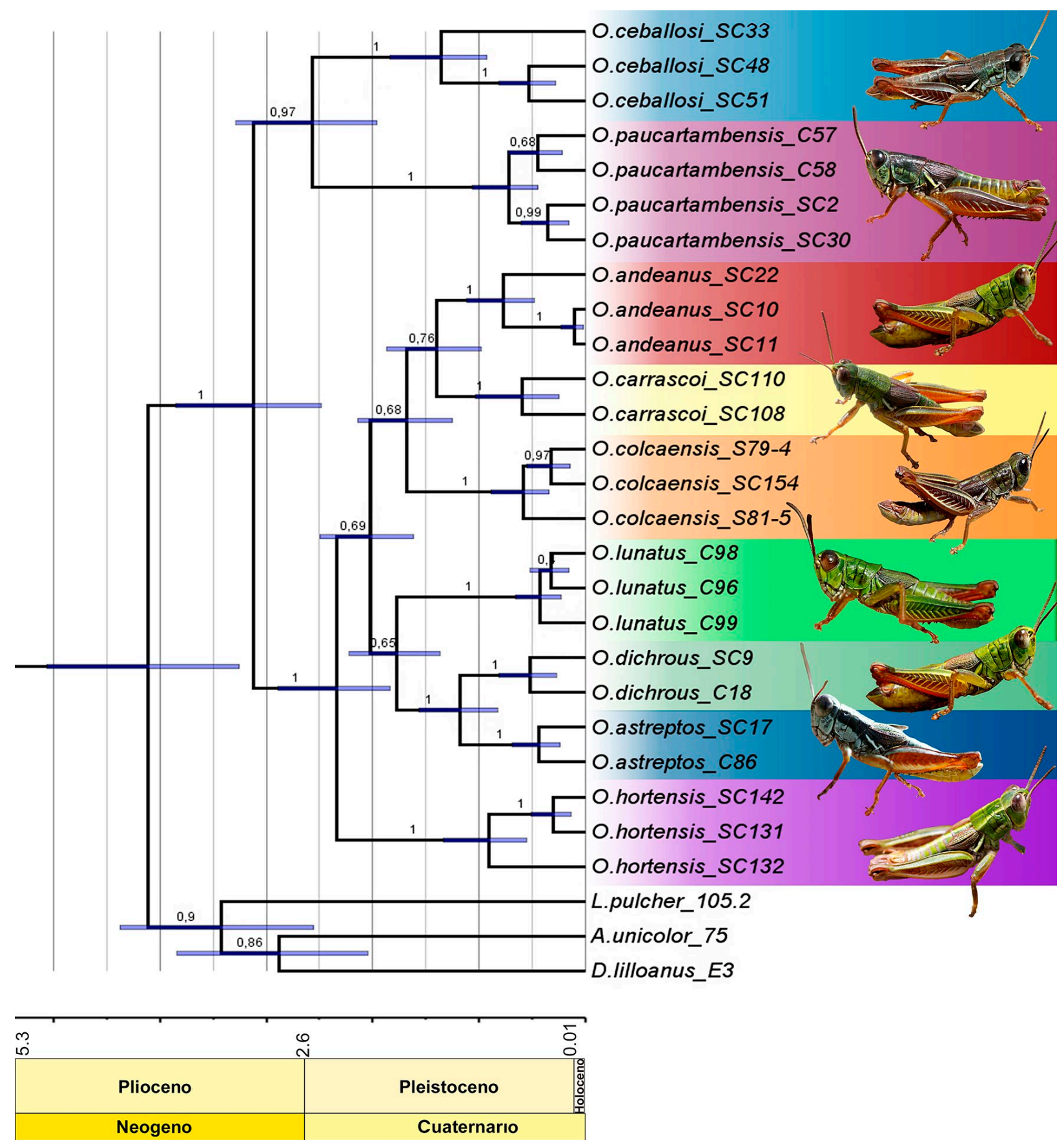

Figura 5: Árbol de consenso para las 9 especies de Orotettix y las tres especies del grupo externo obtenido a partir del análisis Bayesiano de las secuencias de COI, ND2, H3. Los números sobre las ramas indican las probabilidades posteriores. Las barras de los nodos indican los intervalos del $95 \%$ de credibilidad para la edad de los nodos Bajo el árbol se indican las principales épocas geológicas 


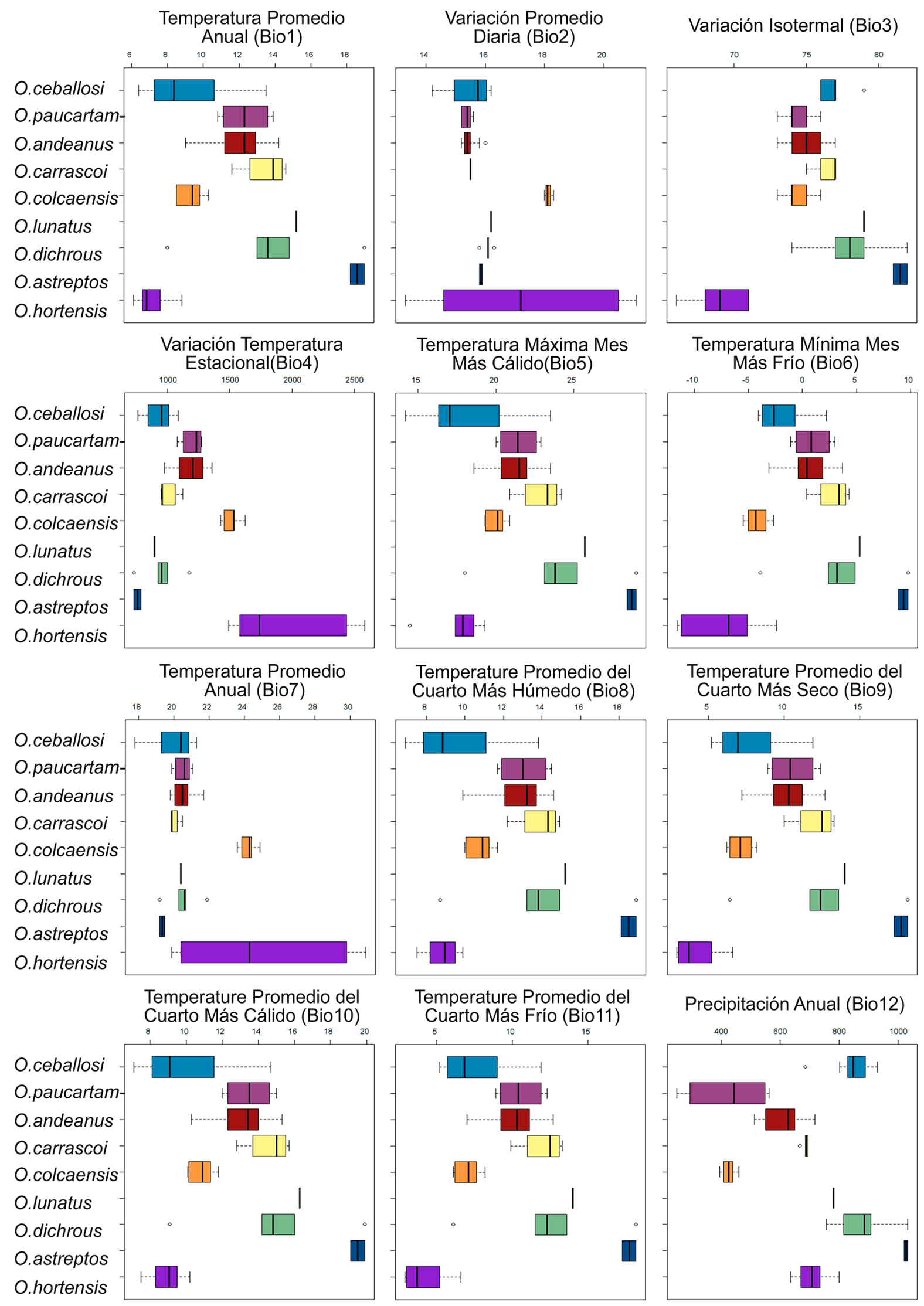

Figura 6: Gráfico de caja de las variables bioclimáticas (var. 1-12). 


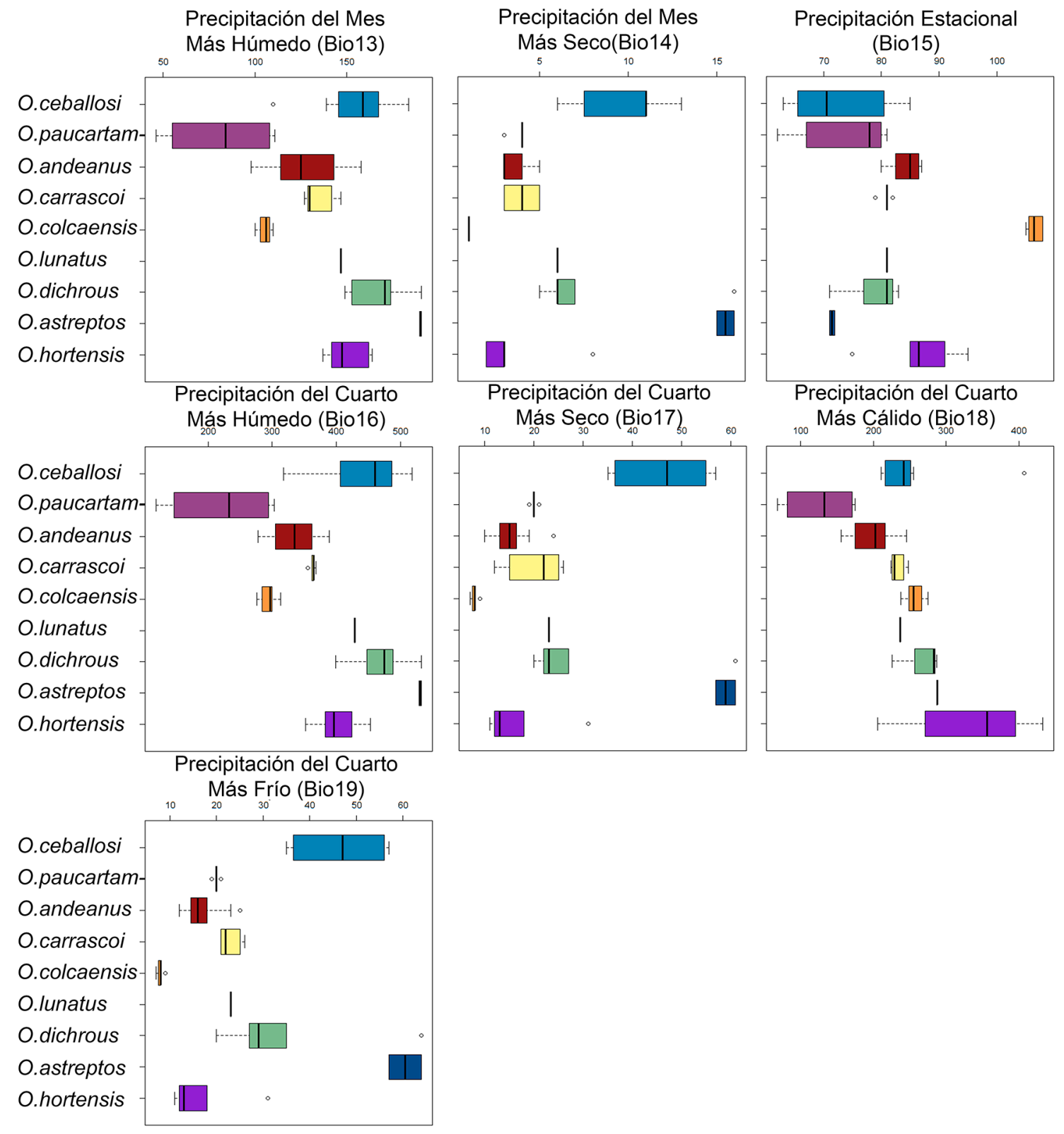

Figura 7: Gráfico de caja de la variables bioclimáticas (var. 13-19).

El clado $O$. astreptus, $O$. lunatus y $O$. dichrous comprende especies que pueden tolerar las temperaturas promedio más altas (Fig. 6), estando 0. astreptos restringido al límite superior o al inferior de la distribución ambiental de 0 . dichrous. De forma similar, O. carrascoi se encuentra restringida a los límites superiores de la distribución ambiental de su especie hermana (O. andeanus) en relación a las variables de temperatura (Figs. 6, 7). 
Similitud de nicho. Los valores de superposición del nicho realizado entre todas las especies se presentan en la Tabla 2. Ambos índices (D e I) mostraron que ninguno de los pares de especies es menos similar de lo esperado por el azar (divergencia de nicho). Seis pares de especies mostraron valores significativos de conservadurismo de nicho en uno o en ambos índices, como se indica, entre paréntesis, a continuación: $O$ andeanus - $O$. dichrous (D e I), O. andeanus - O. carrascoi (D e I), O. carrascoi - O. dichrous (D e I), $O$. andeanus - O. paucartambensis (I), y O. andeanus con el área accesible de $O$. paucartambensis (D), O. andeanus con el área accesible de O. ceballosi (D and I), y $O$. ceballosi con el área accesible de O. dichrous (I) (Fig. 8).

Solo se observó superposición significativa entre algunos pares de especies que se encuentran dentro de la misma ecorregión (ej. O. andeanus, O. carrascoi, O dichrous, $O$. ceballosi y 0 . paucartambensis). Sólo especies que habitan la misma ecorregión (ej. $O$. andeanus, O. carrascoi, O. dichrous, O. ceballosi y O. paucartambensis) mostraron superposición significativa con alguna otra especie, mientras que especies confinadas a diferentes ecorregiones (ej. O. hortensis y 0 . colcaensis) no mostraron superposición (Tabla 2). La superposición de nicho no depende de las relaciones filogenéticas: mientras que las especies hermanas $O$. andeanus - $O$. carrascoi muestra uno de los mayores valores de superposición, las especies hermanas O. ceballosi - O. paucartambensis no muestran ningún tipo de superposición (Tabla 2, Fig. 9). La especie que mostró superposición con el mayor número de especies fue 0 . andeanus (Tabla 2).

\begin{tabular}{|c|c|c|c|c|c|c|c|}
\hline$D / I$ & 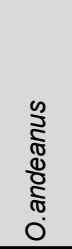 & 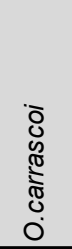 & $\begin{array}{l}\bar{s} \\
\stackrel{0}{\pi} \\
\mathbb{d} \\
0 \\
0 \\
0\end{array}$ & $\begin{array}{l}\frac{y}{0} \\
\mathbb{8} \\
\mathbb{J} \\
\frac{0}{0} \\
0 \\
0\end{array}$ & $\begin{array}{l}0 \\
0 \\
\frac{0}{0} \\
\frac{0}{0} \\
0\end{array}$ & $\begin{array}{l}\frac{\omega}{\omega} \\
\frac{2}{\Phi} \\
\frac{5}{5} \\
\frac{0}{0}\end{array}$ & 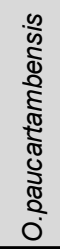 \\
\hline O.andeanus & & 0.48 & 0.28 & 0 & 0.52 & 0 & 0.41 \\
\hline O.carrascoi & 0.30 & & 0.16 & 0 & 0.47 & 0 & 0.04 \\
\hline O.ceballosi & 0.15 & 0.11 & & 0 & 0.33 & 0.03 & 0.04 \\
\hline O.colcaensis & 0 & 0 & 0 & & 0 & 0.02 & 0.02 \\
\hline O.dichrous & 0.35 & 0.23 & 0.15 & 0 & & 0.01 & 0.13 \\
\hline O.hortensis & 0 & 0 & 0.02 & 0.02 & 0.01 & & 0 \\
\hline O.paucartambensis & 0.26 & 0.01 & 0.02 & 0.01 & 0.10 & 0 & \\
\hline
\end{tabular}

Tabla 2: Valores de superposición de nicho. En la mitad superior se muestran los valores de distancia I de Hellinger y en la mitad inferior los valores de D de Schoener. Letras en negrita representan $p<0,05$. 

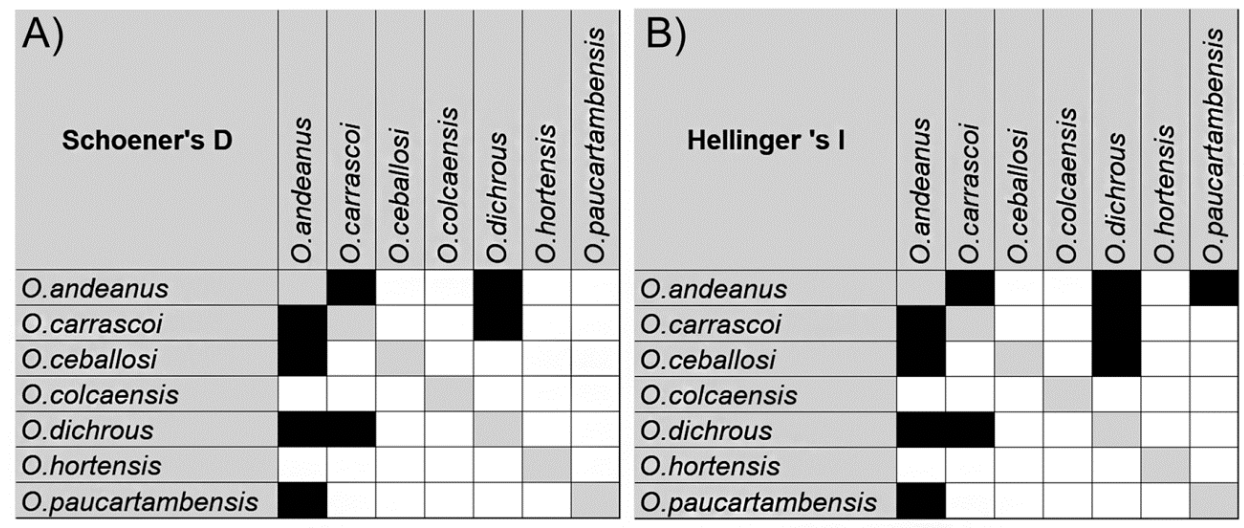

Figura 8: Resultados del test de similitud de conservadurismo de nicho entre pares de especies realizados con las distancias D de Schoener (I) y la I de Hellinger (II). Las filas representan los puntos de ocurrencia y las columnas el área accesible de la especie en el test de similitud. Los resultados basados en los dos índices son similares. La letra negrita indica que los nichos son más similares de lo esperado por el azar $(\mathrm{P}<0,05)$.
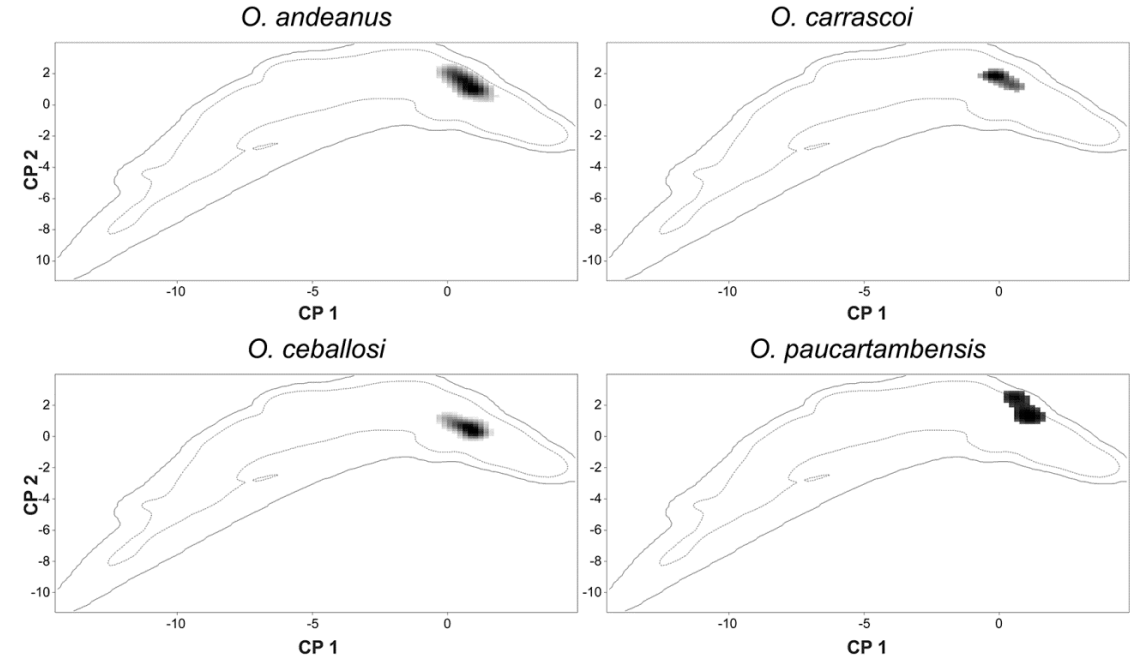

O. paucartambensis

Figura 9: Distribución ambiental de Broennimann para especies hermanas.

Análisis de Componentes Principales. La comparación de nicho realizado obtenido del Análisis de Componentes Principales (ACPs) y calculado a partir de todas las variables bioclimáticas, siguiendo la topología del árbol se muestra en la Figura 10. Como se indicó en la sección de Metodología, este análisis no constituye reconstrucciones ancestrales del nicho, sino que constituye una representación gráfica de cada ACP que fue calculado a partir de las especies que comprenden cada nodo (Smith \& Donoghue, 2010). Los primeros dos componentes principales explican entre el 75,4\% y el 96,8\% de la variación total (Tabla S2) en todos los análisis. El CP1representa principalmente las variables de temperatura. Entre las variables que más contribuyen a este componente son los cuartos más seco y frío (variable bioclimática 6, 9 y 11) variables que están relacionadas positivamente, y la temperatura estacional (variable bioclimática 4), rango anual de temperaturas (variable bioclimática 7), y rango promedio diario (variable bioclimática 2) 
están relacionadas negativamente. Las variables que tienen un mayor peso en el CP2 se corresponde con las variables de la precipitación (ej. Variable bioclimática 15, 18 y 19).

El test de ANOVA entre especies hermanas para el CP1 y CP2 brindó los siguientes resultados: entre 0 . paucartambensis - 0 . ceballosi se obtuvieron diferencias significativas a lo largo del CP1 ( $\mathrm{F}=40,23$; $\mathrm{P}=$ 9,8 E-6) (dominado por las temperaturas promedio anuales y de los cuartos más húmedos y cálidos) y las especies 0 . andeanus - O. carrascoi difieren significativamente a lo largo del CP2 (F = 25,01; P = 5,3E-5) (dominado por la precipitación de los cuartos más cálido y más frío y la precipitación anual). Orotettix colcaensis está claramente separada del nodo O. andeanus - O. carrascoi a lo largo del CP1. Asimismo, los gráficos de ACPs muestran que O. astreptos y 0 . lunatus están relacionadas cercanamente al espacio ambiental de $O$. dichrous. Mientras que $O$. colcaensis y $O$. hortensis están claramente diferenciadas a lo largo del CP1 del resto de las especies del género, y entre ellas por el CP2.

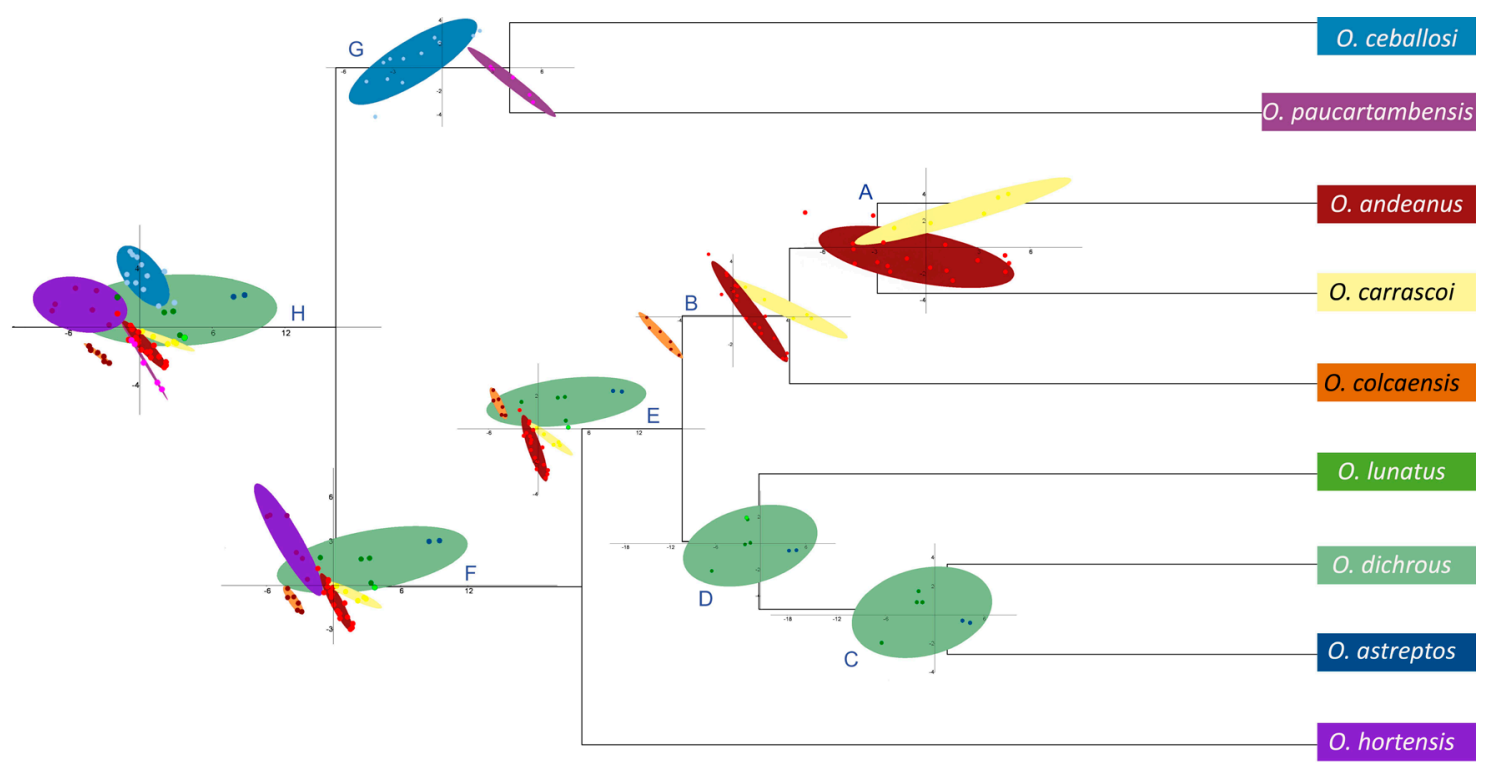

Figura 10: ACP de las 19 variables bioclimáticas graficado sobre la topología del árbol filogenético. El gráfico ilustrado sobre cada nodo muestra los resultados del ACP realizado para las especies incluidas en dicho nodo. Las letras en los nodos corresponden a la referencia de la Tabla 4

Modelado de Nicho

Los resultados de MNE realizado sobre las siete especies con la metodología de elipsoides (Fig. 11) y Maxent (Fig. 12) mostraron distribuciones geográficas similares. Los elipsoides muestran distribuciones ligeramente más restringidas para algunas especies, pero las predicciones generales coinciden con las distribuciones conocidas para las especies. Los modelados generados a partir de Maxent indican un rendimiento confiable 
(Tabla 3) con valores de área bajo la curva (AUC) que van desde 0,79 a 0,99. El análisis estadístico de "Delete-one jackknife approach" indica que se generaron modelos válidos con ambas metodologías, excepto para una especie (O. hortensis) con Maxent. Dado que ambas metodologías dieron resultados similares y uno de los modelos generados con Maxent no pudo validarse, se optó por realizar el resto de los análisis utilizando únicamente los resultados obtenidos con la metodología de elipsoides.

\begin{tabular}{|l|l|}
\hline Especie & AUC \\
\hline O. andeanus & 0.992 \\
O. carrascoi & 0.995 \\
O. ceballosi & 0.918 \\
O. colcaensis & 0.999 \\
O. dichrous & 0.911 \\
O. hortensis & 0.794 \\
O. paucartambensis & 0.998 \\
\hline \hline
\end{tabular}

Tabla 3: Valores de área bajo la curva (AUC) para los modelos generados en Maxent.

La distribución potencial de $O$. ceballosi comprende la mayor parte de la región noroeste de las tierras altas centrales y los profundos valles del río Apurimac. Por otro lado 0 . paucartambensis se encuentra restringida al límite superior de las Yungas en la Cordillera Oriental, en las laderas del río Huailluca y en las pendientes de ríos cercanos (Fig. 11A). La distribución potencial de Orotettix andeanus abarca los valles comprendidos desde el río Huailluca al Apurimac, y O. carrascoi se distribuye a lo largo del río Urubamba, superponiendo distribución con su especie hermana (Fig. 11B). Orotettix colcaensis se encuentra restringida casi exclusivamente al Valle del Colca en la Cordillera Occidental. (Fig. 11B). La distribución potencial de O. hortensis se extiende en el Altiplano en las tierras altas centrales entre los ríos Huailluca y Apurimac y 0 . dichrous abarca las tierras altas centrales en la cordillera Oriental (Fig. 11C).

Los modelos de elipsoides muestran que las especies 0 . hortensis y 0 . ceballosi presentan las mayores amplitudes de nicho, mientras que 0 . carrascoi, O. paucartambensis у O. colcaensis exhiben los menores valores (Tabla 4). La posición del centroide de nicho de cada especie en el espacio ambiental multivariado se representa en la Figura 13, donde se observa que los elipsoides de las especies que comparten la misma ecorregión se superponen en el espacio ambiental delimitado por los CPs, mientras que las especies que habitan diferentes ecorregiones (O. hortensis y $O$. colcaensis) se encuentran claramente separadas de las restantes especies del género. 


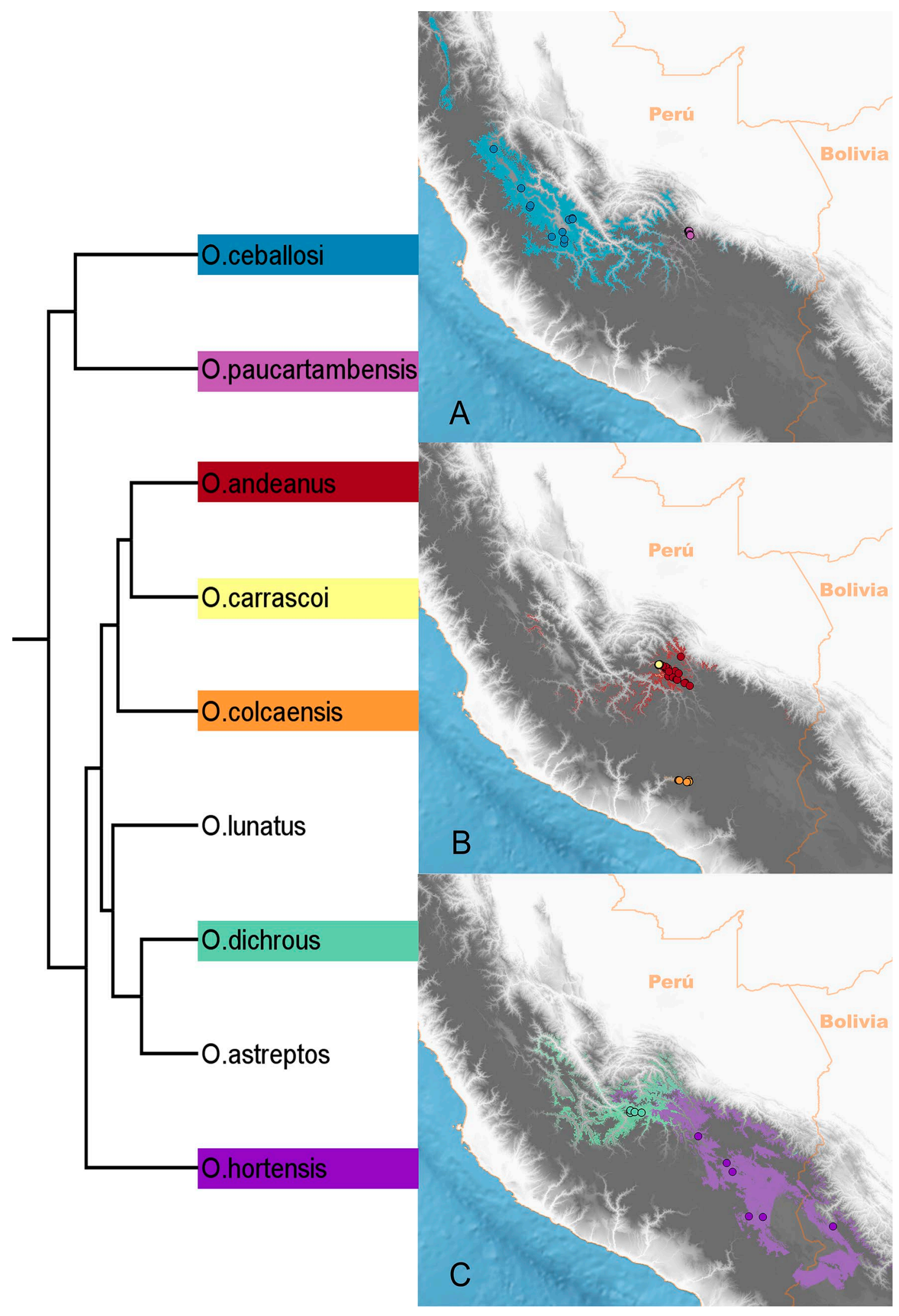

Figura 11: Distribuciones potenciales de las especies de Orotettix generadas con la metodología de Elipsoides e ilustradas siguiendo las relaciones filogenéticas. 


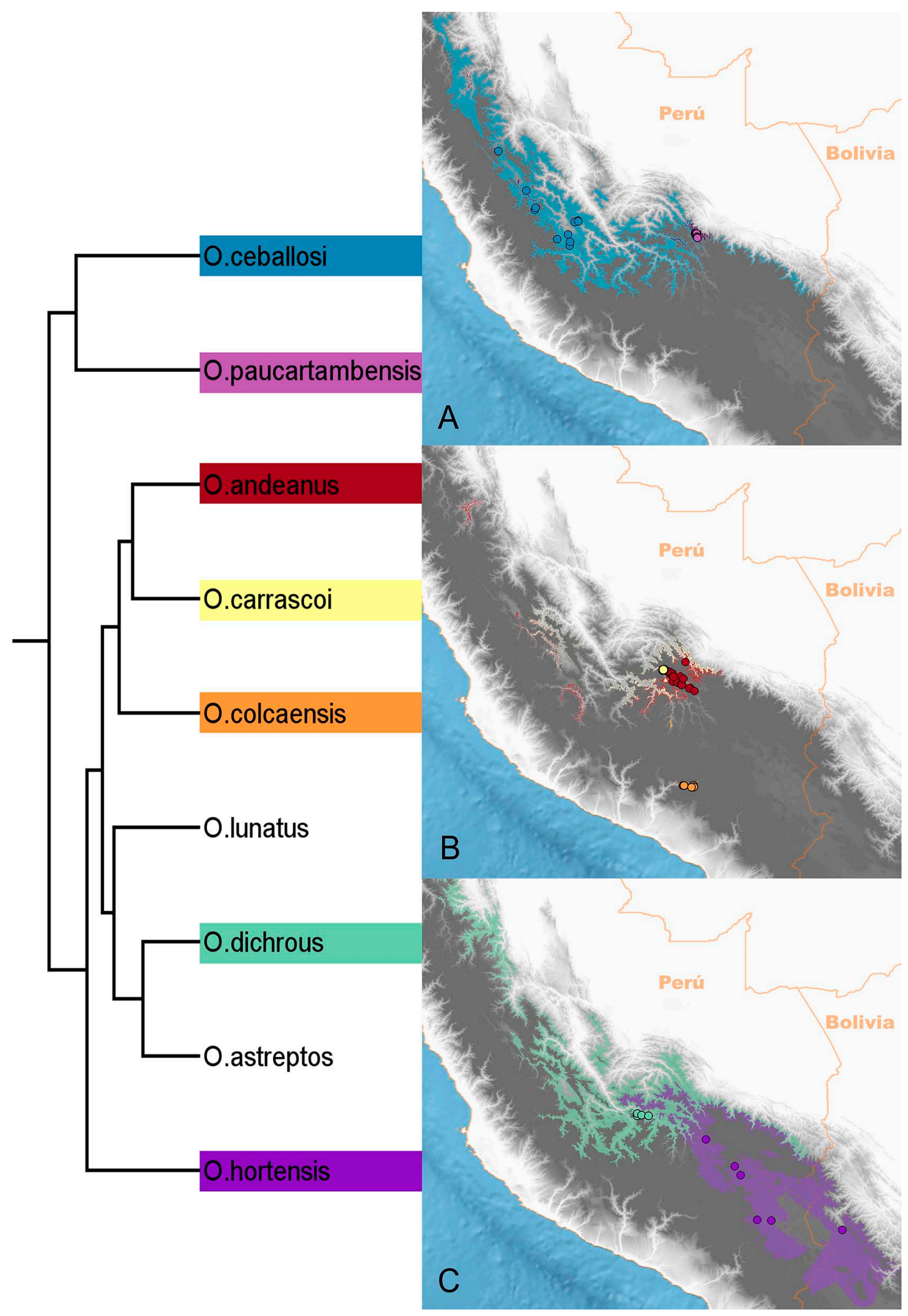

Figura 12: Mapas binarios generados con Maxent (10 \% umbral logístico) mostrando la distribución potencial de las especies de Orotettix, siguiendo las relaciones filogenéticas. 


\begin{tabular}{|c|c|}
\hline Especie & A.N. \\
\hline O.andeanus & 0.273 \\
O.carrascoi & 0.008 \\
O.ceballosi & 1.473 \\
O.colcaensis & 0.020 \\
O.dichrous & 0.646 \\
O.hortensis & 2.234 \\
O.paucartambensis & 0.015 \\
\hline
\end{tabular}

Tabla 4: Valores de amplitud de nicho (A.N.) de cada especie.

\section{Señal filogenética}

El test de Mantel no mostró resultados significativos para la correlación entre las distancias filogenéticas con los centros geográficos, los óptimos de nicho ni la superposición de nicho (Tabla 5). Sin embargo, la superposición de nicho estuvo negativamente correlacionada con las distancias filogenéticas $\left(r_{D}=-0,171 ; r_{I}=0,154\right)$. También se encontró que las distancias filogenéticas tenían una mayor asociación positiva con las distancias al centro geográfico $(r=0,26)$ que a los centroides de nicho $(r=0,005)$. Los valores de superposición de nicho mostraron mayor asociación con los centroides de nicho que con las distancias a los centros geográficos.

\begin{tabular}{|c|c|c|c|c|c|c|}
\hline \multirow{2}{*}{} & \multicolumn{5}{|c|}{ Dist. Filog. } & \multicolumn{2}{c|}{ D } \\
\cline { 2 - 7 } & D & I & C.G. & O.N. & C.G. & O.N. \\
\hline $\mathbf{r}$ & -0.171 & -0.154 & 0.259 & 0.005 & -0.652 & -0.729 \\
\hline
\end{tabular}

Tabla 5: Resultados del análisis de correlación de Mantel entre distancia filogenética, superposición de nicho, distancia de centro geográfico y distancia de centroide de nicho. "Dist. Filog." = distancia filogenética, O.N. = centroide/óptimo de nicho, C.G. = centro geográfico. D e I son los valores de superposición de nicho D de Schoener e I de Hellinger respectivamente. "r" es el coeficiente de correlación de Mantel, *p<0,05. 


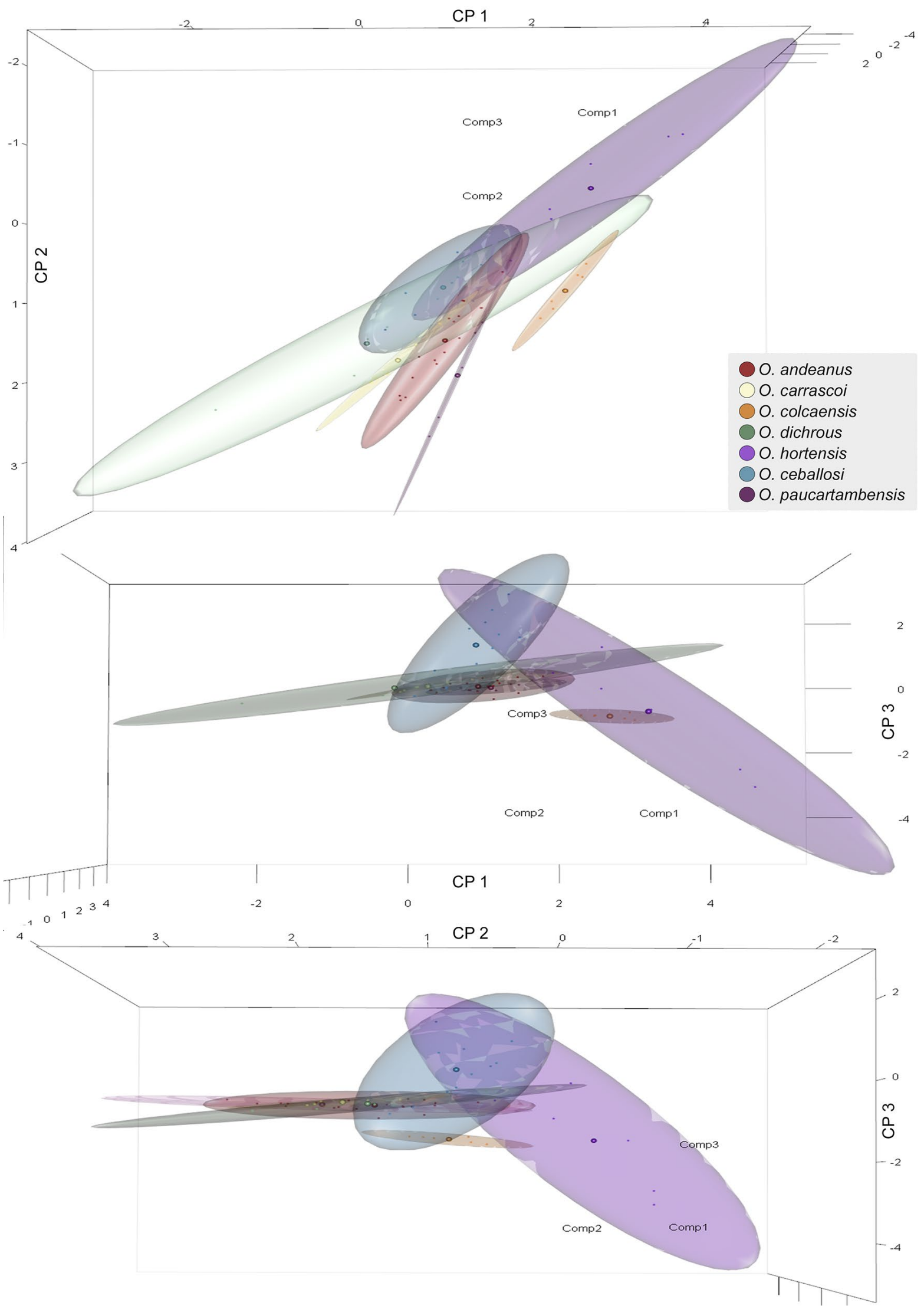

Figura 13: Modelos de nicho generados con la metodología de Elipses 


\section{DISCUSIÓN}

Relaciones filogenéticas y diversificación de especies.

En este estudio se recupera la monofilia del género y las relaciones filogenéticas entre las especies de Orotettix se resuelven con un alto soporte (Fig. 5). Las relaciones recuperadas entre los clados: O. paucartambensis - O. ceballos, ((O. astreptos - O. dichrous) O.lunatus $)$ ), y ((O. colcaensis (O. andeanus - O. carrascoi $)$ ) son altamente congruentes con la evidencia morfológica observada en la genitalia masculina en Pocco et al. (2015).

El patrón de diversificación en Orotettix (Fig. 5) sugiere que la especiación no se restringió a un único período geológico. La edad estimada de diversificación filogenética de Orotettix, alrededor de los 3,25 Ma., sugiere que el origen de las especies pudo haber coincidido con los ciclos glaciales-interglaciares ocurridos durante el Pleistoceno. Para ese momento el segundo levantamiento de los Andes ya habría cesado, coincidiendo con el último enfriamiento de las glaciaciones del Pleistoceno, que comenzaron en el Plioceno Tardío (Graham, 2012). Durante el Pleistoceno, los Andes Peruanos mostraron un paisaje complejo, caracterizado por cimas cubiertas de glaciares, valles secos y laderas de las montañas con marcados gradientes de humedad (Graham, 2009; Pocco et al., 2015), que se intensificaron con las glaciaciones (Imbrie et al., 2011). La combinación de altitudes máximas y temperaturas frías habría dado lugar al surgimiento de la vegetación de Páramo y de Puna alrededor de los 3 - 5 Ma., creando oportunidades para radiaciones adaptativas súbitas, características de los procesos de especiación de islas, como se ha sugerido para varios grupos de plantas y artrópodos (Hughes \& Eastwood, 2006; Graham, 2009; Cigliano \& Amedegnato, 2010; Särkinen et al., 2012; Pocco et al., 2013; Ceccarelli et al., 2016; Guzman et al., 2017). Como ya he mencionado anteriormente, las especies de Orotettix son morfológicamente muy similares y solo difieren en su genitalia interna, lo que sugiere que pudo haber existido un aislamiento reproductivo rápido, resultado de la selección sexual (Eberhard, 1985, 1996; Arnqvist, 1997). Este proceso rápido podría haber permitido la especiación en el grupo, independientemente de los frecuentes cambios ocurridos en las distribuciones asociados con los ciclos glaciales del Pleistoceno. Este patrón es similar al observado en los acridios melanoplinos de las Montañas Rocosas de América del Norte (Knowles \& Otte, 2000).

Los análisis realizados utilizando varios enfoques proporcionan evidencia acerca de los procesos de diversificación ocurridos en Orotettix. El par de especies O. ceballosi - $O$. paucartambensis habitan en alopatría (Fig. 11) y no presentan superposición ambiental 
(Figs. 9, 10, 13), sin mostrar señal de conservadurismo de nicho (Tabla. 2). En el ACP muestran diferencias significativas a lo largo del CP1 [(dominado por temperatura promedio anual, variable bioclimática 1) y temperaturas de los cuartos más húmedos y más cálidos (variables bioclimáticas 8 y 10, respectivamente)] (Fig. 7) y también se encontraron diferencias en la mayoría de las variables de precipitación, excepto la estacional. Orotettix ceballosi muestra uno de los mayores valores de amplitud de nicho (Tabla 4) y una de las tolerancias más amplias del género en la mayoría de las variables ambientales (Figs. 6, 7), mientras que 0. paucartambensis muestra uno de los valores más bajos de amplitud de nicho (Tabla 4) y valores de precipitación extremadamente restringidos para el mes más seco (variable bioclimática 14), cuarto más seco (variable bioclimática 17) y cuarto más frío (variable bioclimática 19). Orotettix ceballosi se distribuye ampliamente en la región noroeste de las tierras altas centrales, donde la planicie de altura que las caracteriza da lugar a un sistema de profundos valles, separados por cordones montañosos orientados NO-SE (Gonzalez \& Pfiffner, 2012; Blandin \& Purser, 2013); mientras que 0 . paucartambensis está restringida al límite superior de las Yungas en las laderas este de la Cordillera Oriental (Gonzalez \& Pfiffner, 2012).

Orotettix hortensis muestra una de las distribuciones más amplias (Fig. 11) y los mayores valores de amplitud de nicho del género (Fig. 13; Tabla 4), sin evidenciarse superposición de nicho con el resto de las especies (Tabla 2). Asimismo, se diferencia claramente de las restantes especies de Orotettix en el espacio ecológico a lo largo del CP1 (Fig. 10) mostrando el mayor rango de tolerancia en temperatura (diurna, estacional y anual) y tolerancia a las temperaturas más frías (Figs. 6, 7). Orotettix hortensis es la especie que más se diferencia del género no solo con respecto a su nicho, sino también a su morfología, ya que es la única especie del género que puede ser reconocida por sus caracteres morfológicos externos (Pocco et al., 2015). Asimismo, es la única especie que se extiende hacia el sudeste de la distribución del género, donde las tierras altas centrales se abren en el Altiplano Boliviano. Topográficamente, el relieve del altiplano es moderado en comparación con las empinadas laderas de las cordilleras Oriental y Occidental de los Andes. Las temperaturas son más constantes durante el año, pero muestran una amplitud diaria mayor (Sarmiento, 1986).

Otra de las especies con distribución alopátrica y sin superposición de nicho con las restantes especies del género es $O$. colcaensis (Tabla 2). Contrario al patrón observado en 0 . hortensis, se caracteriza por una amplitud de nicho extremadamente reducida (Fig. 13; Tabla 4). Orotettix colcaensis se diferencia claramente en el espacio ecológico del resto de las especies a lo largo del CP1 y de O. hortensis a lo largo del CP2 (Fig. 10). Muestra los 
valores de precipitación más bajos del género para el mes más seco, el cuarto más seco y el cuarto más frío (Figs. 6, 7). Es la única especie endémica de la Cordillera Occidental, distribuida a lo largo del Valle del Colca, uno de los cañones más profundos del mundo, que debe haber influido en su diversificación. Las especies hermanas O. andeanus - $O$. carrascoi son las únicas que presentan superposición significativa, por lo tanto se sugiere que para ellas existiría conservadurismo filogenético de nicho (CFN; Tabla 2). También se encontraron varios niveles de superposición en sus nichos (Figs. 9, 10, 13). Orotettix carrascoi muestra valores levemente mayores que 0 . andeanus para las variables de temperatura (Figs. 6, 7). Estas especies hermanas se distribuyen en la cordillera Oriental junto con 0 . dichrous, que muestra una de las mayores amplitudes de nicho (Tabla 4) para el género, evidenciando superposición significativa (Tabla 2, 10) con $O$. andeanus y $O$. carrascoi. Orotettix dichrous y su especie hermana, O. astreptos, se encuentran muy cercanas geográficamente, superponiendo su espacio ambiental (Fig. 10). Orotettix astreptos se encuentra restringida al límite superior o inferior de la distribución ambiental de 0 . dichrous (Figs. 6, 7). La región que alberga estas especies en la cordillera Oriental, se caracteriza por sus profundos valles (Blandin \& Purser, 2013), que crean barreras biogeográficas que podrían haber promovido la diversificación de Orotettix.

\section{Evolución de Nicho}

Los resultados indican que algunos pares de especies mostraron conservadurismo de nicho (Tabla 2) pero ningún par mostró mayor divergencia de la esperada por el azar. En función de estos resultados y la compleja topografía existente en la zona, se infiere que la especiación alopátrica podría haber sido el patrón predominante en la diversificación del género. Asimismo, algunas especies filogenéticamente cercanas difieren levemente $(O$. andeanus - O. carrascoi), mientras que otras son muy diferentes (O. paucartambensis - $O$. ceballosi) ecológicamente. También se observó el patrón inverso, donde especies distantes filogenéticamente son ecológicamente muy similares (O. andeanus - O.paucartambensis) (Tabla 2, Figs. 9, 10). Los resultados también indican que la diferenciación de nicho ocurrió a una velocidad donde solo las similitudes ecológicas entre especies cercanas presentan señal filogenética evidente. Sin embargo, la falta de correlación entre distancia filogenética vs. distancia geográfica, centroides ambientales y superposición de nicho indicaría que no hay una asociación significativa entre la filogenia y el nicho ambiental o el espacio geográfico (Tabla 5). Varios autores (Webb et al., 2002; Edwards \& Donoghue, 2006; Losos, 2008) han sugerido que la falta de señal filogenética puede deberse a un fenómeno de islas y, coincidentemente, los patrones de diversificación en los Andes han sido muchas veces comparados con este tipo de proceso (Hughes \& Eastwood, 2006; 
Särkinen et al., 2012; Husemann et al., 2013; Guzman et al., 2017). (Husemann et al, 2013; Guzman et al., 2017). Patrones similares de diversificación a los aquí observados también se evidencian en otros grupos de animales y plantas (Chesser, 2000; Young et al., 2001; Hughes \& Eastwood, 2006; Koscinski et al., 2008; Sáez et al., 2014; Benham \& Witt, 2016). Estudios recientes en los Andes centrales de Perú del género de tucuras Trimerotropis Stål también muestran un patrón de diversificación rápida promovida por una topografía compleja combinada con condiciones climáticas inestables del Pleistoceno (Guzman et al., 2017). Comparativamente, otros géneros de acridios Melanoplinos, como Jivarus GiglioTos, Maylasacris Cigliano \& Amédégnato, Huaylasacris Cigliano, Pocco \& Lange, Tiyantiyana Cigliano, Pocco \& Lange, Maeacris Ronderos, Pediella Roberts y Ponderacris Ronderos \& Cigliano también constituyen ejemplos de endemismos y diversificaciones recientes en los Andes Centrales y Septentrionales (Cigliano \& Amedegnato, 2010; Cigliano et al., 2011; Pocco et al., 2013).

Basados en la falta de señal filogenética y la evidencia obtenida a partir de los patrones biogeográficos y ecológicos encontrados en este estudio, se considera que la diversificación en Orotettix pudo haber sido impulsada principalmente por el aislamiento geográfico, combinado con oportunidades ecológicas dadas por los hábitats emergentes posteriores al surgimiento de los Andes. La topografía compleja del paisaje, unido a las fluctuaciones del Cuaternario desencadenadas por las glaciaciones, podrían haber llevado a la diferenciación de las especies altamente endémicas de Orotettix. 


\section{CAPÍTULO 2: DIVERSIFICACIÓN DEL GRUPO DE GÉNEROS SCOTUSSAE}

(ORTHOPTERA: ACRIDIDAE)

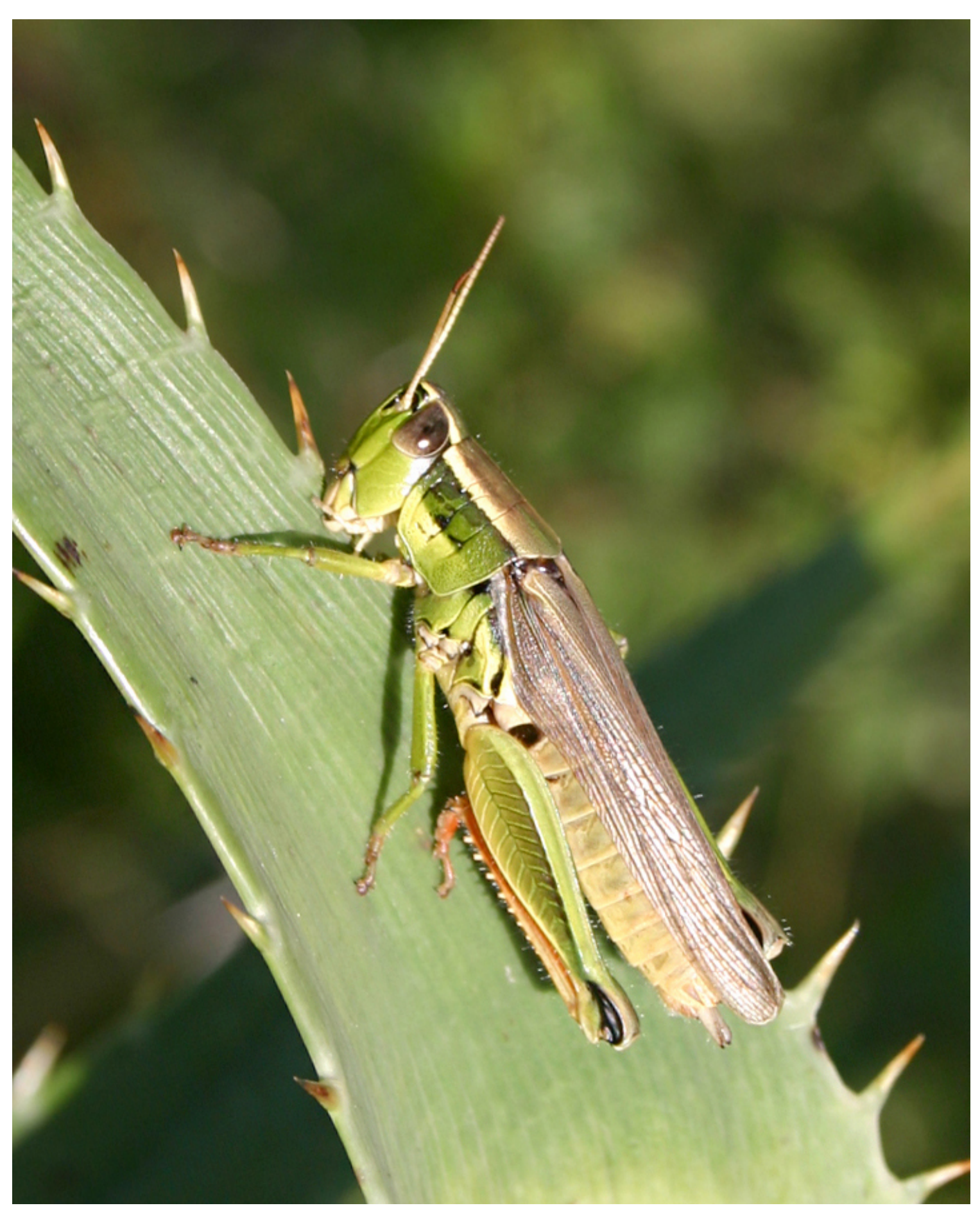




\section{INTRODUCCIÓN}

Como se mencionó previamente, dentro de la tribu Dichroplini, Ronderos (1981) considera que habrían existido dos centros de diversificación, uno en los Andes y el otro a nivel de la cuenca Parano-Platense, donde se habría llevado a cabo la mayor diversificación la tribu Dichroplini. Dentro de esta región Ronderos (1981) caracterizó a los géneros: Leiotettix Bruner, Eurotettix Bruner, Dichromatos Cigliano, Atrachelacris Giglio-Tos, Chlorus Bruner, Scotussa Giglio-Tos y Ronderosia Cigliano, como "netos pobladores Paranense-Pampeanos". Asimismo, estudios filogenéticos recientes (Dinghi et al., 2009) establecieron que este grupo de géneros, compuesto por 7 géneros y 48 especies válidas, (Cigliano et al., 2018), constituye un clado dentro de la tribu al que denominaron Scotussae. Este grupo de géneros, se distribuye en los ecosistemas abiertos del Bosque Tropical Seco Estacional (BTSE), Bosque Lluvioso Tropical (BLT), la Pampa, el Chaco, el Cerrado y Biomas del Sur (Fig. 14).

Scotussae es un grupo diverso, presentando formas, tanto braquípteras como macrópteras, con especies caracterizadas por distribuciones extremadamente reducidas a muy amplias (abarcando casi la mitad del continente Sudamericano), e incluso incluye especies desde muy raras hasta muy abundantes y perjudiciales para el agro (Carbonell et al., 2018).

Todos sus integrantes, al igual que los restantes melanoplinos Neotropicales, oviponen en el suelo (hipodáfica) a excepción del género Scotussa, donde se ha registrado oviposición sobre hojas de plantas (Liebermann, 1951; Zolessi, 1958; Mesa \& Zolessi, 1968). La homogeneidad en la estructura del ovipositor de las especies de Dichroplini contrasta con la diversidad morfológica presente en Scotussa, donde todas sus especies se caracterizan por presentar un ovipositor con valvas rectas, pero altamente variable (Cigliano \& Ronderos, 1994; Cigliano, 1997). Sobre la base de un estudio filogenético morfológico de Scotussa y Leiotettix, Cigliano, Ronderos, \& Kemp, (1996) determinaron que los caracteres de las valvas del ovipositor son informativos a nivel específico y consideraron que el cambio estructural de este carácter observado en Scotussa estaría asociado con un cambio en el hábito de oviposición de las especies. Si bien Cigliano, Ronderos, \& Kemp, (1996) mencionan que este cambio estructural en el ovipositor podría estar relacionado con una distribución más amplia del género en comparación con el género hermano, Leiotettix, se desconoce cuáles habrían sido las ventajas adaptativas, si es que existieron, que esta novedad evolutiva pudo haber aportado a las especies de Scotussa. 


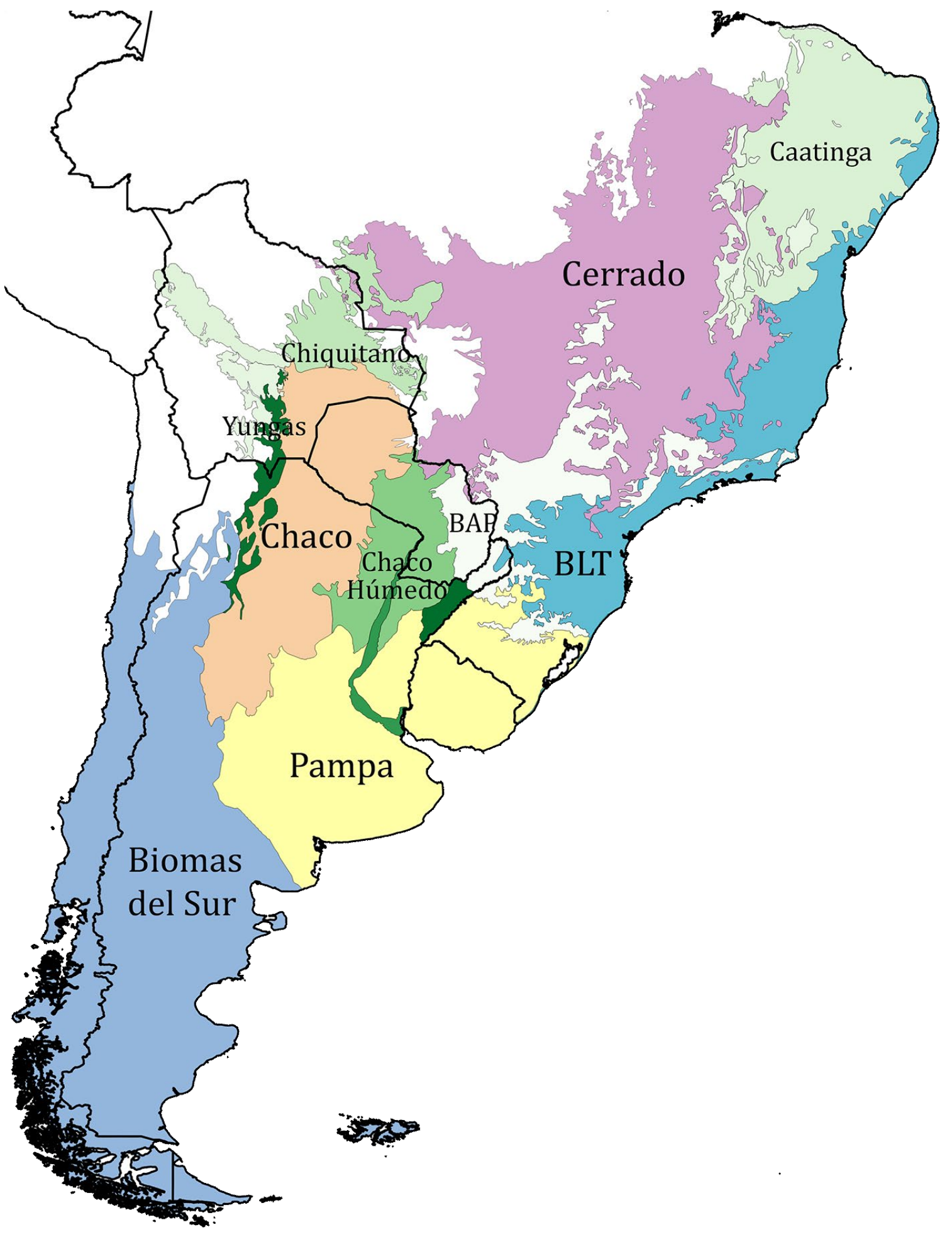

Figura 14: Mapa de la región de estudio

El grupo también se caracteriza por presentar re-arreglos cromosómicos complejos, muchos de los cuales son informativos a nivel genérico y/o específico (Castillo et al., 2018). Así, por ejemplo, Dichromatos presenta un mecanismo de determinación del sexo exclusivo para el género (Carbonell \& Mesa, 2006). Especies de los géneros Scotussa y Leiotettix presentan una alta variabilidad de re-arreglos, pudiendo encontrarse diversos 
mecanismos de determinación, así como cromosomas neo-sexuales (Mesa et al., 1982), mientras que las especies de Atrachelacris no presentan re-arreglos cromosómicos característicos (Mesa et al., 1982; Castillo et al., 2018). Estudios recientes realizados en el género Ronderosia muestran que sus especies presentan reordenamientos cromosómicos, diversos sistemas de determinación de cromosomas neo-sexuales y en menor medida, fusión central Autosoma-Autosoma (Castillo et al., 2010 a, b; 2018).

En función de la gran diversidad observada en este clado, característico de la región de mayor diversificación de la tribu, se considera relevante aplicar un enfoque integrativo sobre la evolución y biogeografía del grupo Scotussae. Para dichos estudios se analizarán los patrones biogeográficos históricos que permitan explicar la distribución actual del grupo de géneros Scotussae; los roles de la ecología, la geografía y la prevalencia del conservadurismo filogenético de nicho vs. la divergencia de nicho; las posibles interacciones en la configuración y estructuración de los patrones geohistóricos de la diversidad. Esto permitirá establecer los posibles roles de los factores extrínsecos (ambientales, geohistóricos) e intrínsecos (morfología alar, ovipositor, cromosomas) que impulsan la diversificación, cómo interactúan entre si y si determinan patrones diferentes de especiación.

\section{MATERIALES Y MÉTODOS}

\section{Análisis Filogenético}

Se utilizaron 50 especímenes de la tribu Dichroplini para el análisis filogenético. Los ejemplares representan 28 especies del grupo Scotussae y cuatro especies seleccionadas como grupos externos (Orotettix colcaensis, O. hortensis, O. paucartambensis y Neopedies brunneri (Giglio-Tos, 1894)) (Tabla 6). Las secuencias de regiones de tres genes (COI, H3, ND2) se examinaron, recortaron y alinearon usando Geneious 6.1.6 (http://www.geneious.com, Kearse et al., 2012). Se utilizó JModelTest v. 2.1.7 (Posada, 2008) para determinar el modelo de evolución molecular apropiado para cada conjunto de datos (COI: GTR+I+G; ND2: HKI +G, HIS: F81+I) basándose en el Criterio de Información Bayesiano (BIC).

También se realizó un análisis filogenético morfológico de las especies basándose en las revisiones taxonómicas de cada género y en la observación de caracteres a partir de materiales de las colecciones del MLP, FCMU y MACN (Museo de La Plata, Museo Argentino de Ciencias Naturales "Bernardino Rivadavia", Facultad de Ciencias, Uruguay). Se registraron 18 caracteres de la morfología externa, 11 de la genitalia masculina, 2 de las 
valvas ovipositor (Figs. 15, 16; Tabla 7). Se construyó una matriz de los 30 caracteres morfológicos por las 32 especies mencionadas anteriormente (se asignaron los mismos estados a todos los ejemplares pertenecientes a la misma especie; Tabla 8).

La distribución posterior del árbol filogenético se exploró utilizando el algoritmo bayesiano basado en Cadenas de Markov implementado en BEAST 2.4.7 (Bouckaert et al., 2014). El archivo de entrada de BEAST fue generado con el programa BEAUti 2.4.7 (Bouckaert et al., 2014). Las tres regiones genéticas y los datos morfológicos se analizaron simultáneamente, cada partición se trató independientemente para los modelos de sustitución, pero fueron combinados para el cálculo de los modelos de reloj molecular y la construcción del árbol. El proceso de especiación de Yule fue seleccionado como prior del árbol y se estableció como constante el tamaño poblacional. Se corrieron 10.000.000 generaciones para asegurar la convergencia, muestreando los árboles cada 1.000 generaciones. Se infirió que se había alcanzado la convergencia cuando el tamaño muestreal efectivo fue mayor a 200. Se descartó el primer $10 \%$ de los árboles guardados ("burn in"), luego de asegurarse que los valores de verosimilitud habían alcanzado una meseta, aplicando el programa Tracer 1.6 (Rambaut et al., 2014). Se calculó el árbol de máxima credibilidad con el TreeAnnotator v1.7.5 (Drummond \& Rambaut, 2007). Se $\begin{array}{lllllll}\text { visualizaron los árboles en el programa } & \text { FigTree } & 1.4 .2\end{array}$ (http://tree.bio.ed.ac.uk/software/figtree/) mostrando las probabilidades posteriores como soporte de las ramas.

Se estimó la edad del nodo basal del cladograma con el programa BEAST sobre un conjunto restringido de datos, tomando en cuenta solo un individuo por especie y usando la tasa de sustitución del COI de 1,6 \% "substituciones/sitio/linaje/Ma.", estimada para grillos cavernícolas (Allegrucci et al., 2011). Este valor se asignó al nodo basal del cladograma original, a partir del cual se estimaron las edades de los demás nodos del árbol. 


\begin{tabular}{|c|c|c|c|}
\hline Ejemplar & COI & ND2 & HIS \\
\hline A_olivaceus & MH122543 & - & - \\
\hline A_olivaceus_3658 & $*$ & $*$ & $*$ \\
\hline A_olivaceus_DQ083451 & DQ083451.1 & - & - \\
\hline A_unicolor_75 & $*$ & $*$ & $*$ \\
\hline A_unicolor & MH122544 & - & - \\
\hline A_unicolor_Amedeg & AY014360.1 & AY014359.1 & \\
\hline C_bolivianus_FJ829333 & FJ829333.1 & - & - \\
\hline$C_{-}$chiquitensis_C1 & $*$ & - & $*$ \\
\hline C_chiquitensis_FJ829340 & FJ829340.1 & - & - \\
\hline C_spatulus_FJ829335 & FJ829335.1 & - & - \\
\hline C_vittatus & MH122545 & - & - \\
\hline D_lilloanus_E3 & $*$ & $*$ & $*$ \\
\hline D_schrottkyi & MH122547 & - & - \\
\hline D_schrottkyi_FJ829339 & FJ829339.1 & - & - \\
\hline E_minor & MH122548 & - & - \\
\hline L_flavipes_4779 & $*$ & $*$ & $*$ \\
\hline$L_{-}$flavipes_4817 & $*$ & $*$ & $*$ \\
\hline L_flavipes_4893 & $*$ & $*$ & $*$ \\
\hline L_pulcher_105_2 & $*$ & $*$ & $*$ \\
\hline L_pulcher_4905 & $*$ & $*$ & $*$ \\
\hline L_pulcher_DQ083464 & DQ083464.1 & - & - \\
\hline L_sanguineus_DQ083465 & DQ083465.1 & - & - \\
\hline L_viridis_AY014353 & AY014353.1 & AY014352.1 & - \\
\hline Neopedies_72_3 & $*$ & $*$ & $*$ \\
\hline$R \_$bergi_DQ083467 & DQ083467.1 & - & - \\
\hline$R \_$bergii & MH122550 & - & - \\
\hline R_bergii_32 & $*$ & $*$ & $*$ \\
\hline R_bergii_3559 & $*$ & $*$ & $*$ \\
\hline R_bergii_Amedeg & AF539844.1 & AF539843.1 & - \\
\hline$R \_$cinctipes & MH122551 & - & - \\
\hline R_dubia & MH122552 & - & - \\
\hline$R_{-}$forcipata_3594 & $*$ & $*$ & $*$ \\
\hline$R \_$gracilis & MH122554 & - & - \\
\hline$R_{-}$paraguayensis & MH122556 & - & - \\
\hline S_brachyptera_3545 & $*$ & $*$ & $*$ \\
\hline S_brachyptera_3552 & $*$ & $*$ & $*$ \\
\hline S_brachyptera_3563 & $*$ & $*$ & $*$ \\
\hline S_cliens_3500 & $*$ & - & $*$ \\
\hline S_cliens_3535 & $*$ & $*$ & $*$ \\
\hline S_cliens_3568 & $*$ & $*$ & $*$ \\
\hline S_daguerrei_3503 & $*$ & $*$ & $*$ \\
\hline S_daguerrei_71-1 & $*$ & $*$ & $*$ \\
\hline S_impudica_3562 & $*$ & $*$ & $*$ \\
\hline S_impudica_7110 & $*$ & $*$ & $*$ \\
\hline S_lemniscata_105_3 & $*$ & $*$ & $*$ \\
\hline S_lemniscata_3537 & $*$ & $*$ & $*$ \\
\hline O.colcaensis_SC154 & MG948534 & MG948487 & MG948515 \\
\hline O.hortensis_SC142 & MG948536 & MG948492 & MG948520 \\
\hline O.paucartambensis_SC2 & MG948537 & MG948498 & MG948526 \\
\hline O.paucartambensis_SC3O & MG948538 & MG948499 & MG948527 \\
\hline
\end{tabular}

Tabla 6: Secuencias utilizadas en el análisis filogenético, con asterisco se indican las secuencias realizadas para este trabajo. 
0. Relación cabeza/pronoto: tan ancho como (0); más ancho(1); más angosto (2)

1. Desarrollo del fastigium en vista dorsal: poco prominente (0); prominente (1)

2. Carenas Laterales del fastigium: ausente (0); presente (1)

3. Distancia interocular: ancha (0); angosta (1); extremadamente angosta (2)

4. Pronoto: esbelto (0); robusto (1)

5. Bordes laterales de la metazona (vista dorsal): paralelos (0); ligeramente divergentes (1); muy divergentes (2)

6. Bordes laterales de la prozona (vista dorsal): paralelos (0); trapezoidal (1)

7. Margen posterior del disco del pronoto: emarginado (0); expandido (1)

8. Expansión del margen posterior del disco del pronoto: angulada (0); redondeada (1)

9. Fémur posterior: robusto (0); elongado (1)

10. Desarrollo de la tegmina: macróptero (0); braquíptero (1)

11. Tegmina braquíptera: elongada (0); ovalada (1)

12. Ápice de la tegmina braquíptera: semicircular (0); truncada (1); subangular (2); angular (3)

13. Color de la tegmina: homogénea (0); con la porción dorsal más clara que la porción lateral (1); con la porción dorsal con colores brillantes (2)

14. Banda postocular: ausente (0); presente (1)

15. Frente en vista lateral: recta (0); curva (1)

16. Pilosidad en el cuerpo: normal (0); abundante (1)

17. Dimorfismo sexual en la coloración del cuerpo: ausente (0); presente (1)

18. Ápice de la placa subgenital del macho: angulado (0); redondeado (1)

19. Forma de los cercos del macho: recto (0); cónico (1); lanceolado (2); lanceolado con porción distal extremadamente/muy curvada (3)

20. Porción distal del cerco del macho: elongado (0); globoso (1)

21. Cerco del macho: recto (0); curvados hacia adentro gradualmente (1); curvados hacia adentro en ángulo recto (2)

22. Lophi del epiphallus con protuberancia interna cónica (vista dorsal): ausente (0); presente (1); muy prominente (2)

23. Forma del lophi del epiphallus: rectangular (0); elongado horizontalmente (1)

24. Lóbulo medio de la vaina del aedeagus: no desarrollado (0) tan largo como los lóbulos laterales

(1); sobrepasando levemente los lóbulos laterales (2); sobrepasando ampliamente los lóbulos laterales (3)

25. Dirección de las valvas apicales del aedeagus: paralelas (0); curvadas hacia adentro (1); divergen caudalmente (2)

26. Porción divergente de valvas apicales: bien desarrollada (0); reducida (1)

27. Forma de las valvas apicales del aedeagus: subcilíndrica (0); lanceolada (1); aplanada (2)

28. Valvas dorsales del ovipositor (vista dorsal): convergentes (0); divergentes (1)

29. Valvas del ovipositor (vista lateral): curvadas (0); rectas y angostas (1); rectas y robustas (2)

Tabla 7: caracteres morfológicos considerados en el análisis filogenético (Figs. 15, 16). 


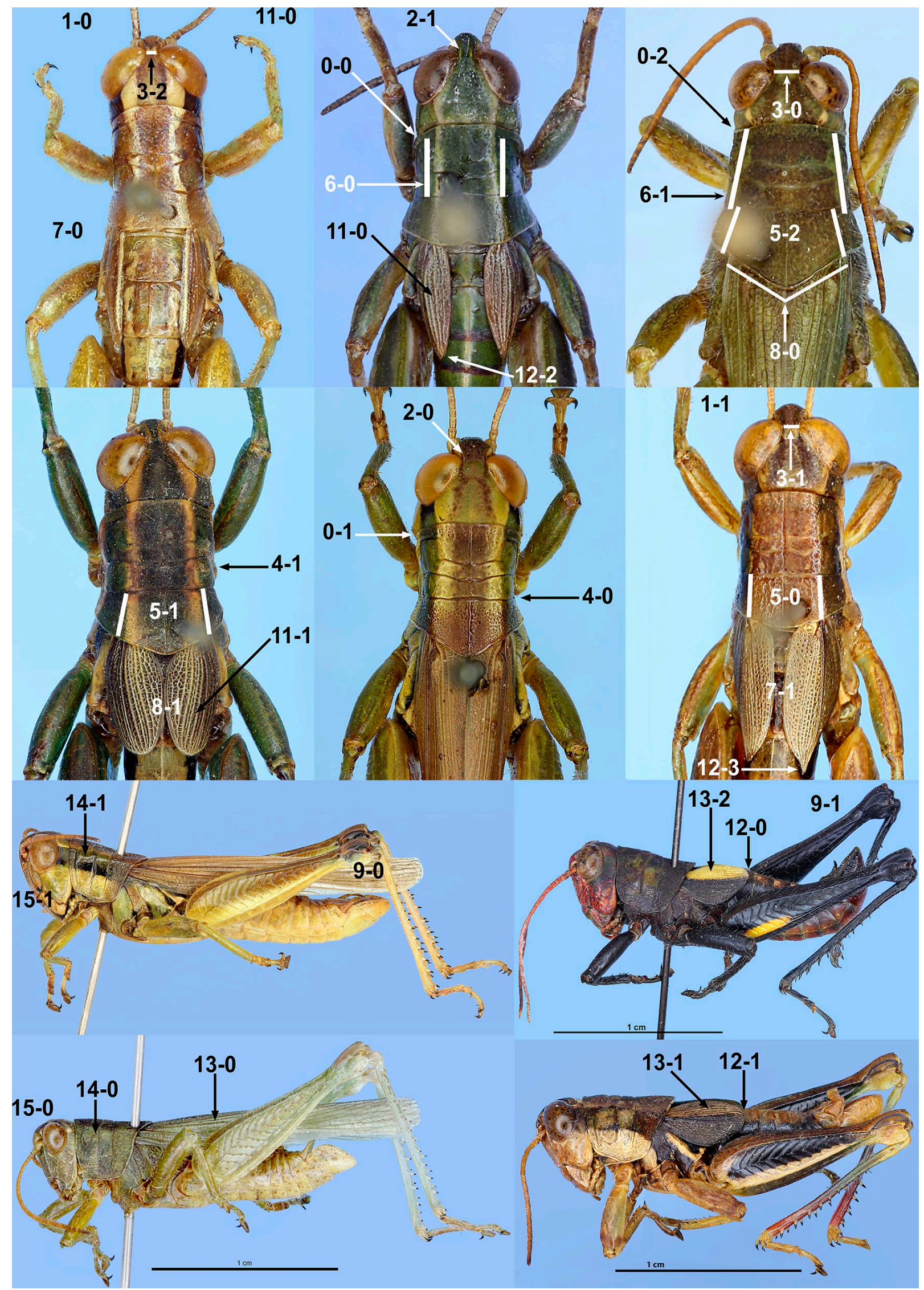

Figura 15: Caracteres de la morfología externa. Número y estados de caracteres según se indica en la Tabla 7. 


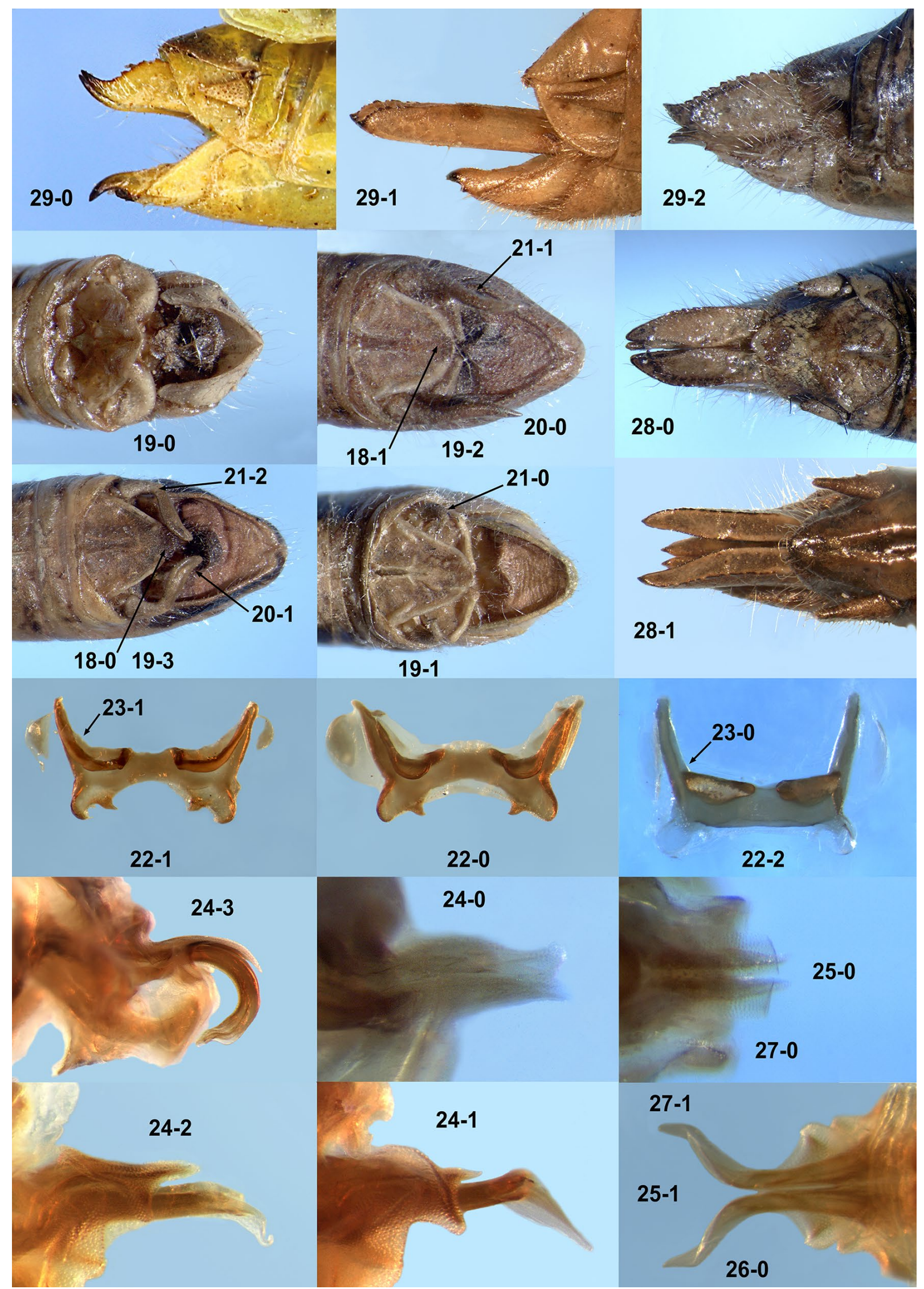

Figura 16: Caracteres de la genitalia del macho interna y externa y caracteres del ovipositors de la hembra. Número y estados de caracteres según se indica en la Tabla 7. 


\begin{tabular}{|c|c|c|c|c|c|c|c|c|c|c|c|c|c|c|c|c|c|c|c|c|c|c|c|c|c|c|c|c|c|c|}
\hline & & 1 & 2 & 3 & 4 & 5 & 6 & 7 & 8 & & 10 & 11 & & 13 & 14 & & 16 & 17 & 18 & 19 & 20 & 21 & 22 & 23 & 24 & 25 & 26 & & 28 & \\
\hline A olivaceus & 2 & 1 & 0 & 0 & 0 & 2 & 1 & 1 & 0 & 0 & 0 & - & - & 0 & 0 & 0 & 1 & 0 & 0 & 2 & 0 & 0 & 1 & 0 & 1 & 1 & 0 & 0 & 0 & 0 \\
\hline color & & 1 & 1 & 0 & 0 & 2 & 1 & 1 & 0 & 0 & 0 & - & _ & 0 & 0 & 0 & 1 & 0 & 0 & 1 & 0 & 0 & 1 & 0 & 1 & 1 & 0 & 0 & 0 & 0 \\
\hline & 0 & & 1 & 1 & & & 0 & $\perp$ & 1 & 0 & 1 & 1 & 1 & & 1 & & & & & 2 & 1 & & & & 3 & & 1 & & & \\
\hline & 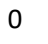 & 1 & 1 & 1 & $\perp$ & $\perp$ & 0 & + & 1 & 0 & 1 & 1 & 1 & 1 & 1 & 0 & 0 & $\sigma$ & & 3 & + & 2 & 1 & & 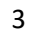 & 1 & 1 & & 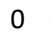 & O \\
\hline C. spatulus & 0 & 1 & 1 & 1 & 1 & 1 & 0 & 1 & 1 & 0 & 1 & 1 & 1 & 1 & 1 & 0 & 0 & 0 & 0 & 2 & 1 & 2 & 1 & 0 & 3 & 1 & 1 & 2 & 0 & 0 \\
\hline & 0 & 1 & 1 & 1 & 1 & 1 & 0 & 1 & 1 & 0 & 1 & 1 & 1 & 1 & 1 & 0 & 0 & 0 & 0 & 2 & 1 & 2 & 1 & 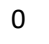 & 3 & 1 & 1 & & 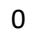 & 0 \\
\hline & 0 & 1 & 1 & 1 & 1 & 1 & 0 & 1 & 1 & 1 & 1 & $\perp$ & 0 & 0 & 0 & 0 & 0 & 1 & & 1 & & 1 & 0 & 0 & 2 & & 1 & 0 & b & \\
\hline D. schottkyi & 0 & 1 & 1 & 1 & 1 & 1 & 0 & 1 & 1 & 1 & 1 & 1 & 0 & 2 & 0 & 0 & 0 & + & 1 & 1 & 0 & 1 & 0 & 0 & 2 & 1 & 1 & 0 & 0 & \\
\hline & 0 & 0 & 1 & 1 & 1 & 1 & 0 & 1 & 1 & 0 & 1 & 1 & 0 & 0 & 1 & 0 & 0 & 0 & 0 & 2 & 0 & 0 & 1 & 0 & 2 & 1 & 1 & 0 & 0 & 0 \\
\hline & 1 & 1 & 0 & 1 & 0 & 0 & 0 & 1 & 0 & 0 & 0 & - & 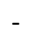 & 0 & 0 & 1 & 0 & 0 & 0 & 2 & 0 & 1 & 0 & 0 & 2 & 1 & 0 & 1 & 0 & 0 \\
\hline & 1 & 1 & 0 & 1 & 0 & 0 & 0 & 1 & 0 & 0 & 0 & - & 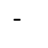 & 0 & 1 & 1 & 0 & 0 & 0 & 2 & 0 & 1 & 1 & 1 & 2 & 1 & 0 & 1 & 0 & 0 \\
\hline & 1 & 1 & 0 & 1 & 0 & 0 & 0 & 1 & 0 & 0 & 0 & - & - & 0 & 1 & 1 & 0 & 0 & 0 & 2 & 0 & 1 & 0 & 0 & 2 & 1 & 0 & 1 & 0 & 0 \\
\hline & 1 & 1 & 0 & 1 & 0 & & 0 & & & 0 & 0 & & - & & 1 & & 0 & & & 2 & & 1 & & & & & 0 & & & ) \\
\hline & 0 & 1 & 1 & $\perp$ & 0 & ר & 0 & $\perp$ & 0 & 0 & 0 & - & - & 0 & 1 & 0 & 0 & 0 & 0 & 2 & 0 & 0 & & 0 & 1 & 1 & 0 & 0 & 0 & \\
\hline & 0 & 1 & 1 & 1 & 0 & 2 & 0 & 1 & 0 & 0 & 0 & - & - & 0 & 0 & 0 & 1 & 0 & 0 & 1 & 0 & 0 & + & 0 & 1 & 1 & 0 & 0 & 0 & \\
\hline & 0 & 1 & 1 & 1 & 0 & & 0 & & 0 & 0 & 0 & & - & & & & 1 & 0 & & 2 & 0 & 0 & & & 1 & & 0 & & 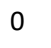 & 0 \\
\hline & 0 & 1 & 0 & 1 & 0 & 2 & 0 & \pm & 0 & 0 & 0 & - & - & 0 & 0 & 0 & 1 & 0 & 0 & 1 & 0 & 0 & $\perp$ & 0 & 1 & 1 & 0 & 0 & 0 & 0 \\
\hline & 0 & 1 & 0 & 1 & 0 & 2 & 0 & 1 & 0 & 0 & 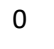 & - & . & 0 & 0 & 0 & 1 & 0 & 0 & 2 & 0 & 0 & 1 & 0 & 1 & 1 & 0 & 0 & 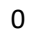 & 0 \\
\hline & 0 & 1 & 1 & 1 & 0 & 2 & 0 & 1 & 0 & 0 & 0 & - & 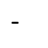 & 0 & 1 & & 1 & 0 & & 1 & 0 & 0 & & 0 & 1 & & 0 & 0 & 0 & 0 \\
\hline & 0 & 1 & 0 & 1 & 0 & 2 & 0 & 1 & 0 & 0 & 0 & - & 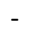 & 0 & 0 & 0 & 1 & 0 & 0 & 1 & 0 & 0 & 1 & 0 & 1 & 1 & 0 & 0 & 0 & \\
\hline R. piceomaculata & 0 & 1 & 1 & 1 & 0 & 2 & 0 & 1 & 0 & 0 & 0 & 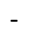 & 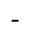 & 0 & 0 & 0 & 1 & 0 & 0 & 1 & 0 & 0 & 1 & 0 & 1 & 1 & 0 & 0 & 0 & \\
\hline S. imp & 0 & 1 & 0 & 1 & 0 & 0 & 0 & 1 & 0 & 0 & 0 & - & - & 1 & 1 & 0 & 0 & 0 & 0 & 2 & 1 & 1 & 1 & 0 & 3 & 1 & 0 & 0 & 1 & \\
\hline & 0 & 1 & 0 & 1 & 0 & 0 & 0 & 1 & 0 & 0 & 0 & - & - & 1 & 1 & 0 & 0 & 0 & 0 & 2 & 0 & 1 & 1 & 0 & 1 & 1 & 0 & 1 & 1 & \\
\hline & 0 & 1 & 1 & 1 & 0 & 0 & 0 & 1 & 0 & 0 & 0 & - & - & 0 & 1 & 0 & 0 & 0 & 0 & 2 & 0 & 1 & 1 & 0 & 1 & 1 & 0 & 0 & 1 & \\
\hline S. daguerrei & 0 & 1 & 0 & 1 & 0 & 0 & 0 & 1 & 0 & 0 & 0 & - & - & 1 & 1 & 0 & 0 & . & 0 & 2 & 0 & 1 & 1 & 0 & 1 & 1 & 0 & 0 & 1 & \\
\hline & 0 & 1 & 1 & 1 & 0 & 0 & 0 & & 0 & 0 & 1 & 0 & 3 & 1 & 1 & 0 & 0 & & 0 & 2 & 0 & 1 & & 0 & 1 & 1 & 0 & 0 & 1 & \\
\hline o. Drumint & 0 & 0 & 0 & 2 & 0 & 0 & 0 & 0 & - & 0 & 1 & 0 & 0 & 0 & 0 & 0 & 0 & 0 & 0 & 0 & 0 & 1 & 2 & 0 & 0 & 0 & - & 0 & 0 & \\
\hline O. paucartambensis & 0 & 1 & 1 & 2 & 0 & $\perp$ & 0 & 1 & 1 & 0 & 1 & 0 & 2 & 0 & 0 & 0 & 0 & 0 & 0 & 1 & . & 1 & 0 & 0 & 0 & 2 & - & 0 & 0 & \\
\hline & 0 & 1 & 1 & 2 & 0 & 1 & 0 & 1 & 1 & 0 & 1 & 0 & 2 & 0 & 0 & 0 & 0 & 0 & 0 & 1 & 0 & 1 & 0 & 0 & 0 & 2 & - & 0 & 0 & \\
\hline O. hortensis & 0 & 1 & 1 & 2 & 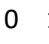 & 1 & 0 & 1 & 1 & 0 & 1 & 0 & 2 & 0 & 0 & 0 & 0 & 0 & 0 & 1 & 0 & 1 & 0 & 0 & 0 & 2 & & 0 & 0 & \\
\hline
\end{tabular}

Tabla 8: Matriz de caracteres morfológicos usados en el análisis combinado del grupo de géneros Scotussae. “-” indica caracteres no comparables.

Registros de Ejemplares y Distribución Geográfica

Los registros georreferenciados utilizados para este estudio se obtuvieron de viajes de campaña, especímenes de las colecciones de varias instituciones (Museo de La Plata, Academy of Natural Sciences de Philadelphia, Muséum National d'Histoire Naturelle París, Museu de Zoologia da Universidade de São Paulo, Museu Nacional do Rio Janeiro, Facultad de Ciencias de Montevideo), literatura y registros descargados de la base de datos mundial Orthoptera Species File (Cigliano et al., 2018). Para cada especie se trataron como registros únicos las localidades más cercanas a 2,5 arc-minutos, y las especies con un elevado número de registros se filtraron a 0,08333 arc-minutos $(\sim 10 \mathrm{~km})$ contando finalmente con 764 registros para las 47 especies, pertenecientes a los 7 géneros del grupo Scotussae. Debido a que varias especies no pudieron ser analizadas por falta de material fresco (para realizar los análisis genéticos) o debido a su bajo número de registros, se 
decidió realizar también un análisis a nivel genérico que incluyera la totalidad de las especies de Scotussae. En los análisis realizados a nivel de género se consideran los registros georreferenciados de las 47 especies, y a nivel de especie se utilizan únicamente las 17 especies del análisis filogenético que presentaban más de 4 registros (Tablas 9, S3).

\begin{tabular}{|c|c|c|}
\hline Género & Especie & № Registros \\
\hline Atrachelacris & olivaceus & 18 \\
\hline Atrachelacris & unicolor & 33 \\
\hline Chlorus & attenuatus & 1 \\
\hline Chlorus & brunneus & 3 \\
\hline Chlorus & chiquitensis & 4 \\
\hline Chlorus & vittatus & 4 \\
\hline Chlorus & spatulus & 5 \\
\hline Chlorus & borellii & 7 \\
\hline Chlorus & bolivianus & 11 \\
\hline Dichromatos & corupa & 6 \\
\hline Dichromatos & montanus & 4 \\
\hline Dichromatos & schrottkyi & 11 \\
\hline Dichromatos & lilloanus & 28 \\
\hline Eurotettix & concavus & 1 \\
\hline Eurotettix & procerus & 1 \\
\hline Eurotettix & simiraphael & 1 \\
\hline Eurotettix & brevicerci & 2 \\
\hline Eurotettix & latus & 2 \\
\hline Eurotettix & femoratus & 3 \\
\hline Eurotettix & monnei & 4 \\
\hline Eurotettix & raphaelandrearum & 4 \\
\hline Eurotettix & carbonelli & 5 \\
\hline Eurotettix & robustus & 7 \\
\hline Eurotettix & minor & 9 \\
\hline Leiotettix & hastatus & 1 \\
\hline Leiotettix & politus & 6 \\
\hline Leiotettix & viridis & 9 \\
\hline Leiotettix & sanguineus & 13 \\
\hline Leiotettix & flavipes & 23 \\
\hline Ronderosia & ommexechoides & 1 \\
\hline Ronderosia & gracilis & 2 \\
\hline Ronderosia & piceomaculata & 2 \\
\hline Ronderosia & dubia & 4 \\
\hline Ronderosia & cinctipes & 4 \\
\hline Ronderosia & paraguayensis & 5 \\
\hline Ronderosia & malloi & 6 \\
\hline Ronderosia & robusta & 6 \\
\hline Ronderosia & forcipata & 33 \\
\hline Ronderosia & bergii & 103 \\
\hline Scotussa & delicatula & 2 \\
\hline Scotussa & brachyptera & 11 \\
\hline Scotussa & liebermanni & 18 \\
\hline Scotussa & daguerrei & 22 \\
\hline Scotussa & impudica & 66 \\
\hline Scotussa & cliens & 82 \\
\hline Leiotettix & pulcher & 79 \\
\hline Scotussa & lemniscata & 138 \\
\hline
\end{tabular}

Tabla 9: Registros por especie. 
Se utilizaron las 19 variables bioclimáticas de WorldClim (http://www.worldclim.org; Hijmans et al., 2005) y 4 capas de radiación solar de WorldClim 2 (Fick \& Hijmans, 2017), correspondientes al verano (diciembre - enero febrero - marzo). Para cada especie, se extrajeron los valores de cada variable bioclimática para todos sus registros, lo que permitió analizar la variabilidad climática de cada especie.

Previo a la estimación de las áreas potenciales de distribución a través de la aplicación de modelos de nicho ecológico, se restringió el área accesible ("background") de cada especie siguiendo la metodología de Barve et al., (2011). Estas áreas accesibles se estimaron basándose en las ecoregiones (Olson et al., 2001) donde se distribuía cada especie añadiendo un radio de $100 \mathrm{~km}$ alrededor del área determinada, utilizando el programa QGIS 2.18.11 (http://qgis.osgeo.org). Para evitar problemas con la multicolinearidad (Dormann et al., 2013) de las variables climáticas, se realizó un Análisis de Componentes Principales (ACP) de las 19 variables bioclimáticas a una resolución de 2,3 arc-min ( $\sim 5 \mathrm{~km}^{2}$ en el ecuador) y otro PCA para las 4 capas de radiación solar correspondientes al verano (diciembre-enero-febrero-marzo). Los ACPs se calcularon para la extensión geográfica que abarca las ecorregiones que habita la tribu Dichroplini añadiendo un radio de $100 \mathrm{~km}$, pero los modelos se calibraron teniendo en cuenta el área accesible de cada especie. Se utilizaron los primeros tres componentes principales (CPs), que en conjunto explican el $83,5 \%$ de la variabilidad total y el primer componente Principal (CP) de la radiación, que explica el 84,5\% de la variación total. En las variables ambientales, el CP 1 se corresponde principalmente con la temperatura, el CP 2 es dominado por la precipitación y el CP3 representa la variación isotermal y la variación de temperatura y precipitación estacional.

\section{Similitud de nicho}

Se utilizó el primer y segundo CP para evaluar las diferencias en el nicho realizado según Broennimann et al., (2012). Los datos de presencia fueron usados para realizar el test de similitud de nicho entre OTUs (especies, géneros) usando el paquete de R 'ecospat' (Broennimann et al., 2012). Para evaluar la superposición de nicho (Warren, Glor, \& Turelli, 2008) se utilizó el estadístico de distancia I de Hellinger (van der Vaart, 1998), el cual no asume ninguna suposición biológica (Warren et al., 2008). Dicho análisis permitió evaluar la conservación o divergencia de nicho entre cada par de OTUs de Scotussae. Estos análisis evalúan el grado de superposición de nicho entre dos OTUs, considerando la distribución de una OTU en relación al área accesible de la otra OTU. Las comparaciones se hicieron en dos niveles jerárquicos: 
Especies: Se evaluó la similitud de nicho entre las 17 especies del análisis filogenético.

Géneros: Se evaluó la similitud de nicho entre los 7 géneros del grupo Scotusae, considerando los puntos de todas las especies pertenecientes a cada género.

\section{Modelado de Nicho}

Los modelos de nicho ecológico (MNE) se realizaron usando los primeros tres CP ambientales y el primer CP de la radiación solar. Se utilizaron dos metodologías para generar los MNE, el ampliamente utilizado Maxent (Phillips, Anderson, \& Schapire, 2006), que usa máxima entropía para computar una medida relacionada a la probabilidad de presencia, usando la distribución de probabilidades de Gibbs; y una metodología basada en elipsoides y siguiendo un criterio simple de representar el nicho como un hipervolumen n-dimensional, como fuera originalmente propuesto por Hutchinson (1957) y recientemente desarrollado por Osorio-Olvera, Falconi, \& Soberón (2016).

Se utilizó el paquete `ENMeval' para generar modelos en Maxent versión 3.4.1, con un máximo de 500 generaciones utilizando los parámetros de "autofeatures". Analizamos la complejidad del modelo reduciendo la sobreparametrización generando los modelos con valores de "beta-regularization multiplier" desde 0,5 a 5, con incrementos de 0,5. Este parámetro afecta el ajuste de la distribución posterior, de modo que a valores mayores se generan predicciones más generalizadas (Razgour, Hanmer, \& Jones, 2011; Shcheglovitova \& Anderson, 2013). El desempeño del modelo fue evaluado considerando los valores de AUC (Training AUC), evaluación de AUC (Test AUC) y la diferencia de AUC (AUC_diff) para todos los modelos generados para cada especie y seleccionamos el que presentaba mejor desempeño siguiendo a Radosavljevic \& Anderson, (2014). Los modelos de elipsoides se realizaron con el paquete de $\mathrm{R}$ 'nichetoolbox' que genera el elipsoide de volumen mínimo (Osorio-Olvera et al., 2016). Esta metodología arroja parámetros útiles como el centroide de nicho (óptimo del nicho) y el volumen de la elipse (amplitud del nicho). Los modelos obtenidos bajo ambas metodologías para las OTUs que cuentan con menos de 25 registros se evaluaron con el método de optimización "delete-one jackknife optimization approach" (Peterson et al., 2011) usando el programa pValueCompute (Pearson et al., 2007), que se ha demostrado que se desempeña bien en estudios con tamaños muestreales pequeños (Pearson et al., 2007; Shcheglovitova \& Anderson, 2013). Para las OTUs con 25 registros o más, los modelos se evaluaron utilizando la ROC parcial (Peterson et al., 2007) con un 
porcentaje de omisión del 0,05\%, 30\% de puntos aleatorios y 1000 iteraciones usando el programa Niche ToolBox (http://shiny.conabio.gob.mx:3838/nichetoolb2/).

Las gráficas de elipsoides están hechas sobre los primeros dos CPs ambientales y el componente de radiación, que fueron las tres variables que mostraron mayor coeficiente de variación para los géneros.

Especies: Los modelos de nicho ecológico (MNE) se realizaron para todas las especies de Scotussae representadas en el análisis filogenético, exceptuando 5 especies $(C$. chiquitensis Cigliano \& Lange, C. vittatus Bruner, R. gracilis (Bruner), R. cinctipes (Bruner) y R. dubia (Bruner)) que presentan menos de 5 registros (Pearson et al., 2007; Schwallier et al., 2016). Para generar los elipsoides se utilizó la matriz de covarianza de los datos entrantes para generar las elipses, ya que la mayoría de las especies cuentan con pocos registros.

Géneros: Se generaron los modelos de elipsoides para los 7 géneros, considerando los registros georreferenciados de las 47 especies utilizando elipsoides de volumen mínimo.

\section{Señal filogenética}

Variables. La señal filogenética fue evaluada con el estadístico K (Blomberg et al., 2003), que cuantifica la "señal filogenética relativa a la señal esperada para un determinado carácter bajo el modelo de evolución Browniano según una topología y largo de ramas determinado" (Blomberg et al., 2003). Cuando $\mathrm{K}=1$ la variable exhibe la señal filogenética esperada bajo el modelo de evolución Browniano (modelo nulo o debido al azar). En el caso de que $K$ tome valores menores a $1(K<1)$ se considera que la variable presenta una dependencia filogenética baja, mientras que si $K>1$ se infiere que la variable presenta una alta señal filogenética. Se evaluó la señal filogenética para los volúmenes de nicho, los valores de centroide de nicho de los 4 CP y para los valores mínimo y máximo de cada variable ambiental. Los análisis se realizaron en R utilizando la función "phylosignal" del paquete 'picante', evaluando su significancia por medio de 9999 permutaciones. Las variables bioclimáticas que presentaban señal filogenética fueron optimizadas independientemente como un carácter continuo y graficadas utilizando la función 'contMap' del paquete 'phytools' estimando los estados de los nodos internos usando el método de Máxima Verosimilitud (Felsenstein, 1985; Revell, 2013). 
Nicho y Distribución. Asimismo, se analizó la señal filogenética comparando la cercanía filogenética con la diversificación ecológica y geográfica a través de análisis de Mantel. La matriz de distancias filogenéticas se calculó entre pares de especies utilizando el paquete 'ape' versión 4.1 (Paradis et al., 2004). Las distancias geográficas entre las especies se calcularon teniendo en cuenta el centro geográfico (latitud y longitud promedio) del rango de cada especie estimada a partir de los registros, y el óptimo de nicho se calculó a partir del centroide del nicho ecológico obtenido de los modelos de elipsoides. Se generaron dos matrices de distancias pareadas, una para las distancias geográficas y otra para las distancias entre centroides de nicho. Ambas matrices fueron construidas calculando las distancias Euclideanas con la función 'dist2', que permite generar las distancias en dos (lat-long) o cuatro (CP1 al CP4) dimensiones, respectivamente. Asimismo, se construyeron matrices de superposición de nicho con los valores de I extraídos del test de superposición descripto previamente. Como dichos valores son de superposición, y el test de Mantel es una correlación entre dos matrices de disimilitud, se calculó el logaritmo de la inversa de la matriz (la inversa para poder trabajar con "distancias" entre especies, y el logaritmo de estos valores para disminuir la diferencia artificial que genera la inversa de valores cercanos a cero)

Finalmente, para evaluar el grado en que la distancia filogenética (distancia patrística entre las especies) está correlacionada con el centro geográfico, el óptimo de nicho y la superposición de nicho, se realizaron análisis de Mantel (Sokal, 1979; Borcard \& Legendre, 2012) con el paquete de R 'vegan' (Oksanen et al., 2017).

\section{Biogeografía histórica del grupo Scotussae}

Para evaluar los posibles patrones biogeográficos históricos y estimar el origen geográfico del grupo se llevó a cabo el análisis probabilístico de estimación del rango ancestral aplicado en el paquete "BioGeoBears". Se utilizó el árbol Bayesiano generado en BEAST considerando todas las especies presentes en el análisis filogenético, incluido los grupos externos, dejando un sólo terminal por especie.

Asimismo, y en función de los patrones de diversificación que resultaron del análisis de superposición de nicho, se realizaron dos análisis independientes, uno considerando todas las especies del clado Braquíptero y otro considerando las especies del clado Macróptero para determinar si los patrones de diversificación son similares en ambos grupos. 
Las áreas consideradas para el análisis biogeográfico, elegidas en función de la distribución de las especies, fueron las siguientes: la provincia Patagónica (Pat) de la Región Antártica (Cabrera \& Willink, 1973, Morrone, 2014) y de la Región Neotropical se consideró la región Pampeana (Pam), Bosque Lluviosos Tropicales (BLT) y, siguiendo la división de los ecosistemas abiertos de Werneck, el Chaco Seco (Ch), Cerrado (Ce) y Bosque Tropical Seco estacional (BTSE) que abarca las ecorregiónes de Caatinga, las Yungas, Paranense, Chaco Húmedo, el Chiquitano y el Bosque Boliviano, entre otras. Se utilizaron los registros y el mapa de ecorregiones (Olson et al., 2001) para extraer las áreas correspondientes a cada especie. Los rangos de las especies fueron codificados como presencia-ausencia, y se eliminaron las zonas que presentaban el registro de solo una especie para reducir el número de áreas.

Los análisis de estimación del rango ancestral se realizaron con el paquete de $\mathrm{R}$ 'BioGeoBears' (Matzke, 2014). 'BioGeoBEARS' permite inferir probabilísticamente la historia biogeográfica y comparar diferentes modelos de evolución del rango de distribución ancestral. La modelización probabilística de la evolución del rango geográfico (Ree et al., 2005; Ree \& Smith, 2008; Ree \& Sanmartín, 2009) fue un avance importante en la biogeografía histórica. El modelado probabilístico de la evolución de rangos geográficos permite poner a prueba diferentes modelos biogeográficos, utilizando procedimientos estándares de elección de un modelo estadístico. El modelo de evolución del rango geográfico más popular, utilizado en cientos de publicaciones, es el de DispersiónExtinción-Cladogénesis (DEC; LAGRANGE). BioGeoBEARS agrega a los modelos que se analizaban en LAGRANGE (Ree \& Smith, 2008) un evento cladogénico adicional: especiación de evento fundador, y también posibilita variar las tasas de los diversos eventos, lo que permite la optimización del modelo. DEC tiene dos parámetros libres, la tasa de expansión ("dispersión", parámetro d) y la de contracción ("extinción”, parámetro e). Los parámetros combinan diversas tasas (Ree \& Smith, 2008) y, en función del largo de ramas calculan las probabilidades de cada estado en los nodos y las terminales del árbol. Dada la filogenia, los rangos geográficos de las terminales, los modelos anagenéticos y cladogenéticos y los valores de los parámetros d, e y j, se puede calcular la verosimilitud del rango observado en función de los datos de las terminales del árbol filogenético. La estimación de los parámetros libres se calcula a partir de un análisis de Máxima Verosimilitud (MV), o un análisis Bayesiano (por medio de MCMC), y se utiliza el modelo de optimización global siguiendo a Mooers (2004). Los modelos analizados fueron los siguientes: DIVALIKE, DIVALIKE+J, DEC, DEC+J, BAYAREALIKE y BAYAREALIKE+J, eligiendo el modelo óptimo por medio del test de Verosimilitud y el AIC. 


\section{RESULTADOS}

\section{Análisis Filogenético}

La amplificación y secuenciación de los fragmentos de los tres genes (COI, ND2, H3) resultaron en un total de 1390 pares de bases, de las cuales 323 corresponden al gen nuclear. La Tabla 6 muestra los códigos de referencia de estas secuencias, incluidas las descargadas del Genbank. El análisis filogenético basado en los tres marcadores y los 30 caracteres morfológicos (Tabla 7; Figs. 15, 16) recuperó la monofilia del grupo y de todos los géneros con un alto soporte de ramas, exceptuando Leiotettix y Scotussa, debido a que Leiotettix pulcher queda incluida dentro del clado conformado por las especies de Scotussa con alto soporte (Fig. 17). El grupo Scotussae se divide en dos clados principales: uno, que incluye especies exclusivamente braquípteras, (las especies de Chlorus, estrechamente relacionadas con las de Eurotettix y Dichromatos); y el otro grupo comprende al resto de los géneros, mayoritariamente macrópteros (Fig. 17). Dentro de este clado mayor, se recupera un grupo constituido por los géneros Atrachelacris y Ronderosia, y otro clado constituido por Scotussa y Leiotettix.

El análisis de reloj molecular, indica que el grupo se habría originado en el Plioceno medio, hace aproximadamente 4,55 Ma, y su mayor diversificación habría ocurrido durante el Pleistoceno.

\section{Similitud de nicho}

Especies: Se presentan en la Tabla 10 los valores de superposición del nicho realizado entre todas las especies. Como hay especies de distribución muy amplia, solo se graficaron las que tenían superposición significativa en ambos sentidos (Tabla 11). Se observa que ninguno de los pares de especies es menos similar de lo esperado por el azar (divergencia de nicho). Asimismo, se determinó que, de las 136 comparaciones entre especies, 47 pares de especies mostraron superposición significativa de nicho, presentando R. bergii (Stål) superposición con el mayor número de especies, seguido por S. lemniscata (Stål). De los 5 pares de especies hermanas que resultaron del análisis filogenético, 3 presentan convergencia de nicho (A. unicolor - A. olivaceus (Bruner), D. lilloanus - D. schrottkyi (Rehn) y L. pulcher - S. lemniscata), y los otros dos (R. bergii - $R$. forcipata (Rehn) y L. flavipes Bruner - L. sanguineus Bruner) presentan valores altos de superposición, pero no son significativos (Tabla 10). 

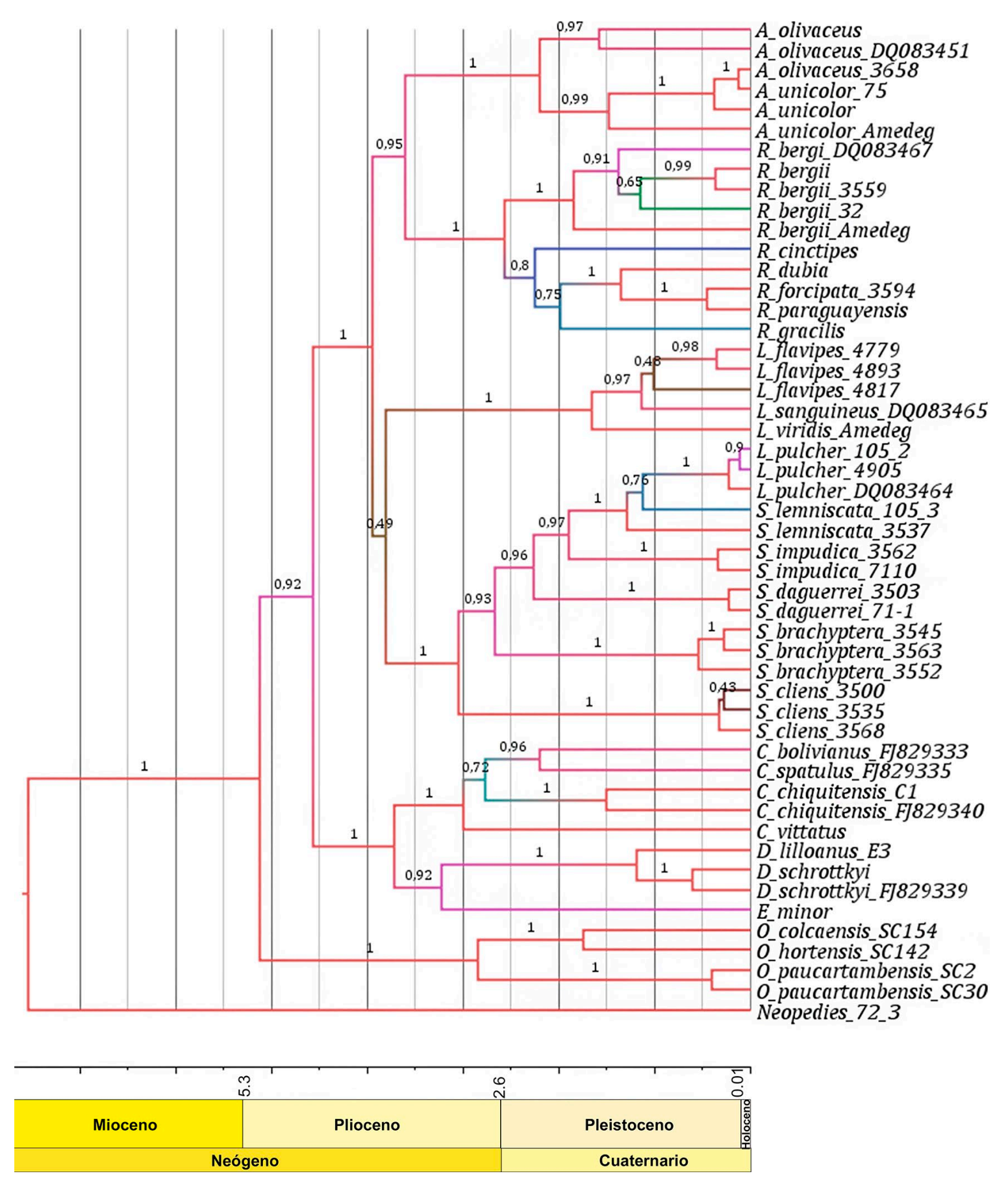

Figura 17: Árbol de consenso para el grupo Scotussae y las cuatro especies del grupo externo obtenido a partir del análisis Bayesiano de las secuencias de COI, ND2, H3 y los caracteres morfológicos. Los números sobre las ramas indican las probabilidades posteriores. Bajo el árbol se indican las principales épocas geológicas-

Géneros: los géneros hermanos Eurotettix y Dichromatos presentan valores de superposición de nicho muy bajos y no significativos, mientras que los restantes géneros hermanos, Scotussa - Leiotettix y Atrachelacris - Ronderosia, presentan superposición significativa (Tablas 12, 13). Los géneros del clado Braquíptero no presentan superposición significativa entre sí, mientras que los géneros del clado Macróptero presentan superposición significativa en la mayoría de los casos (exceptuando 
Atrachelacris - Leiotettix), alcanzando el mayor valor de superposición el par Scotussa Ronderosia, con valores superiores al $80 \%$.

\begin{tabular}{|c|c|c|c|c|c|c|c|c|c|c|c|c|c|c|c|c|c|}
\hline$P(I)$ & 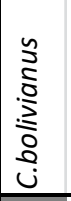 & $\begin{array}{l}\frac{n}{2} \\
\vdots \\
0 \\
\stackrel{5}{5} \\
0\end{array}$ & 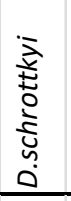 & ذِ & 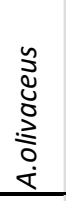 & 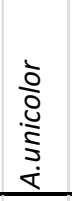 & 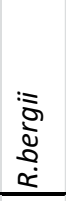 & 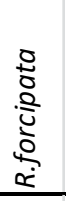 & $\frac{\tilde{d}}{3}$ & 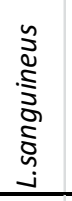 & 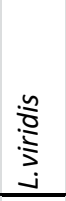 & 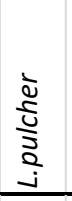 & 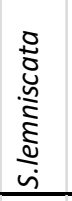 & 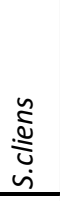 & 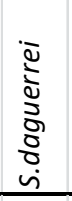 & 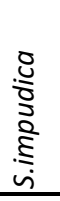 & $\begin{array}{l}0 \\
\frac{0}{ \pm} \\
0 \\
\frac{0}{d} \\
0 \\
0 \\
\vdots \\
\text { vi }\end{array}$ \\
\hline \multicolumn{18}{|l|}{ C.bolivianus } \\
\hline D.lilloanus & 0.00 & & & & & & & & & & & & & & & & \\
\hline D.schrottkyi & 0.00 & 0.42 & & & & & & & & & & & & & & & \\
\hline E.minor & 0.03 & 0.00 & 0.00 & & & & & & & & & & & & & & \\
\hline A.olivaceus & 0.15 & 0.32 & 0.22 & 0.07 & & & & & & & & & & & & & \\
\hline A.unicolor & 0.18 & 0.13 & 0.12 & 0.12 & 0.52 & & & & & & & & & & & & \\
\hline R.bergii & 0.18 & 0.37 & 0.19 & 0.09 & 0.52 & 0.68 & & & & & & & & & & & \\
\hline R.forcipata & 0.08 & 0.04 & 0.01 & 0.03 & 0.16 & 0.27 & 0.32 & & & & & & & & & & \\
\hline L.flavipes & 0.01 & 0.37 & 0.12 & 0.05 & 0.34 & 0.28 & 0.58 & 0.05 & & & & & & & & & \\
\hline L.sanguineus & 0.36 & 0.19 & 0.15 & 0.15 & 0.33 & 0.64 & 0.55 & 0.13 & 0.24 & & & & & & & & \\
\hline L.viridis & 0.31 & 0.10 & 0.12 & 0.13 & 0.25 & 0.52 & 0.44 & 0.10 & 0.19 & 0.76 & & & & & & & \\
\hline L.pulcher & 0.05 & 0.18 & 0.07 & 0.02 & 0.29 & 0.25 & 0.48 & 0.31 & 0.45 & 0.16 & 0.12 & & & & & & \\
\hline S.lemniscata & 0.04 & 0.17 & 0.10 & 0.03 & 0.44 & 0.52 & 0.65 & 0.36 & 0.44 & 0.31 & 0.18 & 0.49 & & & & & \\
\hline S.cliens & 0.06 & 0.22 & 0.09 & 0.03 & 0.32 & 0.34 & 0.53 & 0.59 & 0.36 & 0.23 & 0.17 & 0.58 & 0.53 & & & & \\
\hline S.daguerrei & 0.00 & 0.00 & 0.00 & 0.00 & 0.16 & 0.10 & 0.24 & 0.41 & 0.00 & 0.00 & 0.00 & 0.26 & 0.38 & 0.29 & & & \\
\hline S.impudica & 0.02 & 0.45 & 0.18 & 0.04 & 0.41 & 0.36 & 0.63 & 0.12 & 0.66 & 0.31 & 0.20 & 0.32 & 0.58 & 0.43 & 0.09 & & \\
\hline S.brachyptera & 0.15 & 0.00 & 0.00 & 0.01 & 0.19 & 0.45 & 0.33 & 0.17 & 0.06 & 0.43 & 0.26 & 0.08 & 0.23 & 0.19 & 0.00 & 0.19 & \\
\hline
\end{tabular}

Tabla 10: Resultados test de similitud de conservación de nicho y valores de superposición entre pares de especies realizado con las distancias I de Hellinger. Las celdas grises con letra negrita indican que los nichos son más similares de lo esperado por el azar $(\mathrm{P}<0.05)$ en ambas comparaciones. Se marcaron en líneas suaves las especies hermanas.

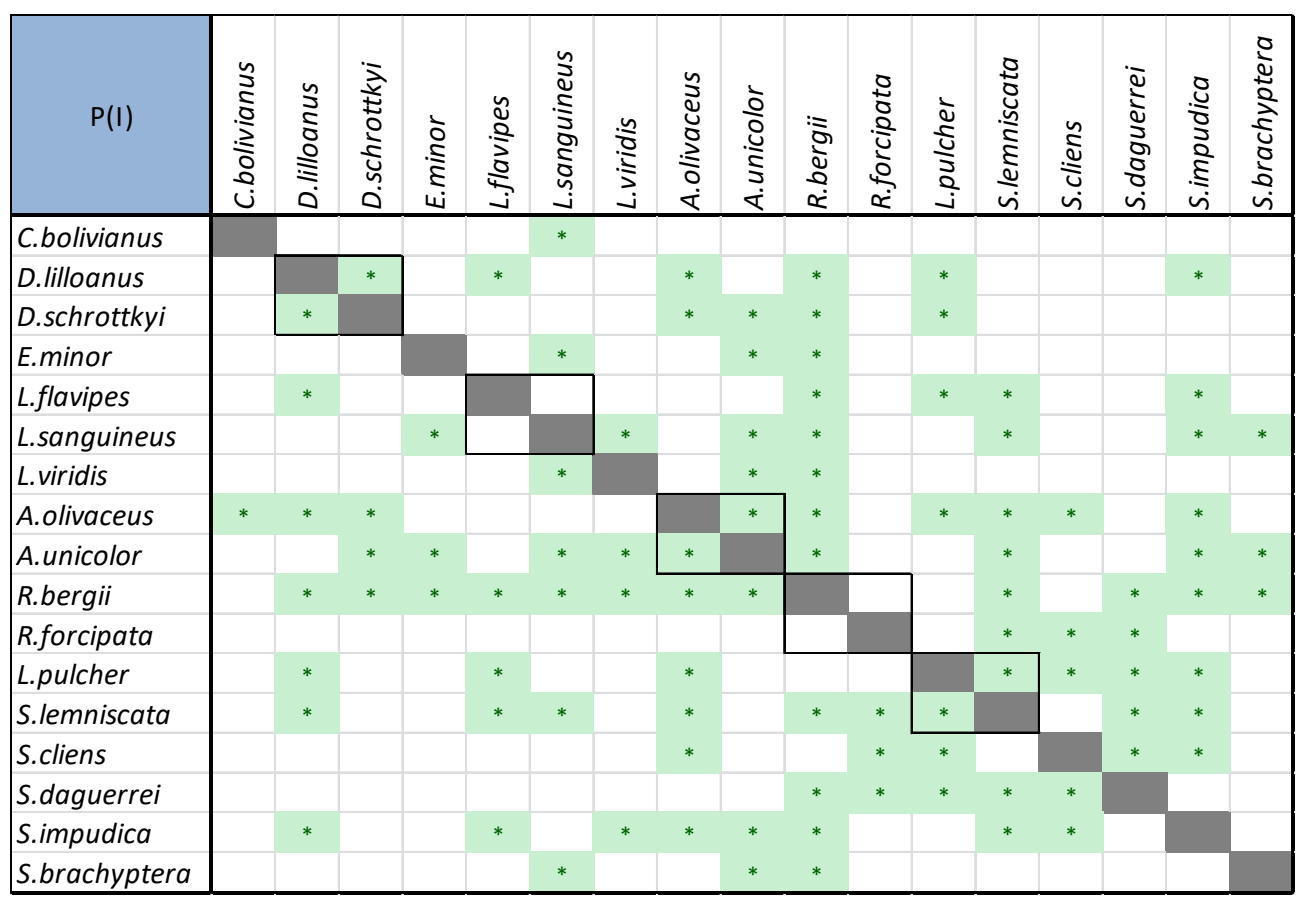

Tabla 11: Resultados del test de similitud de conservación de nicho entre pares de especies realizado con las distancias I de Hellinger. Las filas representan los puntos de ocurrencia y las columnas el área accesible de la especie en el test de similitud. En gris con * se indican los nichos que son más similares de lo esperado por el $\operatorname{azar}(\mathrm{P}<0.05)$. Se marcaron en líneas suaves las especies hermanas. 


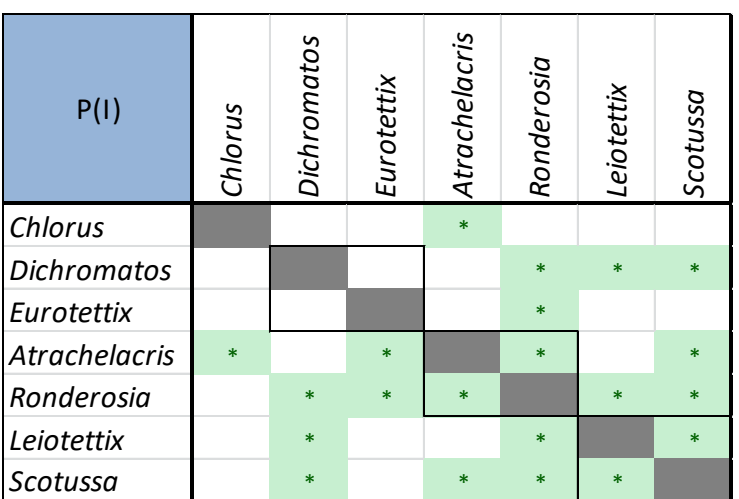

\begin{tabular}{|c|c|c|c|c|c|c|c|}
\hline I & $\frac{\frac{n}{2}}{\frac{5}{d}}$ & 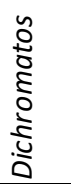 & 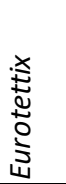 & 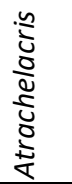 & $\begin{array}{l}\frac{o}{5} \\
\frac{0}{0} \\
\frac{0}{0} \\
0 \\
0\end{array}$ & 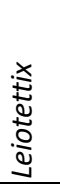 & 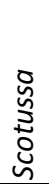 \\
\hline \multicolumn{8}{|l|}{ Chlorus } \\
\hline Dichromatos & 0.09 & & & & & & \\
\hline Eurotettix & 0.18 & 0.07 & & & & & \\
\hline Atrachelacris & 0.32 & 0.26 & 0.17 & & & & \\
\hline Ronderosia & 0.28 & 0.37 & 0.18 & 0.65 & & & \\
\hline Leiotettix & 0.17 & 0.29 & 0.12 & 0.41 & 0.65 & & \\
\hline Scotussa & 0.25 & 0.35 & 0.09 & 0.55 & 0.84 & 0.64 & \\
\hline
\end{tabular}

Tabla 12: Resultados del test de similitud de conservación de nicho entre pares de géneros realizado con las distancias I de Hellinger. Las filas representan los puntos de ocurrencia y las columnas el área accesible de los géneros en el test de similitud. En gris con * se indican los nichos que son más similares de lo esperado por el azar $(\mathrm{P}<$ 0.05). Se indican en líneas finas los géneros hermanos.

\section{Modelado de Nicho}

Tabla 13: Resultados test de similitud de conservación de nicho y valores de superposición entre pares de géneros realizado con las distancias I de Hellinger. Las celdas grises con letra negrita indican que los nichos son más similares de lo esperado por el azar $(\mathrm{P}<0.05)$ en ambas comparaciones. Se indican en líneas finas los géneros hermanos

Los resultados de MNE con la metodología de elipsoides y con la de Maxent revelaron distribuciones geográficas similares. El estadístico de "Delete-one jackknife approach" indica que los modelos generados fueron validados con ambas metodologías, excepto para C. spatulus Cigliano \& Lange y R. paraguayensis (Bruner). Dado que ambas metodologías dieron resultados similares y uno de los modelos generado con Maxent no pudo validarse, se presentan solo los resultados obtenidos con la metodología de elipsoides

Especies Las especies del clado Braquíptero presentan los menores valores de amplitud de nicho (Tabla 14). Con respecto a la distribución geográfica, C. bolivianus Bruner se encuentra restringida al Centro-Este de Bolivia (Fig. 18A) y se presenta tanto geográfica como ambientalmente distante de las restantes especies del clado. Eurotettix minor Bruner se distribuye en el sudeste de Paraguay, presentando un área geográfica y ambiental extremadamente reducida (la más reducida del análisis). Las especies del género Dichromatos se encuentran más hacia el Este, en la región sur de Brasil, si bien se observa que sus nichos ambientales están levemente desplazados, presentan superposición geográfica entre sí (Fig. 18A). 


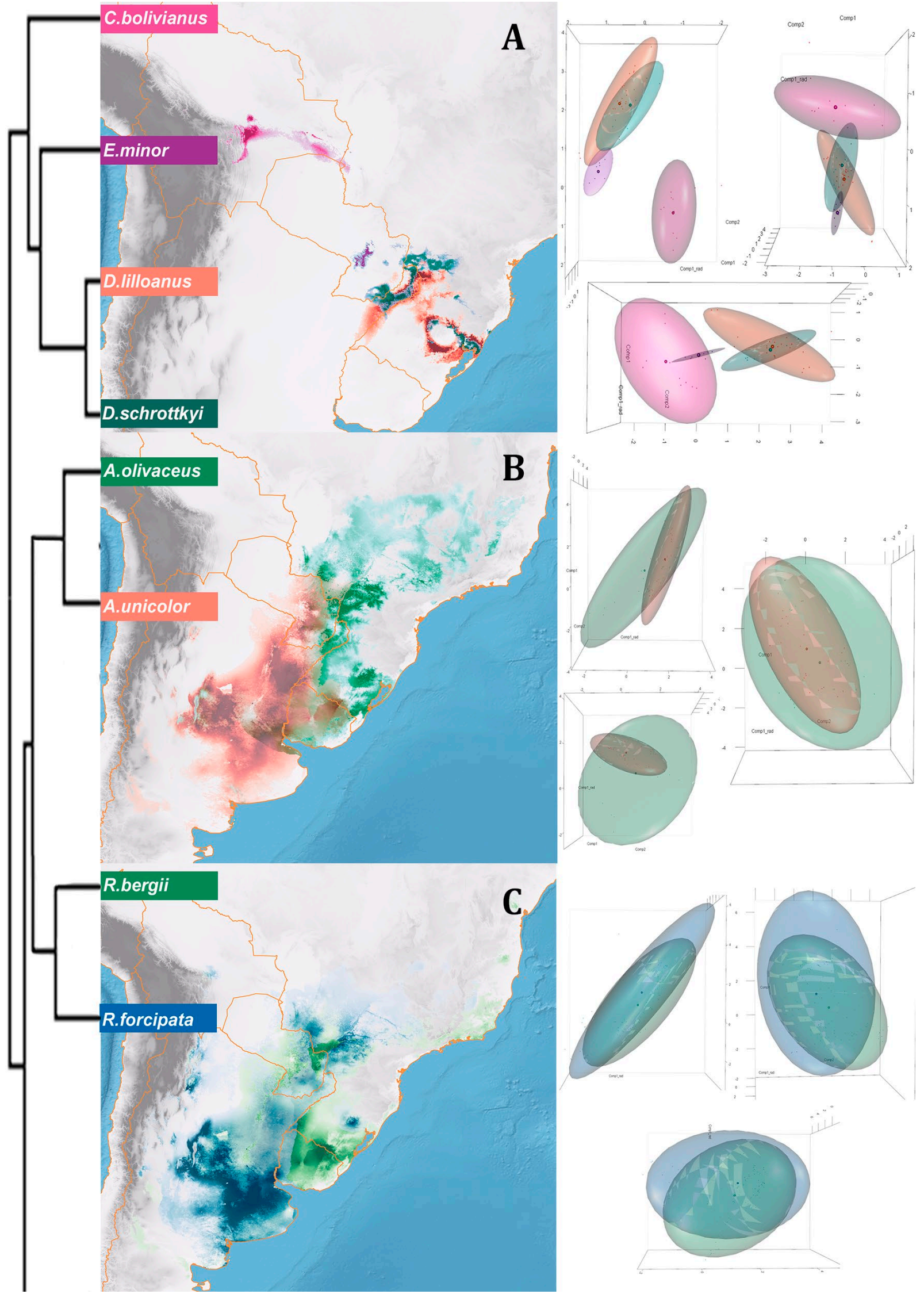

Figura 18: Distribución potencial y nicho ecológico de las especies de los géneros Chlorus, Eurotettix, Dichromatos (A), Ronderosia (B) y Atrachelacris (C) generadas con la metodología de Elipsoides e ilustrado siguiendo las relaciones filogenéticas. 


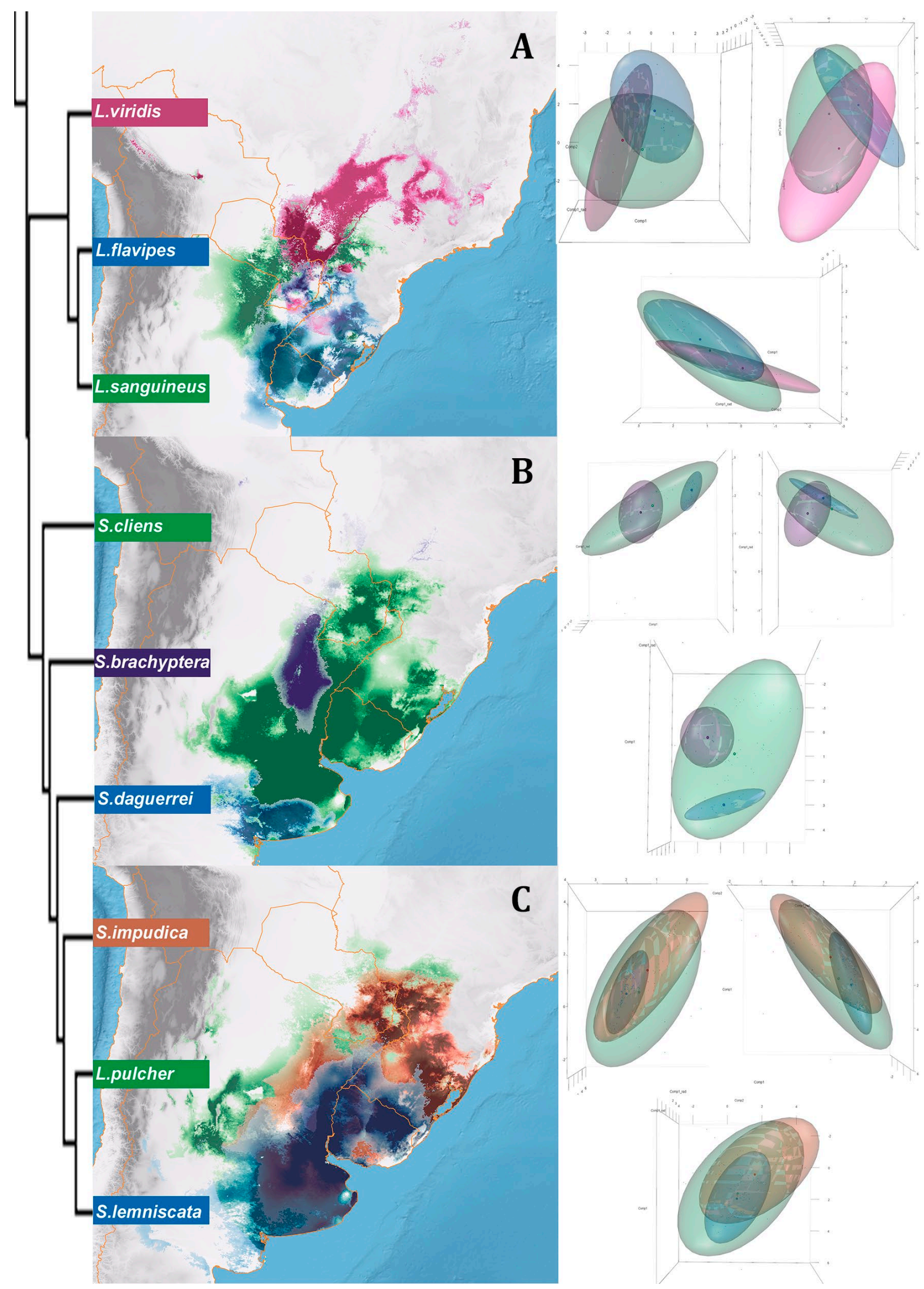

Figura 19: Distribución potencial y nicho ecológico de las especies de los géneros Leiotettix (A) y Scottusa (B y C) generadas con la metodología de Elipsoides e ilustrado siguiendo las relaciones filogenéticas. 


\begin{tabular}{|l|c|l|}
\hline \multicolumn{1}{|c|}{ Especies } & Volumen & Alas \\
\hline Chlorus bolivianus & 2,01 & Braquíptera \\
Dichromatos lilloanus & 0,57 & Braquíptera \\
Dichromatos schrottkyi & 0,26 & Braquíptera \\
Eurotettix minor & 0,02 & Braquíptera \\
Atrachelacris olivaceus & 37,39 & Macróptera \\
Atrachelacris unicolor & 17,79 & Macróptera \\
Ronderosia bergii & 50,16 & Macróptera \\
Ronderosia forcipata & 48,66 & Macróptera \\
Leiotettix flavipes & 6,34 & Macróptera \\
Leiotettix sanguineus & 12,95 & Macróptera \\
Leiotettix viridis & 8,09 & Macróptera \\
Leiotettix pulcher & 46,46 & Macróptera \\
Scotussa lemniscata & 7,84 & Macróptera \\
Scotussa cliens & 22,06 & Macróptera \\
Scotussa daguerrei & 0,24 & Macróptera \\
Scotussa impudica & 16,02 & Macróptera \\
Scotussa brachyptera & 2,37 & Braquíptera \\
\hline
\end{tabular}

Tabla 14: Valores de amplitud de nicho de cada especie.

Las especies del clado Macróptero presentan valores de amplitud de nicho mayores al del clado Braquíptero, siendo la excepción S. daguerrei Liebermann(Tabla 14). El género Ronderosia presenta los mayores valores de amplitud de nicho, seguidos por $L$. pulcher y A. olivaceus. Los géneros hermanos Ronderosia y Atrachelacris presentan sus 4 especies dentro de los 6 valores de nicho más amplios (Tabla 14). Las especies de Atrachelacris se encuentran ampliamente superpuestas en el espacio geográfico, ocupando el centro y noreste de la Argentina, Uruguay y el este de Paraguay desplazándose $A$. olivaceus más hacia el noreste, ingresando en el sur de Brasil (Fig. 18B). Este patrón es concordante con lo observado en el espacio ambiental, donde $A$. unicolor se encuentra casi completamente dentro de la elipse ambiental de A. olivaceous, la cual tiene una amplitud considerablemente mayor (Fig. 18B).

Las especies de Ronderosia presentan las mayores amplitudes de nicho (Tabla 14), encontrándose los óptimos de nicho de $R$. bergii en la región central de Argentina y algunas zonas del sur de Brasil y límite este de la Cordillera de los Andes (Fig. 18C). Ronderosia forcipata también se encuentra en la región central de Argentina, sin embargo, por fuera de esta región se encuentra predominantemente en el noreste de Argentina, Uruguay y este de Paraguay, ingresando en menor medida en el sur de Brasil (Fig. 18C). Leiotettix viridis Bruner se encuentra mayoritariamente en el norte de Paraguay y zonas adyacentes del sur de Brasil (Fig. 19A). Las especies hermanas L. sanguineus y L. flavipes 
encuentran una distribución más hacia el sur, distribuyéndose la primera principalmente en la región central de Paraguay y noreste de Argentina y la última aún más desplazada hacia el sudeste, principalmente en Uruguay (Fig. 19A). Las especies del género Scotussa presentan la mayor variación de amplitud de nicho del grupo, presentando amplitudes de 0.24 a 46.46 (Tabla 14). Scotussa brachyptera Cigliano \& Ronderos se encuentra en las provincias de Entre Ríos, Corrientes, Santa Fé, Chaco y Formosa, mientras que S. daguerrei se encuentra restringida al sur de la provincia de Buenos Aires y La Pampa (Fig. 19B). Las restantes especies del género Scotussa, incluyendo L. pulcher, se encuentran distribuidas en el centro-este y noreste de la Argentina, Uruguay, este de Paraguay y sur de Brasil (Fig. 19B,C). Sus distribuciones potenciales son muy similares a pesar de que sus amplitudes de nicho son altamente variables (entre 7,84 y 46,46; Tabla 14), siendo $S$. impudica Giglio-Tos la más diferente en el centroide de nicho, la cual presenta un desplazamiento hacia el noreste en su distribución potencial (Fig. 19C). Leiotettix pulcher presenta los valores de mayor amplitud de nicho del género (Tabla 14) y Scotussa lemniscata presenta uno de los volúmenes de nicho más reducido del grupo (Tabla 14), sin embargo, es la que llega más al sur en la distribución del género (Fig. 19C).

Géneros Los modelos a nivel de género se realizaron teniendo en cuenta los más de 800 registros georreferenciados del total de las especies (47) del grupo Scotussae (Tabla 9): 7 especies de Chlorus (35 registros), 4 especies de Dichromatos (49 registros), 11 especies de Eurotettix (39 registros), 2 especies de Atrachelacris (51 registros), 10 especies de Ronderosia (166 registros), 5 especies de Leiotettix (52 registros) y 8 especies de Scotussa (incluyendo a L. pulcher) (418 registros).

\begin{tabular}{|lc|}
\hline \multicolumn{1}{|c|}{ Género } & Volumen \\
\hline Chlorus & 34.67 \\
Dichromatos & 8.09 \\
Eurotettix & 4.21 \\
Atrachelacris & 29.99 \\
Ronderosia & 47.78 \\
Leiotettix & 15.37 \\
Scotussa & 22.10 \\
\hline
\end{tabular}

Tabla 15: Valores de amplitud de nicho de los géneros. 


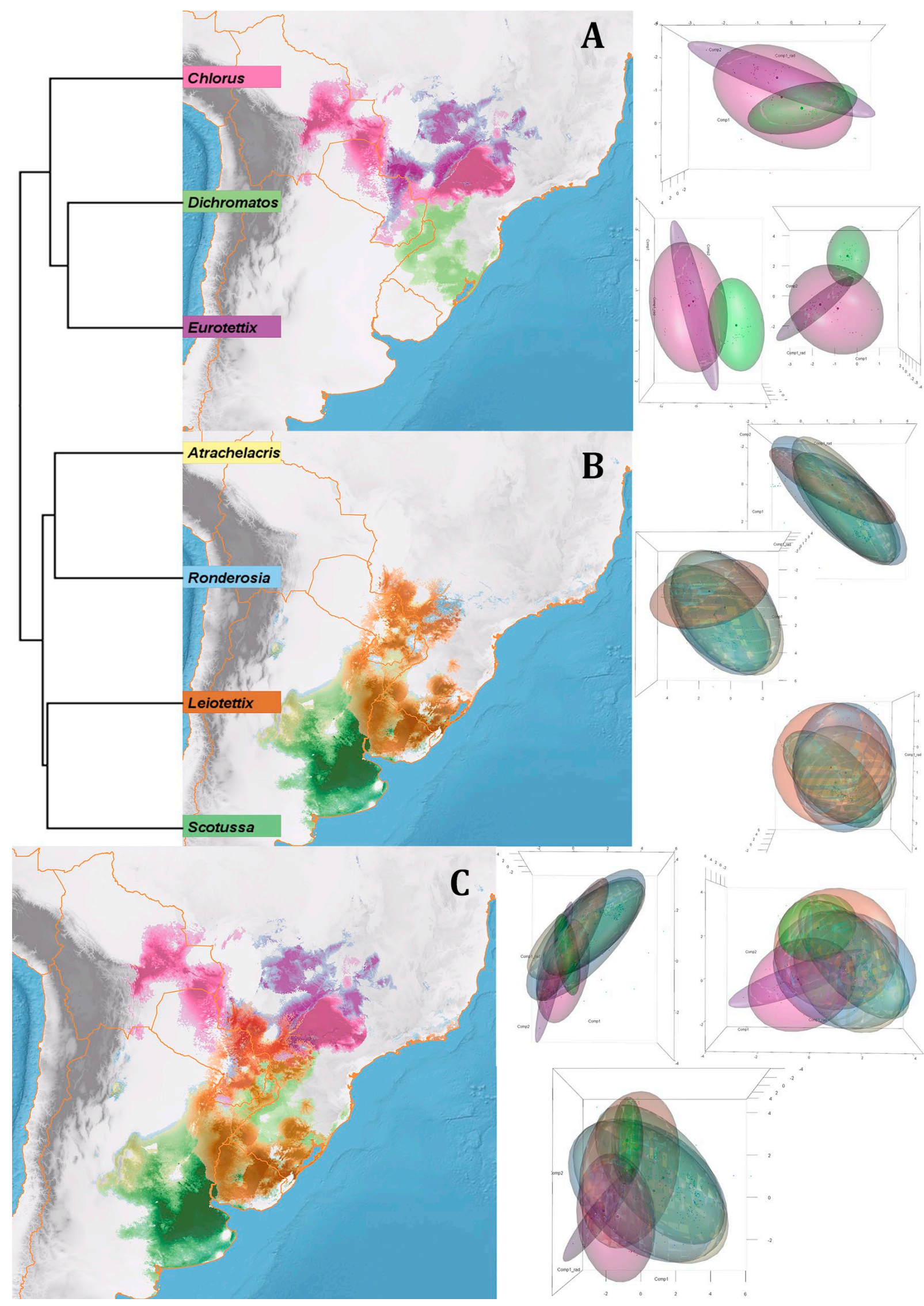

Figura 20: Distribución potencial y nicho ecológico de los géneros realizado con la metodología de Elipsoides e ilustrado siguiendo las relaciones filogenéticas. A) Se presentan el clado Braquíptero, B) presenta el clado Macróptero y C) presentan las relaciones entre todos los géneros del grupo. 
Al analizar el nicho ecológico del clado Braquíptero, Chlorus es el que presenta una mayor variabilidad ambiental con respecto a los otros géneros (Fig. 20A; Tabla 15). A su vez, es más similar a Eurotettix en su espacio ambiental, superponiéndose gran parte de sus elipses ambientales y geográficamente en Brasil (Fig. 20A). A pesar de estar más relacionados Dichromatos y Eurotettix, se observa que Dichromatos está claramente diferenciado en el espacio ambiental de los otros dos géneros.

El clado Macróptero presenta gran superposición en sus nichos ecológicos, sólo se evidencia un desplazamiento de la elipse de Leiotettix hacia uno de los extremos de la distribución ambiental de los otros géneros (Fig. 20B). Los géneros hermanos Ronderosia y Atrachelacris presentan dos de los tres valores más elevados de amplitud de nicho (Tabla 15).

En el mapa de distribuciones potenciales del total del grupo Scotussae se observa que los géneros del clado Braquíptero se encuentran más al norte que los macrópteros, encontrándose Chlorus y Eurotettix más desplazados hacia la periferia de la distribución ambiental del grupo (Fig. 20C).

\section{Señal Filogenética}

Variables: Se evaluó la señal filogenética en los volúmenes de nicho, los valores de centroide de nicho de los 4 componentes principales (CPs) y en los valores mínimos y máximos de cada variable ambiental por medio del estadístico K (Blomberg et al., 2002). En todas las variables con señal filogenética significativa, los valores de $\mathrm{K}$ resultaron mayores a 1, indicando una alta señal filogenética (Figs. 21-25; Tabla 16). En relación a las variables de volumen de nicho y los componentes principales, se encontró que el CP1 (que representa principalmente la temperatura) y el CP1-Radiación fueron los que presentan señal filogenética significativa (Tabla 16). Todas las variables ambientales presentaron señal filogenética significativa salvo la radiación de marzo, las temperaturas máximas del mes más cálido y la temperatura promedio del cuarto más cálido y del cuarto más húmedo (Bio 5, Bio 8 y Bio 10, respectivamente). Asimismo, la única variable que presentó asociación significativa tanto para los valores máximos como para los mínimos fue la variación estacional de precipitación (Bio 15). Las variables que tuvieron señal filogenética en los valores máximos fueron la radiación de diciembre, enero y febrero y las variaciones de temperatura diaria (Bio 2), estacional (Bio4) y la temperatura promedio anual (Bio 7). Todas las variables de precipitación, la isoterma (Bio 3) y las temperaturas promedio anual (Bio 1), temperatura mínima del mes más frío (Bio 6), temperatura 
promedio del cuarto más seco (Bio 9) y del más frío (Bio 11) presentaron señal filogenética en sus valores mínimos.

\begin{tabular}{|c|c|c|c|cc|c|cc|}
\hline Variable & \multirow{2}{*}{ K } & \multirow{2}{*}{ Variable } & \multicolumn{2}{|c|}{ K } & \multirow{2}{*}{ Variable } & \multicolumn{2}{|c|}{ K } \\
\cline { 4 - 5 } Vol & 0.90 & & & Mínimo & Máximo & & Mínimo & Máximo \\
\cline { 4 - 5 } CP1 & 1.20 \\
CP1_rad & 1.02 & Bio 1 & 1.06 & 0.73 & Bio 13 & 1.26 & 0.77 \\
CP2 & 0.85 \\
CP3 & 0.79 & Bio 2 & 0.72 & 1.20 & Bio 14 & 1.44 & 0.83 \\
Bio 3 & 1.23 & 0.73 & Bio 15 & 1.04 & 0.99 \\
& & Bio 4 & 0.73 & 1.27 & Bio 16 & 1.18 & 0.74 \\
Bio 5 & 0.75 & 0.73 & Bio 17 & 1.39 & 0.83 \\
& & Bio 6 & 1.09 & 0.78 & Bio 18 & 1.10 & 0.67 \\
Bio 7 & 0.78 & 1.37 & Bio 19 & 1.27 & 0.83 \\
& Bio 8 & 0.82 & 0.66 & Rad_1 & 0.63 & 1.21 \\
Bio 9 & 1.15 & 0.66 & Rad_2 & 0.71 & 1.26 \\
Bio 10 & 0.82 & 0.66 & Rad_3 & 0.80 & 0.79 \\
Bio 11 & 1.18 & 0.72 & Rad_12 & 0.69 & 1.36 \\
Bio 12 & 1.15 & 0.73 & & & \\
\hline
\end{tabular}

Tabla 16: Valores de K (Blomberg et al., 2002) evaluando la señal filogenética para las variables volumen de nicho (Vol), los cuatro componentes principales (CP1, CP2, CP3, CP1_rad) y las variables bioclimáticas. Las celdas en celeste indican valores significativos $(\mathrm{P}<0,05)$.

Los resultados de la optimización por Máxima Parsimonia de las variables bioclimáticas que presentaban señal filogenética (Figs. 21-25) indicaron que el clado Macróptero tolera mayores valores máximos de variación estacional y, dentro de este clado, los géneros hermanos Ronderosia y Atrachelachis toleran mayor variación diaria de temperatura (Fig. 21). El clado braquíptero tolera valores altos para las variables de mínimos de temperatura promedio anual e isotermalidad, mientras que el género Scotussa tolera los valores más bajos en dichas variables (Fig. 21). Asimismo, el clado Braquíptero precisa valores más elevados de temperaturas mínimas que el clado Macróptero, que presenta los menores valores de temperatura promedio anual máxima (Fig. 22). Los valores mínimos de precipitación, son generalmente menores para el clado Macróptero, tolerando el clado Braquíptero regiones con valores mínimos de precipitación más elevados (Figs. 23, 24). Respecto a los valores máximos de radiación, el clado Macróptero tolera mayores valores de radiación máxima que el clado Braquíptero (Fig. 25). 

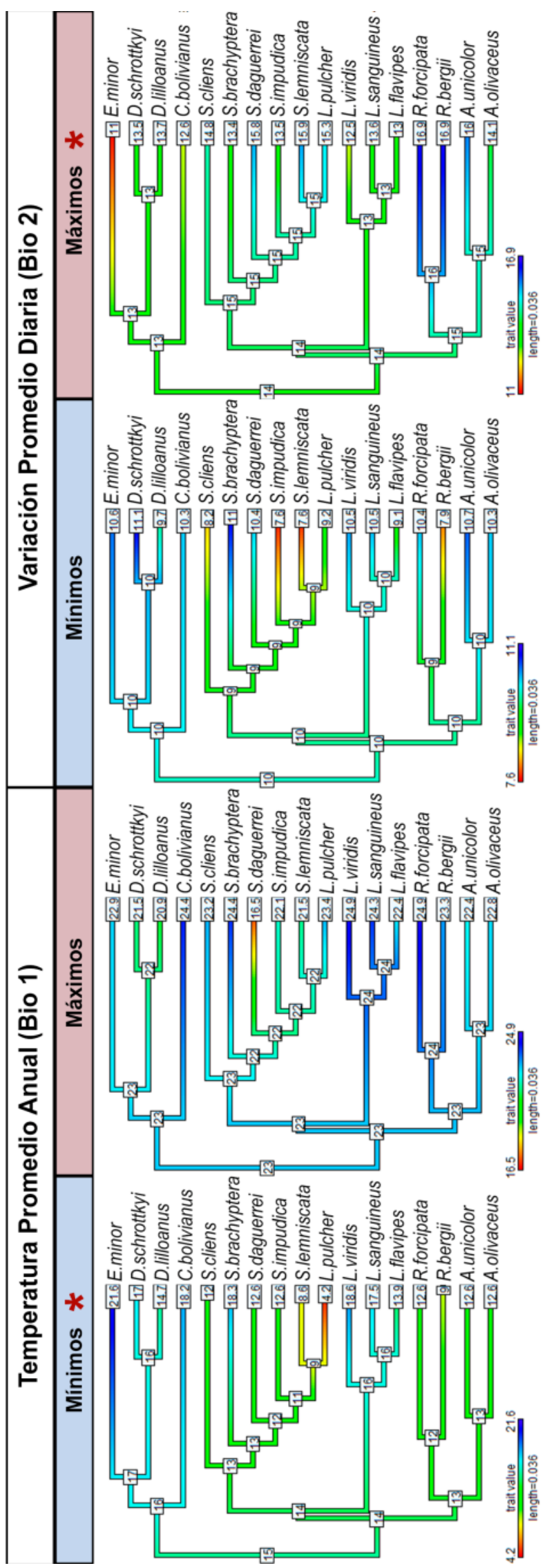

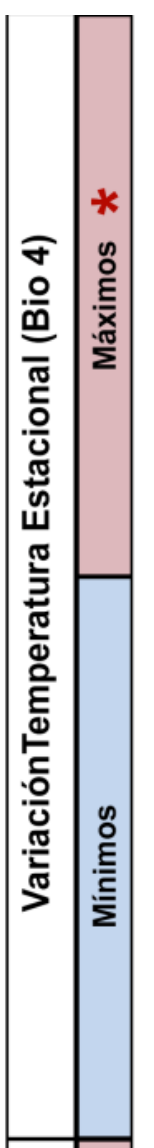

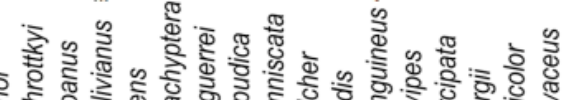

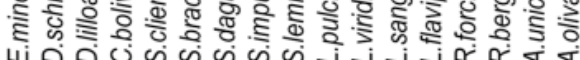

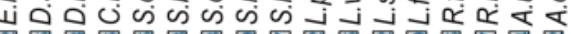

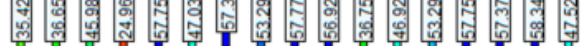
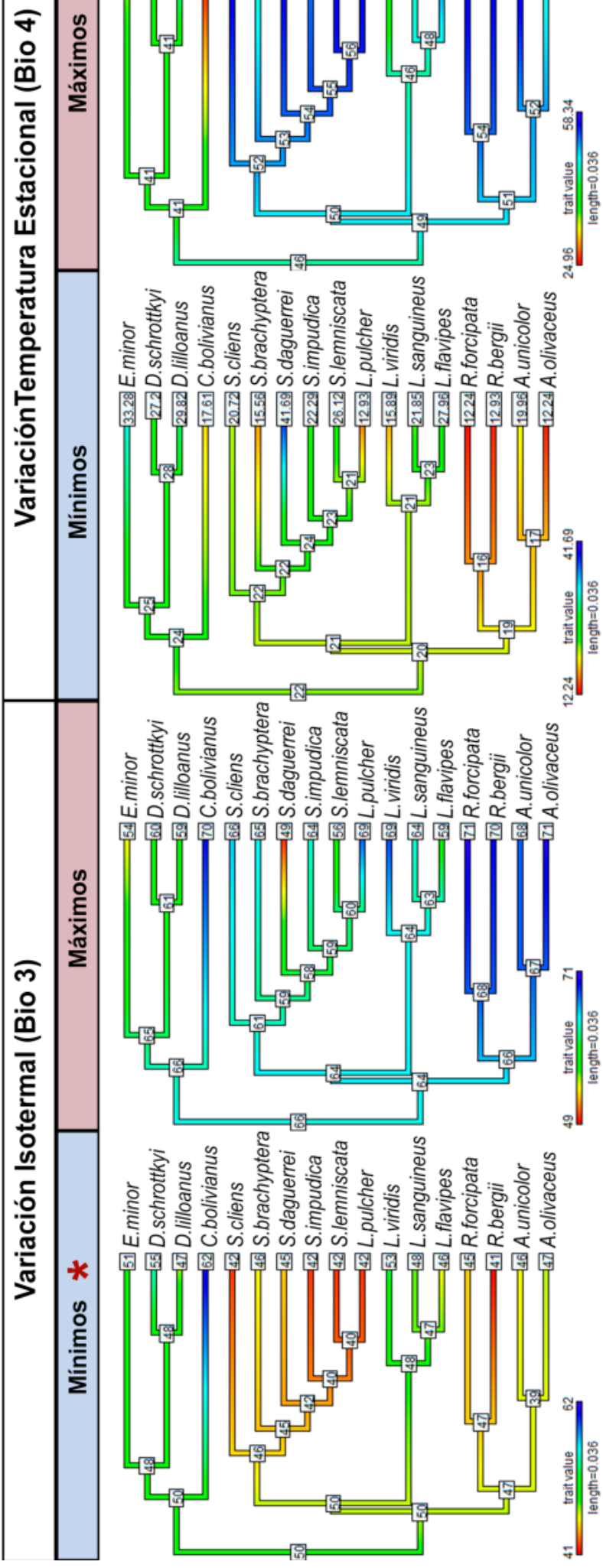

Figura 21: Resultados de la optimización realizada por Máxima Parsimonia de las variables bioclimáticas que presentaban valores significativos de señal filogenética (Blomberg et al., 2002). Se representan los valores mínimos y máximos de cada variable indicando con un * cuales presentan valores significativos $(\mathrm{P}<0,05)$. 

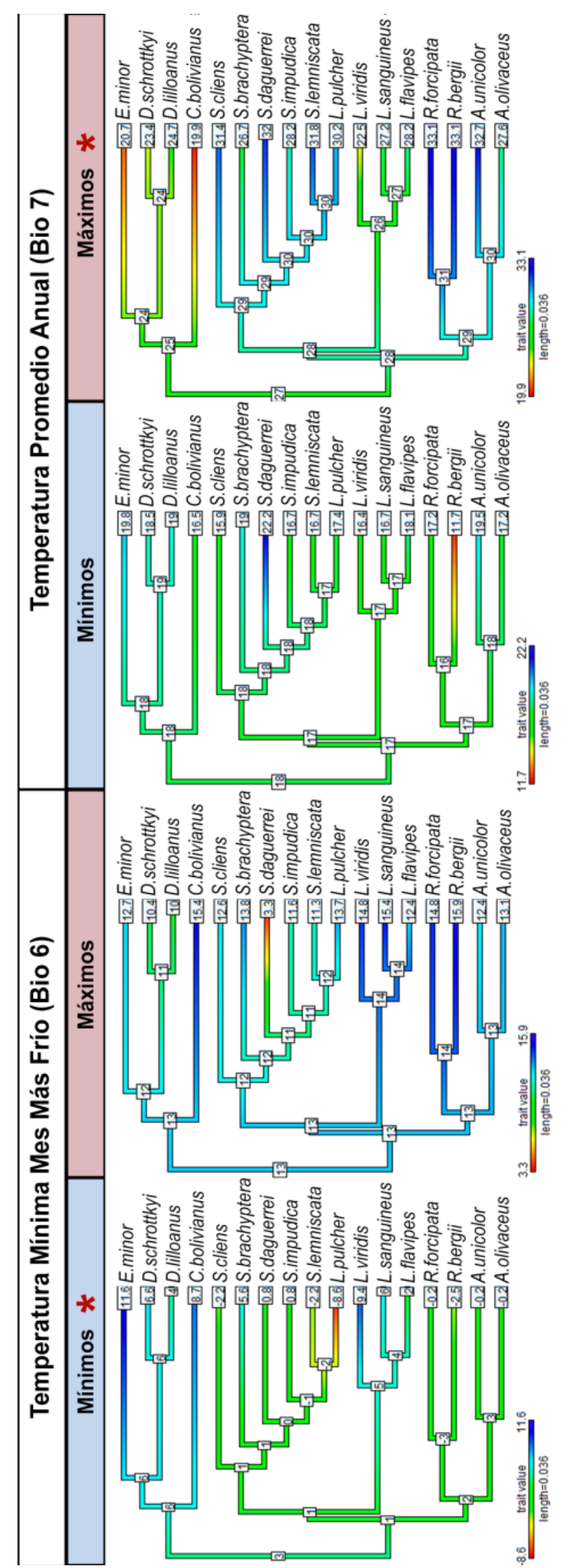
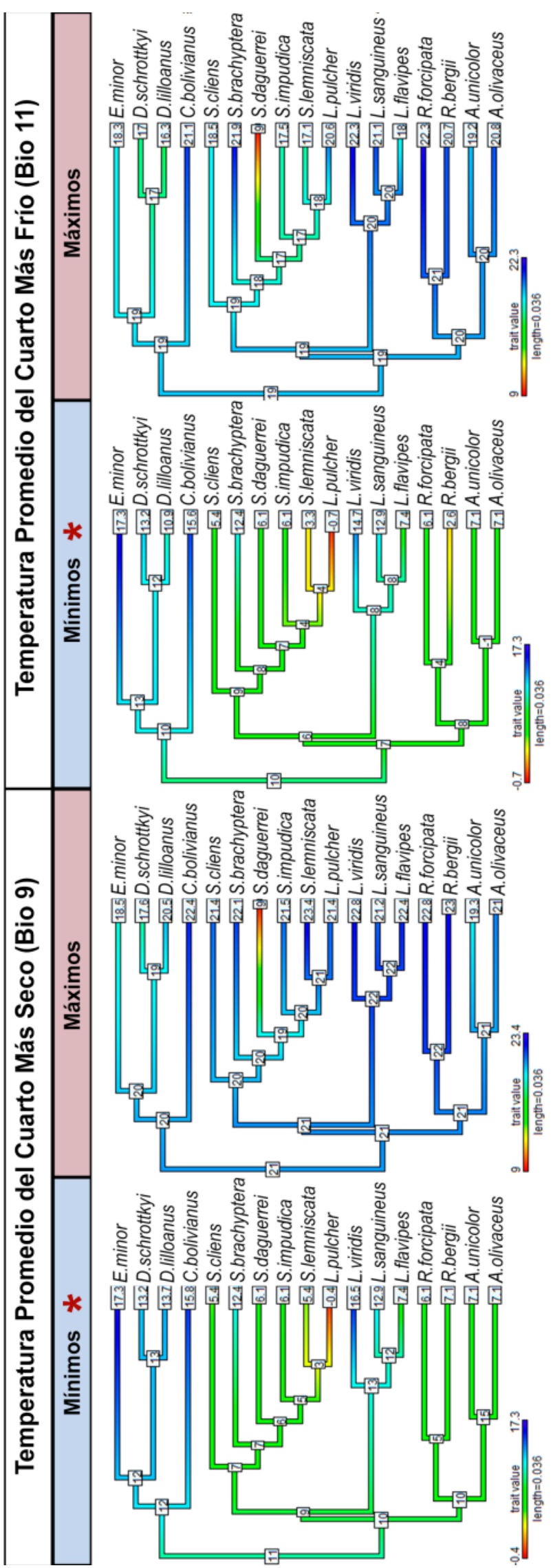

Figura 22: Resultados de la optimización realizada por Máxima Parsimonia de las variables bioclimáticas que presentaban valores significativos de señal filogenética (Blomberg et al., 2002). Se representan los valores mínimos y máximos de cada variable indicando con un * cuales presentan valores significativos $(\mathrm{P}<0,05)$. 

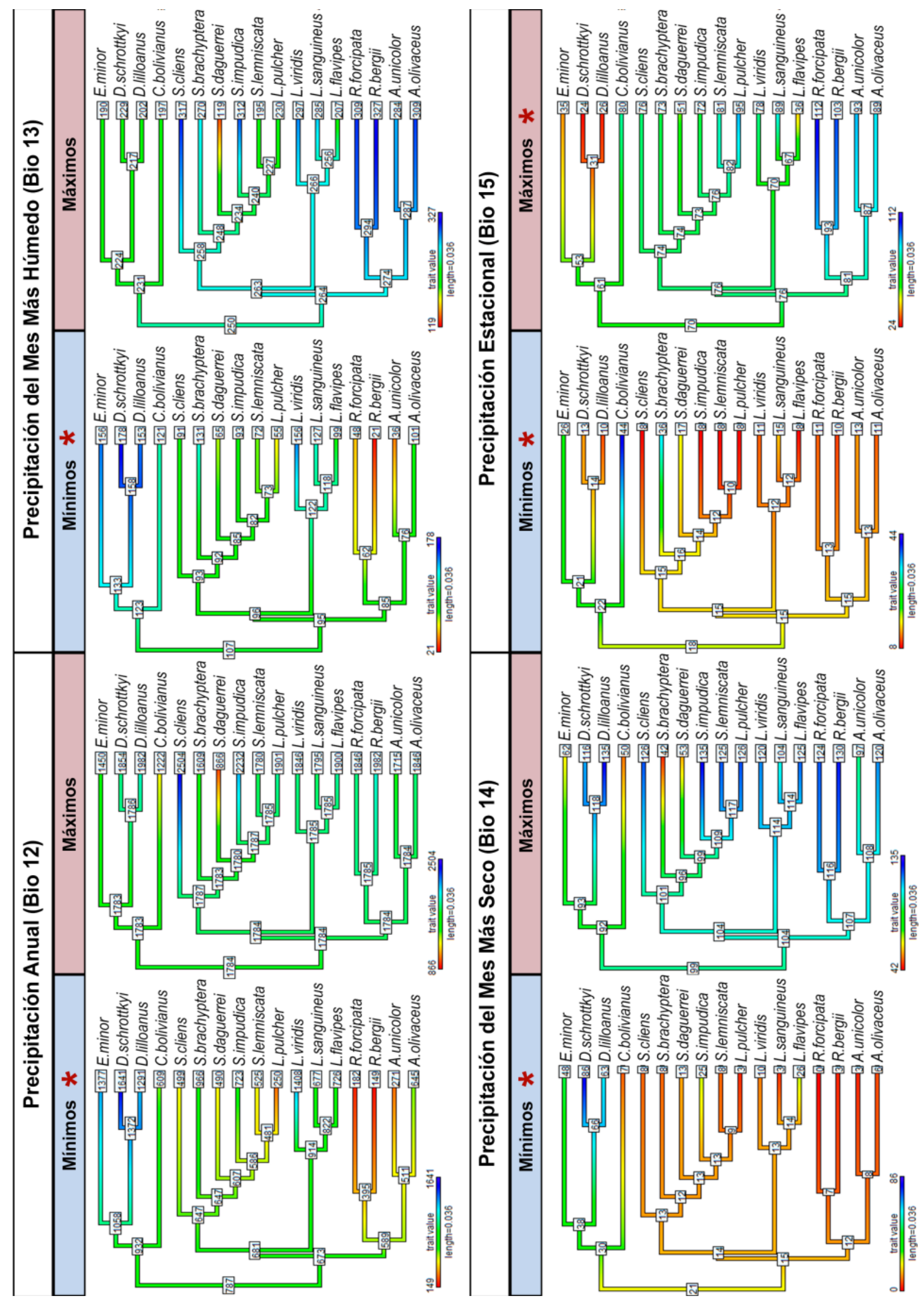

Figura 23: Resultados de la optimización realizada por Máxima Parsimonia de las variables bioclimáticas que presentaban valores significativos de señal filogenética (Blomberg et al., 2002). Se representan los valores mínimos y máximos de cada variable indicando con un * cuales presentan valores significativos $(\mathrm{P}<0,05)$. 

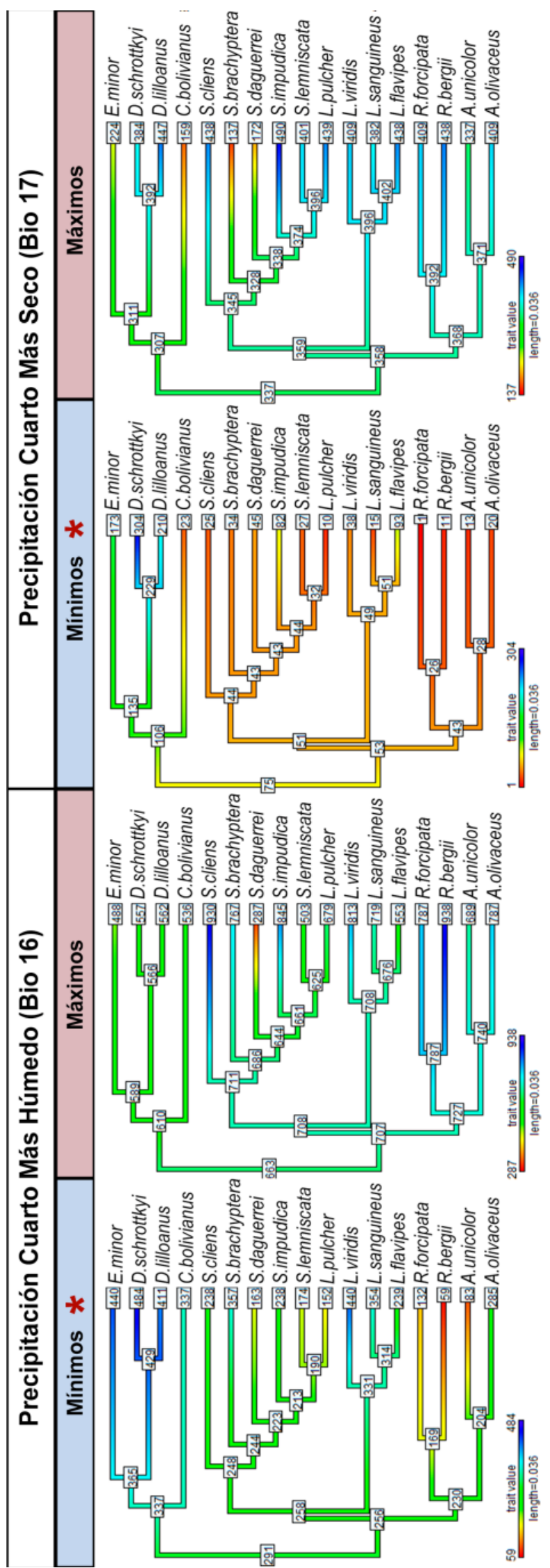

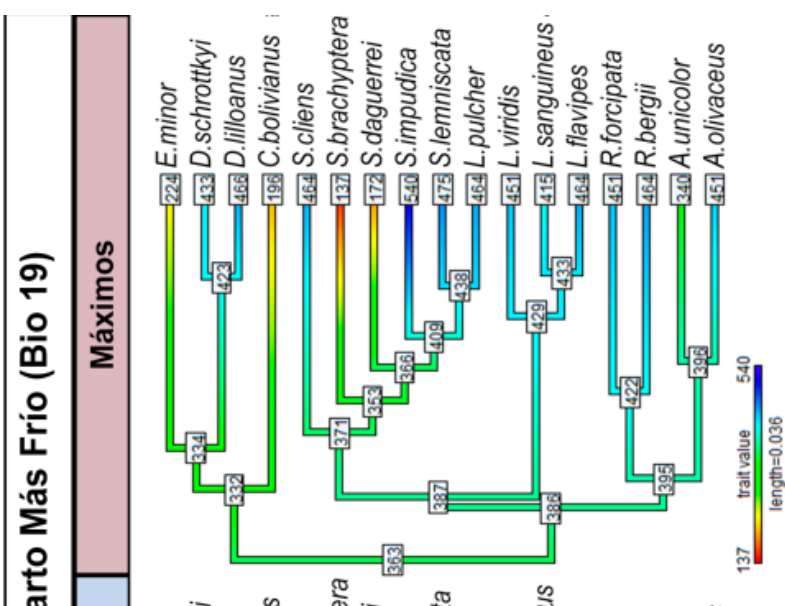

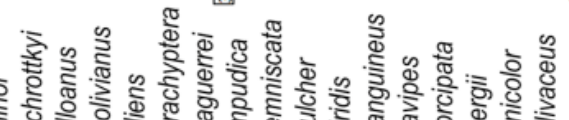

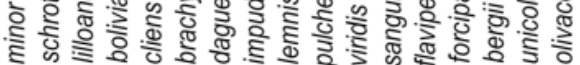

山i

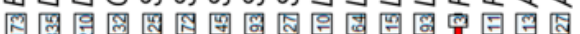

*
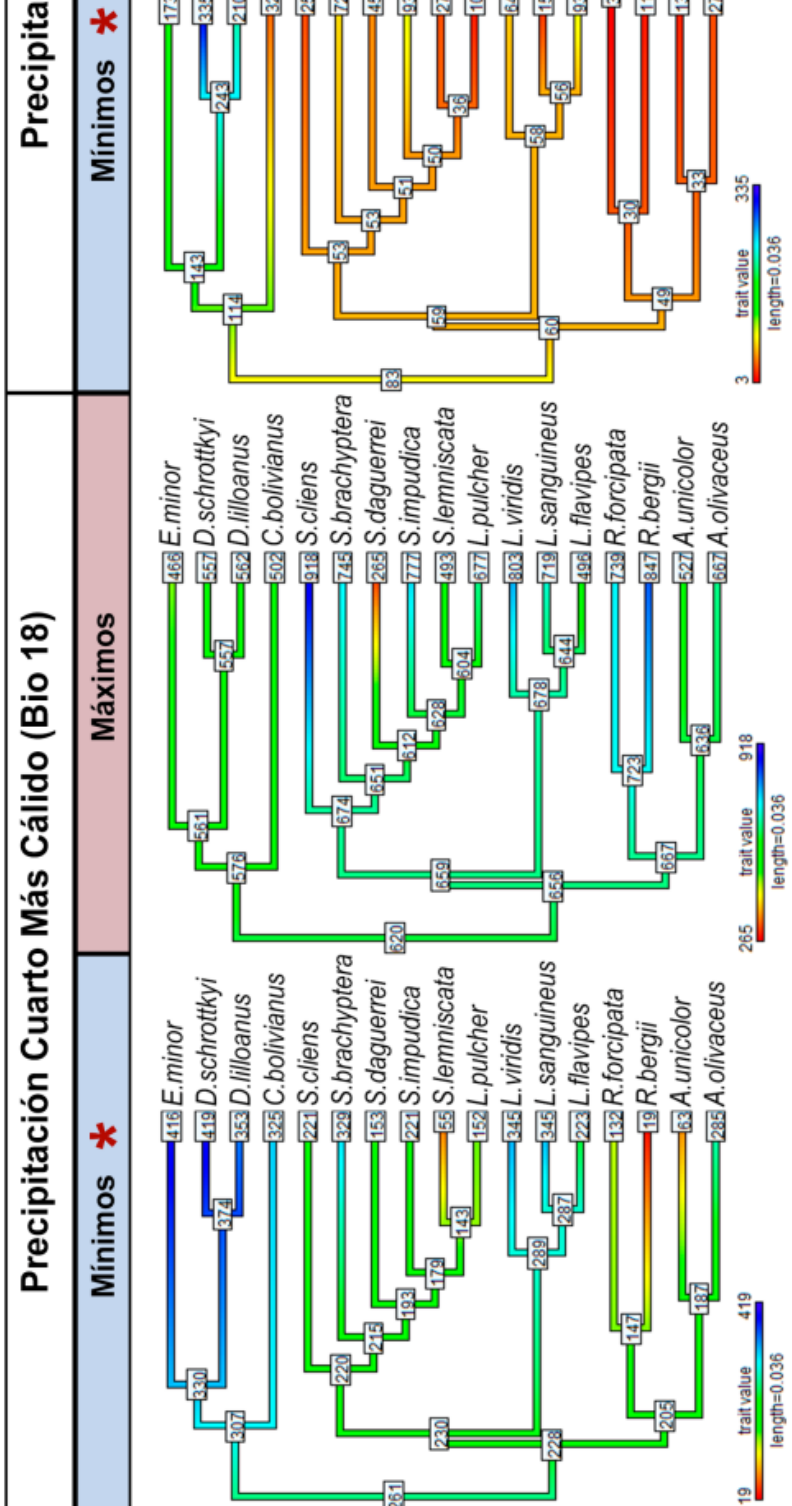

Figura 24: Resultados de la optimización realizada por Máxima Parsimonia de las variables bioclimáticas que presentaban valores significativos de señal filogenética (Blomberg et al., 2002). Se representan los valores mínimos y máximos de cada variable indicando con un * cuales presentan valores significativos $(\mathrm{P}<0,05)$. 

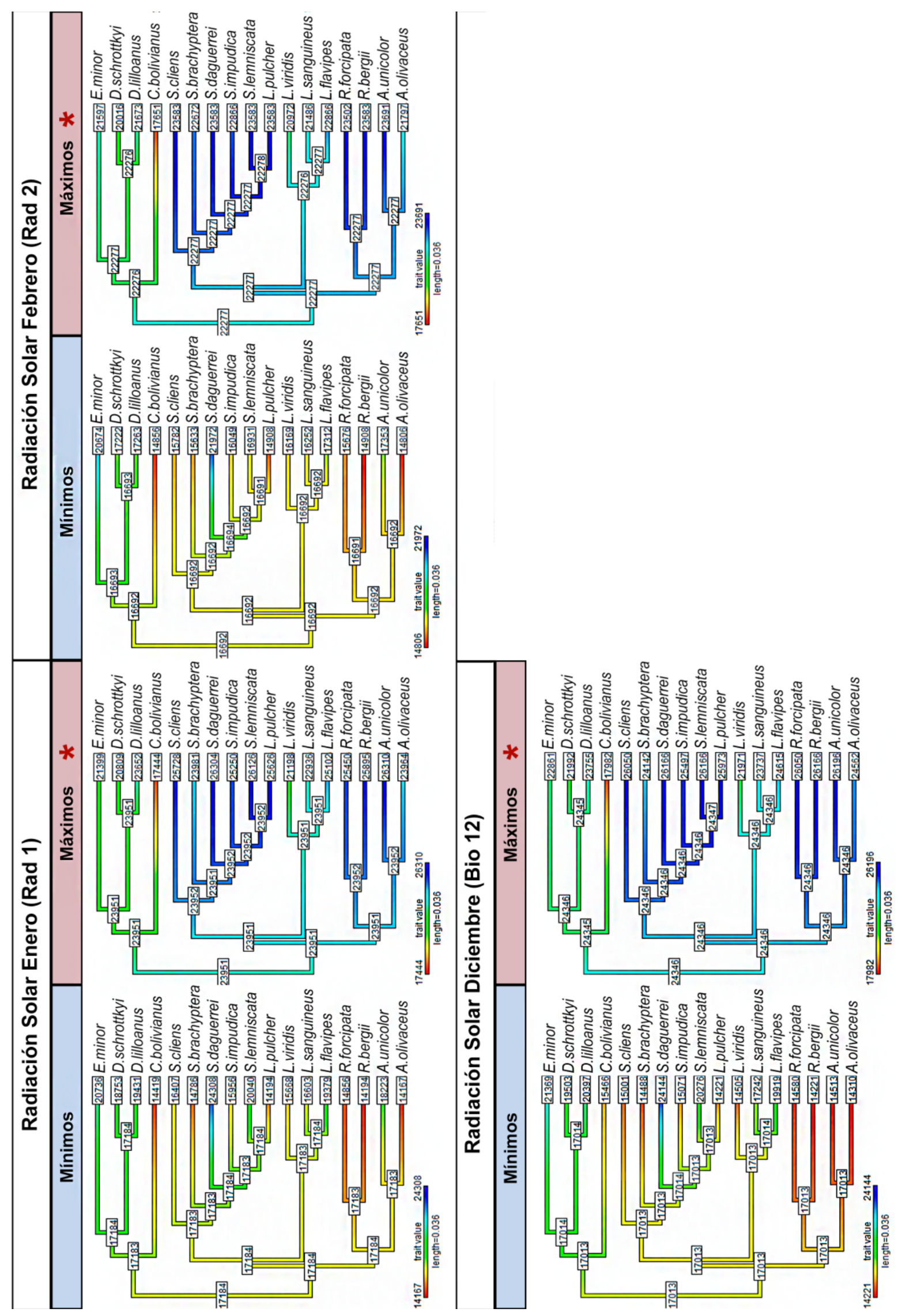

Figura 25: Resultados de la optimización realizada por Máxima Parsimonia de las variables bioclimáticas que presentaban valores significativos de señal filogenética (Blomberg et al., 2002). Se representan los valores mínimos y máximos de cada variable indicando con un * cuales presentan valores significativos $(\mathrm{P}<0,05)$. 
Nicho y Distribución: Los análisis de correlación entre las distancias genéticas y las distancias ambientales y geográficas aplicando el análisis de Mantel fueron significativos (Tabla 17). A partir de dichos resultados se puede inferir que la filogenia tiene una mayor asociación con la distancia ambiental, en comparación con las distancias geográficas y el logaritmo de la inversa de la matriz de superposición. A pesar de que la distancia ambiental y geográfica están altamente correlacionadas entre sí, la distancia ambiental siempre presenta un valor mayor de $\mathrm{R}$ asociado a las otras dos variables que a la distancia geográfica (Tabla 17).

\begin{tabular}{|c|c|c|c|c|c|c|c|c|}
\hline \multirow{2}{*}{ Mantel } & \multicolumn{2}{|c|}{ Filogenia } & \multicolumn{2}{|c|}{ Dist-Amb } & \multicolumn{2}{|c|}{ Dist-Geog } & \multicolumn{2}{|c|}{ Inv-Indice-I } \\
\cline { 2 - 8 } & $\mathrm{R}$ & $\mathrm{p}$ & $\mathrm{R}$ & $\mathrm{p}$ & $\mathrm{R}$ & $\mathrm{p}$ & $\mathrm{R}$ & $\mathrm{p}$ \\
\hline Filogenia & & & & & & & & \\
Dist-Amb & 0.31 & $\mathbf{0 . 0 0 5}$ & & & & & & \\
Dist-Geog & 0.22 & $\mathbf{0 . 0 3 2}$ & 0.91 & $\mathbf{0 . 0 0 1}$ & & & & \\
Inv-Indice-I & 0.20 & $\mathbf{0 . 0 1 9}$ & 0.64 & $\mathbf{1 E - 0 4}$ & 0.55 & $\mathbf{1 E - 0 4}$ & & \\
\hline
\end{tabular}

Tabla 17: Resultados de los análisis de señal filogenética comparando la cercanía filogenética con la distancia ecológica y geográfica, realizados con el estadístico Mantel (R) con valores de significación (p) de las variables. En negrita se indican los valores de p significativos $(\mathrm{P}<0,05)$; "Filogenia" = matriz de distancia filogenética, "Dist-Amb" = matriz de distancia entre centroides de nicho, "Dist-Geog" = matriz de distancia entre centros geográficos, "Inv-Indice-I" = matriz generada realizando el logaritmo de la inversa de la matriz de superposición de nicho (I)

\section{Biogeografía histórica del grupo Scotussae}

La reconstrucción del rango ancestral según 'BioGeoBEARS' indica que el grupo Scotussae se habría originado en el Bosque Tropical Seco Estacional (BTSE) (Fig. 26), y que el grupo de géneros se ajusta al modelo BAYAREALIKE (Tabla 18), indicando que la diversificación del grupo podría deberse principalmente a eventos de especiación simpátrida. Al considerar exclusivamente el clado Macróptero, el modelo que presentó mayor ajuste sigue siendo BAYAREALIKE y el BAYAREALIKE + J (Tabla 19) sin encontrar diferencias significativas entre ambos modelos, mientras que al considerar el clado Braquíptero el modelo con mejor ajuste es el DEC (Tabla 20). La reconstrucción del rango ancestral indica que el grupo Macróptero se habría originado en el BTSE y Pampa (Fig. 26), manteniéndose esta distribución en todos los géneros, a excepción de Ronderosia, cuyo ancestro habría colonizado también el Cerrado. Por otro lado, el ancestro del clado Braquíptero habría estado distribuido en el BTSE, el antecesor de Chlorus habría permanecido principalmente en dicha región, mientras que el ancestro de Dichromatos 
presenta una dispersión hacia el Bosque de Araucaria y Eurotettix se habría dispersado hacia el Cerrado.

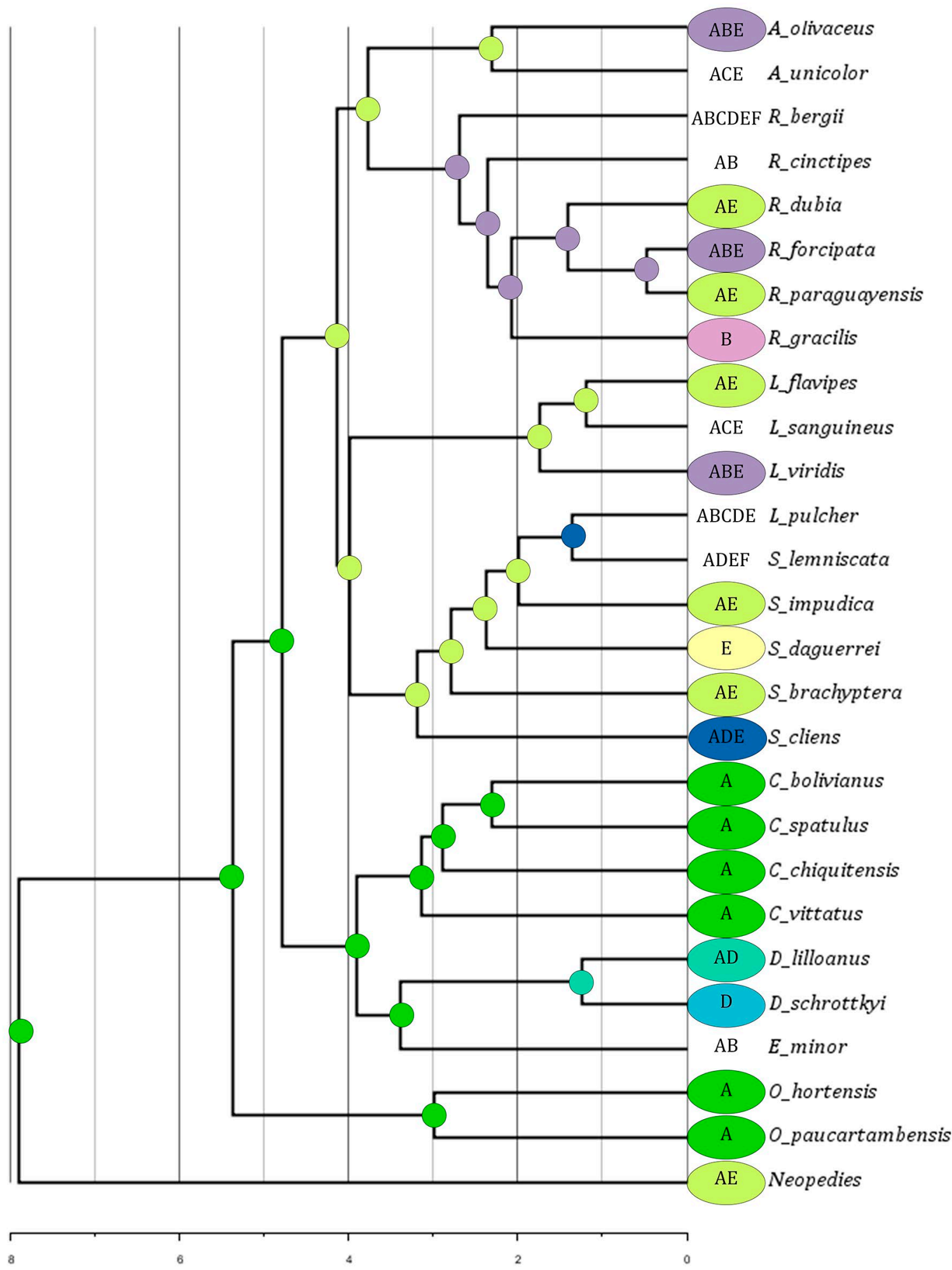

Figura 26: Análisis de estimación de rango ancestral realizado con el BioGeoBEARS. Las letras representan las regiones utilizadas en el análisis: A= BTSE; $\mathrm{B}=$ Cerrado; $\mathrm{C}=$ Chaco; $\mathrm{D}=\mathrm{BLT}$; $\mathrm{E}=$ Pampa; F= Biomas del Sur. Se mantienen los colores de las regiones de la figura 1 y se asignan nuevos colores únicamente a las combinaciones que aparecen en algún nodo interno del árbol. 


\begin{tabular}{|lcccccc|}
\hline \multicolumn{1}{|c}{ Modelo } & LnL & AIC & $\begin{array}{c}\text { No } \\
\text { params }\end{array}$ & $\mathrm{d}$ & $\mathrm{e}$ & $\mathrm{j}$ \\
\hline DEC & -90.83 & 185.7 & 2 & 0.071 & 0.000 & 0.00000 \\
DEC+J & -90.84 & 187.7 & 3 & 0.071 & 0.000 & 0.00001 \\
DIVALIKE & -96.07 & 196.1 & 2 & 0.082 & 0.000 & 0.00000 \\
DIVALIKE+J & -96.07 & 198.1 & 3 & 0.082 & 0.000 & 0.00001 \\
BAYAREALIKE & $\mathbf{- 7 5 . 0 7}$ & $\mathbf{1 5 4 . 1}$ & 2 & 0.035 & 0.070 & 0.00000 \\
BAYAREALIKE+J & -75.07 & 156.1 & 3 & 0.035 & 0.070 & 0.00001 \\
\hline
\end{tabular}

Tabla 18: Comparación entre los modelos estimados en 'BioGeoBEARS' para grupo Scotussae, mostrando para cada modelo el logaritmo de la Verosimilitud (LnL), el criterio de información de Akaike (AIC), el número de parámetros (№ params), la tasa de "dispersión” (d) y de "extinción” (e). En negrita están los valores óptimos para ambas metodologías.

\begin{tabular}{|lcccccc|}
\hline \multicolumn{1}{|c}{ Modelo } & LnL & AIC & $\begin{array}{c}\text { No } \\
\text { params }\end{array}$ & $\mathrm{d}$ & $\mathrm{e}$ & $\mathrm{j}$ \\
\hline DEC & -63.02 & 130 & 2 & 0.119 & 0.000 & 0.00000 \\
DEC+J & -63.02 & 132 & 3 & 0.119 & 0.000 & 0.00001 \\
DIVALIKE & -65.76 & 135.5 & 2 & 0.137 & 0.000 & 0.00000 \\
DIVALIKE+J & -65.76 & 137.5 & 3 & 0.137 & 0.000 & 0.00001 \\
BAYAREALIKE & -52.64 & $\mathbf{1 0 9 . 3}$ & 2 & 0.051 & 0.092 & 0.00000 \\
BAYAREALIKE+J & $\mathbf{- 5 2 . 1 0}$ & 110.2 & 3 & 0.051 & 0.033 & 0.00900 \\
\hline
\end{tabular}

Tabla 19: Comparación entre los modelos estimados en 'BioGeoBEARS' para el clado macróptero, mostrando para cada modelo el logaritmo de la Verosimilitud (LnL), el criterio de información de Akaike (AIC), el número de parámetros (№ params), la tasa de "dispersión" (d) y de "extinción" (e). En negrita están los valores óptimos para ambas metodologías.

\begin{tabular}{|lcccccc|}
\hline \multicolumn{1}{|c}{ Modelo } & LnL & AIC & $\begin{array}{c}\text { No } \\
\text { params }\end{array}$ & $\mathrm{d}$ & $\mathrm{e}$ & $\mathrm{j}$ \\
\hline DEC & $\mathbf{- 6 . 8 4}$ & $\mathbf{1 7 . 6 8}$ & 2 & 0.059 & 0.000 & 0.00000 \\
DEC+J & -6.84 & 19.68 & 3 & 0.059 & 0.000 & 0.00001 \\
DIVALIKE & -8.34 & 20.68 & 2 & 0.092 & 0.000 & 0.00000 \\
DIVALIKE+J & -8.29 & 22.58 & 3 & 0.080 & 0.000 & 0.02113 \\
BAYAREALIKE & -9.33 & 22.66 & 2 & 0.070 & 0.053 & 0.00000 \\
BAYAREALIKE+J & -9.33 & 24.65 & 3 & 0.072 & 0.052 & 0.00001 \\
\hline
\end{tabular}

Tabla 20: Comparación entre los modelos estimados en 'BioGeoBEARS' para el clado braquíptero, mostrando para cada modelo el logaritmo de la Verosimilitud (LnL), el criterio de información de Akaike (AIC), el número de parámetros (№ params), la tasa de “dispersión” (d) y de “extinción” (e). En negrita están los valores óptimos para ambas metodologías. 


\section{DISCUSIÓN}

\section{Análisis Filogenético}

El análisis filogenético combinado recuperó la monofilia del grupo de géneros Scotussae así como la de todos los géneros con un alto soporte de ramas, exceptuando Leiotettix y Scotussa debido a que Leiotettix pulcher queda incluida dentro del clado conformado por las especies de Scotussa (Fig. 17). En función de estos resultados obtenidos se considerará en este trabajo a Leiotettix pulcher como parte del género Scotussa, sin embargo, se mantendrá el nombre original, a pesar de que se considera necesario realizar la nueva combinación [Scotussa pulchera (Rehn, 1913)], debido a que los cambios nomenclaturales no son válidos en un trabajo de tesis.

Se recuperan también dos clados principales: uno, constituido por los géneros con especies exclusivamente braquípteras (Chlorus, Eurotettix y Dichromatos) y otro que comprende al resto de los géneros del grupo, que son mayoritariamente macrópteros. Dentro de este clado, se recupera una estrecha relación entre los géneros Atrachelacris y Ronderosia, y entre Scotussa y Leiotettix. Las relaciones genéricas aquí obtenidas son coincidentes con resultados de trabajos recientes. Así la estrecha relación entre Atrachelacris y Ronderosia también fue recuperada en la filogenia combinada de Castillo et al., (2018); y aquella entre Chlorus, Dichromatos y Eurottetix quedó en evidencia en los análisis filogenéticos de Cigliano (2007), Cigliano \& Lange (2007) y Dinghi, Confalonieri \& Cigliano (2009), mientras que la relación entre Scotussa y Leiotettix se recupera en el análisis cladístico sobre evidencia morfológica de Cigliano et al. (1996) y en el combinado de Dinghi et al. (2009).

\section{Patrones de diversificación del grupo Scotussae}

La diversificación del grupo Scotussae habría ocurrido durante el Plioceno, en la denominada "Era de las llanuras del Sur" (Pascual \& Bondesio, 1982; Pascual et al., 1996; Ortiz-Jaureguizar \& Cladera, 2006), habiéndose originado el ancestro del grupo hace aproximadamente 4,55 Ma. en el ecosistema abierto del Bosque Tropical Seco Estacional (BTSE) (Figs. 17, 26).

La presencia de conservadurismo de nicho es un patrón ampliamente mencionado en la literatura (Duncan \&Williams, 2002; Anderson et al., 2004; Peres-Neto, 2004; Wiens \& Graham, 2005; Mouillot et al., 2006; Swenson et al., 2006; Johnson \& Stinchcombe, 2007; Losos, 2008; Wiens et al., 2010; Peterson, 2011; Pyron et al., 2015), sin embargo, no 
siempre está asociado con las relaciones filogenéticas. Estudios recientes, realizados en murciélagos a nivel global, indican que más del 50\% de las especies de este grupo presentan conservadurismo de nicho, sin embargo no se pudo establecer que estas tendencias estuvieran asociadas a las relaciones filogenéticas (conservadurismo filogenético de nicho) (Peixoto et al., 2017). En este trabajo de tesis se halló que sólo en un tercio de los pares de especies la similitud de nicho fue más alta de lo esperado por el azar, y a pesar de ello se encontró una relación estrecha entre el nicho y la cercanía filogenética (Tablas 12,17). Las diversas aproximaciones realizadas en esta tesis concuerdan en que el grupo Scotussae presentaría un patrón dominante de conservadurismo de nicho (Figs. 18, 19; Tablas 10-13,17), con una fuerte asociación entre las relaciones filogenéticas y el ambiente (Figs. 21, 22, 23, 24, 25; Tablas 16, 17). Por lo tanto, se interpreta que aquellas especies estrechamente relacionadas se parecen más ambientalmente, que aquellas especies menos relacionadas filogenéticamente.

La mayor superposición de nicho, tanto a nivel específico (Figs. 18, 19) como genérico (Fig. 20) se encuentra en la región Paranense del BTSE. La fuerte asociación entre la filogenia y las condiciones ambientales, junto con el alto grado de superposición ambiental encontrada en la región Paranense, nos permite inferir que el ancestro del Scotussae habría poblado los ecosistemas abiertos del tipo BTSE que presentarían características ambientales similares a las encontradas hoy en día en la región Paranense. Así entonces, se considera que el centro de diversificación del grupo habría estado restringido a la actual región Paranense, mientras que si consideramos solo al clado Macróptero habría estado en la región paranense-pampeana, en coincidencia con la propuesta de Ronderos (1981).

\section{Clado Braquíptero}

El ancestro del clado Braquípero habría habitado el BTSE, donde se habría diversificado el antecesor de Chlorus, mientras que el antecesor de Dichromatos se habría dispersado hacia el Bosque Lluvioso Tropical (BLT), y el de Eurotettix hacia el Cerrado. Según la reconstrucción del rango ancestral del grupo, eventos de Dispersión-ExtinciónCladogénesis (DEC) habrían sido los modelos de diversificación más probables (Tabla 20), sin encontrarse evidencia de efecto fundador. Estos resultados son concordantes, tanto a nivel específico como genérico, con la falta de superposición significativa de nicho (Figs. 18, 20; Tablas 10, 12) y con la superposición geográfica escasa o nula (Figs. 18, 20). Asimismo, las especies de este clado se caracterizan por presentar amplitudes de nicho más reducidas que las del clado Macróptero (Tabla 14). 
Chlorus está compuesto por 7 especies, de las cuales 6 se distribuyen dentro del BTSE, en la Paranense, el Chaco Húmedo y en el sudeste de Bolivia, llegando hasta el Chiquitano (Werneck, 2011), encontrándose sólo C. borelli (Giglio-Tos) distribuida en el Chaco. A pesar de que el mayor número de especies se mantiene dentro de la misma región, el género presenta el segundo valor más alto de amplitud de nicho (Fig. 20; Tabla 15). La distribución actual del BTSE es discontinua, y en la región que habita Chlorus se encuentra asimismo subdividida en múltiples ecorregiones. La diversificación de este grupo habría comenzado durante el Plioceno tardío extendiéndose hasta el Pleistoceno. En este período, los avances y retrocesos cíclicos de las glaciaciones produjeron expansiones y retracciones marcadas de los biomas áridos y húmedos (Haffer, 1969; Brown \& Ab'Sáber, 1979; Werneck et al., 2011)). Estos cambios cíclicos de temperatura habrían generado contracciones y expansiones de las áreas forestales, determinando una distribución disyunta durante las glaciaciones mucho más marcada que la observada actualmente, lo que habría promovido la diversificación de las especies (Haffer, 1969; Brown \& Ab'Sáber, 1979). Estos ciclos de expansión y retracción, son concordantes con el período de diversificación del género, lo que explicaría, en parte, su distribución actual.

Los géneros Dichromatos y Eurotettix se habrían diferenciado hace aproximadamente 3,2 Ma. (Fig. 17). A pesar de que estos géneros hermanos actualmente ocupan las mismas regiones biogeográficas (Cigliano, 2007), los nicho ecológicos se encuentran desplazados tanto ambiental como geográficamente (Figs. 18, 20; Tablas 10, 13). Dichromatos presenta 4 especies, dos de ellas, D. lilloanus y D. schrottkyi se encuentran en el BTSE y en los Bosque Lluvioso Tropical (BLT), mientras que las otras dos (D. corupa Carbonell \& Mesa y D. montanus Carbonell \& Mesa) se encuentran exclusivamente en los BLT. Tanto las especies como el género presentan valores de amplitud de nicho reducidos (Tablas 14, 15) y las especies hermanas $D$. lilloanus y $D$. schrottkyi presentan superposición significativa entre sí, sugiriendo conservadurismo de nicho. Estudios realizados en la región del Bosque de Araucaria del BLT han determinado que los pastizales de tierras altas fueron abundantes durante los períodos más fríos, pero se redujeron y restringieron a altitudes más altas durante los períodos interglaciares (Behling, 1995, 1997, 2002; Behling \& Lichte, 1997; Fregonezi et al., 2013). En función de la evidencia encontrada en este trabajo acerca del conservadurismo de nicho entre las especies hermanas: D. lilloanus y D. schrottkyi (Tablas 10,13), la edad de diversificación coincidente con el último período glacial, sumado a una morfología altamente homogénea (Cigliano, 2007), se propone que el principal modelo de diversificación de las especies de Dichromatos sería la especiación alopátrica como resultado del aislamiento altitudinal 
durante los períodos interglaciales. Resultados similares se han encontrado en otros taxa de esta región, donde también se infiere la alopatría como el principal mecanismo de diversificación, ocurrida durante los períodos glaciares (Behling, 1995, 1997, 2002; Behling \& Lichte, 1997; Fregonezi et al., 2013).

Eurotettix es el género más diverso del grupo, presentando actualmente 11 especies, de las cuales 9 son endémicas del Cerrado. La mayoría de las especies del género son poco abundantes (raras) y con distribuciones muy restringidas, con valores de volumen de nicho, a nivel específico y genérico, extremadamente reducidos (Tablas 14, 15). Estos resultados permiten asumir que existiría conservadurismo de nicho, es decir, mantenimiento de preferencias de nicho a través del tiempo, que evidenciaría procesos de especiación alopátrica (Nogueira et al., 2011; Guarnizo et al., 2016). Asimismo, el origen del género coincidiría con la última elevación del Cerrado, un "hotspots" de biodiversidad, caracterizado por un gran número de endemismos (Myers et al., 2000; Pennington et al., 2006; Nogueira et al., 2011), principalmente de organismos pequeños y de poca vagilidad, asociados a los hábitats abiertos de mesetas (Nogueira et al., 2009).

\section{Clado Macróptero}

El clado Macróptero presenta en su mayoría, especies con amplitud de nicho (Tabla 14) y distribuciones geográficas (Figs. 18, 19) extensas. Con alto conservadurismo de nicho a nivel específico (Figs. 18, 19; Tablas 10,11), lo que es concordante con sus distribuciones geográficas (Fig. 20), siendo aún más evidente a nivel de género (Tabla 13). La información brindada por el análisis de biogeografía histórica (Fig. 26; Tabla 19), junto con la evidencia de señal filogenética (Tabla 17) y la superposición ambiental (Tablas 10, 13) indicaría que la especiación simpátrida sería el evento de diversificación principal dentro de este grupo. A partir de la reconstrucción ancestral del grupo se estimó que, tanto el ancestro del clado, como el de todos los géneros, habrían estado distribuidos en la Pampa y el BT, y sólo el ancestro de Ronderosia se habría extendido hacia el Cerrado.

Los géneros hermanos Ronderosia y Atrachelacris presentan dos de los tres valores más elevados de amplitud de nicho (Tabla 15). Las dos especies de Atrachelacris se encuentran ampliamente distribuidas (Fig. 18) y son muy similares, tanto en su morfología externa como interna (Cigliano \& Lange, 2001). Atrachelacris olivaceous presenta una amplitud de nicho mayor, y se encuentra distribuida más hacia al norte, ingresando en la región del Cerrado (Figs. 18, 26). Esta especie es macróptera, por lo que probablemente la topografía heterogénea del Cerrado no ha sido un impedimento para el flujo génico entre 
sus poblaciones. Atrachelacris unicolor presenta la mitad de la amplitud de nicho que su especie hermana, sin embargo, sigue siendo una de las especies con distribución más amplia del grupo (Tabla 14) y presentándose más hacia el sudeste que su especie hermana, ingresando en el Chaco (Figs. 18, 26). Estas especies están ampliamente distribuidas y con un valor de superposición de nicho alto y significativo (Tabla 13), por lo que se infiere que podría haber existido una diversificación de tipo simpátrida. Sin embargo estos resultados no son concluyentes y es necesario realizar nuevos estudios sobre la validez de estas especies, ya que son morfológicamente muy similares (Cigliano \& Lange, 2001), no se recupera la monofilia específica en el análisis filogenético (Fig. 17) y no se ha encontrado diferencias en sus re-arreglos cromosómicos, característica muchas veces diagnóstica en otras especies del grupo (Castillo et al., 2018).

El género Ronderosia presenta el mayor valor de amplitud de nicho del grupo Scotussae (Tabla 15) así como las dos especies con mayores amplitudes de nicho (Tabla 14), sin embargo, presenta también especies raras (1, 2 ó 4 registros) que se distribuyen mayoritariamente en la región Paranenese del BTSE. A pesar de que en los análisis de modelado de nicho no se ha encontrado que la superposición sea significativa entre las dos especies más ampliamente distribuidas ( $R$. bergii y $R$. forcipata) la reconstrucción ancestral indicaría que todos los nodos del género tendrían el mismo origen ancestral (BTSE, Pampa y Cerrado) (Fig. 26). En función a estos resultados se considera que la diversificación del género habría ocurrido en la misma región que su ancestro, encontrándose una mayor diversificación en la región Paranenese del BTSE, habiendo sido la especiación simpátrica la predominante en el grupo. Este resultado es consistente con trabajos recientes donde se postula que los re-arreglos cromosómicos habrían desempeñado un papel clave en el proceso de especiación del género Ronderosia (Castillo et al., 2018).

El género Scotussa se caracteriza por presentar un ovipositor con valvas rectas, pero altamente variable entre sus especies (Cigliano \& Ronderos, 1994; Cigliano et al., 1996), diversidad morfológica que contrasta con la gran homogeneidad presente en los ovipositores de valvas curvas de las restantes especies de Dichroplini. La modificación de la estructura del ovipositor de curvado a recto le permite a las especies del género Scotussa oviponer sobre hojas de plantas (Liebermann, 1951; Zolessi, 1958; Mesa \& Zolessi, 1968; Stauffer \& Whitmann, 1997). Braker (1989) determinó que este tipo de oviposición ocurre principalmente en especies de ambientes inundados o selvas tropicales y está generalmente asociado a la especialización en la alimentación (Rowell \& Flook, 2007). Cigliano et al. (1996) mencionan que este cambio estructural en el ovipositor 
podría estar relacionado con una alguna ventaja adaptativa que le habría permitido a las especies del género Scotussa alcanzar una distribución más amplia y una mayor diversificación en comparación con su género hermano Leiotettix. A pesar de que Scotussa (Tabla 9) presenta un mayor número de especies que su género hermano, no existe una clara evidencia de radiación adaptativa, sin embargo, debe considerarse que la diversificación entre los géneros es reciente, hace aprox. 3,8 Ma. (Fig. 17), y por lo tanto podría no haber transcurrido el tiempo suficiente para ver claramente este patrón. Las especies del género Leiotettix presentan valores intermedios de volumen de nicho (Tabla 14) mientras que en el género Scotussa se observan valores de amplitudes de nicho extremadamente variables (Tabla 14) y con gran superposición entre sus especies (Tabla 10). Scotussa daguerrei presenta una amplitud de nicho sumamente restringida (Tabla 14), una distribución bastante periférica (Fig. 19B-C) y sin embargo presenta superposición significativa con la mayoría de sus congéneres. La única excepción es S. brachyptera, la cual presenta una amplitud de nicho reducida (Tabla 14), en una región geográfica bastante central a la distribución del género (Fig. 19B-C), sin embargo, es la única especie que no presenta superposición significativa con ninguna de sus congéneres (Tabla 10). Los resultados muestran que todas las especies de Scotussa analizadas en esta tesis, a excepción de $S$. brachyptera, presentan una distribución más al sur que su género hermano (Fig. 19A-C) habitando regiones de mayor radiación solar y de mayor variación estacional de temperatura (Figs. 21, 25). Por lo expuesto se considera que el género Scotussa habría sufrido especiación de tipo simpátrida y que la modificación del ovipositor podría haberle otorgado alguna ventaja adaptativa, generando oportunidades que hayan favorecido una diversificación ecológica.

Se concluye que la ecología habría tenido un rol principal en la diversificación del grupo Scotussae, ya que los patrones ambientales presentan una mayor asociación con la filogenia, que la distribución geográfica (Tabla 17). Asimismo, se considera que los patrones de diversificación de los dos linajes principales rescatados en este trabajo son diferentes y que podrían deberse, en parte, a las diferentes ventajas que les otorgaría el desarrollo de sus alas. El desarrollo de alas y la capacidad de volar son rasgos característicos de todos los órdenes de insectos superiores. No obstante, un gran número de taxones de insectos perdió secundariamente la capacidad de vuelo (Roff, 1990, 1994; Wagner \& Liebherr, 1992), interpretado generalmente como una adaptación evolutiva a los hábitats insulares, entornos estables y al clima (Chopard, 1938; Mani, 1968; Rolf, 1986, 1990; Braun, 2002, 2011; Hodkinson, 2005; Maveety et al., 2011; Grzywacz et al., 2018). Según los resultados de esta tesis, el clado Braquíptero ha quedado restringido 
principalmente a los ambientes de BTSE, caracterizados por ambientes estables, patrón consistente con aquellos descriptos por Rolf (1990) quien establece que en las regiones boscosas de Norteamérica existiría una mayor proporción de ortópteros braquípteros. En relación a las condiciones climáticas, el clado Braquíptero habita regiones con una menor radiación solar, con abundantes precipitaciones y temperaturas elevadas, poco variables estacionalmente (Figs. 21-25). Se ha propuesto que los BTSEs se habrían expandido durante el Pleistoceno inferior o el Neógeno, seguido por repetidas fragmentaciones del hábitat durante los ciclos glaciales del Pleistoceno (Werneck, 2011; Werneck et al., 2011). Por lo tanto, se postula que los procesos geohistóricos han jugado un papel predominante en la diversificación alopátrida sufrida por este grupo de especies braquípteras con limitada capacidad de dispersión. Un patrón similar ha sido encontrado en la Subfamilia Phaneropterinae (Orthoptera), donde se considera que la diversificación de clados braquípertos de ambientes de altura se habrían generado a través de especiación alopátrida durante los múltiples ciclos glaciales del Pleistoceno (Grzywacz et al., 2018).

Asimismo, Rolf (1990) establece que en los pastizales de Norteamérica la mayor proporción de especies de ortópteros serían macrópteras, patrón coincidente con los resultados de este trabajo de tesis para la región de la Pampa. El clado Macróptero habita regiones con pocas precipitaciones y gran estacionalidad, alcanzando temperaturas muy bajas en invierno y elevada radiación solar en verano (Fig. 21-25). Dentro de este clado no se encuentra evidencia de que los eventos geohistóricos hayan influido en los procesos de diversificación, encontrándose principalmente indicios de especiación ecológica y barreras citogenéticas determinantes para la diversificación del grupo. 


\section{CAPÍTULO 3: DIVERSIFICACIÓN DE LA TRIBU DICHROPLINI}

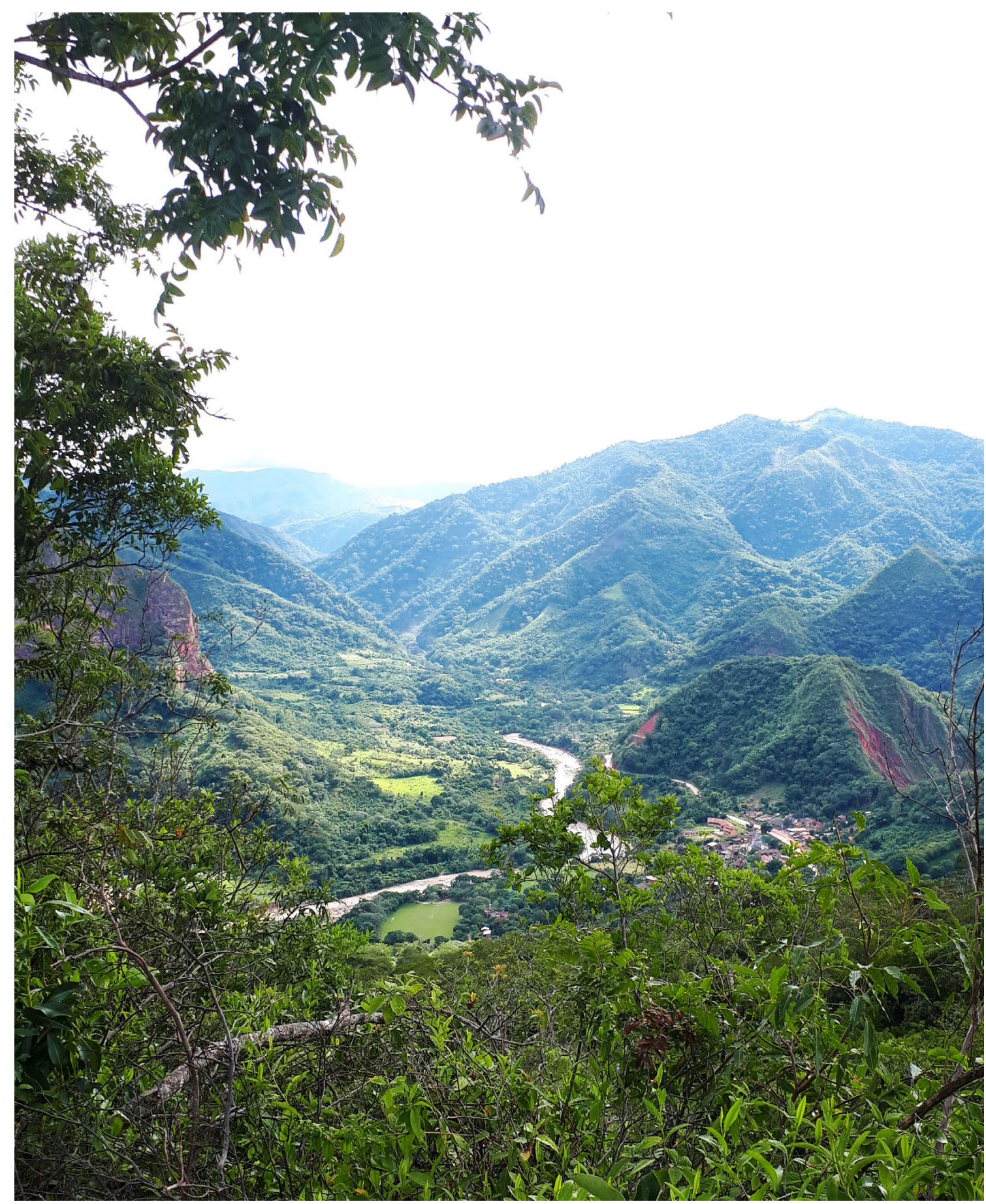


La tribu Dichroplini presenta 163 especies válidas, pertenecientes a 28 géneros (Cigliano et al., 2018). Es una tribu endémica de Sudamérica, encontrándose sólo fuera de esta distribución Dichroplus notatus Bruner, que habita en México y el sur de Estados Unidos, aunque Cigliano (pers. com.) ha puesto en duda las relaciones de esta especie dentro de la tribu. Los dichroplinos se encuentran distribuidos en toda Sudamérica salvo en la región Amazónica. Son especies predominantes en biomas abiertos, siendo particularmente abundantes en los Bosques Tropicales Secos Estacionales (BTSE), particularmente la región Paranense y el Chaco Húmedo. Exhiben la mayor diversificación de melanoplinos sudamericanos, presentando especies con distribuciones extremadamente restringidas hasta especies que abarcan casi la totalidad de la distribución de la tribu. Asimismo, es el grupo dominante tanto en número de especies como de individuos en la mayoría de las comunidades de pastizales de Sudamérica (Cigliano et al., 2000). Como se mencionó previamente, Ronderos (1981) considera que habrían existido dos centros de diversificación para la tribu Dichroplini, uno constituido en los Andes Septentrionales de Colombia y Venezuela, y el otro en la zona central sur del continente, a nivel de la cuenca Parano-Platense donde se habría llevado a cabo la mayor diversificación del grupo. Dentro de estos centros de diversificación, cada género de Dichroplini habría ocupado sectores específicos del continente, con características florísticas y climáticas propias (Ronderos, 1981).

Se han propuesto diversas hipótesis para explicar las variaciones espaciales en las tasas de especiación de los organismos, siendo una de las principales la "teoría metabólica de la ecología" (Rohde, 1992; Brown, 2014), la cual propone que la tasa de especiación aumenta con la temperatura, lo que implicaría que habría mayores tasas de especiación a menores latitudes. Asimismo, Losos y Schluter, (2000) plantean que la tasa de especiación in situ aumentaría con el tamaño del área. También se ha planteado el "aislamiento impulsado por la elevación" como un factor importante que afectaría la tasa de especiación (Steinbauer et al., 2016). Esta hipótesis está estrechamente relacionada a la biogeografía de islas donde se esperaría que a mayores elevaciones (1) exista una mayor diversidad de especies (2) con una mayor proporción de endemismos.

El objetivo principal de este capítulo de tesis es analizar los patrones de diversidad de las especies y géneros de la tribu Dichroplini y contrastar las diversas hipótesis propuestas sobre las variaciones espaciales en las tasas de especiación y los patrones de diversificación en la tribu. 


\section{MATERIALES Y MÉTODOS}

Registros de ejemplares; Distribución Geográfica y registro de desarrollo alar

Los registros georreferenciados utilizados para este estudio se obtuvieron de viajes de campaña, especímenes de las colecciones de varias instituciones (MLP, ANSP, MNHN, MZSP, MNRJ, FCMU), literatura y registros descargados de OSF (Cigliano et al., 2018). Se georreferenciaron las localidades faltantes que presentaban datos precisos y se eliminaron los registros duplicados. La base de datos final será subida a OSF, base de datos taxonómica, de acceso libre, de los Ortópteros mundiales. Para cada especie se trataron como registros únicos las localidades más cercanas a 2,5 arc-minutos. La base de datos final cuenta con 1841 registros para las 163 especies, pertenecientes a los 28 géneros de la tribu Dichroplini (Tabla S4).

Para cada género se registró el promedio de altitud, extraídos de la capa de altura del WorldClim y la región biogeográfica donde se distribuyen. Asimismo, se registró el desarrollo alar de las especies por género.

\section{Riqueza específica}

Matriz Presencia - Ausencia: Se dividió el área de distribución de la tribu en una grilla de cuadrículas de $2^{\circ} \times 2^{\circ}$ en QGIS. A partir de los datos de presencia de las especies en la grilla, se generó una matriz de Presencia - Ausencia de especies utilizando el programa Biodiverse 2.0 (Laffan et al., 2010).

Riqueza y Amplitud de Rango: La información de la riqueza específica, la amplitud de rango de las especies y la relación entre estos dos aspectos de la diversidad se realizaron utilizando el script de R de Arita et al., (2012).

\section{Riqueza genérica}

Modelado de Nicho: Previo a la estimación de las áreas potenciales de distribución, se restringió el área accesible de cada género siguiendo la metodología mencionada en el capítulo anterior. Los modelos de distribución potencial se realizaron siguiendo la metodología de elipsoides utilizando las 4 capas de componentes principales mencionadas en el capítulo 2 (Fig. 27). Para cada género, se trataron como registros únicos las localidades más cercanas a 2,5 arc-minutos (Tabla 21). Los modelos de elipses de los géneros que presentaban menos de 10 registros (Keyopsis Ronderos \& Cigliano, Huaylasacris, Boliviacris Ronderos \& Cigliano, Timotes Roberts, Chibchacris Hebard) fueron 
generados utilizando la matriz de covarianza de los datos entrantes, mientras que para el resto de los géneros se utilizó el volumen mínimo del elipsoide (ver metodología en Capítulo 2). A través del modelado se generaron mapas raster binarios de presenciaausencia, considerando como presencia el 95\% del volumen del elipsoide de cada género.

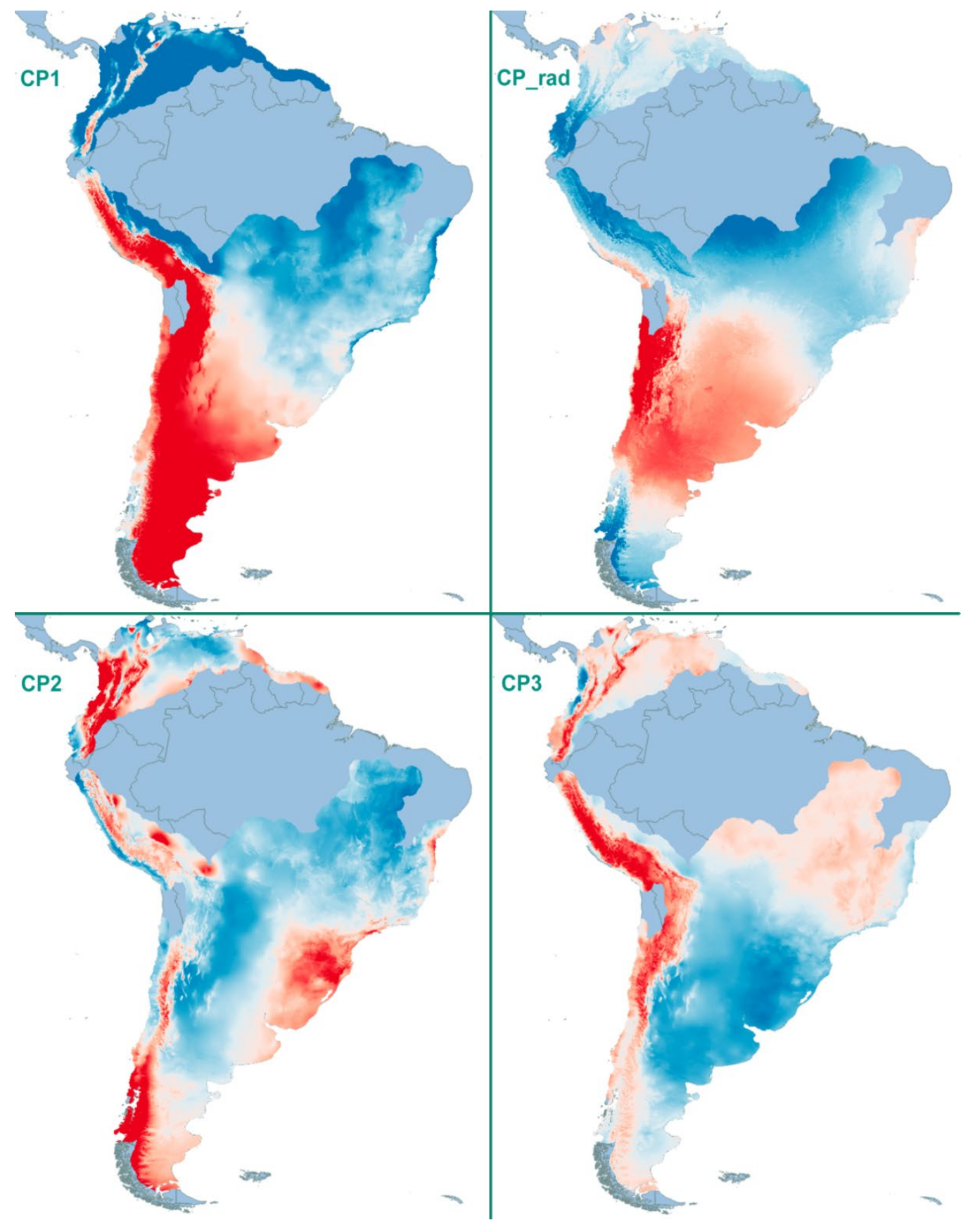

Figura 27: Capas de componentes principales utilizadas para generar los modelos de Nicho. Cp1, 2 y 3 son los primeros tres componentes principales realizados sobre las 19 variables bioclimáticas. Y CP_rad es el primer CP de la Radiación solar. Los colores de los Cp1, 2 y 3 presentan una escala del rojo al azul, representando el color rojo los valores más bajos y el azul los mayores; mientras que en el CP_rad la escala se invierte representando el rojo la mayor y el azul la menor radiación solar. 


\begin{tabular}{|c|c|c|c|}
\hline Géneros & $\mathbf{N}^{0}$ Especies & Registros & Reg. Modelado \\
\hline Yungasus & 1 & 1 & \\
\hline Ciglianacris & 1 & 2 & \\
\hline Hazelacris & 1 & 2 & \\
\hline Mariacris & 1 & 2 & \\
\hline Apacris & 2 & 4 & \\
\hline Coyacris & 3 & 4 & \\
\hline Keyopsis & 2 & 5 & 5 \\
\hline Meridacris & 2 & 6 & 4 \\
\hline Boliviacris & 5 & 7 & 7 \\
\hline Huaylasacris & 1 & 7 & 5 \\
\hline Timotes & 4 & 9 & 8 \\
\hline Bogotacris & 6 & 12 & 11 \\
\hline Digamacris & 2 & 13 & 13 \\
\hline Pediella & 3 & 15 & 13 \\
\hline Chibchacris & 7 & 16 & 9 \\
\hline Chlorus & 7 & 38 & 32 \\
\hline Eurotettix & 12 & 38 & 35 \\
\hline Ponderacris & 8 & 38 & 32 \\
\hline Pseudoscopas & 12 & 39 & 36 \\
\hline Orotettix & 9 & 42 & 32 \\
\hline Atrachelacris & 2 & 49 & 43 \\
\hline Dichromatos & 4 & 50 & 37 \\
\hline Neopedies & 10 & 87 & 77 \\
\hline Leiotettix & 5 & 101 & 40 \\
\hline Ronderosia & 10 & 150 & 130 \\
\hline Baeacris & 9 & 184 & 159 \\
\hline Scotussa & 8 & 309 & 274 \\
\hline Dichroplus & 21 & 386 & 316 \\
\hline Sumatoria & 145 & 1616 & 1318 \\
\hline
\end{tabular}

Tabla 21: Registros para los géneros de la Tribu Dicroplini. "Reg. Modelado": Número de localidades finales con los que se generó el modelo.

Matriz Presencia - Ausencia: Los mapas binarios generados previamente se ingresaron en QGIS y se poligonizaron. Se creó una grilla de cuadrículas de $2^{\circ} \times 2^{\circ}$ sobre el área de distribución de la tribu, en QGIS. Se utilizó la herramienta "unir atributos por localización" para definir el valor de presencia/ausencia de cada cuadrícula en función del modelo de cada género. Posteriormente, se combinaron las capas de todos los géneros a través de los IDs de las cuadrículas de la grilla, generando una matriz de Presencia Ausencia, que se visualiza como mapa de riqueza en QGIS. 
Amplitudes de Nicho: En la matriz de Presencia - Ausencia se reemplazaron las presencias de cada género por el valor de su amplitud de nicho y se extrajo el valor de la mediana de cada cuadrícula. Se considera que en aquellos casos donde existen valores de volumen de nicho muy disímiles, la mediana, al representar el valor de la variable de posición central del conjunto de datos ordenados, es un mejor estimativo de las amplitudes de nicho que el promedio. Estos valores se graficaron en QGIS, donde se dividieron los valores de las amplitudes de nicho en 5 cuartiles (reducidas, reducidas a intermedias, intermedias, altas, muy altas) y se omitieron las zonas que presentaban sólo un género.

\section{RESULTADOS}

Registros de ejemplares y Distribución Geográfica

La base de datos construida para la tribu Dichroplini cuenta con 1841 registros para las 163 especies (Fig. 28; Tabla S4), pertenecientes a los 28 géneros. De las 163 especies de la tribu, $5(3 \%)$ presentan registros que no pudieron ser georreferenciados (Fig. 29), el 56\% cuenta con menos de 5 localidades, el 21\% entre 5 y 10, el 9\% entre 11 y 20 y sólo el $11 \%$ de las especies cuentan con más de 20 registros. Las especies que presentan menos de 5 registros únicos (Fig. 30) se encuentran distribuidas a lo largo de los Andes, los Bosques Lluviosos Tropicales (BLT), el Cerrado, el norte de la Pampa y en la región Paranense y Chaco Húmedo del BTSE. Las especies que presentan más de 40 localidades pertenecen a los siguientes géneros: Baeacris Rowell \& Carbonell (2 spp), Dichroplus Stål (3 spp), Ronderosia (1 spp) y Scotussa (4 spp) (Tabla S4).

Los géneros más ricos en especies (Tabla 21) son Dichroplus (21 spp), Pseudoscopas Hebard (12 spp), Eurotettix (12 spp), Ronderosia (10 spp) y Neopedies Hebard (10 spp), todos se encuentran mayoritariamente distribuidos en la región Pampeana, el Bosque de Araucaria del BLT y las regiones Paranense y Chaco Húmedo del BTSE; a excepción de Eurotettix que se encuentra en el Cerrado.

Al agrupar los registros por género, sólo 7 de los 28 géneros (25\%) presenta menos de 5 registros (Yungasus Mayer, Ciglianacris Cadena-Castañeda \& Cardona, Hazelacris Ronderos, Mariacris Ronderos \& Turk, Apacris Hebard, Coyacris Ronderos y Meridacris Roberts) (Tabla 21). Estos géneros son en su mayoría monoespecíficos, a excepción de Apacris, Yungasus y Meridacris que tienen 2 especies y Coyacris que tiene 3. Todos estos géneros presentan especies braquípteras y se distribuyen principalmente en 
los Andes, tanto del Norte como Centrales, pero también se encuentran en la costa de Ecuador y en el Chaco Húmedo y Seco.

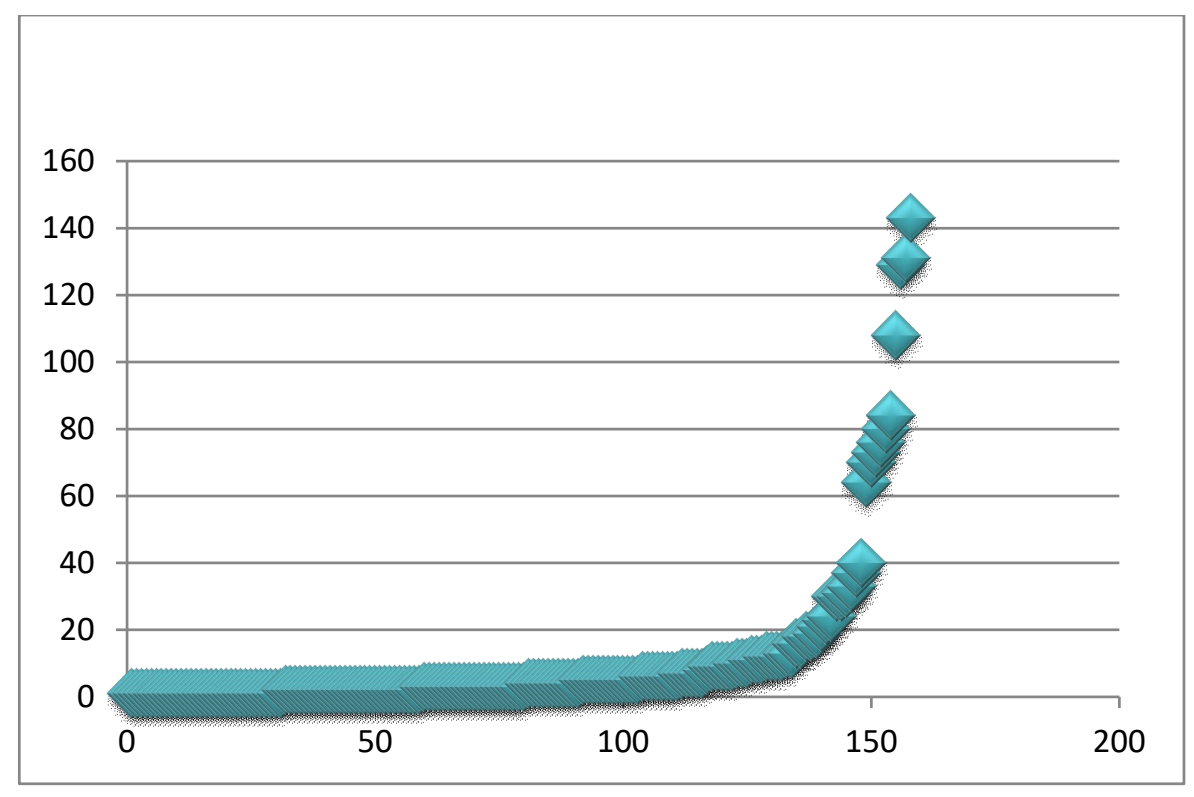

Figura 28: Número de registros por especies.

Matriz Presencia - Ausencia: La matriz de Presencia - Ausencia de 155 especies por 156 cuadrículas (considerando exclusivamente las cuadrícula que presentaban presencia de al menos una especie) se indica en la Tabla S5.

Riqueza y Amplitud de Rango: La mayor riqueza de especies se encuentra en las regiones Paranense y Chaco Húmedo del BTSE y el Bosque de Araucaria del BLT (Fig. 31). Estas regiones presentan entre 19 y 23 especies, representadas principalmente por 11 de los 28 géneros del grupo, dominado por especies de los géneros Scotussa, Ronderosia, Leiotettix, Dichroplus, Atrachelacris, seguido por Neopedies, Dichromatos y Pseudoscopas (Tabla S5). Las regiones de menor riqueza (con menos de 3 especies) se observan en los Biomas del Sur, el Chaco Seco, el Cerrado y los Andes, siendo diferentes especies las que los caracterizan. En los Andes hay un recambio de sur a norte comenzando con especies de Ponderacris y Orotettix en Bolivia y Perú, seguido por Huaylasacris y Pediella; en los Andes del Ecuador comienza a aumenta la diversidad de Baeacris, predominando en los Andes Septentrionales Timotes, Chibchacris y Bogotacris Ronderos. En los Biomas del Sur se encuentran principalmente especies del género Dichroplus, y en el Chaco continúa predominando dicho género, seguido por Chlorus, Ronderosia, Baeacris y Leiotettix. 


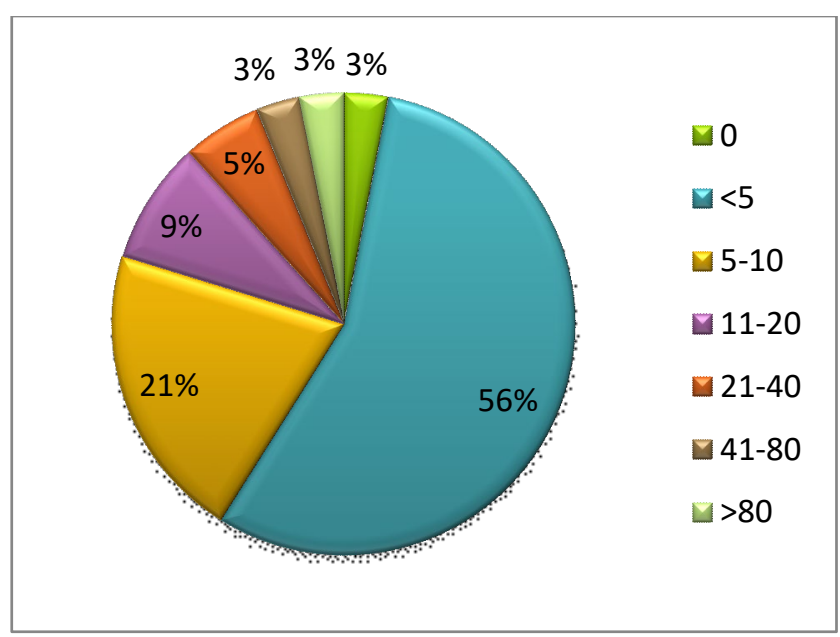

Figura 29: Número de registros por especie graficados por rangos.

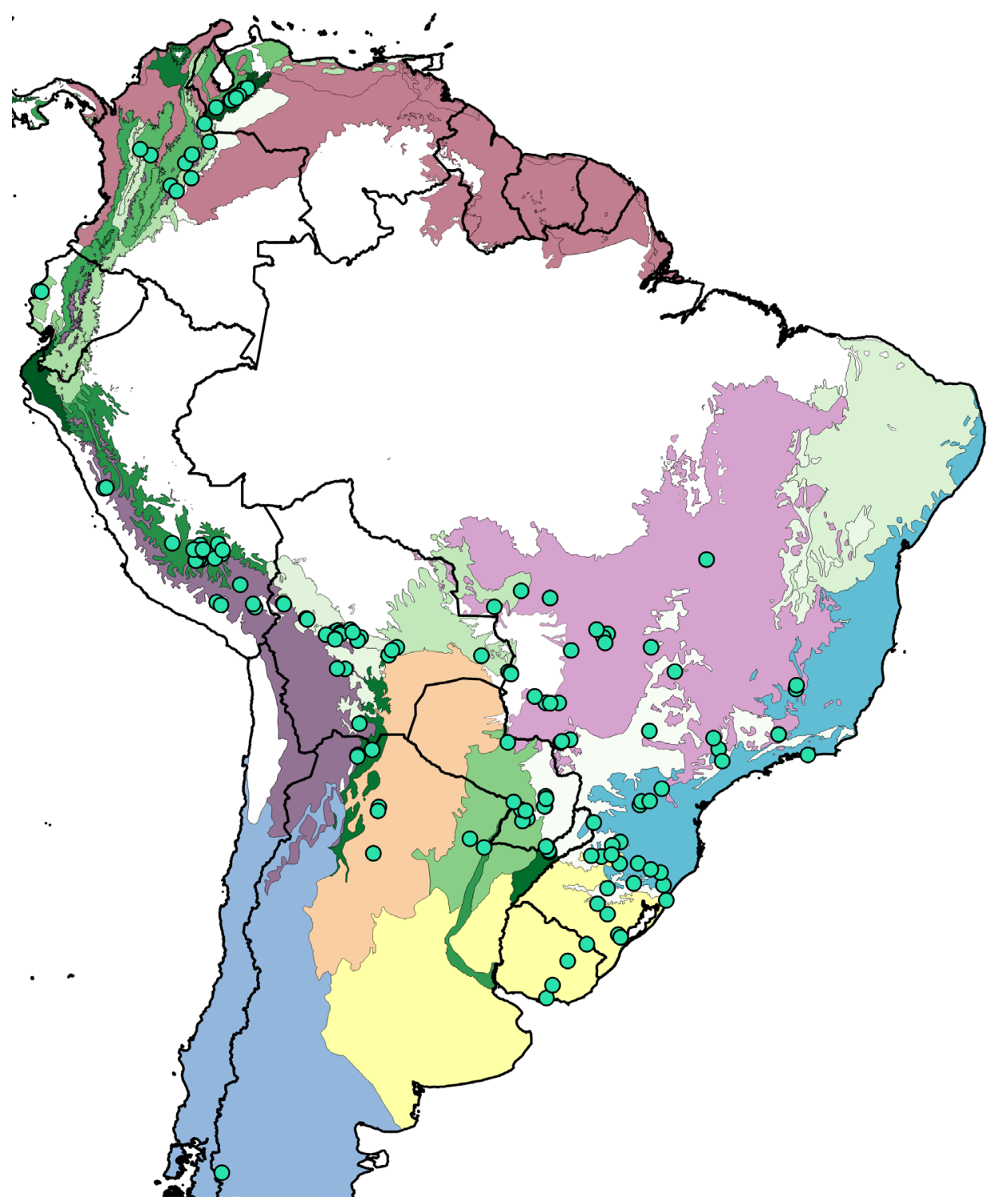

Figura 30: Mapa representando todas las localidades de las especies que presentan menos de 5 registros. 


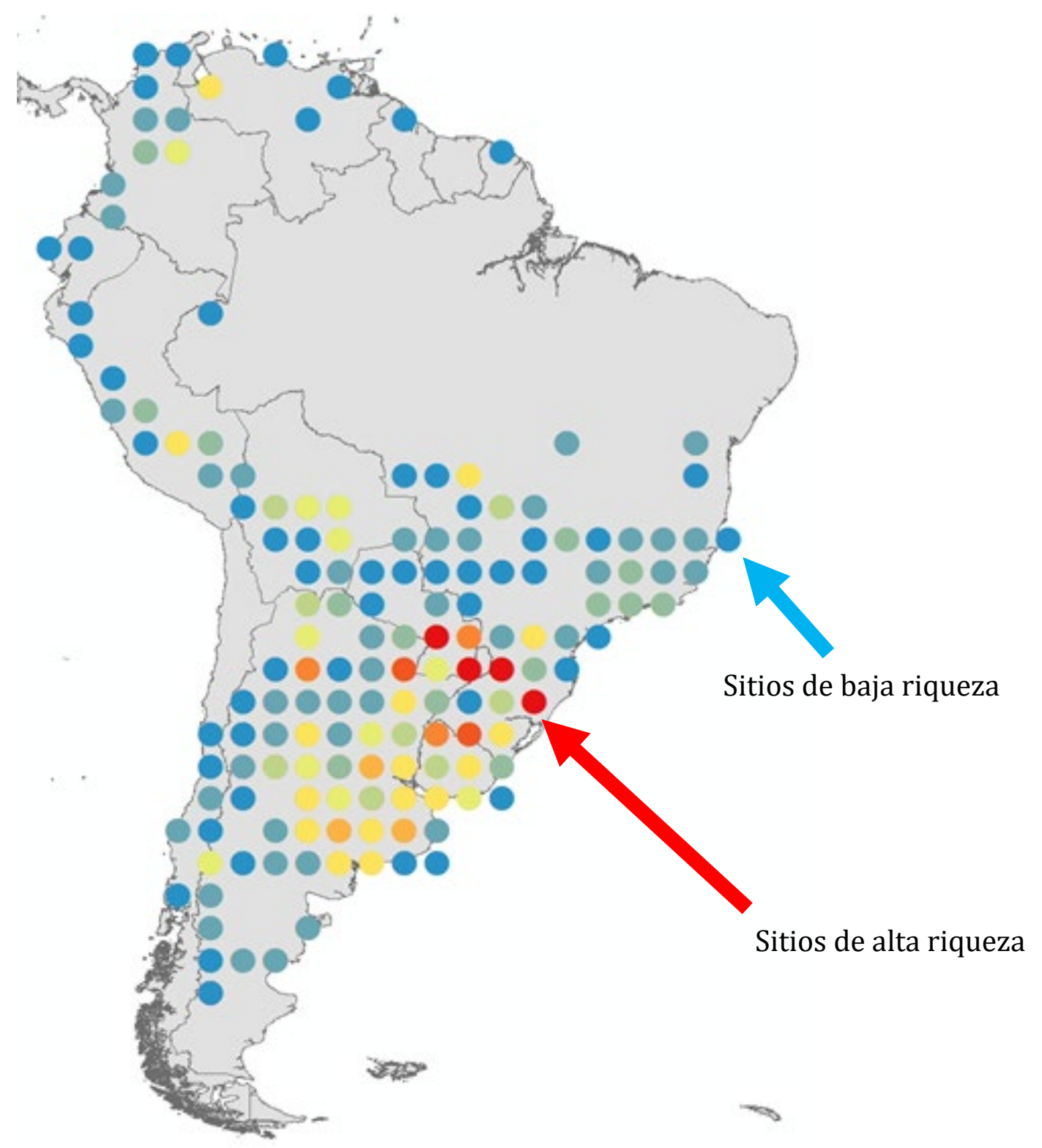

Figura 31: Mapa de riqueza de especies. Se grafican las variaciones en la riqueza local a través de una escala del rojo al azul, representando el color rojo los valores más altos y el azul los menores.

Riqueza específica

Para determinar los patrones del rango de distribución de las especies se omitieron las zonas que presentaban sólo una especie. Las regiones que en promedio albergan especies de mayor rango de distribución se encuentran al sur de la distribución de la tribu (Fig. 32), predominando en los Biomas del Sur, el Chaco Seco, y la Pampa; disminuyendo esta tendencia hacia el noreste. Las regiones que presentan especies con rangos de distribución restringidos son el Cerrado y los Andes Centrales y Septentrionales. 


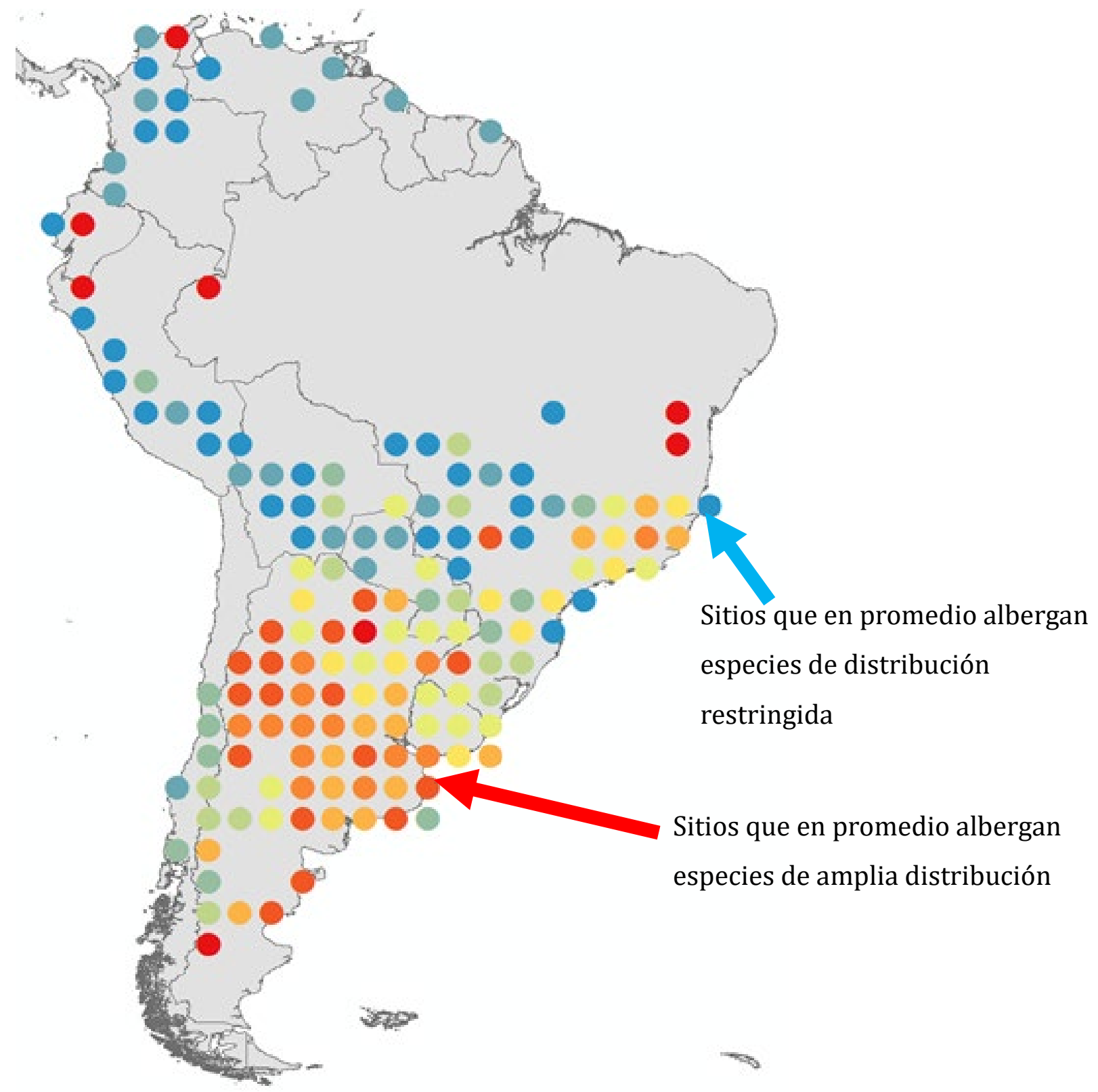

Figura 32: Mapa del rango de distribución de las especies por sitio. Se grafican las variaciones de la amplitud del rango a través de una escala del rojo al azul, representando el color rojo las regiones que albergan especies con rangos más amplios y el azul las regiones que albergan especies más restringidas.

El Chaco Seco, los Biomas del Sur y regiones de la Pampa presentan pocas especies, que se caracterizan por distribuciones amplias (Fig. 33). Las regiones de baja riqueza con especies de distribución restringida se dan principalmente en el Cerrado y los Andes Centrales y Septentrionales. La región Paranense y Chaco Húmedo del BTSE, el Bosque de Araucaria del BLT y el límite norte de la Pampa (Fig. 33) presentan la mayor riqueza y rangos de distribución intermedios. Dentro de esta región de mayor diversidad y amplitudes intermedias se encuentra un área (los esteros del Iberá) que no responde a estas características, presentando menor número de especies, caracterizadas por distribuciones más amplias. 


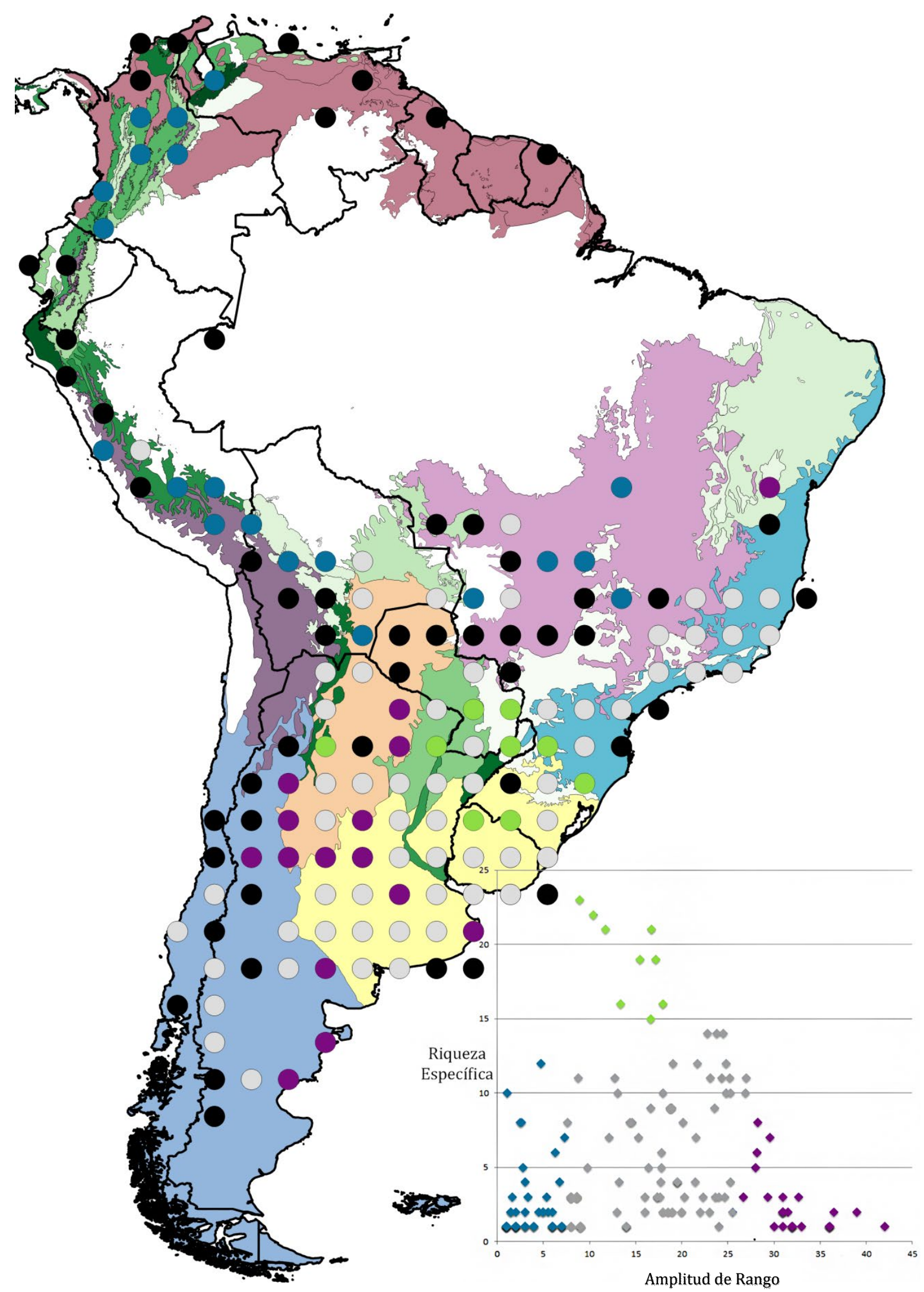

Figura 33: Mapa del rango de distribución de las especies por sitio, se colorea en bordó los sitios con especies de distribuciones amplias y pocas especies; en azul los sitios con especies de distribuciones más restringidas y pobres o medianamente pobres en especies; y en verde los sitios con especies de distribución intermedia y más ricos en especies. En negro se encuentran las cuadrículas omitidas en el análisis por presentar sólo un registro. 
Modelado de Nicho: Luego de filtrar los registros de los géneros, se eliminó del análisis al género Meridacris ya que solo cuenta con 4 registros. (Tabla 22). Los modelos de distribución potencial realizados siguiendo la metodología de elipsoides (ver Capítulo 1) arrojaron valores de amplitudes de nicho altamente variables (Tabla S5). Aproximadamente el $50 \%$ de los géneros presentaron volúmenes de nicho inferiores a 10, mientras que el género más amplio tuvo un volumen de nicho de 237.

Matriz Presencia - Ausencia: Se obtuvo una matriz de Presencia - Ausencia de 21 géneros por 258 cuadrículas (considerando exclusivamente las cuadrículas que presentaban al menos un género; Tabla S6). La mayor riqueza genérica se encuentra en la región Paranense y Chaco Húmedo del BTSE y el Bosque de Araucaria del BLT (Fig. 34). Estas regiones presentan entre 10 y 11 géneros de los 21 analizados en este estudio. La riqueza disminuye gradualmente hacia el sudoeste y abruptamente hacia el norte, encontrándose las zonas más pobres hacia la periferia de la distribución de la Tribu. Se encuentra otra región de diversidad moderada en las Yungas Bolivianas.

\begin{tabular}{|lcccc|}
\hline \multicolumn{1}{|c}{ Géneros } & Volumen & Altitud & Región & Alas \\
\hline Pediella & 0.02 & 3805.2 & Andes & Braquípteras \\
Huaylasacris & 0.06 & 3795.1 & Andes & Braquípteras \\
Keyopsis & 0.14 & 2379.2 & Andes & Braquípteras \\
Chibchacris & 1.63 & 3270.6 & Andes & Braquípteras \\
Timotes & 2.55 & 2611.2 & Andes & Braquípteras \\
Digamacris & 2.85 & 237.1 & Mata_Atlántica & Braquípteras \\
Orotettix & 3.61 & 3332.8 & Andes & Braquípteras \\
Eurotettix & 4.21 & 452.0 & Cerrado & Braquípteras \\
Pseudoscopas & 5.25 & 506.4 & Pamp-Paran & Braquípteras \\
Dichromatos & 8.09 & 564.6 & Pamp-Paran & Braquípteras \\
Neopedies & 13.73 & 269.5 & Pamp-Paran & Braquípteras \\
Bogotacris & 14.72 & 2231.8 & Andes & Braquípteras \\
Leiotettix & 15.37 & 393.9 & Pamp-Paran & Macrópteras \\
Ponderacris & 19.75 & 1990.3 & Andes & Braquípteras \\
Scotussa & 22.10 & 258.9 & Pamp-Paran & Dimórficas \\
Atrachelacris & 29.99 & 463.8 & Pamp-Paran & Macrópteras \\
Chlorus & 34.67 & 598.3 & Pamp-Paran & Braquípteras \\
Ronderosia & 47.78 & 462.8 & Pamp-Paran & Dimórficas \\
Dichroplus & 51.45 & 428.4 & Pamp-Paran & Dimórficas \\
Boliviacris & 89.03 & 2734.3 & Chaco-Andes & Braquípteras \\
Baeacris & 237.56 & 749.5 & Todas las regiones & Dimórficas \\
\hline
\end{tabular}

Tabla 22: Se indican los valores de amplitud de nicho (Volumen) para cada género; el promedio de altitud de los registros por género (Altitud); la región donde se distribuyen y el desarrollo alar de géneros (Alas), se indica con "Dimórficas" cuando el género está constituido por especies braquípteras y macrópteras. 
Amplitudes de Nicho: Para determinar los patrones de amplitud de nicho de los géneros de Dichroplini, los valores de amplitud se agruparon en 5 cuartiles (reducidas, reducidas a intermedias, intermedias, altas, muy altas) y se omitieron las zonas que presentaban sólo un género (Fig. 35). Se observan 4 regiones con amplitudes de nicho menores: la Mata Atlántica, el oeste del Cerrado y dos núcleos en los Andes, uno en los Andes de Perú y el otro en de los Andes del Norte. Las regiones con géneros con amplitud de nicho reducidas a intermedias se encuentran principalmente en el norte de la Pampa, regiones del Cerrado, el BLT y del BTSE las regiones Paranense y Chaco Húmedo. Las regiones intermedias se encuentran en los Biomas del Sur, sur de la Pampa, límite entre Chaco Seco y Húmedo y las zonas lindantes con las ecoregiones del Cerrado y el Chiquitano. Las regiones de amplitud de nicho altas y muy altas se encuentran principalmente en el Chaco Seco y regiones adyacentes en la cordillera y en los límites sur y noreste de la distribución de la Tribu.

Las regiones que presentan géneros con amplitud de nicho muy altas generalmente están asociadas a zonas donde habitan exclusivamente uno o dos géneros de muy amplia distribución, a excepción de la región del norte del Chaco, el Chiquitano y el norte de las Yungas, donde efectivamente se encuentran distribuciones de varios géneros, predominantemente con un volumen de nicho amplio. 


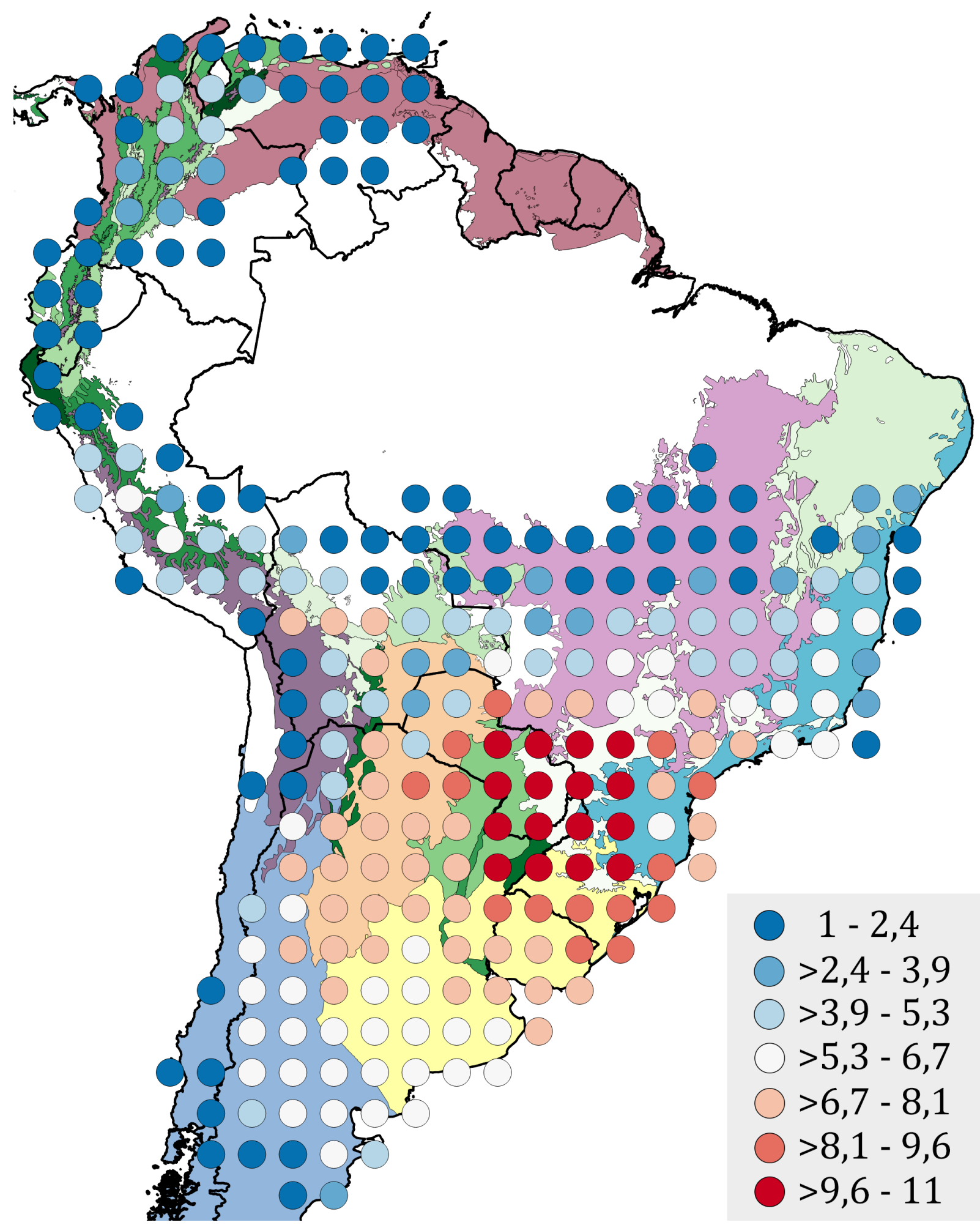

Figura 34: Mapa de riqueza generado a partir de los modelos de distribución potencial de géneros de la Tribu Dichroplini. 


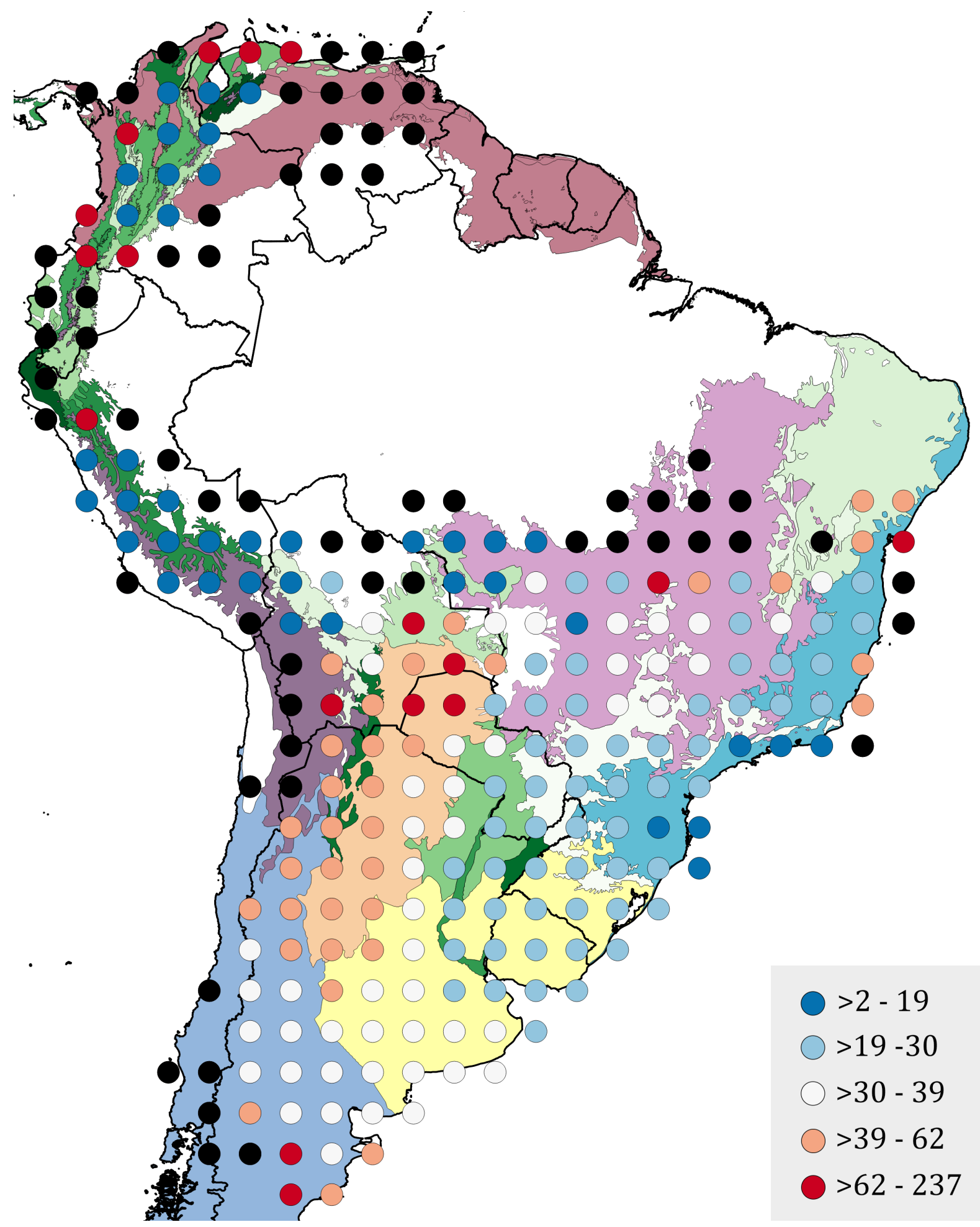

Figura 35: Mapa de la mediana de volumen de nicho generado con los modelos de distribución potencial de los géneros de la tribu Dichroplini. En negro se encuentran las cuadrículas omitidas en el análisis por presentar sólo un género. 


\section{DISCUSIÓN:}

De acuerdo con la hipótesis de Ronderos (1981) y con los resultados aquí obtenidos, el centro de diversificación de la cuenca Parano-Platense es el que contiene el área de mayor diversidad de la tribu Dichroplini, donde habita más del $40 \%$ de sus géneros (Fig. 34). Asimismo, en esta región se encuentran los géneros más diversos (Tabla 21), presentando diferentes patrones de diversificación y amplitudes de nicho. Así entonces, los géneros Dichroplus y Ronderosia se caracterizan por poseer valores elevados de amplitud de nicho (Tabla 22), con especies tanto braquípteras como macrópteras desde muy bien a poco representadas (Tabla S4). Ambos géneros presentan distribuciones que abarcan desde los BTSE al sur del Amazonas hasta los Biomas del Sur. Los géneros braquípteros que presentan mayor diversificación en esta región son Pseudoscopas y Eurotettix, con muy pocos registros y amplitudes de nicho reducidas (Tabla 22). Pseudoscopas se distribuye en la Pampa uruguaya, la región Paranense y Bosque de Araucaria del BTSE mientras que, el género Eurotettix habita casi exclusivamente el Cerrado. El Cerrado es el segundo bioma abierto más grande de Sudamérica, dominado por vastas mesetas separadas por una red de drenajes recientes, lo que genera un paisaje complejo con una marcada estratificación horizontal. El patrón de diversificación de este género cumpliría con lo propuesto por Kisel \& Barraclough (2010) que consideran que aquellas regiones amplias, con reducciones locales al flujo génico (Kisel \& Barraclough, 2010), favorecerían el aumento de tasas de especiación. Otros estudios realizados en organismos pequeños y de poca vagilidad asociados a los hábitats abiertos de mesetas del Cerrado también presentan valores elevados de riqueza específica y endemismo (Nogueira et al., 2009).

Dentro de la cuenca Parano-Platense se encuentra, a su vez, la región de mayor riqueza local (no de registros por cuadrícula), presente en la Paranense y Chaco Húmedo del BTSE y el Bosque de Araucaria de BLT, caracterizada por su gran heterogeneidad geográfica y ambiental. Estas regiones han sufrido diversas modificaciones geológicas y ambientales recientes, durante los últimos ciclos glaciales (Ortiz- Jaureguizar \& Cladera 2006; Antonelli et al., 2009; Behling \& Pillar, 2007; Hoorn et al., 2010; Lorenz-Lemke et al., 2010; Werneck, 2011; Werneck et al., 2011, 2012; Fregonezi et al., 2013). Las especies que habitan esta región son, en igual proporción, braquípteras y macrópteras, presentando rangos de distribución de medios a reducidos (Fig. 32).

Desde esta región de mayor diversidad hacia el sudoeste hay un aumento gradual de los rangos de distribución de las especies, aumentando también la proporción de 
especies macrópteras. En este trabajo se consideró la región de la Pampa como una sola unidad, sin embargo, a partir de los resultados aquí obtenidos se desprende que la región pampeana que se extiende en Uruguay y Mesopotamia presenta diferencias en su composición específica en relación al resto de la Pampa. El límite norte de la Pampa, en la frontera entre Brasil - Uruguay, presenta una mayor riqueza y rangos de distribución intermedios, en comparación con el sur, donde se observan valores de riqueza menores y especies con rangos de distribución mayores (Fig. 33). Este patrón se repite a nivel genérico, donde la mayor riqueza se encuentra en el límite norte de la Pampa y va decreciendo paulatinamente hacia el sudoeste. Los valores de amplitud de nicho no muestran diferencias entre las regiones de mayor diversidad de la tribu y la Pampa, sin embargo, a partir de la provincia de Buenos Aires y hacia el sur predominan los géneros con especies más abundantes y con valores elevados de amplitud de nicho. A pesar de que el pastizal es el bioma predominante de la Pampa, en Uruguay existe una mayor heterogeneidad ambiental dada por su variabilidad topográfica (Fig. 2) que podría haber sido un factor determinante en la diversificación de la tribu. El sur de la Pampa es un ambiente de pastizales más homogéneo, donde encontramos principalmente especies macrópteras ampliamente distribuidas. Este patrón es similar al descripto por Roff (1990) para pastizales de Norteamérica, donde la mayor proporción de especies de ortópteros en estos biomas son macrópteras.

Los Andes Centrales y Septentrionales se caracterizan por presentar especies braquípteras, con amplitudes de nicho y rangos de distribución muy reducidos (Figs. 29, 30, 35; Tablas S4, 21) y bajos valores de riqueza local (no de especies por cuadrícula). El grado de endemismo observado en esta región coincide parcialmente con la hipótesis de “aislamiento impulsado por la elevación" (Steinbauer et al., 2016), sin embargo, no se observa un aumento en la riqueza local. A su vez, las especies de la tribu no se encuentran representadas en los Andes de Ecuador, por lo tanto, las tasas de especiación del grupo tampoco se ajustarían a la "teoría metabólica de la ecología" (Rohde, 1992; Brown, 2014), que sostiene que habría mayores tasas a menores latitudes. La diversidad presente en esta región, caracterizada por formas braquípteras y endémicas, es similar a lo observado en escarabajos de los Andes de Perú por Maveety et al. (2011), quienes demostraron que a mayor altura disminuye la riqueza local y aumenta la proporción de especies braquípteras (Maveety et al., 2011). Patrones similares han sido registrados para el género braquíptero Jivarus (Acrididae: Jivarini), el cual presenta 29 especies, todas restringidas a los Andes de Ecuador y sur de Colombia, con distribuciones muy reducidas (Cigliano \& Amedegnato, 2010); así como en otros ortópteros de esta región (Braun, 2002, 2011; Guzman et al., 
2017) y melanoplinos andinos (Pocco et al., 2013) y de las Rocallosas de Norteamérica (Knowles \& Otte, 2000). Asimismo, se han observado patrones similares en diversos grupos de artrópodos y plantas de los Andes (Hughes \& Eastwood, 2006; Graham, 2009; Maveety et al., 2011; Särkinen et al., 2012; Ceccarelli et al., 2016). Por último, es importante destacar que estas regiones de baja riqueza local, presentan una alta riqueza regional, albergando la mitad de los géneros de la tribu, existiendo un recambio gradual de taxa hacia el sur, a excepción de los Andes del Ecuador, donde no se encuentran representantes de la tribu. Los Andes del Norte se caracterizan por los géneros Bogotacris, Chibchacris, Ciglianacri, Meridacris y Timotes, mientras que Centrales están caracterizados por Boliviacris, Coyacris, Huaylasacris, Keyopsis, Orotettix, Pediella, Ponderacris y Yungasus. Por lo tanto, los Andes Centrales y Septentrionales que son considerados uno de los principales "hotspots" de biodiversidad y centros de endemismo del mundo (Myers et al., 2000; Tabarelli et al., 2005; Pennington et al., 2006, 2010, Nogueira et al., 2009, 2011; Guarnizo et al., 2016) debería considerarse de vital importancia para futuros estudios de conservación del grupo.

En conclusión, se considera que los centros de diversificación del grupo coincidirían con aquellos mencionados por Ronderos (1981) en los Andes Septentrionales y la cuenca Parano-Platense, sumándose un tercer centro evolutivo en la región de los Andes Centrales. Asimismo, se mantiene que el centro evolutivo de la cuenca ParanoPlatense es donde se habría llevado a cabo la mayor diversificación de la tribu Dichroplini. 


\section{CONCLUSIONES}

El enfoque biogeográfico integrativo aplicado en este trabajo de tesis permitió dilucidar patrones de diversificación a distintos niveles jerárquicos de la tribu Dichroplini a lo largo de su ámbito de distribución en Sudamérica,

En función de las hipótesis planteadas y a partir de los resultados aquí obtenidos se llega a las siguientes conclusiones:

Los centros de diversificación de la tribu Dichroplini coincidirían con aquellos mencionados por Ronderos (1981) en los Andes Septentrionales y la cuenca ParanoPlatense, sumándose un tercer centro evolutivo en la región de los Andes Centrales.

Los Andes se caracterizan por presentar especies braquípteras, con amplitudes de nicho y rangos de distribución reducidos, con un alto grado de endemismo y elevada riqueza regional. Los Andes del Norte quedan caracterizados por la presencia de los géneros Bogotacris, Chibchacris, Ciglianacris, Meridacris y Timotes, mientras que los Centrales por Boliviacris, Coyacris, Huaylasacris, Keyopsis, Orotettix, Pediella, Ponderacris y Yungasus.

El estudio de Orotettix permitió determinar la existencia de conservadurismo de nicho y la ausencia de señal filogenética en el género. Estos resultados junto con el análisis de los procesos geohistóricos ocurridos en la región permitieron determinar que su diversificación podría haber sido impulsada principalmente por el aislamiento geográfico, combinado con oportunidades ecológicas dadas por los hábitats emergentes posteriores al surgimiento de los Andes. La topografía compleja del paisaje, unido a las fluctuaciones del Cuaternario desencadenadas por las glaciaciones, podrían haber llevado a la diferenciación de las especies de Orotettix caracterizadas por sus endemismos restringidos. Patrones similares han sido observados en otros géneros de la tribu de los Andes por lo que se considera que estos mecanismos podrían ser los principales desencadenantes de la diversificación de la tribu en esta región.

El centro evolutivo de la cuenca Parano-Platense es la región de mayor diversificación de la tribu, donde habita más del $40 \%$ de sus géneros, muchos de los cuales son los más diversos. Esta región está conformada por numerosos biomas, encontrándose la mayor riqueza en la Paranense y Chaco Húmedo del BTSE (Bosque Tropical Seco Estacional) y el Bosque de Araucaria de BLT (Bosque Lluvioso Tropical), con especies 
tanto braquípteras como macrópteras con rangos de distribución variables. Dentro del BTSE, no se encontraron diferencias entre los patrones de diversificación de las regiones Paranense y Chaco Húmedo. Sin embargo, si se detectaron diferencias entre la riqueza del Bosque de Araucaria y la Mata Atlántica del BLT, siendo esta última menos diversa y con especies de distribución más restringida.

Las diversas aproximaciones realizadas en esta tesis concuerdan en que el grupo Scotussae presenta una fuerte asociación entre las relaciones filogenéticas y el ambiente. La diversificación del grupo Scotussae habría ocurrido durante el Plioceno, en la denominada "Era de las llanuras del Sur" (Pascual \& Bondesio, 1982; Pascual et al., 1996; Ortiz- Jaureguizar \& Cladera, 2006), habiéndose originado el ancestro del grupo hace aproximadamente 4,55 Ma. en el ecosistema abierto del BTSE. Existirían diferentes patrones de diversificación según los dos linajes (clados) recuperados. Estas diferencias estarían, en parte, relacionadas con el desarrollo alar. El clado Braquíptero se encuentra principalmente en hábitats del BTSE, caracterizados por ser ambientes estables, poco variables estacionalmente, con una menor radiación solar, con abundantes precipitaciones y temperaturas elevadas. Se ha propuesto que estas regiones se habrían expandido durante el Pleistoceno inferior o el Neógeno, seguido por repetidas contracciones y expansiones del BTSE y el BLT durante los ciclos glaciales del Plioceno tardío Pleistoceno. Asimismo, no se ha encontrado evidencia de conservadurismo de nicho en el clado braquíptero y los análisis de biogeografía histórica arrojaron como escenario más probable de su diversificación eventos de Dispersión-Extinción-Cladogénesis. Se postula que los procesos geohistóricos han jugado un papel predominante en la diversificación alopátrida sufrida por este grupo de especies braquípteras con limitada capacidad de dispersión. El clado Macróptero habita regiones con gran estacionalidad, alcanzando temperaturas muy bajas en invierno y elevada radiación solar en verano. La información brindada por el análisis de biogeografía histórica, junto con la evidencia de señal filogenética y la superposición ambiental indicaría que la especiación simpátrida sería el evento de diversificación principal dentro del clado Macróptero. Dentro de este clado no se encuentra evidencia de que los eventos geohistóricos hayan influido en los procesos de diversificación, encontrándose principalmente indicios de especiación ecológica y barreras citogenéticas determinantes para la diversificación del grupo.

Por último, se determina que el Chaco Seco es una región de muy baja riqueza, dominada por especies de dicroplinos macrópteras de muy amplia distribución. Asimismo, a partir de los resultados aquí obtenidos se desprende que la Pampa no sería un bioma homogéneo, presentando una gran variación en su composición específica de norte a sur. 
El límite norte de la Pampa, en la frontera entre Brasil - Uruguay es una región de mayor heterogeneidad ambiental, dada por su variabilidad topográfica y presenta una mayor riqueza específica y rangos de distribución intermedios. El sur, en cambio, es un ambiente de pastizales más homogéneo, donde se observan valores de riqueza menores y especies con rangos de distribución mayores. La porción sur de la Pampa y los Biomas del Sur presenta casi exclusivamente especies macrópteras con distribuciones muy amplias. 


\section{BIBLIOGRAFÍA}

Ab’Sáber, A. N. (1983). `O domínio dos cerrados: introdução ao conhecimento. Revista do Serviço Público, 111, 41-55.

Aceñolaza, F. G. (2004) 'Paleobiogeografía de la región mesopotámica', En: Aceñolaza, F. G. (Ed.), Temas de la Biodiversidad del Litoral Fluvial Argentino, Vol. 12, INSUGEO, Miscelánea, San Miguel del Tucumán, pp. 25-30.

Ackerly, D. D. (2003) 'Community assembly, niche conservatism and adaptive evolution in changing environments', International Journal of Plant Sciences, 164, pp. 165-184.

Akaike, H. (1973) 'Information theory and an extension of the maximum likelihood principle', En: Petrov, B. N., Csaki, B. F., Eds. Second International Symposium on Information Theory. Budapest: Academiai Kiado, pp. 267-281.

Alberdi, M. T., Bonadonna, F. P. y Ortiz-Jaureguizar, E. (1997) 'Chronological correlation, paleoecology, and paleobiogeography of the late Cenozoic South American "Rionegran" landmammal fauna: a review', Revista Española de Paleontología, 12, pp. 249-255.

Allegrucci, G., Trucchi, E. y Sbordoni, V. (2011) 'Tempo and mode of species diversification in Dolichopoda cave crickets (Orthoptera, Rhaphidophoridae)', Molecular Phylogenetics and Evolution. Elsevier Inc., 60(1), pp. 108-121. doi: 10.1016/j.ympev.2011.04.002.

Amédégnato, C., Chapco, W. y Litzenberger, G. (2003) 'Out of South America? Additional evidence for a southern origin of melanopline grasshoppers', Molecular Phylogenetics and Evolution, 29(1), pp. 115-119. doi: 10.1016/S1055-7903(03)00074-5.

Anderson, M. T., Lachance, M. A. A. y Starmer, W. T. (2004) 'The relationship of phylogeny to community structure: the cactus yeast community', American Naturalist, 164, 709-721.

Andrade-Lima, D., (1982) 'Present-day forest refuges in northeastern Brazil', in Biological Diversification in the Tropics, Prance, G. T., Ed, Plenum Press, New York, pp. 220.

Antonelli, A., Nylander, J. A. A., Persson, C. y Sanmartin I. (2009) 'Tracing the impact of the Andean uplift on Neotropical plant evolution', Proceedings of the National Academy of Sciences of the United States of America 24, pp. 9749-9754.

Antonelli, A., y Sanmartin I. (2011) 'Why are there so many plant species in the Neotropics?' Taxon 60, pp. 403-414.

Arita, H. T., Christen, A., Rodríguez, P. y Soberón, J. (2012) 'The presence-absence matrix reloaded: The use and interpretation of range-diversity plots', Global Ecology and Biogeography, 21(2), pp. 282-292. doi: 10.1111/j.1466-8238.2011.00662.x.

Arnqvist, G. (1997) 'The evolution of animal genitalia: distinguishing between hypotheses by single species studies', Biological Journal of the Linnean Society 60, pp. 365-379.

Barve, N., Barve, V., Jiménez-Valverde, A., Lira-Noriega, A., Maher, S. P., Peterson, A. T., Soberón, J. y Villalobos, F. (2011) 'The crucial role of the accessible area in ecological niche modeling and species distribution modeling', Ecological Modelling. Elsevier B.V., 222(11), pp. 1810-1819. doi: 10.1016/j.ecolmodel.2011.02.011.

Bazelet, C. S., y Samways M. J. (2014) 'Habitat quality of grassland fragments affects dispersal ability of a mobile grasshopper, Ornithacris cyanea (Orthoptera: Acrididae)', African Entomology, 22, pp. $714-725$.

Behling, H. (1995) `A high-resolution Holocene pollen record from Lago do Pires, SE Brazil vegetation, climate and fire history', Journal of Paleolimnology, 14, pp. 253-268.

Behling, H. (1997) 'Late Quaternary vegetation, climate and fire history of the Araucaria forest and campos region from Serra Campos Gerais, Parana State (South Brazil)', Review of Palaeobotany and Palynology, 97, pp. 109-121. 
Behling, H. (2002) 'South and southeast Brazilian grasslands during late Quaternary times: a synthesis' Palaeogeography, Palaeoclimatology, Palaeoecology, 177, pp. 19-27.

Behling, H. y Lichte, M. (1997) 'Evidence of dry and cold climatic conditions at glacial times in tropical Southeastern Brazil', Quaternary Research 48, pp. 348-358.

Belovsky, G. E. y Slade, J. B. (1993) 'The role of vertebrate and invertebrate predators in a grasshopper community', OIKOS, 68, pp. 193-201.

Benham, P. M. y Witt, C. C. (2016) 'The dual role of Andean topography in primary divergence: functional and neutral variation among populations of the hummingbird, Metallura tyrianthina', BMC Evolutionary Biology. BMC Evolutionary Biology, 16(1), p. 22. doi: 10.1186/s12862-016-05952.

Bensasson, D., Zhang, D. X. y Hewitt, G. M. (2000) 'Frequent assimilation of mitochondrial DNA by grasshopper nuclear genomes', Molecular Biology and Evolution, 17, pp. 406-415.

Blandin, P. y Purser, B. (2013) 'Evolution and Diversification of Neotropical Butterflies: Insights From the Biogeography and Phylogeny of the Genus Morpho Fabricius, 1807 (Nymphalidae: Morphinae), With a Review of the Geodynamics of South America', Tropical Lepidoptera, 23(2), pp. 62-85.

Blomberg, S. P. y Garland, T. (2002) 'Tempo and mode in evolution: Phylogenetic inertia, adaptation and comparative methods', Journal of Evolutionary Biology, 15(6), pp. 899-910. doi: 10.1046/j.1420-9101.2002.00472.x.

Blomberg, S. P., Garland, T. y Ives, A. R. (2003) 'Testing for Phylogenetic Signal in Comparative Data: Behavioral Traits Are More Labile', Evolution, 57(4), p. 717. doi: 10.1554/00143820(2003)057[0717:TFPSIC]2.0.C0;2.

Blonder, B., Lamanna, C., Violle, C. y Enquist, B. J. (2014) 'The n-dimensional hypervolume', Global Ecology and Biogeography, 23(5), pp. 595-609. doi: 10.1111/geb.12146.

Borcard, D. y Legendre, P. (2012) 'Is the Mantel correlogram powerful enough to be useful in ecological analysis? A simulation study', Ecology, 93(6), pp. 1473-1481. doi: 10.1890/11-1737.1.

Bouckaert, R., Heled, J., Kühnert, D., Vaughan, T., Wu C. H., Xie, D., Suchard, M. A., Rambaut, A. y Drummond, A. J. (2014) 'BEAST 2: A Software Platform for Bayesian Evolutionary Analysis', PLoS Computational Biology, 10(4), pp. 1-6. doi: 10.1371/journal.pcbi.1003537.

Braker, H. E. (1989) 'Evolution and ecology of oviposition on host plants by acridoid grasshoppers', Biological Journal of the Linnean Society, 38(4), pp. 389-406. doi: 10.1111/j.10958312.1989.tb01584.x.

Braun, H. (2002) 'Die Laubheuschrecken (Orthoptera, Tettigoniidae) eines Bergregenwaldes in SüdEcuador-faunistische, bio- akustische und ökologische Untersuchungen' [Doctoral thesis, Erlangen University] 143 pp.

Braun, H. (2010) 'On the neotropical species described under the genus Isophya (Orthoptera, Tettigoniidae, Phaneropterinae)', Zootaxa, 2444, pp. 58-60.

Braun, H. (2011) 'A brief revision of brachypterous phaneropterinae of the tropical andes (orthoptera, tettigoniidae, odonturini)', Zootaxa, (2991), pp. 35-43.

Broennimann, O., Fitzpatrick, M. C., Pearman, P. B., Petitpierre, B., Pellissier, L., Yoccoz, N. G., Thuiller, W., Fortin, M. J., Randin, C., Zimmermann, N. E., Graham, C. H. y Guisan, A. (2012) 'Measuring ecological niche overlap from occurrence and spatial environmental data', Global Ecology and Biogeography, 21(4), pp. 481-497. doi: 10.1111/j.1466-8238.2011.00698.x.

Brown, J. H. (2014) 'Why are there so many species in the tropics?', Journal of Biogeography, 41(1), pp. 8-22. doi: 10.1111/jbi.12228.

Brown, K. S. y Ab'Sáber, A. N. (1979) 'Ice-age forest refuges and evolution in Neotropics: correlation of paleoclimatological, geomorphological and pedological data with biological endemism', Paleoclimas, 5, pp. 1-30.

Brumfield, R. T. y Edwards, S. V. (2007) 'Evolution into and out of the Andes: A Bayesian analysis of 
historical diversification in Thamnophilus antshrikes', Evolution, 61(2), pp. 346-367. doi: 10.1111/j.1558-5646.2007.00039.x.

Burnham, R. J. y Graham, A. (1999) 'The History of Neotropical Vegetation: New Developments and Status', Annals of the Missouri Botanical Garden, 86, pp. 546-589.

Cabrera, A. L. y Willink, A. (1973) `Biogeografía de América Latina’, Monografia 13, Serie de Biología. OEA, Washington D. C.

Carbonell, C. S., Cigliano, M. M. y Lange, C. E. 'Acridomorph (Orthoptera) species from Argentina and Uruguay Version II' 2018. <https://biodar.io/acridomorph/>

Carbonell, C. S. y Mesa, A. (2006a) `A new Brazilian species of the genus Eurotettix Bruner 1906 and its distinctive karyotype (Orthoptera, Acrididae, Melanoplinae)', Neotropical Entomology.

Cardillo, M. y Warren, D. L. (2016) 'Analysing patterns of spatial and niche overlap among species at multiple resolutions', Global Ecology and Biogeography, 25(8), pp. 951-963. doi: 10.1111/geb.12455.

Carlquist, S. (1974) 'Island Biology', Columbia University Press, New York.

Castillo, E. R. D., Bidau, C. J. y Marti, D. A. (2010a) `Neo-sex chromosome diversity in Neotropical melanopline grasshoppers (Melanoplinae, Acrididae)', Genetica, 138, pp. 775-786.

Castillo, E. R. D., Marti, D. A. y Bidau, C. J. (2010b) `Sex and neo-sex chromosomes in Orthoptera: a review', Journal of Orthoptera Research, 19, pp. 213-231.

Castillo, E. R. D., Martí, D. A., Maronna, M. M., Scattolini, M. C., Cabral-de-Mello, D. C. y Cigliano, M. M. (2018) 'Chromosome evolution and phylogeny in Ronderosia (Orthoptera, Acrididae, Melanoplinae): clues of survivors to the challenge of sympatry?', Systematic Entomology. doi: $10.1111 /$ syen.12317.

Ceccarelli, F. S., Ojanguren-Affilastro, A. A., Ramírez, M. J., Ochoa, J. A., Mattoni, C. I. y Prendini, L. (2016) 'Andean uplift drives diversification of the bothriurid scorpion genus Brachistosternus', Journal of Biogeography, 43(10), pp. 1942-1954. doi: 10.1111/jbi.12760.

Centre for Overseas Pest Research (COPR) (1982) 'The locust and grasshopper agricultural manual', COPR, London.

Chan, S. (2011) 'Predicting Potential Invasive Species Distribution : An Application to New Zealand Mudsnails in the Pacific Northwest Youngah Lim Munisamy Gopinath Michael Harte'.

Chintauan-Marquier, I. C., Jordan, S., Berthier, P., Amédégnato, C. y Pompanon, F. (2011) 'Evolutionary history and taxonomy of a short-horned grasshopper subfamily: the Melanoplinae (Orthoptera: Acrididae).', Molecular phylogenetics and evolution. Elsevier Inc., 58(1), pp. 22-32. doi: 10.1016/j.ympev.2010.07.003.

Chase, J. M., and Leibold, M. A. (2003) `Ecological niches: Linking classical and contemporary approaches', Chicago, IL and London, U.K.; University of Chicago Press.

Chaves, J. A., Weir, J. T. and Smith, T. B. (2011) 'Diversification in Adelomyia hummingbirds follows Andean uplift', Molecular Ecology, 20, pp. 4564-4576.

Chesser, R. T. (2000) 'Evolution in the high Andes: the phylogenetics of Muscisaxicola ground-tyrants' Molecular Phylogenetics and Evolution, 15, pp. 369-380.

Chopard, L. (1938) La biologie des orthoptères. Encyclopédie Entomologique, Paul Lechevalier, Paris.

Cigliano, M. M. (1997) 'Ronderosia,a new genus of south american Melanoplinae (orthptera, Acrididae)', Journal of Orthopeta Research, 6(6), pp. 1-19.

Cigliano, M. M. (2007) 'Review of the South American genus Eurotettix Bruner (Orthoptera, Acridoidea, Melanoplinae)', Systematic Entomology, 32(1), pp. 176-195. doi: 10.1111/j.13653113.2006.00353.x.

Cigliano, M. M. y Amedegnato, C. (2010) 'The high-Andean Jivarus Giglio-Tos (Orthoptera, Acridoidea, Melanoplinae): Systematics, phylogenetic and biogeographic considerations', Systematic Entomology, 35(4), pp. 692-721. doi: 10.1111/j.1365-3113.2010.00538.x. 
Cigliano, M. M., Braun, H., Eades D.C. and Otte, D. (2018) `Orthoptera Species File', Version 5.0/5.0. <http://Orthoptera.SpeciesFile.org>.

Cigliano, M. M. y Lange, C. E. (2001) 'Revision of the South American Genus Atrachelacris Giglio-Tos (Orthoptera, Acridoidea, Melanoplinae)', Transactions of the American Entomological Society, 127(3), pp. 359-370. Available at: http://www.jstor.org/stable/25078751.

Cigliano, M. M. y Lange, C. E. (2007) 'Systematic revision and phylogenetic analysis of the South American genus Chlorus (Orthoptera, Acridoidea, Melanoplinae)', Zoologica Scripta, 36(3), pp. 241254. doi: 10.1111/j.1463-6409.2007.00274.x.

Cigliano, M. M., Pocco, M. E. y Lange, C. E. (2011) 'Grasshoppers of the Andes: New Melanoplinae and Gomphocerinae taxa (Insecta, Orthoptera, Acrididae) from Huascarán national park and Callejón de Huaylas, Ancash, Peru', Zoosystema, 33(4), pp. 523-544. doi: 10.5252/z2011n4a5.

Cigliano, M. M. y Ronderos, R. A. (1994) 'Revision of the South American Grasshopper Bruner and Scotussa Giglio- Genera Leiotettix Tos ( Orthoptera , Acrididae, Melanoplinae )', Transactions of the American Entomological Society, 120(2), pp. 145-180.

Cigliano, M. M., Ronderos, R. A. y Kemp, W. P. (1996) 'Phylogenetic Relationships of Scotussa and Leiotettix (Orthoptera: Acrididae)', Cladistics, 12, pp. 125-138.

Cigliano, M. M., de Wysiecki, M. L. y Lange, C. E. (2000) 'Grasshopper ( Orthoptera: Acridoidea ) Species Diversity in the Pampas , Argentina', Diversity and Distributions, 6(2), pp. 81-91.

Cody, S., Richardson, J. E., Rull, V., Ellis, C. and Pennington, R. T. (2010) 'The great American biotic interchange revisited', Ecography, 33, pp. 326-332.

Cole, M. M. (1986) 'The savannas: biogeography and geobotany', Academic Press, London.

Colli, G. R., (2005) `As origens e a diversificação da herpetofauna do Cerrado'. En: Scariot, A., SousaSilva, J. C., Felfili, J. M. (Eds.), Cerrado: Ecologia, Biodiversidade e Conservação. Ministério do MeioAmbiente, Brasília, Distrito Federal, pp. 249-264.

Colli, G. R., Bastos, R. P. \& Araújo, A. F. B. (2002) 'The character and dynamics of the Cerrado herpetofauna', The cerrados of Brazil: ecology and natural history of a neotropical savanna (Eds.) Oliveira, P.S. and Marquis, R. J., pp. 223-241. Columbia University Press, New York.

Colwell, R. K. (1992) 'Niche: A bifurcation in the conceptual lineage of the term', En Keywords in Evolutionary Biology, (Eds.) Keller, E. F. and Lloyd, E. A., , pp. 241- 248. Harvard University Press, Cambridge, MA.

Colwell, R. K. y Rangel, T. F. (2009) 'Hutchinson's duality: The once and future niche', Proceedings of the National Academy of Sciences, 106(Supplement_2), pp. 19651-19658. doi: 10.1073/pnas.0901650106.

Couvreur, T. L., Porter-Morgan, H., Wieringa, J. J. y Chatrou, L. W. (2011) 'Little ecological divergence associated with speciation in two African rain forest tree genera', BMC Evolutionary Biology, 11(1), p. 296. doi: 10.1186/1471-2148-11-296.

da Silva, J. M. C. (1997) 'Endemic bird species and conservation in the Cerrado region, South America', Biodiversity and Conservation, 6, pp. 435-450.

da Silva, J. M. C. and Bates, J. M. (2002) 'Biogeographic patterns and conservation in the South American Cerrado: a tropical savanna hotspot'. BioScience, 52, pp.225-233.

Darwin, C. (1859) 'On the origin of species', John Murray; London.

De Moraes, M. y Viveiros, C. (2012) 'Does environmental suitability explain the relative abundance of the tailed tailless bat, Anoura caudifer?', Natureza a Conservacao, 10, pp. 221-227.

Dinghi, P. A., Confalonieri, V. A. y Cigliano, M. M. (2009) 'Phylogenetic studies in the South American tribe Dichroplini ( Orthoptera : Acrididae : Melanoplinae )': Zootaxa, 62, pp. 51-62.

Diniz-Filho, J. A. F., Terribile, L. C., Da Cruz, M. J. R. y Vieira, L. C. G. (2010) 'Hidden patterns of phylogenetic non-stationarity overwhelm comparative analyses of niche conservatism and divergence', Global Ecology and Biogeography, 19(6), pp. 916-926. doi: 10.1111/j.14668238.2010.00562.x. 
Dormann, C. F., Elith, J., Bacher, S., Buchmann, C., Carl, G., Carré, G., Marquéz, J. R. G., Gruber, B., Lafourcade, B., Leitao, P. J., Münkemüller, T., Mcclean, C., Osborne, P. E., Reineking, B., Schroder, B., Skidmore, A. K., Zurell, D. y Lautenbach, S. (2013) 'Collinearity: A review of methods to deal with it and a simulation study evaluating their performance', Ecography, 36(1), pp. 027-046. doi: 10.1111/j.1600-0587.2012.07348.x.

Drew, B. T. y Sytsma, K. J. (2012) 'Phylogenetics, biogeography and evolution of dioecy in South American Lepechinia (Lamaiaceae)', Botanical Journal of the Linnean Society, 171, pp. 171-190.

Drummond, A. J. y Rambaut, A. (2007) 'BEAST: Bayesian evolutionary analysis by sampling trees', BMC Evolutionary Biology, 7(1), p. 214. doi: 10.1186/1471-2148-7-214.

Drummond, A. J., Suchard, M. A., Xie, D. y Rambaut, A. (2012) 'Bayesian phylogenetics with BEAUti and the BEAST 1.7', Molecular Biology and Evolution, 29(8), pp. 1969-1973. doi: 10.1093/molbev/mss075.

Duncan, R. P. y Williams, P. A. (2002) 'Darwins naturalization hypothesis challenged', Nature, 417, pp. 608-609.

Eberhard, W. G. (1985) 'Sexual selection and animal genitalia', Cambridge: Harvard University Press.

Eberhard, W. G. (1996) 'Female control: sexual selection by cryptic female choice', Princeton University Press, Princeton, NJ.

Edwards, E. J. y Donoghue, M. J. (2006) 'Pereskia and the Origin of the Cactus Life-Form', The American Naturalist, 167(6), pp. 777-793. doi: 10.1086/504605.

Eiten, G. (1972) 'The Cerrado vegetation of Brazil', The Botanical Review, 38, pp. 201-341.

Elias, M., Joron, M., Willmott, K., Silva-Brandão, K. L., Kaiser, V., Arias, C. F., Gomez Piñerez, L. M., Uribe, S., Brower, A. V., Freitas, A. V. y Jiggins, C. D. (2009) 'Out of the Andes: Patterns of diversification in clearwing butterflies', Molecular Ecology, 18(8), pp. 1716-1729. doi: 10.1111/j.1365294X.2009.04149.x.

Elith, J., Graham, C. H., Anderson, R. P., Dudı, M., Ferrier, S., Guisan, A., Hijmans, R. J., Huettmann, F., Leathwick, J. R., Lehmann, A., Li, J., Lohmann, L. G., Loiselle, B. A., Manion, G., Moritz, C., Nakamura, M., Nakazawa, Y., Overton, J. M., Peterson, A. T., Phillips, S. J., Richardson, K., Scachettipereira, R., Schapire, R. E., Williams, S., Wisz, M. S. y Zimmermann, N. E. (2006) 'Novel methods improve prediction of species ' distributions from occurrence data', Ecography, 29, pp. 129-151.

Escalante, T. y Martínez-Meyer, E. (2013) `Ecological niche modeling and wild- life management units (UMAS): an application to deer in campeche, México', Tropical and Subtropical Agroecosystems, 16, pp. 183-191.

Evans, M. E. K., Smith, S. A., Flynn, R. S. y Donoghue, M. J. (2009) 'Climate, Niche Evolution, and Diversification of the "Bird Cage" Evening Primroses (Oenothera, Sections Anogra and Kleinia)', The American Naturalist, 173(2), pp. 225-240. doi: 10.1086/595757.

Feder, J. L. (1998) 'The apple maggot fly, Rhagoletis pomonella: flies in the face of convential wisdom about speciation', Pp. 130-144 en Howard, D. J. and Berlocher, S. H. (Eds.) Endless forms: species and speciation. Oxford University Press, Oxford, U.K.

Felsenstein, J. (1985) 'Phylogenies and the Comparative Method', American Society of Naturalists, 125(1), pp. 1-15.

Fick, S. E. y Hijmans, R. J. (2017) 'WorldClim 2: new 1-km spatial resolution climate surfaces for global land areas', International Journal of Climatology, 37(12), pp. 4302-4315. doi: 10.1002/joc.5086.

Fregonezi, J. N., Turchetto, C., Bonatto, S. L. y Freitas, L. B. (2013) 'Biogeographical history and diversification of Petunia and Calibrachoa (Solanaceae) in the Neotropical Pampas grassland', Botanical Journal of the Linnean Society, 171(1), pp. 140-153. doi: 10.1111/j.10958339.2012.01292.x.

Gangwere, S. K., Muralirangan, M. C. y Muralirangan M. (eds.) (1997) `The bionomics of grasshoppers, katydids, and their kin', CAB International, New York, N.Y.

Garzione, C. N. et al. (2008) 'Rise of the Andes.', Science, 320(5881), pp. 1304-1307. doi: 10.1126/science.1148615. 
Gebeyehu, S., y Samways, M. J. (2002) 'Grasshopper assemblage response to a restored national park (Mountain Zebra National Park, South Africa)', Biodiversity \& Conservation, 11, pp. 283-304.

Gonzalez, L. y Pfiffner, O. A. (2012) 'Morphologic evolution of the Central Andes of Peru', International Journal of Earth Sciences, 101(1), pp. 307-321. doi: 10.1007/s00531-011-0676-9.

Graham, A. (2009) 'The Andes: A Geological Overview From A Biological Perspective', Annals of the Missouri Botanical Garden, 96(3), pp. 371-385. doi: 10.3417/2007146.

Graham, A. (2012) 'Sequencing New World Ecosystems: Comparison of the Cretaceous and Cenozoic Appearance of Habitats with Biome-Characterizing Plant Groups 1', Annals of the Missouri Botanical Garden, 98(4), pp. 524-538. doi: 10.3417/2011082.

Graham, C. H., Ron, S. R., Santos, J. C., Schneider, C. J. y Moritz, C. (2004) 'Integrating phylogenetics and environmental niche models to explore speciation mechanisms in dendrobatid frogs.', Evolution, 58(8), pp. 1781-93. doi: 10.1111/j.0014-3820.2004.tb00461.x.

Gregory-Wodzicki, K. M. (2000) 'Uplift history of the Central and Northern Andes: a review.', Geological Society of America Bulletin, 112, pp. 1091-1105.

Grzywacz, B., Lehmann, A. W., Chobanov, D. P. y Lehmann, G. U. C. (2018) 'Multiple origin of flightlessness in Phaneropterinae bushcrickets and redefinition of the tribus Odonturini ( Orthoptera: Tettigonioidea: Phaneropteridae )', Organisms Diversity \& Evolution. Organisms Diversity \& Evolution, (Mayhew 2007).

Guarnizo, C. E., Werneck, F. P., Giugliano, L. G., Santos, M. G., Fenker, J., Sousa, L., D’Angiolella, A. B., dos Santos, A. R., Strüssmann, C., Rodrigues, M. T., Dorado-Rodrigues, T. F., Gamble y T., Colli, G. R. (2016) 'Cryptic lineages and diversification of an endemic anole lizard (Squamata, Dactyloidae) of the Cerrado hotspot', Molecular Phylogenetics and Evolution. Elsevier Inc., 94, pp. 279-289. doi: 10.1016/j.ympev.2015.09.005.

Guo, Z. W., Li, H. C. y Gan, Y. L. (2006) 'Grasshopper (Orthoptera: Acrididae) biodiversity and grassland ecosystems', Insect Science, 13(3), pp. 221-227. doi: 10.1111/j.1744-7917.2006.00086.x.

Guzman, N. V., Pietrokovsky, S. M., Cigliano, M. M. y Confalonieri, V. A. (2017) 'Unraveling the diversification history of grasshoppers belonging to the "Trimerotropis pallidipennis" (Oedipodinae: Acrididae) species group: a hotspot of biodiversity in the Central Andes', PeerJ, 5, p. e3835. doi: $10.7717 /$ peerj.3835.

Haffer, J. (1969) 'Speciation in Amazonian forest birds', Science, 165, pp. 131-137.

Hamlin, J. A. P., Simmonds, T. J. y Arnold, M. L. (2016) 'Niche conservatism for ecological preference in the Louisiana iris species complex', Biological Journal of the Linnean Society. doi: 10.1111/bij.12884.

Hammer, Ø., Harper, D. A. T. y Ryan, P. D. (2009) 'PAST-PAlaeontological STatistics, ver. 1.89', Palaeontologia Electronica, (1999), pp. 1-31. Available at: http://www.researchgate.net/publication/228393561_PASTPalaeontological_statistics_ver._1.89/f ile/32bfe5135d45cd6b3b.pdf.

Haq, B. U., Hardenbol, J. y Vail, P. R. (1987) 'Chronology of fluctuating sea levels since the Triassic', Science, 235, pp.1156-1167.

Harvey, P. H. y Pagel, M. R. (1991) 'The comparative method in evolutionary biology', Oxford University Press.

Hijmans, R. J., Cameron, S. E., Parra, J. L., Jones, P. G. y Jarvis, A. (2005) 'Very high resolution interpolated climate surfaces for global land areas', International Journal of Climatology, 25(15), pp. 1965-1978. doi: 10.1002/joc.1276.

Hinojosa, L. F. y Villagrán, C. (1997) 'Historia de los bosques del sur de Sudamérica: antecedentes paleobotánicos, geológicos y climáticos del Terciario del cono sur de América', Revista Chilena de Historia Natural, 70, pp. 225-239.

Hodkinson, I. D. (2005) 'Terrestrial insects along elevation gradients: Species and community responses to altitude', Biological Reviews, 80, pp. 489-513. 
Holt, R. D. (2009) 'Bringing the Hutchinsonian niche into the 21st century: Ecological and evolutionary perspectives', Proceedings of the National Academy of Sciences USA 106, pp. 1965919665.

Hoorn, C. et al. (2010) 'Amazonia through time: Andean uplift, climate change, landscape evolution, and biodiversity.', Science, 330(6006), pp. 927-31. doi: 10.1126/science.1194585.

Hughes, C. E., Pennington, R. T. y Antonelli, A. (2013) 'Neotropical Plant Evolution: Assembling the Big Picture', Botanical Journal of the Linnean Society, 171(1), pp. 1-18. doi: 10.1111/boj.12006.

Hughes, C. y Eastwood, R. (2006) 'Island radiation on a continental scale: exceptional rates of plant diversification after uplift of the Andes.', Proceedings of the National Academy of Sciences of the United States of America, 103(27), pp. 10334-10339. doi: 10.1073/pnas.0601928103.

Humboldt A. (1820) 'Voyage aux regions equinoxiales du Nouveau Continent'. Paris: N. Mazé.

Husemann, M., Guzman, N. V., Danley, P. D., Cigliano, M. M. y Confalonieri, V. A. (2013) 'Biogeography of Trimerotropis pallidipennis (Acrididae: Oedipodinae): deep divergence across the Americas', Journal of Biogeography, 40(2), pp. 261-273. doi: 10.1111/jbi.12007.

Husemann, M., Habel, J. C., Namkung, S., Hochkirch, A., Otte, D. y Danley, P. D. (2015) 'Molecular Evidence for an Old World Origin of Galapagos and Caribbean Band-Winged Grasshoppers (Acrididae: Oedipodinae: Sphingonotus)', Plos One, 10(2), p. e0118208. doi: 10.1371/journal.pone.0118208.

Husemann, M., Namkung, S., Habel, J. C., Danley, P. D. y Hochkirch, A. (2012) 'Phylogenetic analyses of band-winged grasshoppers (Orthoptera, Acrididae, Oedipodinae) reveal convergence of wing morphology', Zoologica Scripta, 41(5), pp. 515-526. doi: 10.1111/j.1463-6409.2012.00548.x.

Hutchinson, G. E. (1957) 'Concluding remarks', Cold Spring Harbor Symposia on Quantitative Biology, 22, pp. 415-427.

Ikeda, H., Nishikawa, M. y Sota, T. (2012) 'Loss of flight promotes beetle diversification', Nature Communications. Nature Publishing Group, 3. doi: 10.1038/ncomms1659.

Imbrie, J. Z., Imbrie-Moore, A. y Lisiecki, L. E. (2011) 'A phase-space model for Pleistocene ice volume', Earth and Planetary Science Letters. Elsevier B.V., 307(1-2), pp. 94-102. doi: 10.1016/j.epsl.2011.04.018.

Jabaily, R. S. y Sytsma, K. J. (2012) 'Historical biogeography and life history evolution of Andean Puya (Bromeliaceae)' Botanical Journal of the Linnean Society, 171, pp. 201-224.

Johnson, M. T. J. y Stinchcombe, J. R. (2007) `An emerging synthesis between community ecology and evolutionary biology', Trends in Ecology \& Evolution, 22, pp. 250-257.

Kalin-Arroyo, M. T., Squeo, F. A., Armesto, J. J. y Villagrán, C. (1988) `Effects of aridity on plant diversity in the northern Chilean Andes: results of a natural experiment', Annals of the Missouri Botanical Garden, 75, pp. 55-78.

Kearse, M., Moir, R., Wilson, A., Stones-Havas, S., Cheung, M., Sturrock, S., Buxton, S., Cooper, A., Markowitz, S. y Duran, C. (2012) 'Geneious Basic: An integrated and extendable desktop software platform for the organization and analysis of sequence data', Bioinformatics, 28(12), pp. 16471649. doi: 10.1093/bioinformatics/bts199.

Kisel, Y. y Barraclough, T.G. (2010) 'Speciation has a spatial scale that depends on levels of gene flow', The American Naturalist, 175, pp. 316-334

Knouft, J. H., Losos, J. B., Glor, R. E. y Kolbe, J. J. (2006) 'Phylogenetic analysis of the evolution of the niche in lizard of the Anolis sagrei group', Ecology, 87(sp7), pp. S29-S38. doi: doi: http://dx.doi.org/10.1890/0012-9658(2006)87[29:PAOTE0]2.0.CO;2.

Knowles, L. L., Carstens, B. C. y Keat, M. L. L. (2007) 'Coupling Genetic and Ecological-Niche Models to Examine How Past Population Distributions Contribute to Divergence', Current Biology, 17(11), pp. 940-946. doi: 10.1016/j.cub.2007.04.033.

Knowles, L. L. y Otte, D. (2000) 'Phylogenetic analysis of montane grasshoppers from western North America (Genus Melanoplus, Acrididae: Melanoplinae)', Annals of the Entomological Society of America, 93(3), pp. 421-431. doi: 10.1603/0013-8746(2000)093[0421:PAOMGF]2.0.C0;2. 
Koscinski, D., Handford, P., Tubaro, P. L., Sharp, S. y Lougheed, S. C. (2008) 'Pleistocene climatic cycling and diversification of the Andean treefrog, Hypsiboas andinus', Molecular Ecology, 17(8), pp. 2012-2025. doi: 10.1111/j.1365-294X.2008.03733.x.

Kozak, K. H. y Wiens, J. J. (2006) 'Does niche conservatism promote speciation? A case study in North American salamanders.', Evolution, 60(12), pp. 2604-2621. doi: 10.1111/j.00143820.2006.tb01893.x.

Lacey Knowles, L. y Alvarado-Serrano, D. F. (2010) 'Exploring the population genetic consequences of the colonization process with spatio-temporally explicit models: Insights from coupled ecological, demographic and genetic models in montane grasshoppers', Molecular Ecology, 19(17), pp. 37273745. doi: 10.1111/j.1365-294X.2010.04702.x.

Laffan, S. W., Lubarsky, E. y Rosauer, D. F. (2010) 'Biodiverse, a tool for the spatial analysis of biological and related diversity', Ecography, 33(4), pp. 643-647. doi: 10.1111/j.16000587.2010.06237.x.

Lavin, M. (2006) 'Floristic and geographic stability of discontinuous seasonally dry tropical forests explains patterns of plant phylogeny and endemism' En: Pennington, R. T., Ratter, J. A. y Lewis, G. P., (Eds.) Neotropical savannas and seasonally dry forests: plant biodiversity, biogeography and conservation. Boca Raton: CRC Press, 433-447.

Leibold, M. A. (1995) 'The niche concept revisited: Mechanistic models and community context', Ecology, 76, pp. 1371-1382.

Lieberman, J. (1951) 'Sobre una nueva forma de oviposición en un acridio sudamericano', Revista de Investigaciones Agrícolas, 5, pp. 235-281.

Loera, I., Sosa, V. y Ickert-Bond, S. M. (2012) 'Diversification in North American arid lands: Niche conservatism, divergence and expansion of habitat explain speciation in the genus Ephedra', Molecular Phylogenetics and Evolution. Elsevier Inc., 65(2), pp. 437-450. doi: 10.1016/j.ympev.2012.06.025.

Lorenz-Lemke, A. P. et al. (2010) 'Diversification of plant species in a subtropical region of eastern South American highlands: A phylogeographic perspective on native Petunia (Solanaceae)', Molecular Ecology, 19(23), pp. 5240-5251. doi: 10.1111/j.1365-294X.2010.04871.x.

Losos, J. B. (2008) 'Phylogenetic niche conservatism, phylogenetic signal and the relationship between phylogenetic relatedness and ecological similarity among species', Ecology Letters, 11(10), pp. 995-1003. doi: 10.1111/j.1461-0248.2008.01229.x.

Losos, J. B., Leal, M., Glor, R. E., Queiroz, K. De y Lara, A. C. (2003) 'Niche lability in the evolution of a Caribbean lizard community', Nature, 424(July), pp. 542-545. doi: 10.1038/nature01814.

Losos, J. B. y Schluter, D. (2000) `Analysis of an evolutionary species-area relationship', Nature, 408, pp. 847-850.

Lu, G., y Bernatchez, L. (1999) 'Correlated trophic specialization and genetic divergence in sympatric lake whitefish ecotypes (Coregonus clupeaformis): support for the ecological speciation hypothesis', Evolution, 53, pp.1491-1505.

Lunt, D. H., Zhang, D. X., Szymura, J. M. y Hewitt, G. M. (1996) `The insect cytochrome oxidase I gene: evolutionary patterns and conserved primers for phylogenetic studies', Insect Molecular Biology, 5, pp. 153-165.

Luteyn, J. L. (1999) `Páramos: A checklist of plant diversity, geographical distribution, and botanical literature', Memoirs of the New York Botanical Garden, 84, pp. 1-278.

Magnussen Saffer, M. (2005) 'Transgresiones y regresiones marinas en la Región Pampeana' Artículo divulgativo publicado en PaleoWeb - Boletín Paleontológico. Año 3, 11, pp. 32-35.

Malhi, Y. et al. (2009) 'Exploring the likelihood and mechanism of a climate-change-induced dieback of the Amazon rainforest', Proceedings of the National Academy of Sciences, 106(49), pp. 2061020615. doi: 10.1073/pnas.0804619106.

Matteucci, S. D. (2012) 'Ecorregión Pampa', in Morello, Jorge Matteucci, Silvia D Rodríguez, Andrea F. Argentina: Orientación Gráfica Editora, pp. 391-446. 
Mani, M. S. (1968) 'Ecology and biogeography of high altitude insects', Junk N. V. Publishers, The Hague.

Marshall, L. G. (1985) `Geochronology and land-mammal biochronology of the trans-American faunal interchange' En: Stheli, F., Webb, S. D. (Eds.), The Great American Biotic Interchange. Plenum Press, New York, pp. 49-85.

Marshall, L. G. y Cifelli, R. L. (1990) `Analysis of changing diversity patterns in Cenozoic Land Mammal Age faunas South America' Palaeovertebrata, 19, pp. 169-210.

Marshall, L. G., Hoffstetter, R. y Pascual, R. (1983) `Mammals and stratigraphy: geochronology of the continental mammal-bearing Tertiary of South America' Palaeovertebrata, Mémoire Extraordinaire, pp. 1-93.

Martínez-Meyer, E., Díaz-Porras, D., Townsend, P. y Yáñez-Arenas, C. (2013) `Ecological niche structure and range wide abundance patterns of species', Biology Letters, 9, pp. 1-5.

Massa, B. (2015) 'Taxonomy and distribution of some katydids (Orthoptera Tettigoniidae) from tropical Africa', ZooKeys, 524, pp. 17-44.

Matzke, N. J. (2014) 'Model selection in historical biogeography reveals that founder-event speciation is a crucial process in island clades', Systematic Biology, 63(6), pp. 951-970. doi: 10.1093/sysbio/syu056.

Maveety, S. A., Browne, R. A. y Erwin, T. L. (2011) 'Carabidae diversity along an altitudinal gradient in a Peruvian cloud forest (Coleoptera)’, ZooKeys, 147, pp. 651-666. doi: 10.3897/zookeys.147.2047.

Mesa, A., Ferreira, A. y Carbonell, C. S. (1982) `Cariologia de los Acridoideos Neotropicales: estado actual de su conocimiento y nuevas contribuciones', Annales Société Entomologique de France (N.S.), 18, pp. 507-526.

Mesa, A. y Zolessi, L. (1968) `Descripción y observaciones bioecológicas sobre una nueva especie de Scotussa (Orthoptera, Acrididae)', Apartado Revista Sociedad Uruguaya de Entomología, 7, pp. 1-19.

Mitchell, J. E. y Pfadt, R. E. (1974) 'The role of grasshoppers in a short-grass prairie ecosystem' Environmental Entomology, 3, pp. 358-360.

Mooers A. (2004) 'Effects of tree shape on the accuracy of maximum likelihood-based ancestor reconstructions', Systematic Biology, 53, pp. 809-814.

Mooney, H. A., Bullock, S. H. y Medina, E. (1995) 'Introduction in Seasonally Dry Tropical Forests' Bullock, S. H., Mooney, H. A. y Medina, E. (Eds) Cambridge University Press, Cambridge.

Moritz, C., Patton, J. L., Schneider, C. J. y Smith, T. B. (2000) 'Diversification of Rainforest Faunas: An Integrated Molecular Approach', Annual Review of Ecology and Systematics, 31, pp. 533-563.

Mörner, N. A., Sylwan, C. (1989) 'Magnetostratigraphy of the Patagonian moraine sequence at Lago Buenos Aires', Journal of South American Earth Sciences, 2, pp. 385-389.

Morrone, J. J. (2001) 'Homology, biogeography and areas of endemism', Diversity <html_ent glyph="@amp;" ascii="\&"/> Distributions, 7(6), pp. 297-300. doi: 10.1046/j.13669516.2001.00116.x.

Morrone, J. J. (2004) 'Panbiogeografía, componentes bióticos y zonas de transición', Revista Brasileira de Entomologia, 48(2), pp. 149-162. doi: 10.1590/S0085-56262004000200001.

Morrone, J. J. (2014) 'Biogeographical regionalisation of the Neotropical region', Zootaxa, 3782(1), pp. 1-110. doi: 10.11646/zootaxa.3782.1.1.

Morrone, J. J. y Crisci, J. V. (1995) 'Historical Biogeography: Introduction to Methods', Annual Review of Ecology and Systematics, 26, pp. 373-401.

Mouillot, D., Krasnov, B. R., Shenbrot, G. I., Gaston, K. J. y Poulin, R. (2006) `Conservatism of host specificity in parasites', Ecography, 29, pp. 596-602.

Myers, N., Mittermeier, R. A., Mittermeier, C. G., Da Fonseca, G. A. y Kent, J. (2000) 'Biodiversity hotspots for conservation priorities.', Nature. Nature Publishing Group, 403(6772), pp. 853-858. Available at: http://www.ncbi.nlm.nih.gov/pubmed/10706275. 
Myers, P. y Wetzel, R. M. (1983) 'Systematics and Zoogeography of the Bats of the Chaco Boreal', vol. 165. Miscellaneous Publications, Museum of Zoology, University of Michigan.

Nogueira, C., Colli, G. R. y Martins, M. (2009) 'Local richness and distribution of the lizard fauna in natural habitat mosaics of the Brazilian Cerrado', Austral Ecology, 34(1), pp. 83-96. doi: 10.1111/j.1442-9993.2008.01887.x.

Nogueira, C., Ribeiro, S., Costa, G. C. y Colli, G. R. (2011) 'Vicariance and endemism in a Neotropical savanna hotspot: Distribution patterns of Cerrado squamate reptiles', Journal of Biogeography, 38(10), pp. 1907-1922. doi: 10.1111/j.1365-2699.2011.02538.x.

Nunes, L. A. y Pearson, R. G. (2017) 'A null biogeographical test for assessing ecological niche evolution', Journal of Biogeography, 44(6), pp. 1331-1343. doi: 10.1111/jbi.12910.

Odling-Smee, F. J., Laland, K. N. y Feldman, M. W. (2003) `Niche Construction: The Neglected Process in Evolution', Princeton University Press, Princeton, NJ.

Oksanen J., Blanchet, G.F., Friendly, M., Kindt, R., Legendre, P., McGlinn D, Minchin, P. R., O'Hara, R. B., Simpson, G. L., Solymos, P., Stevens, M. H. H., Szoecs, E. y Wagner H. (2017) vegan: Community Ecology Package. $R$ package version 2.4-4. Available at: https://CRAN.R-project.org/package=vegan.

Olalla-Tárraga, M., González-Suárez, M., Bernardo-Madrid, R., Revilla, E. y Villalobos, F. (2017) 'Contrasting evidence of phylogenetic trophic niche conservatism in mammals worldwide', Journal of Biogeography, 44(1), pp. 99-110. doi: 10.1111/jbi.12823.

Oliveira-Filho, A. T. y Ratter, J. A. (2002) 'Vegetation physiognomies and woody flora of the Cerrado biome', The cerrados of Brazil: ecology and natural history of a neotropical savanna, Oliveira, P. S. y Marquis R. J. (Eds.), pp. 91-120. Columbia University Press, New York.

Olson, D. M., Dinerstein, E., Wikramanayake, E. D., Burgess, N. D., Powell, G. V. N., Underwood, E. C., D'Amico, J. A., Itoua, I., Strand, H. E., Morrison, J. C., Loucks, C. J., Allnutt, T. F., Ricketts, T. H., Kura, Y., Lamoreux, J. F., Wettengel, W. W., Hedao, P. y Kassem, K. R. (2001) 'Terrestrial Ecoregions of the World: A New Map of Life on Earth', BioScience, 51(11), p. 933. doi: 10.1641/00063568(2001)051[0933:TEOTWA]2.0.CO;2.

Ortiz Jaureguizar, E. (1998) 'Paleoecología y evolución de la fauna de mamíferos de América del Sur durante la "Edad de las Planicies Australes" (Mioceno superior-Plioceno superior)' Estudios Geológicos 54: 161-169.

Ortiz-Jaureguizar, E. y Cladera, G. A. (2006) 'Paleoenvironmental evolution of southern South America during the Cenozoic', Journal of Arid Environments, 66(3 SPEC. ISS.), pp. 498-532. doi: 10.1016/j.jaridenv.2006.01.007.

Osorio-Olvera, L. A., Falconi, M. y Soberón, J. (2016) ‘Sobre la relación entre idoneidad del hábitat y la abundancia poblacional bajo diferentes escenarios de dispersión', Revista Mexicana de Biodiversidad. Universidad Nacional Autónoma de México, Instituto de Biología, 87(3), pp. 10801088. doi: 10.1016/j.rmb.2016.07.001.

Paradis, E., Claude, J. y Strimmer, K. (2004) 'APE: Analyses of phylogenetics and evolution in R language', Bioinformatics, 20(2), pp. 289-290. doi: 10.1093/bioinformatics/btg412.

Pascual, R. y Bondesio, P. (1982) 'Un roedor Cardiatheriinae (Hydrochoeridae) de la Edad Huayqueriense (Mioceno tardío) de La Pampa. Sumario de los ambientes terrestres en la Argentina durante el Mioceno', Ameghiniana, 19, pp. 19-36.

Pascual, R., Ortiz-Jaureguizar, E. y Prado, J.L. (1996) 'Land mammals: paradigm of Cenozoic South American geobiotic evolution', En: Arratia, G. (Ed.), Contribution of Southern South America to Vertebrate Paleontology, Müncher Geowissenschaftliche Abhandlungen (A), vol. 30, pp. 265-319.

Pearce, J. y Ferrier, S. (2000) 'Evaluating the predictive performance of habitat models developed using logistic regression', Ecological Modelling, 133(3), pp. 225-245. doi: 10.1016/S03043800(00)00322-7.

Pearson, R. G., y Dawson, T. P. (2003) 'Predicting the impacts of climate change on the distribution of species: Are bioclimate envelope models useful?', Global Ecology and Biogeography, 12, pp. 361371. 
Pearson, R. G., Raxworthy, C. J., Nakamura, M. y Peterson, T. A. (2007) 'Predicting species distributions from small numbers of occurrence records: a test case using cryptic geckos in Madagascar', Journal of Biogeography, 34(1), pp. 102-117. doi: 10.1111/j.1365-2699.2006.01594.x.

Peixoto, F. P., Villalobos, F. y Cianciaruso, M. V. (2017) 'Phylogenetic conservatism of climatic niche in bats', Global Ecology and Biogeography, 26(9), pp. 1055-1065. doi: 10.1111/geb.12618.

Pennington, R. T. y Dick, C. W. (2010) `Diversification of the Amazonian flora and its relation to key geological and environmental events: a molecular perspective'. En: Hoorn, C., Wesselingh, F. Amazonia, landscape and species evolution, 1st edition. Oxford: Blackwell Publishing, pp. 373-385.

Pennington, R. T., Lavin, M. y Oliveira-Filho, A. (2009) 'Woody plant diversity, evolution, and ecology in the tropics: perspectives from seasonally dry tropical forests', Annual Review of Ecology, Evolution, and Systematics, pp. 437-457.

Pennington, R. T., Lavin, M., Särkinen, T., Lewis, G. P., Klitgaard, B. B. y Hughes, C. E. (2010) 'Contrasting plant diversification histories within the Andean biodiversity hotspot.', Proceedings of the National Academy of Sciences of the United States of America, 107(31), pp. 13783-13787. doi: 10.1073/pnas.1001317107.

Pennington, T. R., Lewis, G. P. y Ratter, J. A. (2006) Neotropical Savannas and Seasonally Dry Forests. CRC Press, Neotropical Savannas and Seasonally Dry Forests. CRC Press. Edited by T. R. Pennington, G. P. Lewis, and J. A. Ratter. Florida. doi: 10.1201/9781420004496.

Peres-Neto, P. R. (2004) 'Patterns in the co-occurrence of fish species in streams: the role of site suitability, morphology and phylogeny versus species interactions', Oecologia, 140, pp. 352-360.

Peterson, A. T. (2003) 'Projected climate change effects on Rocky Mountain and Great Plains birds: Generalities of biodiversity consequences', Global Change Biology, 9, pp. 647-655.

Peterson, A. T. (2011) 'Ecological niche conservatism: A time-structured review of evidence', Journal of Biogeography, 38(5), pp. 817-827. doi: 10.1111/j.1365-2699.2010.02456.x.

Peterson, A. T. ,Soberón, J., Pearson, R. G., Anderson, R. P., Martínez-Meyer, E., Nakamura, M. y Araújo, M.B (2011) Ecological niches and geographic distributions. First, Princeton University Press. First. Princeton, New Jersey: Princeton University Press.

Peterson, A. T., Papeş, M. y Eaton, M. (2007) 'Transferability and model evaluation in ecological niche modeling: a comparison of GARP and Maxent', Ecography, 30(4), pp. 550-560. doi: 10.1111/j.2007.0906-7590.05102.x.

Peterson, A. T., Soberón, J., Sanchez-Cordero, V. V y Sánchez-Cordero, V. (1999) 'Conservatism of Ecological Niches in Evolutionary Time', Science, 285(5431), pp. 1265-1267. doi: 10.1126/science.285.5431.1265.

Peterson, A. T., y Vieglais, D. A. (2001) `Predicting species invasions using ecological niche modeling: New approaches from bioinformatics attack a pressing problem', BioScience, 51, pp. 363-371.

Phillips, S. J., Anderson, R. P. y Schapire, R. E. (2006) 'Maximum entropy modeling of species geographic distributions', Ecological Modelling, 190(3-4), pp. 231-259. doi: 10.1016/j.ecolmodel.2005.03.026.

Picard, D., Sempere, T. y Plantard, O. (2008) 'Direction and timing of uplift propagation in the Peruvian Andes deduced from molecular phylogenetics of highland biotaxa', Earth and Planetary Science Letters, 271(1-4), pp. 326-336. doi: 10.1016/j.epsl.2008.04.024.

Pocco, M. E., Minutolo, C., Dinghi, P. A., Lange, C. E., Confalonieri, V. A. y Cigliano, M. M. (2015) 'Species delimitation in the Andean grasshopper genus Orotettix Ronderos \& Carbonell (Orthoptera: Melanoplinae): an integrative approach combining morphological, molecular and biogeographical data', Zoological Journal of the Linnean Society, 174, pp. 733-759. doi: 10.1111/zoj.12251.

Pocco, M. E., Posadas, P., Lange, C. E. y Cigliano, M. M. (2013) 'Patterns of diversification in the high Andean Ponderacris grasshoppers (Orthoptera: Acrididae: Melanoplinae)', Systematic Entomology, 38(2), pp. 365-389. doi: 10.1111/syen.12001. 
Porzecanski, A. L. y Cracraft, J. (2005) 'Cladistic analysis of distributions and endemism (CADE): using raw distributions of birds to unravel the biogeography of the South American aridlands', Journal of Biogeography, 32, pp. 261-275.

Posada, D. (2008) 'jModelTest: Phylogenetic model averaging', Molecular Biology and Evolution, 25(7), pp. 1253-1256. doi: 10.1093/molbev/msn083.

Potter P. E. y Szatmari, P. (2009) 'Global Miocene tectonics and the modern world', Earth Science. Review, 96 (4), pp. 279-295.

Pyron, R. A., Costa, G. C., Patten, M. A. y Burbrink, F. T. (2015) 'Phylogenetic niche conservatism and the evolutionary basis of ecological speciation', Biological Reviews, 90(4), pp. 1248-1262. doi: $10.1111 /$ brv.12154.

Rabassa, J. (1999) 'Cuaternario de la cordillera patagónica y Tierra del Fuego' En: Caminos, R. (Ed.), Geología Argentina. Anales del Instituto de Geología y Recursos Minerales, Buenos Aires, pp. 710714

Radosavljevic, A. y Anderson, R. P. (2014) 'Making better Maxent models of species distributions: Complexity, overfitting and evaluation', Journal of Biogeography. Edited by M. Araújo, 41(4), pp. 629-643. doi: 10.1111/jbi.12227.

Rambaut, A., Suchard, M. A., Xie, D. y Drummond, A. J. (2014) Tracer v1.6. Available at: http://tree.bio.ed.ac.uk/software/tracer/.

Razgour, O., Hanmer, J. y Jones, G. (2011) 'Using multi-scale modelling to predict habitat suitability for species of conservation concern: The grey long-eared bat as a case study', Biological Conservation. Elsevier Ltd, 144(12), pp. 2922-2930. doi: 10.1016/j.biocon.2011.08.010.

Ree, R. H., Moore, B. R., Webb, C. O. y Donoghue, M. J. (2005) 'Alikelihood Framework for Inferring Theevolution of Geographic Range on Phylogenetic Trees', Evolution, 59(11), pp. 2299-2311. doi: 10.1554/05-172.1.

Ree, R. H. y Sanmartín, I. (2009) 'Prospects and challenges for parametric models in historical biogeographical inference', Journal of Biogeography, 36(7), pp. 1211-1220. doi: 10.1111/j.13652699.2008.02068.x.

Ree, R. H. y Smith, S. A. (2008) 'Maximum likelihood inference of geographic range evolution by dispersal, local extinction, and cladogenesis', Systematic Biology, 57(1), pp. 4-14. doi: 10.1080/10635150701883881.

Revell, L. J. (2013) 'Two new graphical methods for mapping trait evolution on phylogenies', Methods in Ecology and Evolution, 4(8), pp. 754-759. doi: 10.1111/2041-210X.12066.

Ribas, C. C., Moyle, R. G., Miyaki, C. Y. y Cracraft J. (2007) 'The assembly of montane biotas: linking Andes tectonics and climatic oscillations to independent regimes of diversification in Pionus parrots', Proceedings of The Royal Society, 274, pp. 2399-2408.

Riddle, B. R., Dawson, M. N., Hadly, E. A., Hafner, D. J., Hickerson, M. J., Mantooth, S. J. y Yoder, A. D. (2008) 'The role of molecular genetics in sculpting the future of integrative biogeography', Progress in Physical Geography, 32(2), pp. 173-202. doi: 10.1177/0309133308093822.

Rizzini, C. T. (1979) 'Tratado de fitogeografia do Brasil', 2ovolumen. Aspectos Sociológicos e Florísticos, Editora Univ. São Paulo, São Paulo, Brazil.

Roff, D. A. (1986) 'The Evolution of Wing Dimorphism in Insects', Evolution, 40(5), p. 1009. doi: $10.2307 / 2408759$.

Roff, D. A. (1990) 'The evolution of flightlessness in insects', Ecological Monographs, 60(4), pp. 389421. doi: $10.2307 / 1943013$.

Roff, D. A. (1994) 'Habitat persistence and the evolution of wing dimorphism in insects', The American Naturalist, 144, pp. 772-798.

Rohde, K. (1992) 'Latitudinal gradients in species diversity: the search for the primary cause', Oikos, 65 , pp. 514-527. 
Romero, E. J. (1993) 'South American paleofloras', En: Goldblatt, P. (Ed.), Biological Relationships between Africa and South America. Yale University Press, New Haven, CT, pp. 62-85.

Ronderos, R. A. (1981) `Consideraciones sobre la biogeografía de los Melanoplinae en Sudamérica (Orthoptera: Acrididae)', Proceedings, Triennial Meeting Pan-American Acridological Society, 3, pp. 53-54.

Ronquist, F. y Sanmartín, I. (2011) 'Phylogenetic Methods in Biogeography', Annual Review of Ecology, Evolution, and Systematics, 42(1), pp. 441-464. doi: 10.1146/annurev-ecolsys-102209-144710.

Le Roux, J. P. (2012) 'A review of Tertiary climate changes in southern South America and the Antarctic Peninsula. Part 2: continental conditions', Sedimentary Geology. Elsevier B.V., 247-248, pp. 21-38. doi: 10.1016/j.sedgeo.2011.12.001.

Rowell, C. H. F. y Flook, P. K. (2007) 'A Dated Molecular Phylogeny of the Proctolabinae ( Orthoptera, Acrididae ), Especially the Lithoscirtae, and the Evolution of Their Adaptive Traits and Present Biogeography', 13(1), pp. 35-56.

Rundle, H. D., Nagel, L., Boughman, J. W.y Schluter, D. (2000) `Evidence for parallel speciation in sympatric sticklebacks', Science, 287, pp. 306-308.

Sáez, P. A. et al. (2014) 'A new endemic lineage of the Andean frog genus Telmatobius (Anura, Telmatobiidae) from the western slopes of the central Andes', Zoological Journal of the Linnean Society, 171(4), pp. 769-782. doi: 10.1111/zoj.12152.

Samways, M. J., y Sergeev, M. G. (1997) 'Orthoptera and landscape change', pp. 147-162. En Gangwere, S. K., Muralirangan, M. C. y Muralirangan M. (Eds.), The bionomics of grasshoppers, katydids and their kin. CAB International, Wallingford, United Kingdom.

Sanmartín, I. (2012) 'Historical Biogeography: Evolution in Time and Space', Evolution: Education and Outreach, 5(4), pp. 555-568. doi: 10.1007/s12052-012-0421-2.

Särkinen, T., Pennington, R. T., Lavin, M., Simon, M. F. y Hughes, C. E. (2012) 'Evolutionary islands in the Andes: Persistence and isolation explain high endemism in Andean dry tropical forests', Journal of Biogeography, 39(5), pp. 884-900. doi: 10.1111/j.1365-2699.2011.02644.x.

Sarmiento, G. (1986) Ecologically crucial features of climate in high tropical mountains, High Altitude Tropical Biogeography.

Schliewen, U. K., Rassman, K., Markmann, J. y Tautz, D. (2001) `Genetic and ecological divergence of a monophyletic cichlid species pair under fully sympatric conditions in Lake Ejagham, Cameroon', Molecular Ecology, 10, pp. 1471-1488.

Schluter, D. (2000) 'The Ecology of Adaptive Radiation', Oxford University Press, Oxford.

Schoener, T. W. (1968) 'The Anolis lizard of Bimini: resourse partitioning in a complex fauna', Ecology, 49(4), pp. 704-726.

Schwallier, R., Raes, N., de Boer, H. J., Vos, R. A., van Vugt, R. R. y Gravendeel, B. (2016) 'Phylogenetic analysis of niche divergence reveals distinct evolutionary histories and climate change implications for tropical carnivorous pitcher plants', Diversity and Distributions, 22(1), pp. 97-110. doi: 10.1111/ddi.12382.

Sempere, T., Folguera, A. y Gerbault, M. (2008) 'New insights into Andean evolution: An introduction to contributions from the 6th ISAG symposium (Barcelona, 2005)', Tectonophysics, 459(1-4), pp. 113. doi: 10.1016/j.tecto.2008.03.011.

Shcheglovitova, M. y Anderson, R. P. (2013) 'Estimating optimal complexity for ecological niche models: A jackknife approach for species with small sample sizes', Ecological Modelling. Elsevier B.V., 269, pp. 9-17. doi: 10.1016/j.ecolmodel.2013.08.011.

Short, L. L. (1975) 'A zoogeographic analysis of the South American Chaco avifauna', Bulletin of the American Museum of Natural History, 154, pp. 163-352.

Simpson, G. G. (1980) 'Splendid isolation: the curious history of South American mammals', New Haven: Yale University Press.

Simpson, G. G. (1953) 'The Major Features of Evolution', Columbia University Press, New York. 
Siqueira, T., Bini, L., Cianciaruso, M., Oliveira, F. y Trivinho-Strixino, S. (2009) 'The role of niche measures in explaining the abundance-distribution relationship in tropical lotic chironomids', Hydrobiologia, pp. 1-10.

Sklenár, P., Dušková, E., Balslev, H. (2011) `Tropical and temperate: evolutionary history of páramo flora', The Botanical Review, 77, pp. 71-108.

Smith, S. A. y Donoghue, M. J. (2010) 'Combining historical biogeography with niche modeling in the caprifolium clade of lonicera (Caprifoliaceae, Dipsacales)', Systematic Biology, 59(3), pp. 322-341. doi: $10.1093 /$ sysbio/syq011.

Soberón, J. (2007) 'Grinnellian and Eltonian niches and geographic distributions of species', Ecology Letters, 10, pp. 1115-1123.

Soberón, J., y Nakamura, M. (2009) `Niches and distributional areas: Concepts, methods, and assumptions', Proceedings of the National Academy of Sciences, USA 106, pp. 19644-19650.

Soberón, J., Llorente, J. y Benítez, H. (1996) 'An international view of national biological surveys', Annals of the Missouri Botanical Garden, 83, pp.562-573.

Soberón, J. y Peterson, T. (2005) 'Interpretation of models of fundamental ecological niches and species' distributional areas', Biodiversity Informatics, 2, pp.1-10.

Sokal, R. R. (1979) 'Testing Statistical Significance of Geographic Variation Patterns', Society of Systematic Biologists, 28(2), pp. 227-232.

Solis-Neffa, V. G. (2009) 'Geographic patterns of morphological variation in Turnera sidoides subsp. pinnatifida (Turner- aceae)', Plant Systematics and Evolution, 284, pp. 231-253.

Song, H., Mariño-Pérez, R., Woller, D. A. y Cigliano, M. M. (2018) 'Evolution, Diversification, and Biogeography of Grasshoppers (Orthoptera: Acrididae)', Insect Systematics and Diversity, 2(4). doi: 10.1093/isd/ixy008.

Steinbauer, M. J., Field, R., Grytnes, J. A., Trigas, P., Ah - Peng, C. Attorre, F., Birks, H. J. B., Borges, P. A. V., Cardoso, P., Chou, C - H, De Sanctis, M., de Sequeira, M. M., Duarte, M. C., Elias, R. B. José María Fernández - Palacios Rosalina Gabriel Roy E. Gereau Rosemary G. Gillespie Josef Greimler David E. V. Harter Tsurng - Juhn Huang Severin D. H. Irl Daniel Jeanmonod Anke Jentsch Alistair S. Jump Christoph Kueffer Sandra Nogué Rüdiger Otto Jonathan Price Maria M. Romeiras Dominique Strasberg Tod Stuessy Jens - Christian Svenning Ole R. Vetaas Carl Beierkuhnlein (2016) 'Topography-driven isolation, speciation and a global increase of endemism with elevation', Global Ecology and Biogeography, 25(9), pp. 1097-1107. doi: 10.1111/geb.12469.

Sorenson, M. D., Fleischer, R. C. (1996) 'Multiple independent transposition of mitochondrial DNA control region sequences to the nucleus', Proceedings of the National Academy of Sciences of the United States of America, 93, pp. 15239-15243.

Southwood, T. R. E. (1962) 'Migration of terrestrial arthropods in relation to habitat', Biological Reviews, 37, pp. 171-214.

Speranza, P. R., Seijo, J. G., Grela, I. A. y Solis-Neffa, V. G. (2007) `Chloroplast DNA variation in the Turnera sidoides L. complex (Turneraceae): biogeographical implications', Journal of Biogeography, 34, pp. 427-436.

Spichiger, R. et al., (1995) 'Origin, affinities and diversity hotspots of the Paraguayan dendrofloras' Candollea, 50, pp. 515.

Spichiger, R., Calange, C., y Bise, B., (2004) `Geographical zonation in the Neotropics of tree species characteristic of the Paraguay-Paraná Basin', Journal of Biogeography, 31, pp. 1489-1501.

Stauffer, T. W. y Whitman, D.W. (1997) 'Grasshopper Oviposition’ pp. 231- 280. En: Gangwere, S. K., Muralirangan, M. C. y Muralirangan, M. (Eds) The Bionomics of Grasshoppers, Katydids and Their Kin. CAB International, Wallingford, UK.

Stehli, F. G., Webb, S. D. (1985) 'The Great American biotic interchange', New York: Plenum Press.

Stigall, A. L. y Lieberman, B. S. (2006) 'Quantitative palaeobiogeography: GIS, phylogenetic biogeographical analysis, and conservation insights', Journal of Biogeography, 33(12), pp. 2051- 
2060. doi: 10.1111/j.1365-2699.2006.01585.x.

Swenson, N. G., Enquist, B. J., Pither, J., Thompson, J. y Zimmerman, J. K. (2006) `The problem and promise of scale dependency in community phylogenetics', Ecology, 87, pp. 2418-2424.

Tabarelli, M., Pinto, L. P., Silva, J. M. C., Hirota, M. M. y Bedê, L. C. (2005) 'Desafios e oportunidades para a conservação da biodiversidade na Mata Atlântica brasileira', Megadiversidade, 1(1), pp. 132138. doi: 10.1590/S0102-05362005000400034.

The Nature Conservancy, Fundación Vida Silvestre Argentina (2005) `Evaluación Ecoregional del Gran Chaco Americano' - 1a ed. - Buenos Aires: The Nature Conservanc y. Fundación l Desarrollo Sustentable del Chaco: Wildlife Conservation Society-Bolivia, 24 p. ISBN 950- 9427-12-8.

Torres, M. N., Júnior, P. D. M., Santos, T., Silveira, L., Jácomo-de Almeida, A. T. y Diniz-Filho, A. F. (2012) 'Can species' distribution modelling provide estimates of population densities? A case study with jaguars in the Neotropics', Diversity and Distributions, 18, pp. 615-627.

Uvarov, B. P. (1966) 'Grasshoppers and Locusts', vol. 1. Cambridge University Press, Cambridge, UK.

Van der Vaart, A. W. (1998) 'Asymptotic statistics' Cambridge: Cambridge University Press.

VanDerWal, J., Shoo, L., Johnson, C. y Williams, S. (2009) 'Abundance and the environmental niche: environmental suitability estimated from niche models predicts the upper limit of local abundance' The American Naturalist, 174, pp. 282-291.

Via, S. (2001) 'Sympatric speciation in animals: the ugly ducking grows up', Trends Ecology and Evolution, 16, pp. 381-390.

Wagner, D. L. y Liebherr, J. K. (1992) 'Flightlessness in insects', Trends in Ecology and Evolution, 7(7), pp. 216-220. doi: 10.1016/0169-5347(92)90047-F.

Warren, D. L., Glor, R. E. y Turelli, M. (2008) 'Environmental niche equivalency versus conservatism: quantitative approaches to niche evolution.', Evolution; international journal of organic evolution, 62(11), pp. 2868-83. doi: 10.1111/j.1558-5646.2008.00482.x.

Webb, S. D. (1978) `A history of savanna vertebrates in the New World. Part II: South America and the Great Interchange', Annual Review of Ecology and Systematics, 9, pp. 393-426.

Webb, S. D. (1991) 'Ecography and the Great American Interchange', Paleobiology, 17, pp. 266-280.

Webb, C. O., Ackerly, D. D., McPeek, M. A. y Donoghue, M. J. (2002) 'Phylogenies and Community Ecology', Annual Review of Ecology and Systematics, 33(1), pp. 475-505. doi: 10.1146/annurev.ecolsys.33.010802.150448.

Webb, S. D., Rancy, A. (1996) 'Late Cenozoic evolution of the Neotropical mammal fauna', En: Jackson, J. B. C., Budd, A. F. y Coates, A. G. (Eds.), Evolution and Environments in Tropical Americas, The University of Chicago Press, Chicago, pp. 335-358.

Werneck, F. P. (2011) 'The diversification of eastern South American open vegetation biomes: Historical biogeography and perspectives', Quaternary Science Reviews. Elsevier Ltd, 30(13-14), pp. 1630-1648. doi: 10.1016/j.quascirev.2011.03.009.

Werneck, F. P., Costa, G. C., Colli, G. R., Prado, D. E. y Sites, J. W. (2011) 'Revisiting the historical distribution of Seasonally Dry Tropical Forests: New insights based on palaeodistribution modelling and palynological evidencegeb', Global Ecology and Biogeography, 20(2), pp. 272-288. doi: 10.1111/j.1466-8238.2010.00596.x.

Werneck, F. P., Gamble, T., Colli, G. R., Rodrigues, M. T. y Sites, J. W. (2012) 'Deep diversification and long-term persistence in the south american "dry diagonal": Integrating continent-wide phylogeography and distribution modeling of geckos', Evolution, 66(10), pp. 3014-3034. doi: 10.1111/j.1558-5646.2012.01682.x.

Whittaker, R. H., Levin, S. A. y Root, R. B. (1973) 'Niche, habitat, and ecotope', American Naturalist, 955, pp. 321-338.

Wiens, J. J. (2004) 'Speciation and Ecology Revisited: Phylogenetic Niche Conservatism and the Origin of Species', Evolution, 58(1), p. 193. doi: 10.1554/03-447.

Wiens JJ, Ackerly DD, Allen AP, Anacker BL, Buckley LB, Cornell HV, Damschen EI, Jonathan Davies T, 
Grytnes JA, Harrison SP. (2010) 'Niche conservatism as an emerging principle in ecology and conservation biology', Ecology Letters, 13(10), pp. 1310-1324. doi: 10.1111/j.14610248.2010.01515.x.

Wiens, J. J. y Graham, C. H. (2005) 'Niche Conservatism: Integrating Evolution, Ecology, and Conservation Biology', Annual Review of Ecology, Evolution, and Systematics, 36(1), pp. 519-539. doi: 10.1146/annurev.ecolsys.36.102803.095431.

Willig, M. R., Presley, S. J., Owen, R. D. y López-González, C. (2000) `Composition and structure of bat assemblages in Paraguay: a subtropical-temperate interface', Journal of Mammalogy, 81, pp. 386401.

Willmott, K. R., Hall, J. P. W. y Lamas, G. (2001) 'Systematics of Hypanartia (Lepidoptera: Nymphalidae: Nymphalinae), with a test for geographical speciation mechanism in the Andes', Systematic Entomology, 26, pp. 369-399.

Yáñez-Arenas, C., Guevara, R., Martínez-Meyer, E., Mandujano, S. y Lobo, J. M. (2014) 'Predicting species' abundances from occurrence data: effects of sample size and bias', Ecological Modelling, 294, pp. 36-41.

Yáñez-Arenas, C., Martínez-Meyer, E., Mandujano, S. y Rojas-Soto, O. (2012) `Modelling geographic patterns of population density of the white-tailed deer in central Mexico by implementing ecological niche theory', Oikos, 121, pp. 2081-2089.

Young, K. R., Ulloa, C. U., Luteyn, J.L. y Knapp, S. (2002) 'Plant evolution and endemism in andean South America: An introduction', The Botanical Review 68, pp. 4-21.

Yrigoyen, M. R. (1979) 'Cordillera principal', En: Actas del II Simposio de Geología Regional Argentina, vol. 1, Córdoba, pp. 651-694.

Zachos, J., Pagani, M., Sloan, L., Thomas, E. y Billups, K. (2001) 'Trends, rhythms, and aberrations in global climate 65 Ma to present', Science, p. 686-693, doi:10.1126/science.1059412.

Zhang, D. X., Hewitt, G. M. (1996) 'Nuclear integrations: challenges for mitochondrial DNA markers', Trends in Ecology \& Evolution, 11, pp. 247-251.

Zolessi, L. C. D. E. (1958) 'Bioecologia y Ontogenesis de Scotussa cliens (Stal) Lieb. (Acridoidea, Catantopidae) en el Uruguay'. 


\section{ANEXO}

Tabla Suplementaria 1: Datos de los registros de las especies de Orotettix incluidos en el estudio

\begin{tabular}{|c|c|c|c|}
\hline Especie & Localidad & Longitud & Latitud \\
\hline O. andeanus & Perú; Cusco; A Urcos, Ruinas Pikillaqta & -71.70781 & -13.62081 \\
\hline O. andeanus & Perú; Cusco; Cachimayo, pasando Poroy & -72.06142 & -13.48928 \\
\hline O. andeanus & Perú; Cusco; Cardonpata, a 53 km Cachimayo & -72.40894 & -13.45414 \\
\hline O. andeanus & Perú; Cusco; Casi desvio Tamillopata & -72.06778 & -13.32383 \\
\hline O. andeanus & Perú; Cusco; Chincheros & -72.04713 & -13.38955 \\
\hline O. andeanus & Perú; Cusco; Cusco. Entre Coya y Lamay & -71.91372 & -13.38203 \\
\hline O. andeanus & Perú; Cusco; Kaira & -71.87466 & -13.55855 \\
\hline O. andeanus & Perú; Cusco; Lucre & -71.72644 & -13.62772 \\
\hline O. andeanus & Perú; Cusco; Lucre & -71.96697 & -13.51039 \\
\hline O. andeanus & Perú; Cusco; Maras & -72.11119 & -13.33892 \\
\hline O. andeanus & Perú; Cusco; Perayoc & -72.13580 & -13.29895 \\
\hline O. andeanus & Perú; Cusco; Pisac, 35 km Cuzco & -71.84594 & -13.42897 \\
\hline O. andeanus & Perú; Cusco; San Jerónimo & -71.87707 & -13.55949 \\
\hline O. andeanus & Perú; Cusco; San Jerónimo & -71.89312 & -13.55102 \\
\hline O. andeanus & Perú; Cusco; Tipon & -71.80239 & -13.08683 \\
\hline O. andeanus & Perú; Cusco; Urcos & -71.61782 & -13.68364 \\
\hline O. andeanus & Perú; Cusco; Urubamba & -72.11981 & -13.30746 \\
\hline O. andeanus & Perú; Cusco; Urubamba & -72.11095 & -13.29419 \\
\hline O. andeanus & Perú; Cusco; Yanahuara & -72.17444 & -13.27369 \\
\hline O. astreptos & Perú; Cusco; A 20 km de Curahuasi hacia Cusco & -72.52348 & -13.54032 \\
\hline O. carrascoi & Perú; Cusco; Ollantaytambo & -72.26516 & -13.24883 \\
\hline O. carrascoi & Perú; Cusco; Ollantaytambo ruinas & -72.24508 & -13.25979 \\
\hline O. carrascoi & Perú; Cusco; Ollantaytambo ruinas & -72.26183 & -13.25892 \\
\hline O. carrascoi & Perú; Cusco; Ollantaytambo ruinas & -72.25262 & -13.24607 \\
\hline O. carrascoi & Perú; Cusco; Ollantaytambo ruinas & -72.23506 & -13.24092 \\
\hline O. ceballosi & Perú; Ayacucho; 5 km Bosque de Piedras de Huaraca & -74.44683 & -13.31619 \\
\hline O. ceballosi & Perú; Ayacucho; Condorcocha & -74.19397 & -13.44989 \\
\hline O. ceballosi & Perú; Ayacucho; de Tambo a San Francisco & -74.02489 & -12.93497 \\
\hline O. ceballosi & Perú; Ayacucho; de Toccto a Condorcocha & -74.18747 & -13.36873 \\
\hline O. ceballosi & Perú; Ayacucho; e/Tambo y Ayacucho & -74.09433 & -12.96619 \\
\hline O. ceballosi & Perú; Ayacucho; e/Tambo y Ayacucho & -74.08875 & -12.96375 \\
\hline O. ceballosi & Perú; Ayacucho; hacia Toccto-Condorcocha & -74.22697 & -13.21781 \\
\hline O. ceballosi & Perú; Ayacucho; Tambo & -74.01922 & -12.95325 \\
\hline O. ceballosi & Perú; Huancavelica; A 24 km de Huancavelica desde Huancayo & -74.90125 & -12.71317 \\
\hline O. ceballosi & Perú; Huancavelica; Bosque de Piedra Sachapite a 16.5 km N. de Huancavelica. & -74.88531 & -12.67318 \\
\hline O. ceballosi & Perú; Junín; 17 km de Tarma a Jauja & -75.64367 & -11.51792 \\
\hline O. ceballosi & Perú; Junín; Imperial, 35 km S. de Huancayo & -75.07625 & -12.32258 \\
\hline O. colcaensis & Perú; Arequipa; Valle del Colca. Coporaque & -71.63111 & -15.65077 \\
\hline O. colcaensis & Perú; Arequipa; Valle del Colca. Coporaque & -71.65000 & -15.63056 \\
\hline O. colcaensis & Perú; Arequipa; Valle del Colca. Coporaque & -71.64013 & -15.61701 \\
\hline O. colcaensis & Perú; Arequipa; Valle del Colca. Pinchollo & -71.83188 & -15.62217 \\
\hline O. colcaensis & Perú; Arequipa; Valle del Colca. Pinchollo & -71.85406 & -15.61922 \\
\hline O. colcaensis & Perú; Arequipa; Valle del Colca. Yanque. & -71.67842 & -15.65739 \\
\hline
\end{tabular}


Tabla Suplementaria 1 Continuación:

\begin{tabular}{|c|c|c|c|}
\hline Especie & Localidad & Longitud & Latitud \\
\hline O. dichrous & Perú; Apurimac; A 10 km de Curahuasi hacia Abancay & -72.75814 & -13.54936 \\
\hline O. dichrous & Perú; Apurimac; A 39 km de Curahuasi hacia Abancay. & -72.82219 & -13.56803 \\
\hline O. dichrous & Perú; Apurimac; Cachora & -72.81972 & -13.51889 \\
\hline O. dichrous & Perú; Apurimac; Curahuasi & -72.73342 & -13.55064 \\
\hline O. dichrous & Perú; Cusco; Limite entre Cusco y Apurimac & -72.59142 & -13.56414 \\
\hline O. hortensis & Bolivia; La Paz; Sorata. La Cumbre de Sonata. Altiplano & -68.65495 & -15.89745 \\
\hline O. hortensis & Perú; Cusco; A 18 km de Cuisipata & -71.44761 & -14.04869 \\
\hline O. hortensis & Perú; Dpto. de Puno; Hacienda La Huerta, cerca de la ciudad de Puno & -70.38405 & -15.69119 \\
\hline O. hortensis & Perú; Puno; Atuncolla hacia Chulpas de Silustani & -70.09664 & -15.70564 \\
\hline O. hortensis & Perú; Puno; De Cusco a Puno. Chuquibambilla, a $20 \mathrm{~km}$ antes de Ayaviri & -70.72111 & -14.77806 \\
\hline O. hortensis & Perú; Puno; De Cusco a Puno. Km antes de Santa Rosa. & -70.84097 & -14.59694 \\
\hline O. lunatus & Perú; Apurimac; A 3 km de Abancay hacia Cusco. & -72.86417 & -13.61203 \\
\hline O. paucartambensis & Perú; Cusco; A 20 km de Paucartambo hacia Pillahuata, casi abra Ajanacu & -71.63512 & -13.22015 \\
\hline O. paucartambensis & Perú; Cusco; A 20 km de Paucartambo hacia Pillahuata, casi abra Ajanacu & -71.61747 & -13.19972 \\
\hline O. paucartambensis & Perú; Cusco; A 20 km de Paucartambo hacia Pillahuata, casi abra Ajanacu & -71.64192 & -13.19800 \\
\hline O. paucartambensis & Perú; Cusco; Parpacalla saliendo de Paucartambo & -71.59933 & -13.28875 \\
\hline O. paucartambensis & Perú; Cusco; Parpacalla saliendo de Paucartambo & -71.61089 & -13.26854 \\
\hline
\end{tabular}


Tabla Suplementaria 2: Pesos y varianza acumulada del CP1 y CP2 de las 19 variables bioclimáticas graficadas sobre la topología del árbol filogenético. Resaltado en rojo se encuentran los tres valores mayores positivos y en verde los tres mayores negativos para cada CP. Node A: (O. andeanus, O. carracoi); Nodo B: ((O. andeanus, $O$. carracoi) O. colcaensis); Nodo C: (O. dichrous, O. astreptos); Nodo D: ((O. dichrous, O.astreptos) O. lunatus); Nodo E: (((O. andeanus, O. carracoi) O. colcaensis) ((O. dichrous, O. astreptos) O. lunatus )); Nodo F: (( (CO. andeanus, $O$. carracoi) O. colcaensis) ((O. dichrous, O. astreptos) O. lunatus)) O. hortensis); Nodo G: (O. paucartambensis, $O$. ceballosi); Nodo H: ((c((O. andeanus, O. carracoi $)$ O. colcaensis $)((O$. dichrous, O. astreptos $)$ O. lunatus $))$ O. hortensis) (O. paucartambensis, O. ceballosi)).

\begin{tabular}{|c|c|c|c|c|c|c|c|c|c|c|c|c|c|c|c|c|c|c|c|c|c|}
\hline \multirow{2}{*}{$\begin{array}{l}\text { I } \\
\text { 음 } \\
\text { Z }\end{array}$} & ป & $\frac{0}{\frac{0}{i}}$ & $\begin{array}{l}\text { న్ } \\
\text { i. } \\
\text { în }\end{array}$ & \begin{tabular}{l}
0 \\
\multirow{0}{0}{} \\
0
\end{tabular} & $\begin{array}{l}\text { ô } \\
\text { ơ } \\
\text { is }\end{array}$ & $\frac{\infty}{\check{c}}$ & $\frac{0}{c}$ & $\begin{array}{l}\text { ô } \\
\text { o. }\end{array}$ & $\begin{array}{l}\underset{i}{i} \\
\text { ì }\end{array}$ & 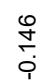 & $\frac{\text { ֻ }}{\frac{1}{1}}$ & $\frac{\infty}{\stackrel{\infty}{+}}$ & $\begin{array}{l}\text { \& } \\
\text { ల్ } \\
0\end{array}$ & ஜ్ల్లి & 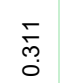 & $\frac{\infty}{\infty}$ & 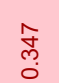 & $\begin{array}{c}\text { న్లి } \\
\text { Oे }\end{array}$ & ڤ్ & $\underset{\substack{\text { m} \\
0}}{0}$ & $\begin{array}{l}\text { ฟै } \\
\text { ผ }\end{array}$ \\
\hline & $\bar{\vdots}$ & ্ָডি & $\stackrel{\circ}{\stackrel{\infty}{\circ}}$ & م્م & $\begin{array}{l}\text { Ñ} \\
\stackrel{N}{1}\end{array}$ & 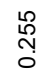 & స్ & 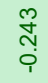 & 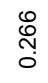 & 今్ & 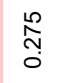 & 周 & 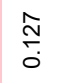 & $\begin{array}{l}\text { N} \\
\text { O̊. } \\
0\end{array}$ & ָัָ & 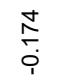 & $\begin{array}{l}\infty \\
\infty \\
0 \\
0 \\
0\end{array}$ & $\stackrel{\hat{~}}{\stackrel{0}{0}}$ & $\frac{8}{\circ}$ & 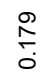 & 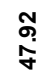 \\
\hline \multirow{2}{*}{$\begin{array}{l}\text { 0 } \\
\text { 울 } \\
\text { z }\end{array}$} & ̃ & $\begin{array}{l}\frac{1}{2} \\
0 \\
0\end{array}$ & 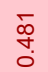 & $\frac{\overline{0}}{0}$ & 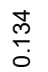 & 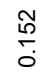 & $\begin{array}{l}\widehat{\text { o }} \\
\text { O. }\end{array}$ & 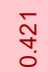 & $\begin{array}{l}\text { 웅 } \\
\text { o. }\end{array}$ & $\widehat{\ddot{o}}$ & $\begin{array}{l}\mathscr{\infty} \\
\stackrel{0}{0} \\
0\end{array}$ & $\begin{array}{l}\text { Ð } \\
\stackrel{0}{0}\end{array}$ & 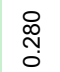 & f) & $\stackrel{m}{\stackrel{m}{0}}$ & $\begin{array}{c}\bar{\infty} \\
\prod_{0}\end{array}$ & f) & $\frac{O}{0}$ & 용 & $\frac{\text { Oे }}{0}$ & $\underset{\infty}{\mathbb{N}}$ \\
\hline & $\overline{0}$ & స్ & 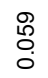 & 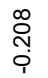 & 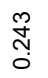 & $\begin{array}{l}\text { đ్ } \\
\text { N̦ }\end{array}$ & 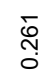 & 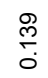 & 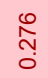 & 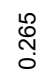 & 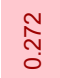 & $\begin{array}{l}\stackrel{0}{0} \\
\stackrel{1}{0} \\
0\end{array}$ & $\begin{array}{l}\infty \\
\text { N̦ } \\
\stackrel{1}{1}\end{array}$ & $\begin{array}{l}\text { ثે } \\
\text { ị }\end{array}$ & 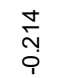 & $\begin{array}{l}\text { Õ } \\
0 \\
0\end{array}$ & $\begin{array}{l}\text { مָ } \\
\text { ơ }\end{array}$ & 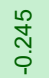 & $\begin{array}{l}\bar{\sim} \\
\text { N̦ } \\
\text { î }\end{array}$ & $\begin{array}{l}\stackrel{\text { I }}{N} \\
\text { ị }\end{array}$ & 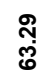 \\
\hline \multirow{2}{*}{$\begin{array}{l}\text { L } \\
\text { 을 } \\
\text { Z }\end{array}$} & ป & $\frac{\widetilde{\delta}}{\cos }$ & $\frac{\mathscr{\infty}}{\stackrel{\infty}{0}}$ & 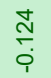 & $\frac{\mathscr{\odot}}{\check{\circ}}$ & $\begin{array}{l}\hat{0} \\
\text { O̊. } \\
\text { in }\end{array}$ & $\frac{\infty}{m}$ & 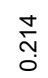 & $\begin{array}{l}\text { ஜे } \\
\text { : } \\
1\end{array}$ & $\stackrel{0}{\stackrel{0}{c}}$ & $\begin{array}{l}\hat{o} \\
0 \\
0 \\
\end{array}$ & $\frac{0}{\frac{1}{c}}$ & $\begin{array}{l}\stackrel{0}{0} \\
\text { ల్ } \\
0\end{array}$ & $\begin{array}{l}\text { o } \\
\text { ల్ } \\
0\end{array}$ & ণ্ণু & 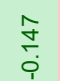 & 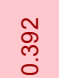 & $\stackrel{m}{\stackrel{m}{N}}$ & $\begin{array}{l}\text { N} \\
\text { O }\end{array}$ & ָָ ָָ & 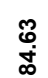 \\
\hline & $\bar{\vdots}$ & 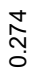 & $\stackrel{\infty}{\stackrel{\infty}{\circ}}$ & 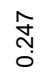 & $\begin{array}{l}\text { O্ } \\
\text { N̦} \\
\text { i }\end{array}$ & 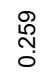 & 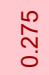 & 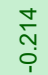 & 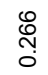 & 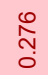 & $\begin{array}{l}\text { N } \\
\text { O }\end{array}$ & 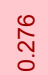 & $\stackrel{\circ}{\frac{\circ}{\circ}}$ & $\frac{\text { q }}{\stackrel{0}{\circ}}$ & 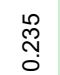 & $\begin{array}{l}\text { N̦ } \\
\text { ọ }\end{array}$ & 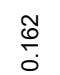 & 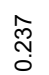 & $\begin{array}{l}\text { Na } \\
0 \\
0\end{array}$ & 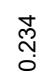 & $\underset{\hat{0}}{\overline{0}}$ \\
\hline \multirow{2}{*}{$\begin{array}{l}\text { ய } \\
\text { 응 } \\
\text { z }\end{array}$} & ̃ & $\frac{8}{\frac{8}{i}}$ & 仓ે & $\begin{array}{l}\text { 尺े } \\
\text { o. }\end{array}$ & $\stackrel{?}{\underset{丶}{5}}$ & $\stackrel{N}{\check{0}}$ & 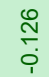 & 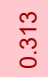 & $\begin{array}{l}\mathscr{0} \\
\circ \\
0 \\
1\end{array}$ & $\begin{array}{l}\circ \\
\infty \\
0 \\
i\end{array}$ & $\begin{array}{l}\hat{o} \\
\text { o } \\
\text { i. }\end{array}$ & $\begin{array}{l}\text { 옹 } \\
\text { ị }\end{array}$ & $\frac{5}{\circ}$ & \begin{tabular}{l}
\multirow{2}{N}{} \\
$\underset{0}{0}$
\end{tabular} & $\stackrel{\bar{\infty}}{\check{0}}$ & $\frac{\hat{\sigma}}{0}$ & 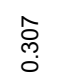 & $\stackrel{\overline{0}}{\stackrel{0}{0}}$ & 莡 & $\frac{\widetilde{\sigma}}{\sigma}$ & 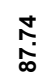 \\
\hline & $\bar{\vdots}$ & $\begin{array}{l}\text { مึ } \\
\text { مึ }\end{array}$ & $\frac{\circ}{\circ}$ & 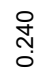 & $\begin{array}{l}\text { స్ } \\
\text { o }\end{array}$ & 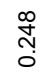 & 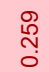 & 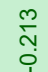 & 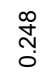 & 怘 & 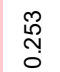 & 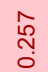 & 芯 & $\stackrel{\text { }}{\stackrel{\sigma}{\circ}}$ & $\begin{array}{l}\underset{\text { J }}{0} \\
\end{array}$ & స̃ & 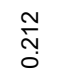 & 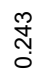 & 守 & ্ֻণ & 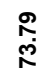 \\
\hline \multirow{2}{*}{$\begin{array}{l}\text { 口 } \\
\text { 음 } \\
\text { z }\end{array}$} & ป & $\stackrel{\mathscr{\Omega}}{\stackrel{\circ}{\circ}}$ & $\begin{array}{l}\infty \\
\stackrel{0}{0} \\
0 \\
0\end{array}$ & $\frac{8}{\circ}$ & $\frac{\circ}{\stackrel{0}{i}}$ & $\begin{array}{l}\stackrel{\sim}{N} \\
\text { O }\end{array}$ & స్ & 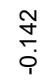 & $\stackrel{\infty}{\infty}_{0}^{-\infty}$ & 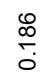 & $\stackrel{\circ}{\stackrel{N}{0}}$ & $\stackrel{+}{\frac{\pi}{0}}$ & 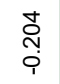 & $\begin{array}{l}\stackrel{2}{N} \\
\stackrel{N}{i}\end{array}$ & $\begin{array}{l}\stackrel{\infty}{N} \\
\text { ị }\end{array}$ & 疋 & 움 & 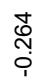 & $\begin{array}{l}\text { t } \\
\text { م. } \\
0\end{array}$ & $\begin{array}{l}\text { ơ } \\
\text { ơ } \\
\text { ì }\end{array}$ & 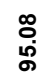 \\
\hline & $\bar{\vdots}$ & 尺్లి & $\begin{array}{l}\text { ָ̃ } \\
\text { i̦ }\end{array}$ & $\begin{array}{l}\stackrel{\infty}{\dddot{N}} \\
0\end{array}$ & 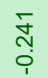 & $\begin{array}{l}\stackrel{N}{N} \\
0\end{array}$ & $\underset{\hat{N}}{\stackrel{N}{0}}$ & 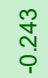 & 吕 & 亣 & 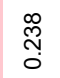 & 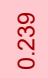 & $\underset{\widetilde{N}}{\stackrel{N}{0}}$ & $\stackrel{\widehat{N}}{\text { స̃ }}$ & $\begin{array}{l}\text { N̦ } \\
\text { O }\end{array}$ & 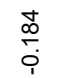 & 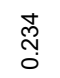 & $\begin{array}{l}\text { N̦ } \\
\text { O }\end{array}$ & $\frac{\bar{\sigma}}{\circ}$ & م્Nָ & $\begin{array}{l}\stackrel{+}{\infty} \\
\stackrel{\infty}{\infty}\end{array}$ \\
\hline \multirow{2}{*}{$\begin{array}{l}0 \\
\text { 음 } \\
\text { ¿ }\end{array}$} & ป & $\stackrel{\text { ని }}{\stackrel{0}{0}}$ & $\bar{\sigma}_{0}$ & $\underset{\leftarrow}{\frac{\pi}{0}}$ & 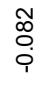 & 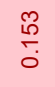 & $\frac{⿱}{\circ}$ & $\underset{\dot{i}}{\check{c}}$ & $\stackrel{\infty}{\leftarrow}$ & $\stackrel{\stackrel{d}{\sim}}{\circ}$ & $\frac{5}{5}$ & $\stackrel{\stackrel{\infty}{N}}{\circ}$ & $\begin{array}{l}0 \\
0 \\
0 \\
i\end{array}$ & $\begin{array}{l}\infty \\
\infty \\
0 \\
0 \\
i\end{array}$ & $\begin{array}{l}\bar{m} \\
\text { o. } \\
\text { i. }\end{array}$ & 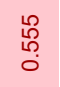 & $\begin{array}{l}\mathscr{0} \\
\varnothing \\
0\end{array}$ & 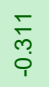 & 令 & $\begin{array}{l}0 \\
\stackrel{0}{0} \\
0 \\
i\end{array}$ & $\begin{array}{l}\text { م. } \\
\stackrel{\infty}{\circ}\end{array}$ \\
\hline & $\bar{o}$ & ঙ্ণু & $\begin{array}{l}\text { ָ̃ } \\
\text { ָ̦ }\end{array}$ & ल̂̀ & 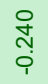 & 仓ָ̃ & 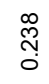 & $\begin{array}{l}\text { Pे } \\
\text { Ț } \\
\text { T. }\end{array}$ & ণ্] & ్ֻల్రా & 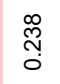 & ণ্ల్ & 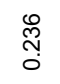 & ڤ્N & 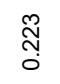 & $\frac{\stackrel{R}{R}}{\stackrel{0}{i}}$ & 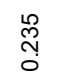 & $\begin{array}{l}\text { N̦ } \\
0\end{array}$ & 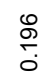 & ণัָ & ָั \\
\hline \multirow{2}{*}{$\begin{array}{l}\text { m } \\
\text { 웅 } \\
\text { z }\end{array}$} & $\frac{N}{0}$ & 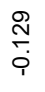 & $\frac{0}{\stackrel{0}{\circ}}$ & $\begin{array}{l}\stackrel{0}{N} \\
\text { ị }\end{array}$ & $\stackrel{10}{\circ}$ & $\begin{array}{l}\text { ज̃ } \\
\text { ị }\end{array}$ & $\begin{array}{l}0 \\
0 \\
0 \\
0\end{array}$ & 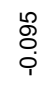 & 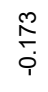 & $\stackrel{⿱ 亠 䒑}{\grave{c}}$ & 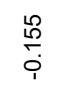 & $\stackrel{\stackrel{N}{i ̣}}{\stackrel{i}{i}}$ & $\begin{array}{l}\text { ळ్ } \\
\text { లె }\end{array}$ & $\begin{array}{l}\stackrel{乛}{+} \\
\stackrel{+}{0}\end{array}$ & 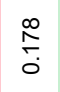 & $\frac{\infty}{\stackrel{\infty}{\circ}}$ & $\begin{array}{l}\infty \\
\stackrel{0}{0} \\
\stackrel{0}{0}\end{array}$ & $\begin{array}{l}0 \\
\tilde{O} \\
0 \\
0\end{array}$ & $\frac{\stackrel{n}{0}}{0}$ & $\frac{\widehat{\infty}}{\stackrel{0}{0}}$ & $\stackrel{\leftarrow}{\grave{\infty}}$ \\
\hline & $\bar{o}$ & 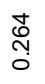 & 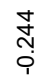 & $\frac{\circ}{\circ}$ & 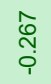 & ஸָ๊ & 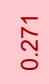 & 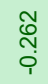 & 芯 & $\begin{array}{l}\text { \& } \\
\stackrel{\text { N }}{0}\end{array}$ & 芯 & 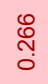 & $\frac{N}{\stackrel{N}{0}}$ & $\begin{array}{l}0 \\
0 \\
0\end{array}$ & ণ্ల్ & $\begin{array}{l}\stackrel{i}{N} \\
\text { ị }\end{array}$ & $\begin{array}{l}\mathbb{D} \\
\stackrel{0}{0} \\
0\end{array}$ & 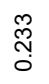 & \begin{tabular}{l}
\multirow{\infty}{*}{} \\
$\stackrel{0}{\phi}$
\end{tabular} & ָָ & $\begin{array}{l}\text { ల్ } \\
\stackrel{8}{0}\end{array}$ \\
\hline \multirow{3}{*}{$\begin{array}{l}\varangle \\
\text { ¿ } \\
\text { ㅇ } \\
\text { Z }\end{array}$} & $\frac{N}{0}$ & 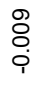 & 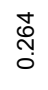 & $\stackrel{\stackrel{J}{*}}{\circ}$ & 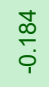 & $\begin{array}{l}\text { Õ } \\
\text { Oे. } \\
0\end{array}$ & $\overline{\grave{\sigma}}$ & 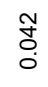 & $\begin{array}{l}\text { ơ } \\
\text { o. } \\
\text { in }\end{array}$ & ్ָ & $\begin{array}{l}8 \\
\text { ه } \\
\text { i. }\end{array}$ & ్ָరి & $\begin{array}{l}\text { ڤొ } \\
\text { లై } \\
0\end{array}$ & $\frac{\infty}{\stackrel{\infty}{\leftarrow}}$ & ڤ્心 & $\begin{array}{l}\hat{\omega} \\
\stackrel{p}{i} \\
\end{array}$ & స్ণ & $\begin{array}{l}0 \\
\text { ర్ల. } \\
0\end{array}$ & ⿸్ల్ల & $\begin{array}{l}\hat{i} \\
\text { fo }\end{array}$ & $\stackrel{0}{\stackrel{0}{\infty}}$ \\
\hline & $\overline{0}$ & 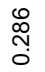 & $\stackrel{5 n}{\frac{5}{i}}$ & 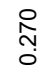 & 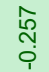 & $\begin{array}{l}\stackrel{\leftrightarrow}{\infty} \\
\text { N̦ }\end{array}$ & 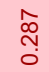 & 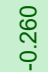 & 总 & $\begin{array}{c}\widehat{\infty} \\
\stackrel{\sim}{0}\end{array}$ & $\begin{array}{l}\stackrel{0}{0} \\
\stackrel{0}{0}\end{array}$ & $\begin{array}{l}\text { ô } \\
\stackrel{\text { Ond }}{0}\end{array}$ & 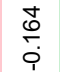 & $\begin{array}{c}\hat{N} \\
\text { O̦ }\end{array}$ & 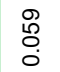 & $\frac{\text { م⿱ 口) }}{\stackrel{0}{0}}$ & $\frac{\text { న్ }}{\stackrel{1}{\circ}}$ & $\frac{⿱}{\check{0}}$ & $\stackrel{\hat{m}}{\grave{i}}$ & $\begin{array}{l}0 \\
\stackrel{0}{0} \\
0\end{array}$ & $\frac{\bar{s}}{0}$ \\
\hline & & $\begin{array}{l}\bar{\varepsilon} \\
\frac{\overline{\underline{E}}}{\mathrm{o}} \\
\stackrel{\circ}{\Phi}\end{array}$ & 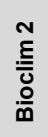 & 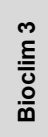 & 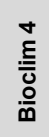 & 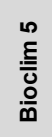 & 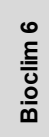 & 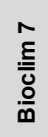 & 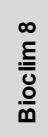 & 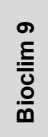 & $\begin{array}{l}\frac{0}{E} \\
\frac{\underline{g}}{\bar{g}} \\
\frac{\circ}{0}\end{array}$ & $\begin{array}{l}\bar{\tau} \\
\frac{g}{\bar{g}} \\
\frac{\mathrm{g}}{0}\end{array}$ & 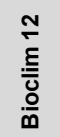 & $\frac{\stackrel{m}{\xi}}{\frac{\underline{\Xi}}{0}}$ & 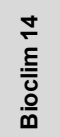 & $\begin{array}{l}\frac{\omega}{\xi} \\
\frac{\underline{\xi}}{0} \\
\frac{\circ}{0}\end{array}$ & $\begin{array}{l}\frac{\varrho}{\xi} \\
\frac{\underline{\xi}}{0} \\
\frac{\circ}{0}\end{array}$ & 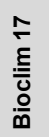 & $\begin{array}{l}\frac{\infty}{\xi} \\
\frac{\underline{E}}{0} \\
\frac{0}{0}\end{array}$ & 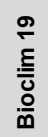 & $\vec{ن}^{\circ}$ \\
\hline
\end{tabular}


Tabla Suplementaria 3: Registros por especie del grupo de géneros Scotussae.

\begin{tabular}{|c|c|c|c|c|c|c|c|}
\hline Género & Especie & Latitud & Longitud & Género & Especie & Latitud & Longitud \\
\hline Atrachelacris & olivaceus & -31.0087 & -64.4364 & Chlorus & chiquitensis & -16.3333 & -62.6667 \\
\hline Atrachelacris & olivaceus & -32.1726 & -64.7543 & Chlorus & chiquitensis & -16.2083 & -62.2251 \\
\hline Atrachelacris & olivaceus & -30.7888 & -64.4747 & Chlorus & chiquitensis & -16.3521 & -62.1578 \\
\hline Atrachelacris & olivaceus & -31.3223 & -64.6079 & Chlorus & chiquitensis & -16.5730 & -62.4924 \\
\hline Atrachelacris & olivaceus & -30.8464 & -64.5350 & Chlorus & spatulus & -27.3833 & -55.8834 \\
\hline Atrachelacris & olivaceus & -27.4739 & -58.7673 & Chlorus & spatulus & -18.1641 & -63.5336 \\
\hline Atrachelacris & olivaceus & -27.8608 & -55.1469 & Chlorus & spatulus & -17.8228 & -64.6165 \\
\hline Atrachelacris & olivaceus & -26.9377 & -54.4342 & Chlorus & spatulus & -17.6681 & -64.4256 \\
\hline Atrachelacris & olivaceus & -17.5777 & -52.2566 & Chlorus & spatulus & -18.1294 & -63.8077 \\
\hline Atrachelacris & olivaceus & -15.4209 & -55.7712 & Chlorus & vittatus & -22.6533 & -56.0272 \\
\hline Atrachelacris & olivaceus & -18.8626 & -48.3595 & Chlorus & vittatus & -26.1740 & -57.1013 \\
\hline Atrachelacris & olivaceus & -18.7574 & -44.4622 & Chlorus & vittatus & -26.0500 & -56.8667 \\
\hline Atrachelacris & olivaceus & -31.7826 & -52.3671 & Chlorus & vittatus & -25.6797 & -56.9502 \\
\hline Atrachelacris & olivaceus & -27.7668 & -52.8024 & Dichromatos & corupa & -25.5494 & -49.2181 \\
\hline Atrachelacris & olivaceus & -25.4731 & -55.9802 & Dichromatos & corupa & -29.1831 & -51.7331 \\
\hline Atrachelacris & olivaceus & -31.0831 & -55.4666 & Dichromatos & corupa & -28.6503 & -50.6367 \\
\hline Atrachelacris & olivaceus & -30.9268 & -55.5792 & Dichromatos & corupa & -27.3714 & -52.7767 \\
\hline Atrachelacris & olivaceus & -31.0500 & -55.7167 & Dichromatos & corupa & -27.5219 & -52.8939 \\
\hline Atrachelacris & unicolor & -25.9516 & -60.6439 & Dichromatos & corupa & -26.9786 & -49.5469 \\
\hline Atrachelacris & unicolor & -27.4522 & -58.9529 & Dichromatos & lilloanus & -26.4486 & -54.1373 \\
\hline Atrachelacris & unicolor & -31.6631 & -64.4634 & Dichromatos & lilloanus & -26.3506 & -54.2079 \\
\hline Atrachelacris & unicolor & -31.4307 & -64.4794 & Dichromatos & lilloanus & -27.3786 & -54.7439 \\
\hline Atrachelacris & unicolor & -31.4991 & -64.1546 & Dichromatos & lilloanus & -27.0333 & -54.1333 \\
\hline Atrachelacris & unicolor & -30.9186 & -64.4956 & Dichromatos & lilloanus & -27.2193 & -54.0271 \\
\hline Atrachelacris & unicolor & -31.3223 & -64.6079 & Dichromatos & lilloanus & -27.1099 & -53.9828 \\
\hline Atrachelacris & unicolor & -32.1726 & -64.7543 & Dichromatos & lilloanus & -27.6383 & -55.4919 \\
\hline Atrachelacris & unicolor & -31.0015 & -64.4400 & Dichromatos & lilloanus & -26.2479 & -53.6654 \\
\hline Atrachelacris & unicolor & -32.3925 & -63.2660 & Dichromatos & lilloanus & -26.3469 & -54.1514 \\
\hline Atrachelacris & unicolor & -27.4739 & -58.7673 & Dichromatos & lilloanus & -26.6219 & -54.7506 \\
\hline Atrachelacris & unicolor & -27.9417 & -58.2667 & Dichromatos & lilloanus & -27.8896 & -55.3478 \\
\hline Atrachelacris & unicolor & -27.9500 & -58.1330 & Dichromatos & lilloanus & -27.0421 & -54.1352 \\
\hline Atrachelacris & unicolor & -31.7202 & -60.4798 & Dichromatos & lilloanus & -27.0419 & -54.1348 \\
\hline Atrachelacris & unicolor & -31.1945 & -57.9444 & Dichromatos & lilloanus & -27.1515 & -53.9012 \\
\hline Atrachelacris & unicolor & -36.7002 & -65.2933 & Dichromatos & lilloanus & -25.9139 & -54.6186 \\
\hline Atrachelacris & unicolor & -27.4861 & -55.8317 & Dichromatos & lilloanus & -27.1000 & -53.9667 \\
\hline Atrachelacris & unicolor & -39.2914 & -65.6765 & Dichromatos & lilloanus & -27.2167 & -54.0167 \\
\hline Atrachelacris & unicolor & -26.1181 & -64.6419 & Dichromatos & lilloanus & -26.3924 & -54.2458 \\
\hline Atrachelacris & unicolor & -33.5975 & -65.1214 & Dichromatos & lilloanus & -26.3469 & -54.1514 \\
\hline Atrachelacris & unicolor & -32.8646 & -61.1029 & Dichromatos & lilloanus & -26.7042 & -54.2175 \\
\hline Atrachelacris & unicolor & -29.8735 & -61.9655 & Dichromatos & lilloanus & -27.1833 & -52.3833 \\
\hline Atrachelacris & unicolor & -18.7574 & -44.4622 & Dichromatos & lilloanus & -29.1831 & -51.7331 \\
\hline Atrachelacris & unicolor & -25.1087 & -56.0150 & Dichromatos & lilloanus & -27.3714 & -52.7767 \\
\hline Atrachelacris & unicolor & -25.4738 & -55.9739 & Dichromatos & lilloanus & -27.5219 & -52.8939 \\
\hline Atrachelacris & unicolor & -25.5333 & -57.0333 & Dichromatos & lilloanus & -26.8167 & -51.6167 \\
\hline Atrachelacris & unicolor & -25.2978 & -57.2764 & Dichromatos & lilloanus & -30.7089 & -57.8228 \\
\hline Atrachelacris & unicolor & -26.0958 & -56.8386 & Dichromatos & lilloanus & -30.5167 & -57.8832 \\
\hline Atrachelacris & unicolor & -25.6783 & -56.9510 & Dichromatos & montanus & -22.3736 & -44.7636 \\
\hline Atrachelacris & unicolor & -31.0500 & -55.7167 & Dichromatos & montanus & -22.5753 & -45.1911 \\
\hline Atrachelacris & unicolor & -31.8844 & -56.0138 & Dichromatos & montanus & -21.9998 & -44.7493 \\
\hline Atrachelacris & unicolor & -31.7195 & -55.9580 & Dichromatos & montanus & -22.7389 & -44.6103 \\
\hline Chlorus & attenuatus & -18.9723 & -49.7065 & Dichromatos & schrottkyi & -26.3469 & -54.1514 \\
\hline Chlorus & bolivianus & -18.4031 & -63.2083 & Dichromatos & schrottkyi & -26.3506 & -54.2079 \\
\hline Chlorus & bolivianus & -17.8867 & -63.3000 & Dichromatos & schrottkyi & -26.3922 & -54.2456 \\
\hline Chlorus & bolivianus & -17.9644 & -63.2181 & Dichromatos & schrottkyi & -25.5000 & -51.9500 \\
\hline Chlorus & bolivianus & -18.1641 & -63.5336 & Dichromatos & schrottkyi & -25.7000 & -52.2500 \\
\hline Chlorus & bolivianus & -17.8589 & -63.1742 & Dichromatos & schrottkyi & -25.1167 & -53.8667 \\
\hline Chlorus & bolivianus & -18.1431 & -63.8085 & Dichromatos & schrottkyi & -25.4333 & -51.4500 \\
\hline Chlorus & bolivianus & -18.9766 & -63.6193 & Dichromatos & schrottkyi & -24.6333 & -54.1167 \\
\hline Chlorus & bolivianus & -17.7756 & -63.0608 & Dichromatos & schrottkyi & -25.5728 & -54.6227 \\
\hline Chlorus & bolivianus & -18.6700 & -63.2406 & Dichromatos & schrottkyi & -26.8533 & -55.5543 \\
\hline Chlorus & bolivianus & -18.1817 & -63.8733 & Dichromatos & schrottkyi & -27.1995 & -55.6404 \\
\hline Chlorus & bolivianus & -17.7995 & -63.1640 & Eurotettix & brevicerci & -21.8327 & -50.9805 \\
\hline Chlorus & borellii & -21.2750 & -63.4589 & Eurotettix & brevicerci & -23.2840 & -47.4655 \\
\hline Chlorus & borellii & -21.9042 & -60.7594 & Eurotettix & carbonelli & -17.8762 & -51.9562 \\
\hline Chlorus & borellii & -21.8167 & -59.9167 & Eurotettix & carbonelli & -17.5777 & -52.2566 \\
\hline Chlorus & borellii & -22.1278 & -60.0325 & Eurotettix & carbonelli & -17.8686 & -51.7443 \\
\hline Chlorus & borellii & -22.5071 & -60.2208 & Eurotettix & carbonelli & -17.5924 & -52.5400 \\
\hline Chlorus & borellii & -26.0500 & -56.8667 & Eurotettix & carbonelli & -18.9723 & -49.7065 \\
\hline Chlorus & borellii & -23.0000 & -57.0000 & Eurotettix & concavus & -17.9456 & -54.7527 \\
\hline Chlorus & brunneus & -19.0267 & -57.6330 & Eurotettix & femoratus & -25.3467 & -57.1942 \\
\hline Chlorus & brunneus & -19.0872 & -57.6591 & Eurotettix & femoratus & -26.0500 & -56.8667 \\
\hline Chlorus & brunneus & -27.1833 & -52.3833 & Eurotettix & femoratus & -26.0500 & -56.8667 \\
\hline
\end{tabular}


Tabla Suplementaria 3 Continuación:

\begin{tabular}{|c|c|c|c|c|c|c|c|}
\hline Género & Especie & Latitud & Longitud & Género & Especie & Latitud & Longitud \\
\hline Eurotettix & latus & -17.1479 & -52.9934 & Leiotettix & viridis & -17.4570 & -63.6511 \\
\hline Eurotettix & latus & -17.3064 & -53.2024 & Leiotettix & viridis & -21.4343 & -55.5670 \\
\hline Eurotettix & minor & -25.3090 & -57.4491 & Leiotettix & viridis & -21.4306 & -55.5659 \\
\hline Eurotettix & minor & -25.4946 & -57.0265 & Leiotettix & viridis & -18.9167 & -54.8333 \\
\hline Eurotettix & minor & -25.2867 & -57.1769 & Leiotettix & viridis & -19.3255 & -48.2546 \\
\hline Eurotettix & minor & -25.5502 & -56.8993 & Leiotettix & viridis & -19.6600 & -47.4655 \\
\hline Eurotettix & minor & -25.4584 & -57.0345 & Leiotettix & viridis & -27.7673 & -52.8022 \\
\hline Eurotettix & minor & -25.3044 & -57.2806 & Leiotettix & viridis & -25.6783 & -56.9510 \\
\hline Eurotettix & minor & -25.2889 & -57.2653 & Ronderosia & bergii & -36.8893 & -62.3664 \\
\hline Eurotettix & minor & -25.6224 & -57.1587 & Ronderosia & bergii & -37.0410 & -59.5893 \\
\hline Eurotettix & minor & -25.6783 & -56.9510 & Ronderosia & bergii & -35.4792 & -62.9798 \\
\hline Eurotettix & monnei & -20.4758 & -55.9790 & Ronderosia & bergii & -34.0734 & -60.1181 \\
\hline Eurotettix & monnei & -20.4761 & -55.3520 & Ronderosia & bergii & -37.6909 & -59.8259 \\
\hline Eurotettix & monnei & -20.4937 & -55.7635 & Ronderosia & bergii & -35.1129 & -60.4643 \\
\hline Eurotettix & monnei & -20.1658 & -56.5139 & Ronderosia & bergii & -37.3459 & -58.9871 \\
\hline Eurotettix & procerus & -15.8458 & -58.4629 & Ronderosia & bergii & -37.0139 & -62.4038 \\
\hline Eurotettix & raphaelandrearum & -17.8769 & -51.8736 & Ronderosia & bergii & -34.4993 & -58.7791 \\
\hline Eurotettix & raphaelandrearum & -17.6319 & -52.3767 & Ronderosia & bergii & -34.5643 & -60.9705 \\
\hline Eurotettix & raphaelandrearum & -16.4514 & -54.3186 & Ronderosia & bergii & -36.8826 & -60.3613 \\
\hline Eurotettix & raphaelandrearum & -17.5855 & -53.1170 & Ronderosia & bergii & -34.6561 & -59.4108 \\
\hline Eurotettix & robustus & -15.8039 & -48.1775 & Ronderosia & bergii & -35.7990 & -61.8576 \\
\hline Eurotettix & robustus & -13.5638 & -48.2222 & Ronderosia & bergii & -34.8271 & -57.9792 \\
\hline Eurotettix & robustus & -15.4209 & -55.7712 & Ronderosia & bergii & -34.7370 & -58.2167 \\
\hline Eurotettix & robustus & -15.4822 & -55.7267 & Ronderosia & bergii & -35.6228 & -59.7966 \\
\hline Eurotettix & robustus & -12.9400 & -55.9192 & Ronderosia & bergii & -37.3159 & -59.1665 \\
\hline Eurotettix & robustus & -19.8090 & -43.9101 & Ronderosia & bergii & -27.2552 & -59.2370 \\
\hline Eurotettix & robustus & -19.6260 & -43.8797 & Ronderosia & bergii & -25.1225 & -60.7164 \\
\hline Eurotettix & simiraphael & -13.5638 & -48.2222 & Ronderosia & bergii & -26.1000 & -59.9000 \\
\hline Leiotettix & flavipes & -38.0971 & -62.2148 & Ronderosia & bergii & -27.4517 & -58.9558 \\
\hline Leiotettix & flavipes & -32.3415 & -58.4540 & Ronderosia & bergii & -26.8050 & -60.4200 \\
\hline Leiotettix & flavipes & -25.8667 & -51.8667 & Ronderosia & bergii & -31.0087 & -64.4364 \\
\hline Leiotettix & flavipes & -29.9489 & -50.8981 & Ronderosia & bergii & -31.0617 & -64.3036 \\
\hline Leiotettix & flavipes & -27.3558 & -52.7673 & Ronderosia & bergii & -31.6671 & -64.4446 \\
\hline Leiotettix & flavipes & -27.7673 & -52.8022 & Ronderosia & bergii & -31.6167 & -64.2173 \\
\hline Leiotettix & flavipes & -28.6773 & -50.4227 & Ronderosia & bergii & -33.4260 & -63.3077 \\
\hline Leiotettix & flavipes & -31.3097 & -52.0208 & Ronderosia & bergii & -31.0850 & -64.5072 \\
\hline Leiotettix & flavipes & -28.5103 & -50.9050 & Ronderosia & bergii & -31.7758 & -64.5367 \\
\hline Leiotettix & flavipes & -25.4731 & -55.9802 & Ronderosia & bergii & -31.1653 & -64.3331 \\
\hline Leiotettix & flavipes & -25.0890 & -55.9524 & Ronderosia & bergii & -32.5308 & -64.5811 \\
\hline Leiotettix & flavipes & -25.2978 & -57.2764 & Ronderosia & bergii & -31.3229 & -64.6078 \\
\hline Leiotettix & flavipes & -25.6783 & -56.9510 & Ronderosia & bergii & -28.0436 & -58.2117 \\
\hline Leiotettix & flavipes & -30.3761 & -57.5325 & Ronderosia & bergii & -27.3776 & -58.4927 \\
\hline Leiotettix & flavipes & -30.7572 & -57.7069 & Ronderosia & bergii & -31.8642 & -58.3278 \\
\hline Leiotettix & flavipes & -30.5507 & -57.8617 & Ronderosia & bergii & -33.0183 & -58.4949 \\
\hline Leiotettix & flavipes & -30.4217 & -56.4791 & Ronderosia & bergii & -26.1483 & -58.1933 \\
\hline Leiotettix & flavipes & -32.1161 & -53.9911 & Ronderosia & bergii & -25.8203 & -58.0711 \\
\hline Leiotettix & flavipes & -34.0928 & -55.6522 & Ronderosia & bergii & -35.8994 & -64.2764 \\
\hline Leiotettix & flavipes & -31.6617 & -57.8925 & Ronderosia & bergii & -36.6160 & -64.3396 \\
\hline Leiotettix & flavipes & -31.0833 & -55.4667 & Ronderosia & bergii & -27.1439 & -54.9142 \\
\hline Leiotettix & flavipes & -31.0500 & -55.7167 & Ronderosia & bergii & -26.2479 & -53.6654 \\
\hline Leiotettix & flavipes & -31.2856 & -55.9829 & Ronderosia & bergii & -27.3306 & -55.0542 \\
\hline Leiotettix & hastatus & -25.6783 & -56.9510 & Ronderosia & bergii & -27.4272 & -55.1686 \\
\hline Leiotettix & politus & -34.7193 & -55.9453 & Ronderosia & bergii & -25.6287 & -54.3394 \\
\hline Leiotettix & politus & -34.7193 & -55.9453 & Ronderosia & bergii & -27.3178 & -55.5336 \\
\hline Leiotettix & politus & -32.1161 & -53.9911 & Ronderosia & bergii & -27.6170 & -55.8177 \\
\hline Leiotettix & politus & -34.0928 & -55.6522 & Ronderosia & bergii & -27.3890 & -55.9556 \\
\hline Leiotettix & politus & -33.0031 & -58.0333 & Ronderosia & bergii & -26.6443 & -54.1002 \\
\hline Leiotettix & politus & -32.9292 & -54.9432 & Ronderosia & bergii & -24.8061 & -65.2317 \\
\hline Leiotettix & sanguineus & -27.4169 & -59.0289 & Ronderosia & bergii & -26.1181 & -64.6419 \\
\hline Leiotettix & sanguineus & -27.4517 & -58.9558 & Ronderosia & bergii & -35.1336 & -65.5750 \\
\hline Leiotettix & sanguineus & -24.6550 & -60.6714 & Ronderosia & bergii & -46.6125 & -70.9664 \\
\hline Leiotettix & sanguineus & -25.2742 & -57.7477 & Ronderosia & bergii & -32.8646 & -61.1029 \\
\hline Leiotettix & sanguineus & -26.8850 & -64.7394 & Ronderosia & bergii & -33.8361 & -61.4947 \\
\hline Leiotettix & sanguineus & -17.6328 & -63.1663 & Ronderosia & bergii & -26.7763 & -65.2160 \\
\hline Leiotettix & sanguineus & -17.4570 & -63.6511 & Ronderosia & bergii & -18.1356 & -63.8147 \\
\hline Leiotettix & sanguineus & -21.4343 & -55.5670 & Ronderosia & bergii & -18.1137 & -63.5964 \\
\hline Leiotettix & sanguineus & -25.4000 & -52.3833 & Ronderosia & bergii & -13.4160 & -40.4526 \\
\hline Leiotettix & sanguineus & -23.4264 & -56.5042 & Ronderosia & bergii & -15.4822 & -55.7267 \\
\hline Leiotettix & sanguineus & -25.6783 & -56.9510 & Ronderosia & bergii & -21.4412 & -43.6436 \\
\hline Leiotettix & sanguineus & -31.0833 & -55.4667 & Ronderosia & bergii & -20.1336 & -43.4991 \\
\hline Leiotettix & sanguineus & -31.0500 & -55.7167 & Ronderosia & bergii & -21.9990 & -44.7402 \\
\hline Leiotettix & viridis & -27.3903 & -55.9558 & Ronderosia & bergii & -22.9486 & -43.2881 \\
\hline
\end{tabular}


Tabla Suplementaria 3 Continuación:

\begin{tabular}{|c|c|c|c|c|c|c|c|}
\hline Género & Especie & Latitud & Longitud & Género & Especie & Latitud & Longitud \\
\hline Ronderosia & bergii & -21.6003 & -41.7833 & Ronderosia & malloi & -22.1761 & -63.9214 \\
\hline Ronderosia & bergii & -22.3336 & -44.5838 & Ronderosia & malloi & -22.2321 & -63.7181 \\
\hline Ronderosia & bergii & -22.6519 & -42.3917 & Ronderosia & malloi & -22.7389 & -64.3528 \\
\hline Ronderosia & bergii & -28.1931 & -51.5369 & Ronderosia & malloi & -25.2726 & -65.4775 \\
\hline Ronderosia & bergii & -27.3557 & -52.7675 & Ronderosia & malloi & -32.8357 & -61.1272 \\
\hline Ronderosia & bergii & -29.1791 & -51.7257 & Ronderosia & malloi & -31.7195 & -55.9580 \\
\hline Ronderosia & bergii & -27.8656 & -53.7856 & Ronderosia & ommexechoides & -22.1764 & -47.8836 \\
\hline Ronderosia & bergii & -23.0986 & -47.1975 & Ronderosia & paraguayensis & -27.7673 & -52.8022 \\
\hline Ronderosia & bergii & -22.7422 & -47.7003 & Ronderosia & paraguayensis & -29.9698 & -50.1768 \\
\hline Ronderosia & bergii & -23.2097 & -47.5192 & Ronderosia & paraguayensis & -25.1242 & -55.9639 \\
\hline Ronderosia & bergii & -25.5728 & -54.6221 & Ronderosia & paraguayensis & -25.6783 & -56.9510 \\
\hline Ronderosia & bergii & -25.5500 & -56.6667 & Ronderosia & paraguayensis & -31.0500 & -55.7167 \\
\hline Ronderosia & bergii & -25.1242 & -55.9639 & Ronderosia & piceomaculata & -28.6596 & -50.4439 \\
\hline Ronderosia & bergii & -25.4738 & -55.9739 & Ronderosia & piceomaculata & -28.5095 & -50.9133 \\
\hline Ronderosia & bergii & -24.0440 & -54.2941 & Ronderosia & robusta & -27.7673 & -52.8022 \\
\hline Ronderosia & bergii & -25.2697 & -57.6650 & Ronderosia & robusta & -25.1242 & -55.9639 \\
\hline Ronderosia & bergii & -25.3650 & -57.1300 & Ronderosia & robusta & -25.4731 & -55.9802 \\
\hline Ronderosia & bergii & -25.2409 & -56.8387 & Ronderosia & robusta & -25.6783 & -56.9510 \\
\hline Ronderosia & bergii & -23.4264 & -56.5042 & Ronderosia & robusta & -31.0500 & -55.7167 \\
\hline Ronderosia & bergii & -25.6783 & -56.9510 & Ronderosia & robusta & -32.9292 & -54.9432 \\
\hline Ronderosia & bergii & -26.0165 & -57.0501 & Scotussa & brachyptera & -26.8081 & -59.6072 \\
\hline Ronderosia & bergii & -30.5166 & -57.8828 & Scotussa & brachyptera & -27.4253 & -58.9701 \\
\hline Ronderosia & bergii & -31.1048 & -55.4322 & Scotussa & brachyptera & -27.7169 & -59.2323 \\
\hline Ronderosia & bergii & -30.7572 & -57.7069 & Scotussa & brachyptera & -27.0110 & -58.9702 \\
\hline Ronderosia & bergii & -34.4358 & -56.4715 & Scotussa & brachyptera & -28.9544 & -59.1278 \\
\hline Ronderosia & bergii & -31.2856 & -55.9829 & Scotussa & brachyptera & -31.6792 & -59.7889 \\
\hline Ronderosia & cinctipes & -25.6783 & -56.9510 & Scotussa & brachyptera & -25.4045 & -59.5698 \\
\hline Ronderosia & cintipes & -16.9439 & -53.5278 & Scotussa & brachyptera & -28.8518 & -59.5071 \\
\hline Ronderosia & cintipes & -15.4822 & -55.7267 & Scotussa & brachyptera & -27.0653 & -65.4064 \\
\hline Ronderosia & cintipes & -25.6783 & -56.9510 & Scotussa & brachyptera & -27.0475 & -65.3833 \\
\hline Ronderosia & dubia & -27.7673 & -52.8022 & Scotussa & brachyptera & -15.9562 & -54.9631 \\
\hline Ronderosia & dubia & -25.1242 & -55.9639 & Scotussa & cliens & -35.4658 & -60.8914 \\
\hline Ronderosia & dubia & -25.4731 & -55.9802 & Scotussa & cliens & -35.1529 & -57.4110 \\
\hline Ronderosia & dubia & -25.6783 & -56.9510 & Scotussa & cliens & -38.0678 & -61.9769 \\
\hline Ronderosia & forcipata & -36.8603 & -62.4969 & Scotussa & cliens & -37.8233 & -58.2579 \\
\hline Ronderosia & forcipata & -36.8255 & -62.2273 & Scotussa & cliens & -37.6423 & -59.3991 \\
\hline Ronderosia & forcipata & -36.8857 & -62.4146 & Scotussa & cliens & -35.1129 & -60.4643 \\
\hline Ronderosia & forcipata & -37.5163 & -62.2389 & Scotussa & cliens & -34.8029 & -58.0229 \\
\hline Ronderosia & forcipata & -38.0678 & -61.9769 & Scotussa & cliens & -34.3761 & -59.8017 \\
\hline Ronderosia & forcipata & -38.1434 & -61.8050 & Scotussa & cliens & -37.0197 & -62.4080 \\
\hline Ronderosia & forcipata & -38.1434 & -61.8050 & Scotussa & cliens & -35.0690 & -57.5138 \\
\hline Ronderosia & forcipata & -38.1434 & -61.8050 & Scotussa & cliens & -37.4847 & -62.1017 \\
\hline Ronderosia & forcipata & -38.0971 & -62.2148 & Scotussa & cliens & -38.1434 & -61.8050 \\
\hline Ronderosia & forcipata & -31.0087 & -64.4364 & Scotussa & cliens & -37.7591 & -62.1418 \\
\hline Ronderosia & forcipata & -31.0015 & -64.4400 & Scotussa & cliens & -37.4369 & -59.3689 \\
\hline Ronderosia & forcipata & -31.6631 & -64.4634 & Scotussa & cliens & -38.0971 & -62.2148 \\
\hline Ronderosia & forcipata & -32.1872 & -64.2369 & Scotussa & cliens & -27.7169 & -59.2323 \\
\hline Ronderosia & forcipata & -31.1518 & -64.3390 & Scotussa & cliens & -27.3177 & -61.2785 \\
\hline Ronderosia & forcipata & -33.1327 & -64.2971 & Scotussa & cliens & -27.4572 & -58.9687 \\
\hline Ronderosia & forcipata & -31.6741 & -64.4589 & Scotussa & cliens & -30.9233 & -64.4992 \\
\hline Ronderosia & forcipata & -31.5000 & -65.0000 & Scotussa & cliens & -32.6952 & -64.7075 \\
\hline Ronderosia & forcipata & -31.3229 & -64.6078 & Scotussa & cliens & -28.5084 & -59.0405 \\
\hline Ronderosia & forcipata & -27.9117 & -58.1076 & Scotussa & cliens & -29.1777 & -59.2500 \\
\hline Ronderosia & forcipata & -27.3776 & -58.4927 & Scotussa & cliens & -27.9241 & -58.1034 \\
\hline Ronderosia & forcipata & -32.3589 & -59.7714 & Scotussa & cliens & -27.3800 & -58.4900 \\
\hline Ronderosia & forcipata & -35.3071 & -64.0017 & Scotussa & cliens & -32.4801 & -58.9567 \\
\hline Ronderosia & forcipata & -26.0711 & -65.9706 & Scotussa & cliens & -33.0819 & -59.3004 \\
\hline Ronderosia & forcipata & -35.1336 & -65.5750 & Scotussa & cliens & -32.8901 & -59.4225 \\
\hline Ronderosia & forcipata & -30.9103 & -60.0465 & Scotussa & cliens & -32.0564 & -59.7653 \\
\hline Ronderosia & forcipata & -17.5777 & -52.2566 & Scotussa & cliens & -31.3981 & -58.0053 \\
\hline Ronderosia & forcipata & -15.9839 & -54.9286 & Scotussa & cliens & -33.0289 & -58.5133 \\
\hline Ronderosia & forcipata & -15.9839 & -54.9286 & Scotussa & cliens & -32.3531 & -59.8308 \\
\hline Ronderosia & forcipata & -18.9167 & -54.8333 & Scotussa & cliens & -31.6690 & -59.8569 \\
\hline Ronderosia & forcipata & -28.0222 & -52.2347 & Scotussa & cliens & -31.5014 & -59.8277 \\
\hline Ronderosia & forcipata & -28.1931 & -51.5369 & Scotussa & cliens & -25.2742 & -57.7477 \\
\hline Ronderosia & forcipata & -27.7673 & -52.8022 & Scotussa & cliens & -25.5642 & -59.2820 \\
\hline Ronderosia & forcipata & -25.6783 & -56.9510 & Scotussa & cliens & -35.3071 & -64.0017 \\
\hline Ronderosia & gracilis & -21.4306 & -55.5659 & Scotussa & cliens & -27.1099 & -53.9828 \\
\hline Ronderosia & gracilis & -15.4822 & -55.7267 & Scotussa & cliens & -26.3506 & -54.2079 \\
\hline Ronderosia & malloi & -39.3769 & -70.9336 & Scotussa & cliens & -27.0421 & -54.1352 \\
\hline Ronderosia & malloi & -24.8061 & -65.2317 & Scotussa & cliens & -27.8947 & -55.3558 \\
\hline Ronderosia & malloi & -24.6535 & -65.0291 & Scotussa & cliens & -27.6170 & -55.8177 \\
\hline
\end{tabular}


Tabla Suplementaria 3 Continuación:

\begin{tabular}{|c|c|c|c|c|c|c|c|}
\hline Género & Especie & Latitud & Longitud & Género & Especie & Latitud & Longitud \\
\hline Scotussa & cliens & -27.3890 & -55.9556 & Scotussa & impudica & -33.8313 & -58.8721 \\
\hline Scotussa & cliens & -26.5303 & -53.9243 & Scotussa & impudica & -33.6868 & -59.0240 \\
\hline Scotussa & cliens & -32.8000 & -66.1000 & Scotussa & impudica & -26.2479 & -53.6654 \\
\hline Scotussa & cliens & -33.1339 & -66.5167 & Scotussa & impudica & -26.3469 & -54.1514 \\
\hline Scotussa & cliens & -31.5681 & -60.7183 & Scotussa & impudica & -26.6219 & -54.7506 \\
\hline Scotussa & cliens & -28.0236 & -59.2319 & Scotussa & impudica & -25.6667 & -54.4500 \\
\hline Scotussa & cliens & -31.5528 & -61.5294 & Scotussa & impudica & -25.5905 & -54.5822 \\
\hline Scotussa & cliens & -31.6630 & -60.7522 & Scotussa & impudica & -26.5290 & -53.9238 \\
\hline Scotussa & cliens & -33.8342 & -61.4899 & Scotussa & impudica & -26.7087 & -54.2594 \\
\hline Scotussa & cliens & -28.4978 & -59.6111 & Scotussa & impudica & -27.8944 & -55.3558 \\
\hline Scotussa & cliens & -21.9998 & -44.7493 & Scotussa & impudica & -31.5063 & -60.4554 \\
\hline Scotussa & cliens & -25.5901 & -49.4262 & Scotussa & impudica & -28.2225 & -59.2661 \\
\hline Scotussa & cliens & -27.3546 & -52.7881 & Scotussa & impudica & -29.1342 & -59.6536 \\
\hline Scotussa & cliens & -22.7422 & -47.7003 & Scotussa & impudica & -21.7744 & -46.5472 \\
\hline Scotussa & cliens & -23.7722 & -46.4294 & Scotussa & impudica & -25.5000 & -51.9500 \\
\hline Scotussa & cliens & -25.1161 & -56.3453 & Scotussa & impudica & -26.4161 & -52.3567 \\
\hline Scotussa & cliens & -25.1124 & -55.9686 & Scotussa & impudica & -25.7500 & -52.2500 \\
\hline Scotussa & cliens & -25.2033 & -56.3889 & Scotussa & impudica & -24.2500 & -51.7500 \\
\hline Scotussa & cliens & -24.9833 & -55.9829 & Scotussa & impudica & -24.5500 & -50.1333 \\
\hline Scotussa & cliens & -25.7217 & -56.3825 & Scotussa & impudica & -25.4500 & -51.8667 \\
\hline Scotussa & cliens & -25.6603 & -56.9697 & Scotussa & impudica & -28.6503 & -50.6367 \\
\hline Scotussa & cliens & -30.8213 & -56.2577 & Scotussa & impudica & -28.2089 & -51.5258 \\
\hline Scotussa & cliens & -30.5506 & -57.8618 & Scotussa & impudica & -31.7292 & -52.2553 \\
\hline Scotussa & cliens & -32.4833 & -53.7167 & Scotussa & impudica & -28.0222 & -52.2347 \\
\hline Scotussa & cliens & -34.0928 & -55.6497 & Scotussa & impudica & -28.9194 & -50.4053 \\
\hline Scotussa & cliens & -34.7667 & -55.3167 & Scotussa & impudica & -29.9917 & -50.1936 \\
\hline Scotussa & cliens & -34.8792 & -55.2564 & Scotussa & impudica & -27.5242 & -52.8961 \\
\hline Scotussa & cliens & -32.0333 & -58.1333 & Scotussa & impudica & -27.1833 & -52.3833 \\
\hline Scotussa & cliens & -32.9792 & -58.0528 & Scotussa & impudica & -25.1124 & -55.9686 \\
\hline Scotussa & cliens & -31.2855 & -55.9834 & Scotussa & impudica & -25.7217 & -56.3825 \\
\hline Scotussa & cliens & -31.2239 & -56.1314 & Scotussa & impudica & -25.6603 & -56.9697 \\
\hline Scotussa & cliens & -32.9292 & -54.9432 & Scotussa & impudica & -34.7795 & -55.8962 \\
\hline Scotussa & daguerrei & -38.0678 & -61.9769 & Scotussa & impudica & -34.0928 & -55.6497 \\
\hline Scotussa & daguerrei & -38.0678 & -61.9769 & Scotussa & impudica & -34.1887 & -55.7384 \\
\hline Scotussa & daguerrei & -38.7708 & -62.6089 & Scotussa & impudica & -33.5850 & -54.7205 \\
\hline Scotussa & daguerrei & -37.6909 & -59.8259 & Scotussa & impudica & -34.3550 & -53.8572 \\
\hline Scotussa & daguerrei & -36.8579 & -62.6596 & Scotussa & impudica & -34.4358 & -56.4715 \\
\hline Scotussa & daguerrei & -37.5408 & -59.4586 & Scotussa & impudica & -31.2500 & -56.0500 \\
\hline Scotussa & daguerrei & -37.1879 & -62.7431 & Leiotettix & pulcher & -37.5583 & -62.5106 \\
\hline Scotussa & daguerrei & -38.1124 & -57.6289 & Leiotettix & pulcher & -36.8603 & -62.4969 \\
\hline Scotussa & daguerrei & -37.0128 & -62.4010 & Leiotettix & pulcher & -37.5135 & -62.2340 \\
\hline Scotussa & daguerrei & -37.0128 & -62.4010 & Leiotettix & pulcher & -36.7483 & -62.5255 \\
\hline Scotussa & daguerrei & -37.2519 & -58.9167 & Leiotettix & pulcher & -37.4592 & -61.9691 \\
\hline Scotussa & daguerrei & -36.0533 & -62.8828 & Leiotettix & pulcher & -37.0245 & -62.4085 \\
\hline Scotussa & daguerrei & -38.9786 & -61.2878 & Leiotettix & pulcher & -37.3923 & -62.4348 \\
\hline Scotussa & daguerrei & -37.5870 & -60.1324 & Leiotettix & pulcher & -36.8180 & -62.6207 \\
\hline Scotussa & daguerrei & -37.0334 & -60.5650 & Leiotettix & pulcher & -37.3667 & -58.9495 \\
\hline Scotussa & daguerrei & -37.0333 & -60.6000 & Leiotettix & pulcher & -37.6366 & -61.8584 \\
\hline Scotussa & daguerrei & -37.5222 & -62.7666 & Leiotettix & pulcher & -38.0678 & -61.9769 \\
\hline Scotussa & daguerrei & -37.3567 & -58.9672 & Leiotettix & pulcher & -37.8233 & -58.2579 \\
\hline Scotussa & daguerrei & -37.5097 & -59.3853 & Leiotettix & pulcher & -37.6909 & -59.8259 \\
\hline Scotussa & daguerrei & -35.0597 & -64.8414 & Leiotettix & pulcher & -37.6046 & -59.7086 \\
\hline Scotussa & daguerrei & -37.3129 & -64.2861 & Leiotettix & pulcher & -37.1879 & -62.7431 \\
\hline Scotussa & daguerrei & -36.6160 & -64.3396 & Leiotettix & pulcher & -37.9747 & -62.3233 \\
\hline Scotussa & delicatula & -17.3827 & -66.1401 & Leiotettix & pulcher & -34.8883 & -58.0242 \\
\hline Scotussa & delicatula & -17.4164 & -63.2131 & Leiotettix & pulcher & -37.3448 & -60.5700 \\
\hline Scotussa & impudica & -38.0678 & -61.9769 & Leiotettix & pulcher & -35.7657 & -61.8576 \\
\hline Scotussa & impudica & -37.6909 & -59.8259 & Leiotettix & pulcher & -37.5839 & -62.4189 \\
\hline Scotussa & impudica & -34.1822 & -58.2492 & Leiotettix & pulcher & -37.0567 & -59.5292 \\
\hline Scotussa & impudica & -34.9667 & -57.9375 & Leiotettix & pulcher & -38.1434 & -61.8050 \\
\hline Scotussa & impudica & -34.8271 & -57.9792 & Leiotettix & pulcher & -37.3144 & -59.1625 \\
\hline Scotussa & impudica & -34.5928 & -59.1017 & Leiotettix & pulcher & -37.6086 & -59.4194 \\
\hline Scotussa & impudica & -35.0769 & -57.5175 & Leiotettix & pulcher & -37.3725 & -59.0886 \\
\hline Scotussa & impudica & -34.4619 & -58.5356 & Leiotettix & pulcher & -37.4369 & -59.3689 \\
\hline Scotussa & impudica & -38.1434 & -61.8050 & Leiotettix & pulcher & -37.3131 & -58.7689 \\
\hline Scotussa & impudica & -38.0971 & -62.2148 & Leiotettix & pulcher & -38.0971 & -62.2148 \\
\hline Scotussa & impudica & -37.3028 & -59.1598 & Leiotettix & pulcher & -27.4169 & -59.0289 \\
\hline Scotussa & impudica & -27.7169 & -59.2323 & Leiotettix & pulcher & -32.1726 & -64.7543 \\
\hline Scotussa & impudica & -27.4572 & -58.9687 & Leiotettix & pulcher & -31.0015 & -64.4400 \\
\hline Scotussa & impudica & -27.0110 & -58.9702 & Leiotettix & pulcher & -30.8464 & -64.5350 \\
\hline Scotussa & impudica & -29.8351 & -57.5212 & Leiotettix & pulcher & -31.3229 & -64.6078 \\
\hline Scotussa & impudica & -27.4775 & -58.7764 & Leiotettix & pulcher & -24.6528 & -60.6739 \\
\hline
\end{tabular}


Tabla Suplementaria 3 Continuación:

\begin{tabular}{|c|c|c|c|c|c|c|c|}
\hline Género & Especie & Latitud & Longitud & Género & Especie & Latitud & Longitud \\
\hline Leiotettix & pulcher & -25.4045 & -59.5698 & Scotussa & lemniscata & -37.7931 & -59.3144 \\
\hline Leiotettix & pulcher & -27.4908 & -55.8269 & Scotussa & lemniscata & -34.9667 & -57.9375 \\
\hline Leiotettix & pulcher & -27.3175 & -55.5275 & Scotussa & lemniscata & -37.5524 & -60.8165 \\
\hline Leiotettix & pulcher & -27.6170 & -55.8177 & Scotussa & lemniscata & -37.1965 & -61.1191 \\
\hline Leiotettix & pulcher & -27.3903 & -55.9558 & Scotussa & lemniscata & -35.0769 & -57.5175 \\
\hline Leiotettix & pulcher & -27.8896 & -55.3478 & Scotussa & lemniscata & -37.3441 & -59.1189 \\
\hline Leiotettix & pulcher & -24.6392 & -64.2478 & Scotussa & lemniscata & -34.6517 & -58.5267 \\
\hline Leiotettix & pulcher & -33.2500 & -66.2000 & Scotussa & lemniscata & -38.8191 & -62.7028 \\
\hline Leiotettix & pulcher & -32.3489 & -64.9817 & Scotussa & lemniscata & -34.6347 & -58.7908 \\
\hline Leiotettix & pulcher & -26.2451 & -61.8222 & Scotussa & lemniscata & -35.8077 & -61.9200 \\
\hline Leiotettix & pulcher & -26.4214 & -65.5594 & Scotussa & lemniscata & -37.6136 & -62.4322 \\
\hline Leiotettix & pulcher & -26.7000 & -65.7153 & Scotussa & lemniscata & -37.0334 & -60.5650 \\
\hline Leiotettix & pulcher & -17.5667 & -65.5000 & Scotussa & lemniscata & -34.8271 & -57.9792 \\
\hline Leiotettix & pulcher & -15.4822 & -55.7267 & Scotussa & lemniscata & -35.3978 & -57.1506 \\
\hline Leiotettix & pulcher & -21.8032 & -53.3962 & Scotussa & lemniscata & -35.5150 & -58.3014 \\
\hline Leiotettix & pulcher & -25.4640 & -51.9546 & Scotussa & lemniscata & -36.4492 & -57.7231 \\
\hline Leiotettix & pulcher & -25.6000 & -51.6333 & Scotussa & lemniscata & -34.4441 & -59.4281 \\
\hline Leiotettix & pulcher & -24.3667 & -52.0000 & Scotussa & lemniscata & -37.8419 & -57.5200 \\
\hline Leiotettix & pulcher & -28.6615 & -50.4434 & Scotussa & lemniscata & -37.6167 & -59.5500 \\
\hline Leiotettix & pulcher & -27.3558 & -52.7673 & Scotussa & lemniscata & -38.1434 & -61.8050 \\
\hline Leiotettix & pulcher & -31.7292 & -52.2553 & Scotussa & lemniscata & -37.1356 & -59.3669 \\
\hline Leiotettix & pulcher & -28.5103 & -50.9050 & Scotussa & lemniscata & -37.4006 & -59.4831 \\
\hline Leiotettix & pulcher & -27.7673 & -52.8022 & Scotussa & lemniscata & -35.3947 & -57.3386 \\
\hline Leiotettix & pulcher & -26.8167 & -51.6167 & Scotussa & lemniscata & -34.5494 & -58.5583 \\
\hline Leiotettix & pulcher & -22.7324 & -45.1461 & Scotussa & lemniscata & -37.1442 & -62.9638 \\
\hline Leiotettix & pulcher & -25.0605 & -55.9320 & Scotussa & lemniscata & -34.3694 & -58.8694 \\
\hline Leiotettix & pulcher & -30.4699 & -57.8356 & Scotussa & lemniscata & -37.5406 & -58.4311 \\
\hline Leiotettix & pulcher & -30.3761 & -57.5325 & Scotussa & lemniscata & -27.0303 & -59.6383 \\
\hline Leiotettix & pulcher & -34.7117 & -55.4439 & Scotussa & lemniscata & -27.7169 & -59.2323 \\
\hline Leiotettix & pulcher & -34.0928 & -55.6522 & Scotussa & lemniscata & -29.4622 & -56.9422 \\
\hline Leiotettix & pulcher & -31.6565 & -57.8954 & Scotussa & lemniscata & -29.3493 & -57.0835 \\
\hline Leiotettix & pulcher & -32.3379 & -58.0881 & Scotussa & lemniscata & -27.9241 & -58.1034 \\
\hline Leiotettix & pulcher & -31.0500 & -55.7167 & Scotussa & lemniscata & -33.0198 & -59.4142 \\
\hline Leiotettix & pulcher & -32.9292 & -54.9432 & Scotussa & lemniscata & -32.8901 & -59.4225 \\
\hline Scotussa & lemniscata & -36.8893 & -62.3664 & Scotussa & lemniscata & -30.7689 & -57.9947 \\
\hline Scotussa & lemniscata & -37.5583 & -62.5106 & Scotussa & lemniscata & -31.3981 & -58.0053 \\
\hline Scotussa & lemniscata & -36.8603 & -62.4969 & Scotussa & lemniscata & -30.9881 & -57.9286 \\
\hline Scotussa & lemniscata & -37.5135 & -62.2340 & Scotussa & lemniscata & -33.0289 & -58.5133 \\
\hline Scotussa & lemniscata & -37.6219 & -61.9038 & Scotussa & lemniscata & -32.0933 & -58.9589 \\
\hline Scotussa & lemniscata & -36.8255 & -62.2273 & Scotussa & lemniscata & -31.8633 & -58.3256 \\
\hline Scotussa & lemniscata & -36.7435 & -62.5286 & Scotussa & lemniscata & -32.3415 & -58.4540 \\
\hline Scotussa & lemniscata & -37.4592 & -61.9691 & Scotussa & lemniscata & -35.3385 & -64.1145 \\
\hline Scotussa & lemniscata & -37.0044 & -62.4150 & Scotussa & lemniscata & -37.1333 & -63.8156 \\
\hline Scotussa & lemniscata & -37.3923 & -62.4348 & Scotussa & lemniscata & -35.8994 & -64.2764 \\
\hline Scotussa & lemniscata & -37.6406 & -58.6192 & Scotussa & lemniscata & -36.6160 & -64.3396 \\
\hline Scotussa & lemniscata & -37.5181 & -62.1264 & Scotussa & lemniscata & -27.8947 & -55.3558 \\
\hline Scotussa & lemniscata & -36.8180 & -62.6207 & Scotussa & lemniscata & -27.6170 & -55.8177 \\
\hline Scotussa & lemniscata & -38.0678 & -61.9769 & Scotussa & lemniscata & -27.3890 & -55.9556 \\
\hline Scotussa & lemniscata & -35.4792 & -62.9798 & Scotussa & lemniscata & -38.0671 & -70.6206 \\
\hline Scotussa & lemniscata & -37.5847 & -60.1506 & Scotussa & lemniscata & -41.1225 & -71.4023 \\
\hline Scotussa & lemniscata & -33.6304 & -60.5947 & Scotussa & lemniscata & -32.8000 & -66.1000 \\
\hline Scotussa & lemniscata & -37.6317 & -58.4948 & Scotussa & lemniscata & -31.5063 & -60.4554 \\
\hline Scotussa & lemniscata & -37.7133 & -58.2368 & Scotussa & lemniscata & -32.8646 & -61.1029 \\
\hline Scotussa & lemniscata & -37.0254 & -59.6010 & Scotussa & lemniscata & -33.8342 & -61.4899 \\
\hline Scotussa & lemniscata & -37.8233 & -58.2579 & Scotussa & lemniscata & -28.4978 & -59.6111 \\
\hline Scotussa & lemniscata & -37.6423 & -59.3991 & Scotussa & lemniscata & -26.7833 & -65.3928 \\
\hline Scotussa & lemniscata & -37.6948 & -59.8144 & Scotussa & lemniscata & -28.7446 & -50.0512 \\
\hline Scotussa & lemniscata & -34.8920 & -57.8816 & Scotussa & lemniscata & -28.6773 & -50.4227 \\
\hline Scotussa & lemniscata & -37.7328 & -61.7219 & Scotussa & lemniscata & -29.9917 & -50.1936 \\
\hline Scotussa & lemniscata & -35.1129 & -60.4643 & Scotussa & lemniscata & -28.5028 & -50.8992 \\
\hline Scotussa & lemniscata & -35.1811 & -58.2497 & Scotussa & lemniscata & -31.7292 & -52.2553 \\
\hline Scotussa & lemniscata & -35.0431 & -58.7874 & Scotussa & lemniscata & -25.6603 & -56.9697 \\
\hline Scotussa & lemniscata & -37.1879 & -62.7431 & Scotussa & lemniscata & -30.4833 & -57.8333 \\
\hline Scotussa & lemniscata & -35.6148 & -61.3433 & Scotussa & lemniscata & -30.8213 & -56.2577 \\
\hline Scotussa & lemniscata & -34.3761 & -59.8017 & Scotussa & lemniscata & -30.4265 & -56.8382 \\
\hline Scotussa & lemniscata & -35.5576 & -58.0290 & Scotussa & lemniscata & -30.2950 & -56.9719 \\
\hline Scotussa & lemniscata & -34.9003 & -60.0192 & Scotussa & lemniscata & -34.7795 & -55.8962 \\
\hline Scotussa & lemniscata & -37.4675 & -59.4286 & Scotussa & lemniscata & -32.1161 & -53.9911 \\
\hline Scotussa & lemniscata & -34.9690 & -57.7103 & Scotussa & lemniscata & -32.8917 & -55.6202 \\
\hline Scotussa & lemniscata & -34.6327 & -58.9550 & Scotussa & lemniscata & -32.9487 & -56.5062 \\
\hline Scotussa & lemniscata & -34.5156 & -58.7661 & Scotussa & lemniscata & -33.8833 & -56.8200 \\
\hline Scotussa & lemniscata & -37.3632 & -61.5408 & Scotussa & lemniscata & -34.0928 & -55.6497 \\
\hline
\end{tabular}


Tabla Suplementaria 3 Continuación:

\begin{tabular}{|llll|llll|}
\hline Género & Especie & Latitud & Longitud & Género & Especie & Latitud & Longitud \\
\hline Scotussa & lemniscata & -33.7277 & -56.3412 & Scotussa & liebermanni & -31.3980 & -58.0377 \\
Scotussa & lemniscata & -34.6500 & -55.2478 & Scotussa & liebermanni & -32.3415 & -58.4540 \\
Scotussa & lemniscata & -32.0333 & -58.1333 & Scotussa & liebermanni & -25.5905 & -54.5822 \\
Scotussa & lemniscata & -32.6622 & -58.1177 & Scotussa & liebermanni & -31.5063 & -60.4554 \\
Scotussa & lemniscata & -31.7363 & -55.2366 & Scotussa & liebermanni & -29.1342 & -59.6536 \\
Scotussa & lemniscata & -31.0500 & -55.7167 & Scotussa & liebermanni & -30.5507 & -57.8617 \\
Scotussa & lemniscata & -32.2236 & -54.9656 & Scotussa & liebermanni & -30.8491 & -56.1932 \\
Scotussa & lemniscata & -32.0833 & -54.9000 & Scotussa & liebermanni & -32.3663 & -54.1917 \\
Scotussa & lemniscata & -31.8178 & -55.1950 & Scotussa & liebermanni & -34.0928 & -55.6522 \\
Scotussa & lemniscata & -31.7195 & -55.9580 & Scotussa & liebermanni & -33.5850 & -54.7205 \\
Scotussa & lemniscata & -33.1103 & -54.6933 & Scotussa & liebermanni & -34.8773 & -56.0362 \\
Scotussa & lemniscata & -32.9292 & -54.9432 & Scotussa & liebermanni & -34.8636 & -56.0191 \\
Scotussa & liebermanni & -34.8271 & -57.9792 & Scotussa & liebermanni & -34.5561 & -57.0024 \\
Scotussa & liebermanni & -29.4622 & -56.9422 & Scotussa & liebermanni & -34.4486 & -56.4036 \\
Scotussa & liebermanni & -29.0367 & -58.2825 & Scotussa & liebermanni & -34.4450 & -56.4167 \\
\hline
\end{tabular}


Tabla Suplementaria 4: Número de registros por especie de la Tribu Dichoplini.

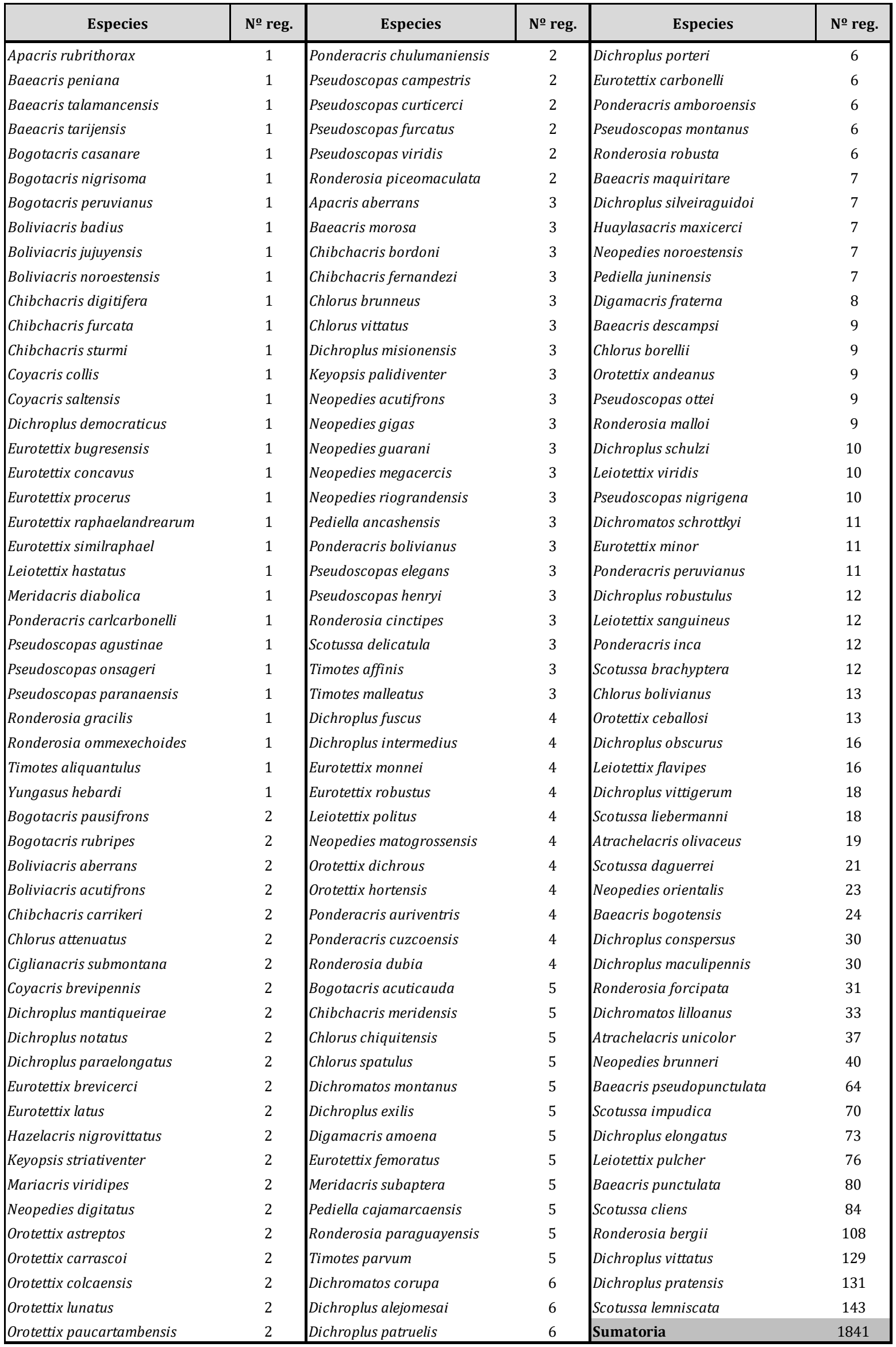


Tabla Suplementaria 5: PAM de las especies

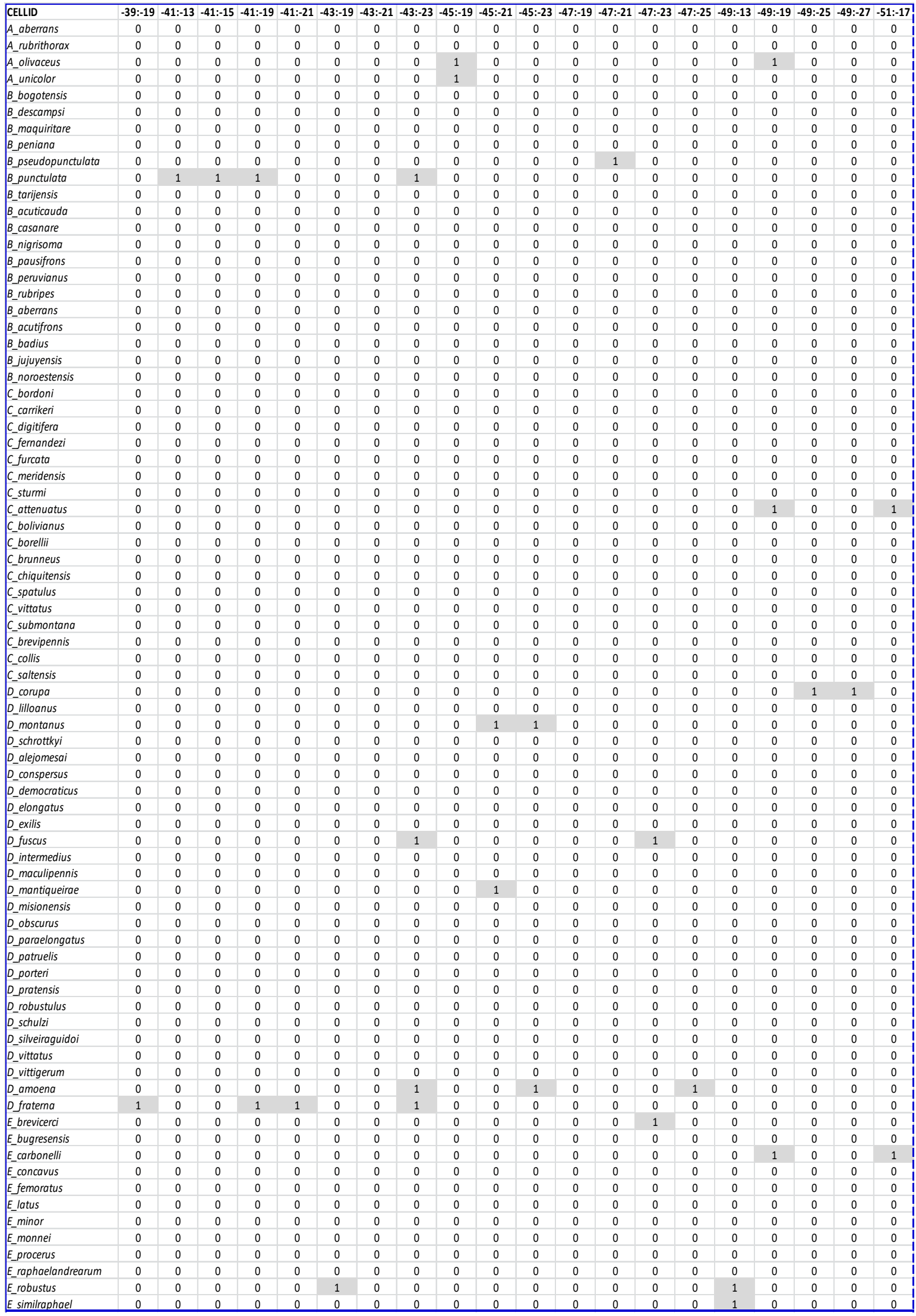


Tabla Suplementaria 5 Continuación:

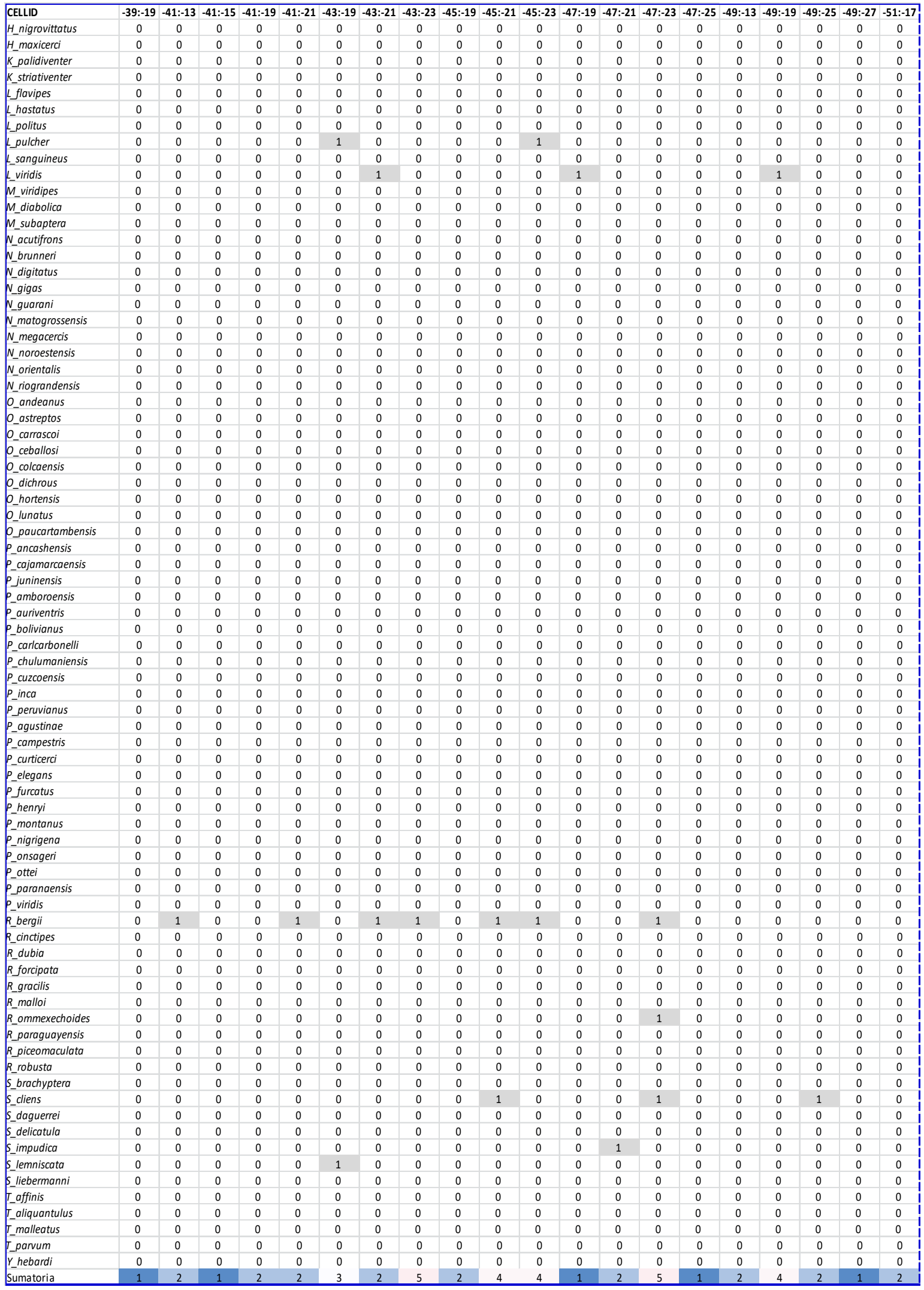


Tabla Suplementaria 5 Continuación:

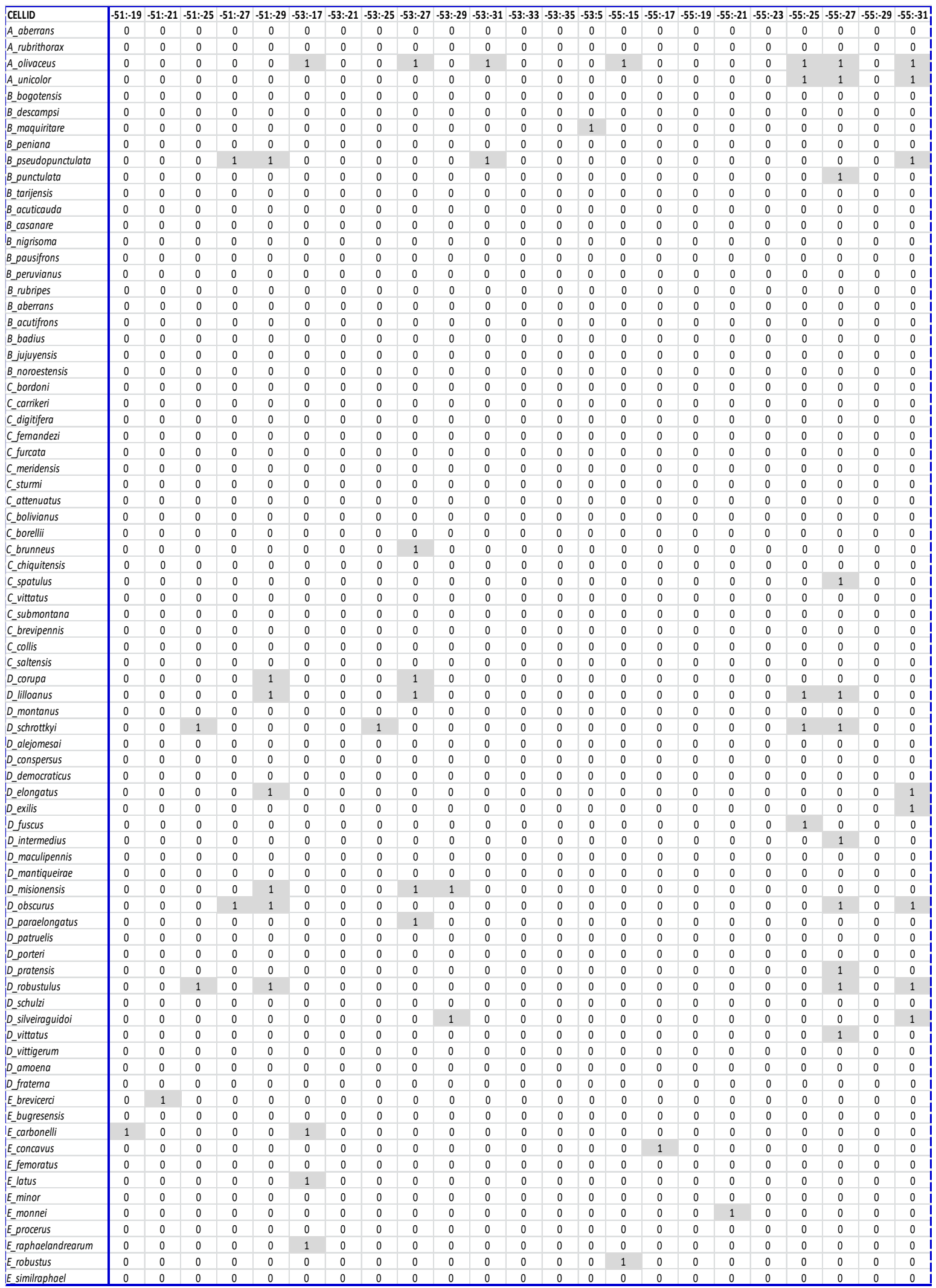


Tabla Suplementaria 5 Continuación:

\begin{tabular}{|c|c|c|c|c|c|c|c|c|c|c|c|c|c|c|c|c|c|c|c|}
\hline CELLID & |-51:-19 & $-51:-21$ & - $-51:-25$ & $-51:-27$ & $-51:-29$ & $-53:-17$ & $-53:-21$ & $-53:-25$ & $-53:-27$ & $-53:-29$ & $-53:-31$ & $-53:-33$ & $-53:-35$ & $-53: 5$ & $-55:-15$ & $-55:-17$ & $-55:-19$ & $-55:-21$ & $-55:-23$ \\
\hline H_nigrovittatus & 0 & 0 & 0 & 0 & 0 & 0 & 0 & 0 & 0 & 0 & 0 & 0 & 0 & 0 & 0 & 0 & 0 & 0 & 0 \\
\hline H_maxicerci & 0 & 0 & 0 & 0 & 0 & 0 & 0 & 0 & 0 & 0 & 0 & 0 & 0 & 0 & 0 & 0 & 0 & 0 & 0 \\
\hline K_palidiventer & 0 & 0 & 0 & 0 & 0 & 0 & 0 & 0 & 0 & 0 & 0 & 0 & 0 & 0 & 0 & 0 & 0 & 0 & 0 \\
\hline K_striativenter & 0 & 0 & 0 & 0 & 0 & 0 & 0 & 0 & 0 & 0 & 0 & 0 & 0 & 0 & 0 & 0 & 0 & 0 & 0 \\
\hline Lflavipes & 0 & 0 & 1 & 0 & 1 & 0 & 0 & 0 & 1 & 0 & 1 & 0 & 0 & 0 & 0 & 0 & 0 & 0 & 0 \\
\hline L_hastatus & 0 & 0 & 0 & 0 & 0 & 0 & 0 & 0 & 0 & 0 & 0 & 0 & 0 & 0 & 0 & 0 & 0 & 0 & 0 \\
\hline L_politus & 0 & 0 & 0 & 0 & 0 & 0 & 0 & 0 & 0 & 0 & 0 & 1 & 0 & 0 & 0 & 0 & 0 & 0 & 0 \\
\hline L_pulcher & 0 & 0 & 1 & 0 & 1 & 0 & 1 & 0 & 1 & 1 & 1 & 0 & 0 & 0 & 1 & 0 & 0 & 0 & 0 \\
\hline L_sanguineus & 0 & 0 & 1 & 0 & 0 & 0 & 0 & 0 & 0 & 0 & 0 & 0 & 0 & 0 & 1 & 0 & 0 & 0 & 0 \\
\hline L_viridis & 0 & 0 & 0 & 0 & 0 & 0 & 0 & 0 & 1 & 0 & 0 & 0 & 0 & 0 & 1 & 0 & 1 & 0 & 0 \\
\hline M_viridipes & 0 & 0 & 0 & 0 & 0 & 0 & 0 & 0 & 0 & 0 & 0 & 0 & 0 & 0 & 0 & 0 & 0 & 0 & 0 \\
\hline M_diabolica & 0 & 0 & 0 & 0 & 0 & 0 & 0 & 0 & 0 & 0 & 0 & 0 & 0 & 0 & 0 & 0 & 0 & 0 & 0 \\
\hline M_subaptera & 0 & 0 & 0 & 0 & 0 & 0 & 0 & 0 & 0 & 0 & 0 & 0 & 0 & 0 & 0 & 0 & 0 & 0 & 0 \\
\hline N_acutifrons & 0 & 0 & 0 & 0 & 1 & 0 & 0 & 0 & 1 & 0 & 0 & 0 & 0 & 0 & 0 & 0 & 0 & 0 & 0 \\
\hline N_brunneri & 0 & 0 & 0 & 0 & 0 & 0 & 0 & 0 & 0 & 0 & 0 & 0 & 0 & 0 & 0 & 0 & 0 & 0 & 0 \\
\hline N_digitatus & 0 & 0 & 0 & 0 & 0 & 0 & 0 & 0 & 0 & 0 & 0 & 0 & 0 & 0 & 0 & 0 & 0 & 0 & 0 \\
\hline N_gigas & 0 & 0 & 0 & 0 & 0 & 0 & 0 & 0 & 0 & 0 & 0 & 0 & 0 & 0 & 0 & 0 & 0 & 0 & 0 \\
\hline N_guarani & 0 & 0 & 0 & 0 & 0 & 0 & 0 & 0 & 0 & 0 & 0 & 0 & 0 & 0 & 0 & 0 & 0 & 0 & 0 \\
\hline N_matogrossensis & 0 & 0 & 0 & 0 & 0 & 0 & 0 & 0 & 0 & 0 & 0 & 0 & 0 & 0 & 0 & 0 & 0 & 0 & 1 \\
\hline N_megacercis & 0 & 0 & 0 & 0 & 0 & 0 & 0 & 0 & 0 & 0 & 0 & 0 & 0 & 0 & 0 & 0 & 0 & 0 & 0 \\
\hline N_noroestensis & 0 & 0 & 0 & 0 & 0 & 0 & 0 & 0 & 0 & 0 & 0 & 0 & 0 & 0 & 0 & 0 & 0 & 0 & 0 \\
\hline N_orientalis & 0 & 0 & 0 & 0 & 0 & 0 & 0 & 0 & 1 & 0 & 0 & 0 & 0 & 0 & 0 & 0 & 0 & 0 & 0 \\
\hline N_riograndensis & 0 & 0 & 1 & 0 & 1 & 0 & 0 & 0 & 1 & 0 & 0 & 0 & 0 & 0 & 0 & 0 & 0 & 0 & 0 \\
\hline O_andeanus & 0 & 0 & 0 & 0 & 0 & 0 & 0 & 0 & 0 & 0 & 0 & 0 & 0 & 0 & 0 & 0 & 0 & 0 & 0 \\
\hline O_astreptos & 0 & 0 & 0 & 0 & 0 & 0 & 0 & 0 & 0 & 0 & 0 & 0 & 0 & 0 & 0 & 0 & 0 & 0 & 0 \\
\hline O_carrascoi & 0 & 0 & 0 & 0 & 0 & 0 & 0 & 0 & 0 & 0 & 0 & 0 & 0 & 0 & 0 & 0 & 0 & 0 & 0 \\
\hline O_ceballosi & 0 & 0 & 0 & 0 & 0 & 0 & 0 & 0 & 0 & 0 & 0 & 0 & 0 & 0 & 0 & 0 & 0 & 0 & 0 \\
\hline O_colcaensis & 0 & 0 & 0 & 0 & 0 & 0 & 0 & 0 & 0 & 0 & 0 & 0 & 0 & 0 & 0 & 0 & 0 & 0 & 0 \\
\hline O_dichrous & 0 & 0 & 0 & 0 & 0 & 0 & 0 & 0 & 0 & 0 & 0 & 0 & 0 & 0 & 0 & 0 & 0 & 0 & 0 \\
\hline O_hortensis & 0 & 0 & 0 & 0 & 0 & 0 & 0 & 0 & 0 & 0 & 0 & 0 & 0 & 0 & 0 & 0 & 0 & 0 & 0 \\
\hline O_lunatus & 0 & 0 & 0 & 0 & 0 & 0 & 0 & 0 & 0 & 0 & 0 & 0 & 0 & 0 & 0 & 0 & 0 & 0 & 0 \\
\hline O_paucartambensis & 0 & 0 & 0 & 0 & 0 & 0 & 0 & 0 & 0 & 0 & 0 & 0 & 0 & 0 & 0 & 0 & 0 & 0 & 0 \\
\hline P_ancashensis & 0 & 0 & 0 & 0 & 0 & 0 & 0 & 0 & 0 & 0 & 0 & 0 & 0 & 0 & 0 & 0 & 0 & 0 & 0 \\
\hline P_cajamarcaensis & 0 & 0 & 0 & 0 & 0 & 0 & 0 & 0 & 0 & 0 & 0 & 0 & 0 & 0 & 0 & 0 & 0 & 0 & 0 \\
\hline P juninensis & 0 & 0 & 0 & 0 & 0 & 0 & 0 & 0 & 0 & 0 & 0 & 0 & 0 & 0 & 0 & 0 & 0 & 0 & 0 \\
\hline P_amboroensis & 0 & 0 & 0 & 0 & 0 & 0 & 0 & 0 & 0 & 0 & 0 & 0 & 0 & 0 & 0 & 0 & 0 & 0 & 0 \\
\hline P_auriventris & 0 & 0 & 0 & 0 & 0 & 0 & 0 & 0 & 0 & 0 & 0 & 0 & 0 & 0 & 0 & 0 & 0 & 0 & 0 \\
\hline P_bolivianus & 0 & 0 & 0 & 0 & 0 & 0 & 0 & 0 & 0 & 0 & 0 & 0 & 0 & 0 & 0 & 0 & 0 & 0 & 0 \\
\hline P_carlcarbonelli & 0 & 0 & 0 & 0 & 0 & 0 & 0 & 0 & 0 & 0 & 0 & 0 & 0 & 0 & 0 & 0 & 0 & 0 & 0 \\
\hline P_chulumaniensis & 0 & 0 & 0 & 0 & 0 & 0 & 0 & 0 & 0 & 0 & 0 & 0 & 0 & 0 & 0 & 0 & 0 & 0 & 0 \\
\hline P_cuzcoensis & 0 & 0 & 0 & 0 & 0 & 0 & 0 & 0 & 0 & 0 & 0 & 0 & 0 & 0 & 0 & 0 & 0 & 0 & 0 \\
\hline P_inca & 0 & 0 & 0 & 0 & 0 & 0 & 0 & 0 & 0 & 0 & 0 & 0 & 0 & 0 & 0 & 0 & 0 & 0 & 0 \\
\hline P_peruvianus & 0 & 0 & 0 & 0 & 0 & 0 & 0 & 0 & 0 & 0 & 0 & 0 & 0 & 0 & 0 & 0 & 0 & 0 & 0 \\
\hline P_agustinae & 0 & 0 & 0 & 0 & 0 & 0 & 0 & 0 & 1 & 0 & 0 & 0 & 0 & 0 & 0 & 0 & 0 & 0 & 0 \\
\hline P_campestris & 0 & 0 & 0 & 0 & 0 & 0 & 0 & 0 & 0 & 0 & 1 & 1 & 0 & 0 & 0 & 0 & 0 & 0 & 0 \\
\hline P_curticerci & 0 & 0 & 0 & 0 & 1 & 0 & 0 & 0 & 0 & 0 & 1 & 0 & 0 & 0 & 0 & 0 & 0 & 0 & 0 \\
\hline P_elegans & 0 & 0 & 0 & 0 & 0 & 0 & 0 & 0 & 0 & 1 & 1 & 0 & 0 & 0 & 0 & 0 & 0 & 0 & 0 \\
\hline P furcatus & 0 & 0 & 1 & 0 & 0 & 0 & 0 & 0 & 0 & 0 & 0 & 0 & 0 & 0 & 0 & 0 & 0 & 0 & 0 \\
\hline P_henryi & 0 & 0 & 1 & 0 & 1 & 0 & 0 & 0 & 0 & 0 & 1 & 0 & 0 & 0 & 0 & 0 & 0 & 0 & 0 \\
\hline P_montanus & 0 & 0 & 0 & 0 & 0 & 0 & 0 & 0 & 0 & 0 & 0 & 0 & 0 & 0 & 0 & 0 & 0 & 0 & 0 \\
\hline P_nigrigena & 0 & 0 & 1 & 0 & 0 & 0 & 0 & 0 & 1 & 0 & 0 & 0 & 0 & 0 & 0 & 0 & 0 & 0 & 0 \\
\hline P_onsageri & 0 & 0 & 0 & 0 & 1 & 0 & 0 & 0 & 0 & 0 & 0 & 0 & 0 & 0 & 0 & 0 & 0 & 0 & 0 \\
\hline P_ottei & 0 & 0 & 1 & 1 & 1 & 0 & 0 & 0 & 1 & 1 & 0 & 0 & 0 & 0 & 0 & 0 & 0 & 0 & 0 \\
\hline P_paranaensis & 0 & 0 & 0 & 0 & 0 & 0 & 0 & 0 & 0 & 0 & 1 & 0 & 0 & 0 & 0 & 0 & 0 & 0 & 0 \\
\hline P_viridis & 0 & 0 & 0 & 0 & 0 & 0 & 0 & 0 & 0 & 0 & 0 & 0 & 0 & 0 & 0 & 0 & 0 & 0 & 0 \\
\hline R_bergii & 0 & 0 & 0 & 1 & 1 & 0 & 0 & 0 & 1 & 0 & 0 & 0 & 0 & 0 & 1 & 0 & 0 & 0 & 0 \\
\hline R_cinctipes & 0 & 0 & 0 & 0 & 0 & 1 & 0 & 0 & 0 & 0 & 0 & 0 & 0 & 0 & 1 & 0 & 0 & 0 & 0 \\
\hline R_dubia & 0 & 0 & 0 & 0 & 0 & 0 & 0 & 0 & 1 & 0 & 0 & 0 & 0 & 0 & 0 & 0 & 0 & 0 & 0 \\
\hline$R$ forcipata & 0 & 0 & 0 & 0 & 1 & 1 & 0 & 0 & 1 & 1 & 0 & 0 & 0 & 0 & 1 & 0 & 1 & 0 & 0 \\
\hline R_gracilis & 0 & 0 & 0 & 0 & 0 & 0 & 0 & 0 & 0 & 0 & 0 & 0 & 0 & 0 & 1 & 0 & 0 & 0 & 0 \\
\hline R_malloi & 0 & 0 & 0 & 0 & 0 & 0 & 0 & 0 & 0 & 0 & 0 & 0 & 0 & 0 & 0 & 0 & 0 & 0 & 0 \\
\hline R_ommexechoides & 0 & 0 & 0 & 0 & 0 & 0 & 0 & 0 & 0 & 0 & 0 & 0 & 0 & 0 & 0 & 0 & 0 & 0 & 0 \\
\hline R_paraguayensis & 0 & 0 & 0 & 0 & 1 & 0 & 0 & 0 & 1 & 0 & 0 & 0 & 0 & 0 & 0 & 0 & 0 & 0 & 0 \\
\hline R_piceomaculata & 0 & 0 & 0 & 0 & 1 & 0 & 0 & 0 & 0 & 0 & 0 & 0 & 0 & 0 & 0 & 0 & 0 & 0 & 0 \\
\hline R_robusta & 0 & 0 & 0 & 0 & 0 & 0 & 0 & 0 & 1 & 0 & 0 & 0 & 0 & 0 & 0 & 0 & 0 & 0 & 0 \\
\hline S_brachyptera & 0 & 0 & 0 & 0 & 0 & 0 & 0 & 0 & 0 & 0 & 0 & 0 & 0 & 0 & 1 & 0 & 0 & 0 & 0 \\
\hline S_cliens & 0 & 0 & 0 & 0 & 0 & 0 & 0 & 1 & 1 & 0 & 0 & 1 & 0 & 0 & 0 & 0 & 0 & 0 & 0 \\
\hline S_daguerrei & 0 & 0 & 0 & 0 & 0 & 0 & 0 & 0 & 0 & 0 & 0 & 0 & 0 & 0 & 0 & 0 & 0 & 0 & 0 \\
\hline S_delicatula & 0 & 0 & 0 & 0 & 0 & 0 & 0 & 0 & 0 & 0 & 0 & 0 & 0 & 0 & 0 & 0 & 0 & 0 & 0 \\
\hline S_impudica & 0 & 0 & 1 & 0 & 1 & 0 & 0 & 1 & 1 & 1 & 1 & 0 & 1 & 0 & 0 & 0 & 0 & 0 & 0 \\
\hline S_lemniscata & 0 & 0 & 0 & 0 & 1 & 0 & 0 & 0 & 0 & 0 & 1 & 1 & 0 & 0 & 0 & 0 & 0 & 0 & 0 \\
\hline S_liebermanni & 0 & 0 & 0 & 0 & 0 & 0 & 0 & 0 & 0 & 0 & 0 & 0 & 0 & 0 & 0 & 0 & 0 & 0 & 0 \\
\hline I_affinis & 0 & 0 & 0 & 0 & 0 & 0 & 0 & 0 & 0 & 0 & 0 & 0 & 0 & 0 & 0 & 0 & 0 & 0 & 0 \\
\hline T_aliquantulus & 0 & 0 & 0 & 0 & 0 & 0 & 0 & 0 & 0 & 0 & 0 & 0 & 0 & 0 & 0 & 0 & 0 & 0 & 0 \\
\hline I_malleatus & 0 & 0 & 0 & 0 & 0 & 0 & 0 & 0 & 0 & 0 & 0 & 0 & 0 & 0 & 0 & 0 & 0 & 0 & 0 \\
\hline T_parvum & 0 & 0 & 0 & 0 & 0 & 0 & 0 & 0 & 0 & 0 & 0 & 0 & 0 & 0 & 0 & 0 & 0 & 0 & 0 \\
\hline Y_hebardi & 0 & 0 & 0 & 0 & 0 & 0 & 0 & 0 & 0 & 0 & 0 & 0 & 0 & 0 & 0 & 0 & 0 & 0 & 0 \\
\hline$\underline{S u m a t o r i a}$ & 1 & 1 & 11 & 4 & 21 & 6 & 1 & 3 & 22 & 7 & 11 & 4 & 1 & 1 & 10 & 1 & 2 & 1 & 1 \\
\hline
\end{tabular}


Tabla Suplementaria 5 Continuación:

\begin{tabular}{|c|c|c|c|c|c|c|c|c|c|c|c|c|c|c|c|c|c|c|c|}
\hline CELLID & $-55:-33$ & $-55:-35$ & $-57:-15$ & $-57:-19$ & $-57:-21$ & $-57:-23$ & $-57:-25$ & $-57:-27$ & $-57:-29$ & $-57:-31$ & $-57:-33$ & $-57:-35$ & $-57:-37$ & $-57:-39$ & $-59:-15$ & $-59:-19$ & $-59:-21$ & $-59:-25$ & $-59:-27$ \\
\hline A_aberrans & 0 & 0 & 0 & 1 & 0 & 1 & 0 & 0 & 0 & 0 & 0 & 0 & 0 & 0 & 0 & 0 & 0 & 0 & 1 \\
\hline A_olivaceus & 0 & 0 & 0 & 0 & 0 & 0 & 0 & 0 & 0 & 0 & 0 & 0 & 0 & 0 & 0 & 0 & 0 & 0 & 1 \\
\hline A_unicolor & 0 & 0 & 0 & 0 & 0 & 0 & 1 & 1 & 0 & 1 & 0 & 0 & 0 & 0 & 0 & 0 & 0 & 0 & 1 \\
\hline B_descampsi & 0 & 0 & 0 & 0 & 0 & 0 & 0 & 0 & 0 & 0 & 0 & 0 & 0 & 0 & 0 & 0 & 0 & 0 & 0 \\
\hline B_maquiritare & 0 & 0 & 0 & 0 & 0 & 0 & 0 & 0 & 0 & 0 & 0 & 0 & 0 & 0 & 0 & 0 & 0 & 0 & 0 \\
\hline B_peniana & 0 & 0 & 0 & 0 & 0 & 0 & 0 & 0 & 0 & 0 & 0 & 0 & 0 & 0 & 0 & 0 & 0 & 0 & 0 \\
\hline B_tarijensis & 0 & 0 & 0 & 0 & 0 & 0 & 0 & 0 & 0 & 0 & 0 & 0 & 0 & 0 & 0 & 0 & 0 & 0 & 0 \\
\hline B_acuticauda & 0 & 0 & 0 & 0 & 0 & 0 & 0 & 0 & 0 & 0 & 0 & 0 & 0 & 0 & 0 & 0 & 0 & 0 & 0 \\
\hline B_casanare & 0 & 0 & 0 & 0 & 0 & 0 & 0 & 0 & 0 & 0 & 0 & 0 & 0 & 0 & 0 & 0 & 0 & 0 & 0 \\
\hline B_nigrisoma & 0 & 0 & 0 & 0 & 0 & 0 & 0 & 0 & 0 & 0 & 0 & 0 & 0 & 0 & 0 & 0 & 0 & 0 & 0 \\
\hline B_pausifrons & 0 & 0 & 0 & 0 & 0 & 0 & 0 & 0 & 0 & 0 & 0 & 0 & 0 & 0 & 0 & 0 & 0 & 0 & 0 \\
\hline B_peruvianus & 0 & 0 & 0 & 0 & 0 & 0 & 0 & 0 & 0 & 0 & 0 & 0 & 0 & 0 & 0 & 0 & 0 & 0 & 0 \\
\hline B_noroestensis & 0 & 0 & 0 & 0 & 0 & 0 & 0 & 0 & 0 & 0 & 0 & 0 & 0 & 0 & 0 & 0 & 0 & 0 & 0 \\
\hline C_bordoni & 0 & 0 & 0 & 0 & 0 & 0 & 0 & 0 & 0 & 0 & 0 & 0 & 0 & 0 & 0 & 0 & 0 & 0 & 0 \\
\hline C_carrikeri & 0 & 0 & 0 & 0 & 0 & 0 & 0 & 0 & 0 & 0 & 0 & 0 & 0 & 0 & 0 & 0 & 0 & 0 & 0 \\
\hline C_digitifera & 0 & 0 & 0 & 0 & 0 & 0 & 0 & 0 & 0 & 0 & 0 & 0 & 0 & 0 & 0 & 0 & 0 & 0 & 0 \\
\hline C fernandezi & 0 & 0 & 0 & 0 & 0 & 0 & 0 & 0 & 0 & 0 & 0 & 0 & 0 & 0 & 0 & 0 & 0 & 0 & 0 \\
\hline C furcata & 0 & 0 & 0 & 0 & 0 & 0 & 0 & 0 & 0 & 0 & 0 & 0 & 0 & 0 & 0 & 0 & 0 & 0 & 0 \\
\hline C_meridensis & 0 & 0 & 0 & 0 & 0 & 0 & 0 & 0 & 0 & 0 & 0 & 0 & 0 & 0 & 0 & 0 & 0 & 0 & 0 \\
\hline C_sturmi & 0 & 0 & 0 & 0 & 0 & 0 & 0 & 0 & 0 & 0 & 0 & 0 & 0 & 0 & 0 & 0 & 0 & 0 & 0 \\
\hline C_attenuatus & 0 & 0 & 0 & 0 & 0 & 0 & 0 & 0 & 0 & 0 & 0 & 0 & 0 & 0 & 0 & 0 & 0 & 0 & 0 \\
\hline C_bolivianus & 0 & 0 & 0 & 0 & 0 & 0 & 0 & 0 & 0 & 0 & 0 & 0 & 0 & 0 & 0 & 1 & 0 & 0 & 0 \\
\hline C_borellii & 0 & 0 & 0 & 0 & 0 & 1 & 1 & 1 & 0 & 0 & 0 & 0 & 0 & 0 & 0 & 0 & 1 & 0 & 0 \\
\hline C_brunneus & 0 & 0 & 0 & 1 & 0 & 0 & 0 & 0 & 0 & 0 & 0 & 0 & 0 & 0 & 0 & 0 & 0 & 0 & 0 \\
\hline C_chiquitensis & 0 & 0 & 0 & 0 & 0 & 0 & 0 & 0 & 0 & 0 & 0 & 0 & 0 & 0 & 0 & 0 & 0 & 0 & 0 \\
\hline D_schrottkyi & 0 & 0 & 0 & 0 & 0 & 0 & 0 & 0 & 0 & 0 & 0 & 0 & 0 & 0 & 0 & 0 & 0 & 0 & 0 \\
\hline D_alejomesai & 0 & 0 & 0 & 0 & 0 & 0 & 0 & 0 & 0 & 0 & 0 & 0 & 0 & 0 & 0 & 0 & 0 & 0 & 0 \\
\hline D_conspersus & 0 & 0 & 0 & 0 & 0 & 0 & 0 & 0 & 0 & 1 & 1 & 0 & 0 & 0 & 0 & 0 & 0 & 0 & 1 \\
\hline D_democraticus & 0 & 0 & 0 & 0 & 0 & 0 & 0 & 0 & 0 & 0 & 0 & 0 & 0 & 0 & 0 & 0 & 0 & 0 & 0 \\
\hline D_elongatus & 0 & 0 & 0 & 0 & 0 & 0 & 0 & 0 & 0 & 0 & 1 & 1 & 0 & 0 & 0 & 0 & 0 & 0 & 0 \\
\hline D_exilis & 0 & 0 & 0 & 0 & 0 & 0 & 0 & 0 & 0 & 0 & 0 & 0 & 0 & 0 & 0 & 0 & 0 & 0 & 1 \\
\hline D fuscus & 0 & 0 & 0 & 0 & 0 & 0 & 0 & 0 & 0 & 0 & 0 & 0 & 0 & 0 & 0 & 0 & 0 & 0 & 1 \\
\hline D_intermedius & 0 & 0 & 0 & 0 & 0 & 0 & 0 & 0 & 0 & 0 & 0 & 0 & 0 & 0 & 0 & 0 & 0 & 0 & 0 \\
\hline D_maculipennis & 0 & 0 & 0 & 0 & 0 & 0 & 0 & 0 & 0 & 0 & 1 & 0 & 0 & 0 & 0 & 0 & 0 & 0 & 0 \\
\hline D_mantiqueirae & 0 & 0 & 0 & 0 & 0 & 0 & 0 & 0 & 0 & 0 & 0 & 0 & 0 & 0 & 0 & 0 & 0 & 0 & 0 \\
\hline D_misionensis & 0 & 0 & 0 & 0 & 0 & 0 & 0 & 0 & 0 & 0 & 0 & 0 & 0 & 0 & 0 & 0 & 0 & 0 & 0 \\
\hline D_obscurus & 1 & 0 & 0 & 1 & 0 & 0 & 0 & 0 & 0 & 1 & 0 & 0 & 0 & 0 & 0 & 0 & 0 & 0 & 1 \\
\hline D_paraelongatus & 0 & 0 & 0 & 0 & 0 & 0 & 0 & 0 & 0 & 0 & 0 & 0 & 0 & 0 & 0 & 0 & 0 & 0 & 0 \\
\hline D_patruelis & 0 & 1 & 0 & 0 & 0 & 0 & 0 & 0 & 0 & 1 & 0 & 1 & 0 & 0 & 0 & 0 & 0 & 0 & 0 \\
\hline D_porteri & 0 & 0 & 0 & 0 & 0 & 0 & 0 & 0 & 0 & 0 & 0 & 0 & 0 & 0 & 0 & 0 & 0 & 0 & 0 \\
\hline D_pratensis & 0 & 0 & 0 & 0 & 0 & 0 & 0 & 0 & 0 & 0 & 0 & 1 & 1 & 0 & 0 & 0 & 0 & 0 & 0 \\
\hline D_robustulus & 0 & 0 & 0 & 0 & 0 & 0 & 0 & 0 & 0 & 1 & 0 & 0 & 0 & 0 & 0 & 0 & 0 & 0 & 0 \\
\hline D_schulzi & 0 & 0 & 0 & 0 & 0 & 0 & 0 & 0 & 0 & 0 & 0 & 0 & 0 & 0 & 0 & 0 & 0 & 0 & 1 \\
\hline D_silveiraguidoi & 0 & 0 & 0 & 0 & 0 & 0 & 0 & 0 & 0 & 1 & 0 & 0 & 0 & 0 & 0 & 0 & 0 & 0 & 0 \\
\hline D_vittatus & 0 & 0 & 0 & 0 & 0 & 0 & 0 & 0 & 0 & 0 & 0 & 0 & 0 & 0 & 0 & 0 & 0 & 0 & 0 \\
\hline D_vittigerum & 0 & 0 & 0 & 0 & 0 & 0 & 0 & 0 & 0 & 0 & 0 & 0 & 0 & 0 & 0 & 0 & 0 & 0 & 0 \\
\hline D_amoena & 0 & 0 & 0 & 0 & 0 & 0 & 0 & 0 & 0 & 0 & 0 & 0 & 0 & 0 & 0 & 0 & 0 & 0 & 0 \\
\hline D fraterna & 0 & 0 & 0 & 0 & 0 & 0 & 0 & 0 & 0 & 0 & 0 & 0 & 0 & 0 & 0 & 0 & 0 & 0 & 0 \\
\hline E_brevicerci & 0 & 0 & 0 & 0 & 0 & 0 & 0 & 0 & 0 & 0 & 0 & 0 & 0 & 0 & 0 & 0 & 0 & 0 & 0 \\
\hline E_bugresensis & 0 & 0 & 1 & 0 & 0 & 0 & 0 & 0 & 0 & 0 & 0 & 0 & 0 & 0 & 0 & 0 & 0 & 0 & 0 \\
\hline E_carbonelli & 0 & 0 & 0 & 0 & 0 & 0 & 0 & 0 & 0 & 0 & 0 & 0 & 0 & 0 & 0 & 0 & 0 & 0 & 0 \\
\hline
\end{tabular}


Tabla Suplementaria 5 Continuación:

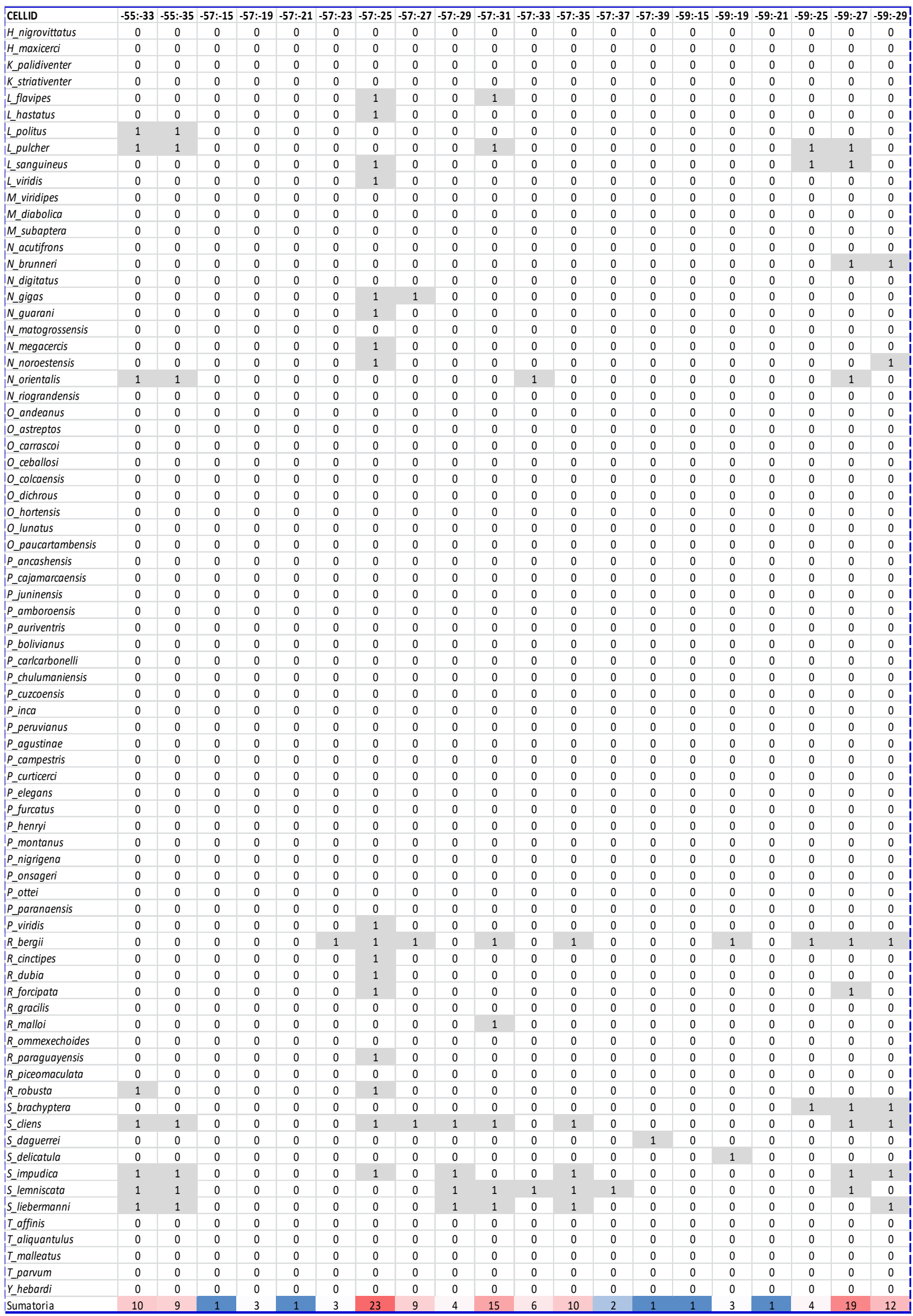


Tabla Suplementaria 5 Continuación:

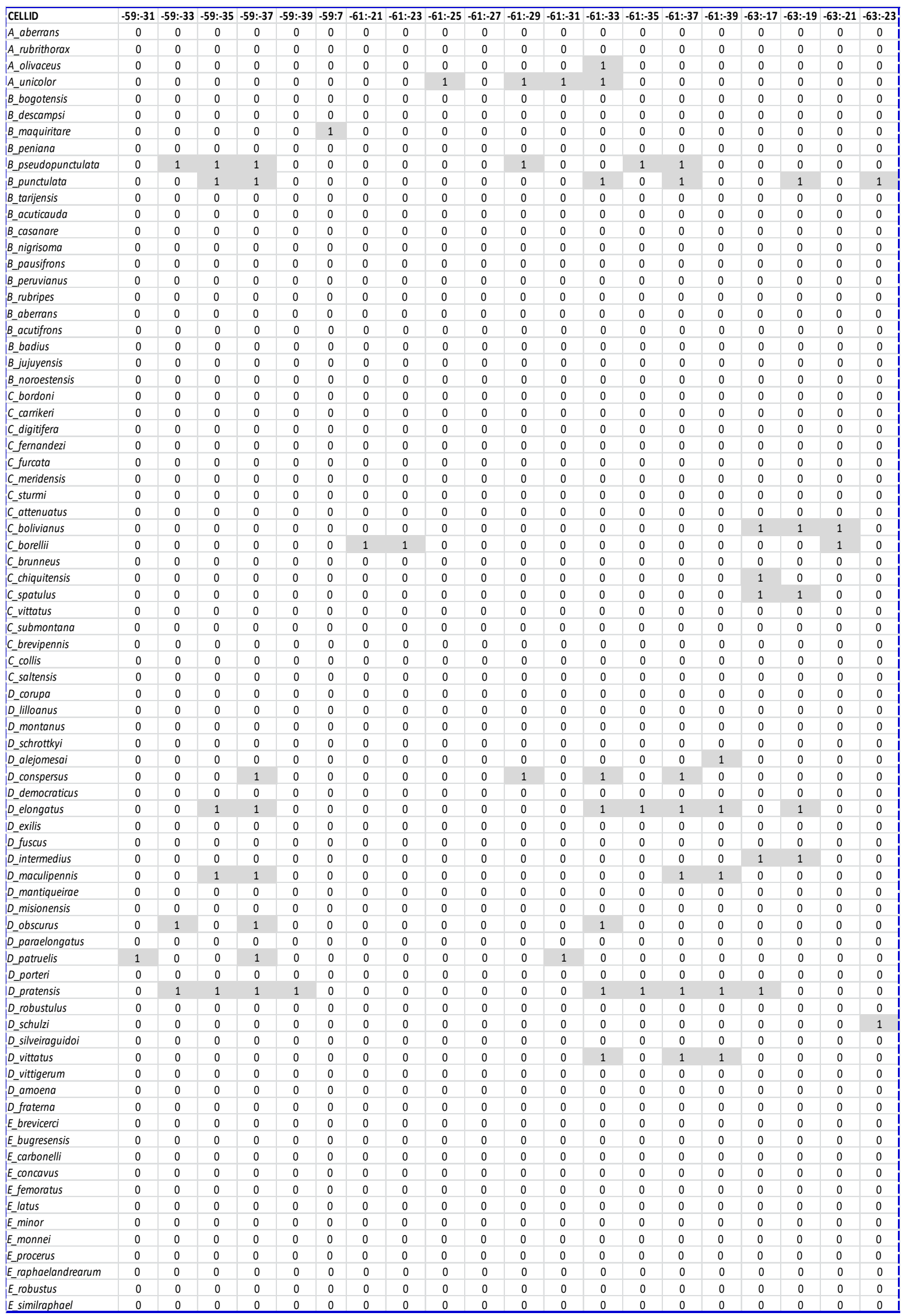


Tabla Suplementaria 5 Continuación:

\begin{tabular}{|c|c|c|c|c|c|c|c|c|c|c|c|c|c|c|c|c|c|c|c|}
\hline CELLID & $-59:-31$ & $-59:-33$ & $-59:-35$ & $-59:-37$ & $-59:-39$ & $-59: 7$ & $-61:-21$ & $-61:-23$ & $-61:-25$ & $-61:-27$ & $-61:-29$ & $-61:-31$ & $-61:-33$ & $-61:-35$ & $-61:-37$ & $-61:-39$ & $-63:-17$ & $\mid-63:-19$ & $-63:-21$ \\
\hline H_nigrovittatus & 0 & 0 & 0 & 0 & 0 & 0 & 0 & 0 & 0 & 0 & 0 & 0 & 0 & 0 & 0 & 0 & 0 & 0 & 0 \\
\hline K_palidiventer & 0 & 0 & 0 & 0 & 0 & 0 & 0 & 0 & 0 & 0 & 0 & 0 & 0 & 0 & 0 & 0 & 0 & 0 & 0 \\
\hline L_hastatus & 0 & 0 & 0 & 0 & 0 & 0 & 0 & 0 & 0 & 0 & 0 & 0 & 0 & 0 & 0 & 0 & 0 & 0 & 0 \\
\hline L_politus & 0 & 0 & 0 & 0 & 0 & 0 & 0 & 0 & 0 & 0 & 0 & 0 & 0 & 0 & 0 & 0 & 0 & 0 & 0 \\
\hline L_pulcher & 0 & 1 & 1 & 1 & 0 & 0 & 0 & 0 & 1 & 1 & 0 & 0 & 1 & 1 & 1 & 1 & 0 & 0 & 0 \\
\hline M_viridipes & 0 & 0 & 0 & 0 & 0 & 0 & 0 & 0 & 0 & 0 & 0 & 0 & 0 & 0 & 0 & 0 & 0 & 0 & 0 \\
\hline M_diabolica & 0 & 0 & 0 & 0 & 0 & 0 & 0 & 0 & 0 & 0 & 0 & 0 & 0 & 0 & 0 & 0 & 0 & 0 & 0 \\
\hline M_subaptera & 0 & 0 & 0 & 0 & 0 & 0 & 0 & 0 & 0 & 0 & 0 & 0 & 0 & 0 & 0 & 0 & 0 & 0 & 0 \\
\hline N_acutifrons & 0 & 0 & 0 & 0 & 0 & 0 & 0 & 0 & 0 & 0 & 0 & 0 & 0 & 0 & 0 & 0 & 0 & 0 & 0 \\
\hline N_brunneri & 0 & 0 & 1 & 0 & 0 & 0 & 0 & 0 & 0 & 0 & 0 & 1 & 1 & 0 & 0 & 1 & 0 & 0 & 0 \\
\hline N_digitatus & 0 & 0 & 0 & 0 & 0 & 0 & 0 & 0 & 0 & 0 & 0 & 0 & 0 & 0 & 0 & 0 & 0 & 0 & 0 \\
\hline N_orientalis & 1 & 1 & 0 & 0 & 0 & 0 & 0 & 0 & 0 & 0 & 0 & 1 & 0 & 0 & 0 & 0 & 0 & 0 & 0 \\
\hline N_riograndensis & 0 & 0 & 0 & 0 & 0 & 0 & 0 & 0 & 0 & 0 & 0 & 0 & 0 & 0 & 0 & 0 & 0 & 0 & 0 \\
\hline O_andeanus & 0 & 0 & 0 & 0 & 0 & 0 & 0 & 0 & 0 & 0 & 0 & 0 & 0 & 0 & 0 & 0 & 0 & 0 & 0 \\
\hline O_astreptos & 0 & 0 & 0 & 0 & 0 & 0 & 0 & 0 & 0 & 0 & 0 & 0 & 0 & 0 & 0 & 0 & 0 & 0 & 0 \\
\hline O_carrascoi & 0 & 0 & 0 & 0 & 0 & 0 & 0 & 0 & 0 & 0 & 0 & 0 & 0 & 0 & 0 & 0 & 0 & 0 & 0 \\
\hline O_ceballosi & 0 & 0 & 0 & 0 & 0 & 0 & 0 & 0 & 0 & 0 & 0 & 0 & 0 & 0 & 0 & 0 & 0 & 0 & 0 \\
\hline O_colcaensis & 0 & 0 & 0 & 0 & 0 & 0 & 0 & 0 & 0 & 0 & 0 & 0 & 0 & 0 & 0 & 0 & 0 & 0 & 0 \\
\hline O_dichrous & 0 & 0 & 0 & 0 & 0 & 0 & 0 & 0 & 0 & 0 & 0 & 0 & 0 & 0 & 0 & 0 & 0 & 0 & 0 \\
\hline O_hortensis & 0 & 0 & 0 & 0 & 0 & 0 & 0 & 0 & 0 & 0 & 0 & 0 & 0 & 0 & 0 & 0 & 0 & 0 & 0 \\
\hline O_lunatus & 0 & 0 & 0 & 0 & 0 & 0 & 0 & 0 & 0 & 0 & 0 & 0 & 0 & 0 & 0 & 0 & 0 & 0 & 0 \\
\hline O_paucartambensis & 0 & 0 & 0 & 0 & 0 & 0 & 0 & 0 & 0 & 0 & 0 & 0 & 0 & 0 & 0 & 0 & 0 & 0 & 0 \\
\hline P_ancashensis & 0 & 0 & 0 & 0 & 0 & 0 & 0 & 0 & 0 & 0 & 0 & 0 & 0 & 0 & 0 & 0 & 0 & 0 & 0 \\
\hline P_cajamarcaensis & 0 & 0 & 0 & 0 & 0 & 0 & 0 & 0 & 0 & 0 & 0 & 0 & 0 & 0 & 0 & 0 & 0 & 0 & 0 \\
\hline P_peruvianus & 0 & 0 & 0 & 0 & 0 & 0 & 0 & 0 & 0 & 0 & 0 & 0 & 0 & 0 & 0 & 0 & 0 & 0 & 0 \\
\hline P_agustinae & 0 & 0 & 0 & 0 & 0 & 0 & 0 & 0 & 0 & 0 & 0 & 0 & 0 & 0 & 0 & 0 & 0 & 0 & 0 \\
\hline P_campestris & 0 & 0 & 0 & 0 & 0 & 0 & 0 & 0 & 0 & 0 & 0 & 0 & 0 & 0 & 0 & 0 & 0 & 0 & 0 \\
\hline P_curticerci & 0 & 0 & 0 & 0 & 0 & 0 & 0 & 0 & 0 & 0 & 0 & 0 & 0 & 0 & 0 & 0 & 0 & 0 & 0 \\
\hline P_elegans & 0 & 0 & 0 & 0 & 0 & 0 & 0 & 0 & 0 & 0 & 0 & 0 & 0 & 0 & 0 & 0 & 0 & 0 & 0 \\
\hline$P$ furcatus & 0 & 0 & 0 & 0 & 0 & 0 & 0 & 0 & 0 & 0 & 0 & 0 & 0 & 0 & 0 & 0 & 0 & 0 & 0 \\
\hline P_henryi & 0 & 0 & 0 & 0 & 0 & 0 & 0 & 0 & 0 & 0 & 0 & 0 & 0 & 0 & 0 & 0 & 0 & 0 & 0 \\
\hline P_montanus & 0 & 0 & 0 & 0 & 0 & 0 & 0 & 0 & 0 & 0 & 0 & 0 & 0 & 0 & 0 & 0 & 0 & 0 & 0 \\
\hline P_nigrigena & 0 & 0 & 0 & 0 & 0 & 0 & 0 & 0 & 0 & 0 & 0 & 0 & 0 & 0 & 0 & 0 & 0 & 0 & 0 \\
\hline P_onsageri & 0 & 0 & 0 & 0 & 0 & 0 & 0 & 0 & 0 & 0 & 0 & 0 & 0 & 0 & 0 & 0 & 0 & 0 & 0 \\
\hline P_ottei & 0 & 0 & 0 & 0 & 0 & 0 & 0 & 0 & 0 & 0 & 0 & 0 & 0 & 0 & 0 & 0 & 0 & 0 & 0 \\
\hline P_paranaensis & 0 & 0 & 0 & 0 & 0 & 0 & 0 & 0 & 0 & 0 & 0 & 0 & 0 & 0 & 0 & 0 & 0 & 0 & 0 \\
\hline P_viridis & 0 & 0 & 0 & 0 & 0 & 0 & 0 & 0 & 0 & 0 & 0 & 0 & 0 & 0 & 0 & 0 & 0 & 0 & 0 \\
\hline R_bergii & 1 & 1 & 1 & 1 & 0 & 0 & 0 & 0 & 1 & 1 & 0 & 0 & 1 & 1 & 1 & 0 & 0 & 1 & 0 \\
\hline$R_{\text {_cinctipes }}$ & 0 & 0 & 0 & 0 & 0 & 0 & 0 & 0 & 0 & 0 & 0 & 0 & 0 & 0 & 0 & 0 & 0 & 0 & 0 \\
\hline R_dubia & 0 & 0 & 0 & 0 & 0 & 0 & 0 & 0 & 0 & 0 & 0 & 0 & 0 & 0 & 0 & 0 & 0 & 0 & 0 \\
\hline$R$ forcipata & 1 & 0 & 0 & 0 & 0 & 0 & 0 & 0 & 0 & 0 & 0 & 1 & 0 & 0 & 0 & 1 & 0 & 0 & 0 \\
\hline R_gracilis & 0 & 0 & 0 & 0 & 0 & 0 & 0 & 0 & 0 & 0 & 0 & 0 & 0 & 0 & 0 & 0 & 0 & 0 & 0 \\
\hline R_malloi & 0 & 0 & 0 & 0 & 0 & 0 & 0 & 0 & 0 & 0 & 0 & 0 & 1 & 0 & 0 & 0 & 0 & 0 & 0 \\
\hline R_ommexechoides & 0 & 0 & 0 & 0 & 0 & 0 & 0 & 0 & 0 & 0 & 0 & 0 & 0 & 0 & 0 & 0 & 0 & 0 & 0 \\
\hline R_paraguayensis & 0 & 0 & 0 & 0 & 0 & 0 & 0 & 0 & 0 & 0 & 0 & 0 & 0 & 0 & 0 & 0 & 0 & 0 & 0 \\
\hline R_piceomaculata & 0 & 0 & 0 & 0 & 0 & 0 & 0 & 0 & 0 & 0 & 0 & 0 & 0 & 0 & 0 & 0 & 0 & 0 & 0 \\
\hline R_robusta & 0 & 0 & 0 & 0 & 0 & 0 & 0 & 0 & 0 & 0 & 0 & 0 & 0 & 0 & 0 & 0 & 0 & 0 & 0 \\
\hline S_brachyptera & 0 & 0 & 0 & 0 & 0 & 0 & 0 & 0 & 0 & 0 & 0 & 0 & 0 & 0 & 0 & 0 & 0 & 0 & 0 \\
\hline S_cliens & 1 & 1 & 1 & 1 & 0 & 0 & 0 & 0 & 0 & 0 & 0 & 1 & 1 & 1 & 0 & 1 & 0 & 0 & 0 \\
\hline S_daguerrei & 0 & 0 & 0 & 1 & 0 & 0 & 0 & 0 & 0 & 0 & 0 & 0 & 0 & 0 & 1 & 1 & 0 & 0 & 0 \\
\hline
\end{tabular}


Tabla Suplementaria 5 Continuación:

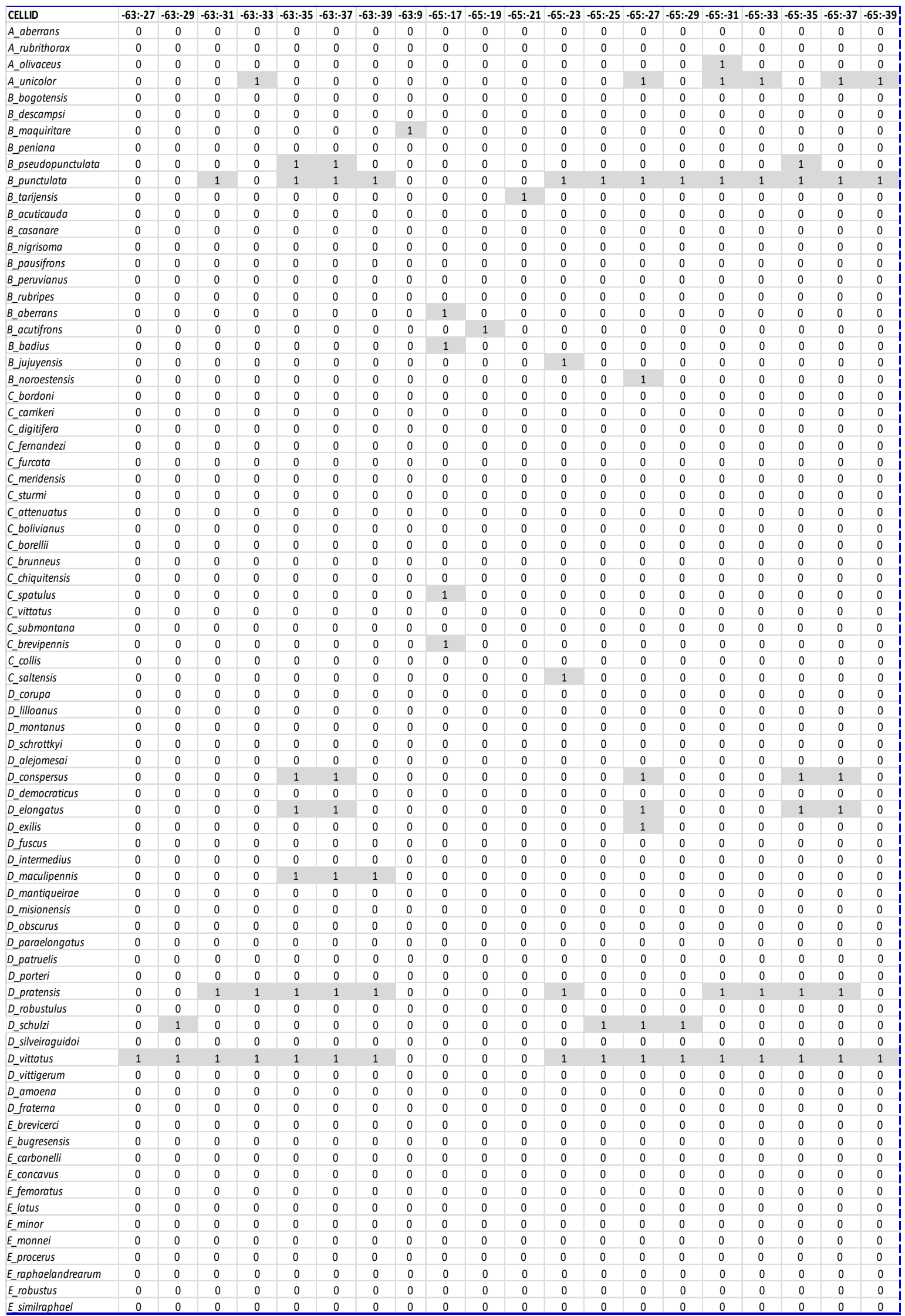


Tabla Suplementaria 5 Continuación:

\begin{tabular}{|c|c|c|c|c|c|c|c|c|c|c|c|c|c|c|c|c|c|c|c|}
\hline CELLID & $-63:-27$ & $-63:-29$ & $-63:-31$ & $-63:-33$ & $-63:-35$ & $-63:-37$ & $-63:-39$ & $-63: 9$ & $-65:-17$ & $-65:-19$ & $-65:-21$ & $-65:-23$ & $-65:-25$ & $-65:-27$ & $-65:-29$ & $-65:-31$ & $-65:-33$ & $-65:-35$ & $-65:-37$ \\
\hline H_nigrovittatus & 0 & 0 & 0 & 0 & 0 & 0 & 0 & 0 & 0 & 0 & 0 & 0 & 0 & 0 & 0 & 0 & 0 & 0 & 0 \\
\hline H_maxicerci & 0 & 0 & 0 & 0 & 0 & 0 & 0 & 0 & 0 & 0 & 0 & 0 & 0 & 0 & 0 & 0 & 0 & 0 & 0 \\
\hline K_palidiventer & 0 & 0 & 0 & 0 & 0 & 0 & 0 & 0 & 1 & 0 & 0 & 0 & 0 & 0 & 0 & 0 & 0 & 0 & 0 \\
\hline K_striativenter & 0 & 0 & 0 & 0 & 0 & 0 & 0 & 0 & 1 & 0 & 0 & 0 & 0 & 0 & 0 & 0 & 0 & 0 & 0 \\
\hline$L$ flavipes & 0 & 0 & 0 & 0 & 0 & 0 & 1 & 0 & 0 & 0 & 0 & 0 & 0 & 0 & 0 & 0 & 0 & 0 & 0 \\
\hline L_hastatus & 0 & 0 & 0 & 0 & 0 & 0 & 0 & 0 & 0 & 0 & 0 & 0 & 0 & 0 & 0 & 0 & 0 & 0 & 0 \\
\hline L_politus & 0 & 0 & 0 & 0 & 0 & 0 & 0 & 0 & 0 & 0 & 0 & 0 & 0 & 0 & 0 & 0 & 0 & 0 & 0 \\
\hline L_pulcher & 0 & 0 & 0 & 0 & 0 & 1 & 1 & 0 & 0 & 0 & 0 & 0 & 0 & 1 & 0 & 1 & 0 & 0 & 0 \\
\hline L_sanguineus & 0 & 0 & 0 & 0 & 0 & 0 & 0 & 0 & 0 & 0 & 0 & 0 & 0 & 1 & 0 & 0 & 0 & 0 & 0 \\
\hline L_viridis & 0 & 0 & 0 & 0 & 0 & 0 & 0 & 0 & 0 & 0 & 0 & 0 & 0 & 0 & 0 & 0 & 0 & 0 & 0 \\
\hline M_viridipes & 0 & 0 & 0 & 0 & 0 & 0 & 0 & 0 & 0 & 0 & 0 & 0 & 1 & 0 & 0 & 0 & 0 & 0 & 0 \\
\hline M_diabolica & 0 & 0 & 0 & 0 & 0 & 0 & 0 & 0 & 0 & 0 & 0 & 0 & 0 & 0 & 0 & 0 & 0 & 0 & 0 \\
\hline M_subaptera & 0 & 0 & 0 & 0 & 0 & 0 & 0 & 0 & 0 & 0 & 0 & 0 & 0 & 0 & 0 & 0 & 0 & 0 & 0 \\
\hline N_acutifrons & 0 & 0 & 0 & 0 & 0 & 0 & 0 & 0 & 0 & 0 & 0 & 0 & 0 & 0 & 0 & 0 & 0 & 0 & 0 \\
\hline N_brunneri & 0 & 0 & 0 & 1 & 1 & 1 & 0 & 0 & 0 & 0 & 0 & 0 & 0 & 1 & 0 & 1 & 1 & 1 & 1 \\
\hline N_digitatus & 0 & 0 & 0 & 0 & 0 & 0 & 0 & 0 & 0 & 0 & 0 & 0 & 0 & 0 & 0 & 0 & 0 & 0 & 0 \\
\hline N_gigas & 0 & 0 & 0 & 0 & 0 & 0 & 0 & 0 & 0 & 0 & 0 & 0 & 0 & 0 & 0 & 0 & 0 & 0 & 0 \\
\hline N_guarani & 0 & 0 & 0 & 0 & 0 & 0 & 0 & 0 & 0 & 0 & 0 & 0 & 0 & 0 & 0 & 0 & 0 & 0 & 0 \\
\hline N_matogrossensis & 0 & 0 & 0 & 0 & 0 & 0 & 0 & 0 & 0 & 0 & 0 & 0 & 0 & 0 & 0 & 0 & 0 & 0 & 0 \\
\hline N_megacercis & 0 & 0 & 0 & 0 & 0 & 0 & 0 & 0 & 0 & 0 & 0 & 0 & 0 & 0 & 0 & 0 & 0 & 0 & 0 \\
\hline N_noroestensis & 0 & 0 & 0 & 0 & 0 & 0 & 0 & 0 & 0 & 0 & 0 & 0 & 1 & 1 & 0 & 0 & 0 & 0 & 0 \\
\hline N_orientalis & 0 & 0 & 0 & 0 & 0 & 0 & 0 & 0 & 0 & 0 & 0 & 0 & 0 & 0 & 0 & 0 & 0 & 0 & 0 \\
\hline N_riograndensis & 0 & 0 & 0 & 0 & 0 & 0 & 0 & 0 & 0 & 0 & 0 & 0 & 0 & 0 & 0 & 0 & 0 & 0 & 0 \\
\hline O_andeanus & 0 & 0 & 0 & 0 & 0 & 0 & 0 & 0 & 0 & 0 & 0 & 0 & 0 & 0 & 0 & 0 & 0 & 0 & 0 \\
\hline O_astreptos & 0 & 0 & 0 & 0 & 0 & 0 & 0 & 0 & 0 & 0 & 0 & 0 & 0 & 0 & 0 & 0 & 0 & 0 & 0 \\
\hline O_carrascoi & 0 & 0 & 0 & 0 & 0 & 0 & 0 & 0 & 0 & 0 & 0 & 0 & 0 & 0 & 0 & 0 & 0 & 0 & 0 \\
\hline O_ceballosi & 0 & 0 & 0 & 0 & 0 & 0 & 0 & 0 & 0 & 0 & 0 & 0 & 0 & 0 & 0 & 0 & 0 & 0 & 0 \\
\hline O_colcaensis & 0 & 0 & 0 & 0 & 0 & 0 & 0 & 0 & 0 & 0 & 0 & 0 & 0 & 0 & 0 & 0 & 0 & 0 & 0 \\
\hline O_dichrous & 0 & 0 & 0 & 0 & 0 & 0 & 0 & 0 & 0 & 0 & 0 & 0 & 0 & 0 & 0 & 0 & 0 & 0 & 0 \\
\hline O_hortensis & 0 & 0 & 0 & 0 & 0 & 0 & 0 & 0 & 0 & 0 & 0 & 0 & 0 & 0 & 0 & 0 & 0 & 0 & 0 \\
\hline O_lunatus & 0 & 0 & 0 & 0 & 0 & 0 & 0 & 0 & 0 & 0 & 0 & 0 & 0 & 0 & 0 & 0 & 0 & 0 & 0 \\
\hline O_paucartambensis & 0 & 0 & 0 & 0 & 0 & 0 & 0 & 0 & 0 & 0 & 0 & 0 & 0 & 0 & 0 & 0 & 0 & 0 & 0 \\
\hline P_ancashensis & 0 & 0 & 0 & 0 & 0 & 0 & 0 & 0 & 0 & 0 & 0 & 0 & 0 & 0 & 0 & 0 & 0 & 0 & 0 \\
\hline P_cajamarcaensis & 0 & 0 & 0 & 0 & 0 & 0 & 0 & 0 & 0 & 0 & 0 & 0 & 0 & 0 & 0 & 0 & 0 & 0 & 0 \\
\hline$P$ juninensis & 0 & 0 & 0 & 0 & 0 & 0 & 0 & 0 & 0 & 0 & 0 & 0 & 0 & 0 & 0 & 0 & 0 & 0 & 0 \\
\hline P_amboroensis & 0 & 0 & 0 & 0 & 0 & 0 & 0 & 0 & 0 & 0 & 0 & 0 & 0 & 0 & 0 & 0 & 0 & 0 & 0 \\
\hline P_auriventris & 0 & 0 & 0 & 0 & 0 & 0 & 0 & 0 & 0 & 0 & 0 & 0 & 0 & 0 & 0 & 0 & 0 & 0 & 0 \\
\hline P_bolivianus & 0 & 0 & 0 & 0 & 0 & 0 & 0 & 0 & 1 & 0 & 0 & 0 & 0 & 0 & 0 & 0 & 0 & 0 & 0 \\
\hline P_carlcarbonelli & 0 & 0 & 0 & 0 & 0 & 0 & 0 & 0 & 0 & 0 & 0 & 0 & 0 & 0 & 0 & 0 & 0 & 0 & 0 \\
\hline P_chulumaniensis & 0 & 0 & 0 & 0 & 0 & 0 & 0 & 0 & 0 & 0 & 0 & 0 & 0 & 0 & 0 & 0 & 0 & 0 & 0 \\
\hline P_cuzcoensis & 0 & 0 & 0 & 0 & 0 & 0 & 0 & 0 & 0 & 0 & 0 & 0 & 0 & 0 & 0 & 0 & 0 & 0 & 0 \\
\hline P_inca & 0 & 0 & 0 & 0 & 0 & 0 & 0 & 0 & 1 & 0 & 0 & 0 & 0 & 0 & 0 & 0 & 0 & 0 & 0 \\
\hline P_peruvianus & 0 & 0 & 0 & 0 & 0 & 0 & 0 & 0 & 0 & 0 & 0 & 0 & 0 & 0 & 0 & 0 & 0 & 0 & 0 \\
\hline P_agustinae & 0 & 0 & 0 & 0 & 0 & 0 & 0 & 0 & 0 & 0 & 0 & 0 & 0 & 0 & 0 & 0 & 0 & 0 & 0 \\
\hline P_campestris & 0 & 0 & 0 & 0 & 0 & 0 & 0 & 0 & 0 & 0 & 0 & 0 & 0 & 0 & 0 & 0 & 0 & 0 & 0 \\
\hline P_curticerci & 0 & 0 & 0 & 0 & 0 & 0 & 0 & 0 & 0 & 0 & 0 & 0 & 0 & 0 & 0 & 0 & 0 & 0 & 0 \\
\hline P_elegans & 0 & 0 & 0 & 0 & 0 & 0 & 0 & 0 & 0 & 0 & 0 & 0 & 0 & 0 & 0 & 0 & 0 & 0 & 0 \\
\hline$P$ furcatus & 0 & 0 & 0 & 0 & 0 & 0 & 0 & 0 & 0 & 0 & 0 & 0 & 0 & 0 & 0 & 0 & 0 & 0 & 0 \\
\hline P_henryi & 0 & 0 & 0 & 0 & 0 & 0 & 0 & 0 & 0 & 0 & 0 & 0 & 0 & 0 & 0 & 0 & 0 & 0 & 0 \\
\hline P_montanus & 0 & 0 & 0 & 0 & 0 & 0 & 0 & 0 & 0 & 0 & 0 & 0 & 0 & 0 & 0 & 0 & 0 & 0 & 0 \\
\hline P_nigrigena & 0 & 0 & 0 & 0 & 0 & 0 & 0 & 0 & 0 & 0 & 0 & 0 & 0 & 0 & 0 & 0 & 0 & 0 & 0 \\
\hline P_onsageri & 0 & 0 & 0 & 0 & 0 & 0 & 0 & 0 & 0 & 0 & 0 & 0 & 0 & 0 & 0 & 0 & 0 & 0 & 0 \\
\hline P_ottei & 0 & 0 & 0 & 0 & 0 & 0 & 0 & 0 & 0 & 0 & 0 & 0 & 0 & 0 & 0 & 0 & 0 & 0 & 0 \\
\hline P_paranaensis & 0 & 0 & 0 & 0 & 0 & 0 & 0 & 0 & 0 & 0 & 0 & 0 & 0 & 0 & 0 & 0 & 0 & 0 & 0 \\
\hline P_viridis & 0 & 0 & 0 & 0 & 0 & 0 & 0 & 0 & 0 & 0 & 0 & 0 & 0 & 0 & 0 & 0 & 0 & 0 & 0 \\
\hline R_bergii & 0 & 0 & 0 & 1 & 0 & 1 & 0 & 0 & 0 & 0 & 0 & 0 & 1 & 1 & 0 & 1 & 1 & 1 & 1 \\
\hline R_cinctipes & 0 & 0 & 0 & 0 & 0 & 0 & 0 & 0 & 0 & 0 & 0 & 0 & 0 & 0 & 0 & 0 & 0 & 0 & 0 \\
\hline R_dubia & 0 & 0 & 0 & 0 & 0 & 0 & 0 & 0 & 0 & 0 & 0 & 0 & 0 & 0 & 0 & 0 & 0 & 0 & 0 \\
\hline$R$ forcipata & 0 & 0 & 0 & 0 & 0 & 1 & 1 & 0 & 0 & 0 & 0 & 0 & 0 & 1 & 0 & 1 & 1 & 1 & 0 \\
\hline R_gracilis & 0 & 0 & 0 & 0 & 0 & 0 & 0 & 0 & 0 & 0 & 0 & 0 & 0 & 0 & 0 & 0 & 0 & 0 & 0 \\
\hline R_malloi & 0 & 0 & 0 & 0 & 0 & 0 & 0 & 0 & 0 & 0 & 0 & 1 & 1 & 0 & 0 & 0 & 0 & 0 & 0 \\
\hline R_ommexechoides & 0 & 0 & 0 & 0 & 0 & 0 & 0 & 0 & 0 & 0 & 0 & 0 & 0 & 0 & 0 & 0 & 0 & 0 & 0 \\
\hline R_paraguayensis & 0 & 0 & 0 & 0 & 0 & 0 & 0 & 0 & 0 & 0 & 0 & 0 & 0 & 0 & 0 & 0 & 0 & 0 & 0 \\
\hline R_piceomaculata & 0 & 0 & 0 & 0 & 0 & 0 & 0 & 0 & 0 & 0 & 0 & 0 & 0 & 0 & 0 & 0 & 0 & 0 & 0 \\
\hline R_robusta & 0 & 0 & 0 & 0 & 0 & 0 & 0 & 0 & 0 & 0 & 0 & 0 & 0 & 0 & 0 & 0 & 0 & 0 & 0 \\
\hline S_brachyptera & 0 & 0 & 0 & 0 & 0 & 0 & 0 & 0 & 0 & 0 & 0 & 0 & 0 & 1 & 0 & 0 & 0 & 0 & 0 \\
\hline S_cliens & 0 & 0 & 0 & 0 & 0 & 1 & 1 & 0 & 0 & 0 & 0 & 0 & 0 & 0 & 0 & 1 & 1 & 1 & 0 \\
\hline S_daguerrei & 0 & 0 & 0 & 0 & 0 & 1 & 1 & 0 & 0 & 0 & 0 & 0 & 0 & 0 & 0 & 0 & 0 & 1 & 1 \\
\hline S_delicatula & 0 & 0 & 0 & 0 & 0 & 0 & 0 & 0 & 0 & 0 & 0 & 0 & 0 & 0 & 0 & 0 & 0 & 0 & 0 \\
\hline S_impudica & 0 & 0 & 0 & 0 & 0 & 0 & 1 & 0 & 0 & 0 & 0 & 0 & 0 & 0 & 0 & 0 & 0 & 0 & 0 \\
\hline S_lemniscata & 0 & 0 & 0 & 0 & 1 & 1 & 1 & 0 & 0 & 0 & 0 & 0 & 1 & 1 & 0 & 0 & 0 & 1 & 1 \\
\hline S_liebermanni & 0 & 0 & 0 & 0 & 0 & 0 & 0 & 0 & 0 & 0 & 0 & 0 & 0 & 0 & 0 & 0 & 0 & 0 & 0 \\
\hline T_affinis & 0 & 0 & 0 & 0 & 0 & 0 & 0 & 0 & 0 & 0 & 0 & 0 & 0 & 0 & 0 & 0 & 0 & 0 & 0 \\
\hline T_aliquantulus & 0 & 0 & 0 & 0 & 0 & 0 & 0 & 0 & 0 & 0 & 0 & 0 & 0 & 0 & 0 & 0 & 0 & 0 & 0 \\
\hline I_malleatus & 0 & 0 & 0 & 0 & 0 & 0 & 0 & 0 & 0 & 0 & 0 & 0 & 0 & 0 & 0 & 0 & 0 & 0 & 0 \\
\hline T_parvum & 0 & 0 & 0 & 0 & 0 & 0 & 0 & 0 & 0 & 0 & 0 & 0 & 0 & 0 & 0 & 0 & 0 & 0 & 0 \\
\hline Y_hebardi & 0 & 0 & 0 & 0 & 0 & 0 & 0 & 0 & 0 & 0 & 0 & 1 & 0 & 0 & 0 & 0 & 0 & 0 & 0 \\
\hline Sumatoria & 1 & 2 & 3 & 5 & 9 & 14 & 11 & 1 & 8 & 1 & 1 & 7 & 8 & 16 & 3 & 10 & 8 & 12 & 10 \\
\hline
\end{tabular}


Tabla Suplementaria 5 Continuación:

\begin{tabular}{|c|c|c|c|c|c|c|c|c|c|c|c|c|c|c|c|c|c|c|c|}
\hline CELLID & $-65:-43$ & $-65: 7$ & $-67:-17$ & $-67:-19$ & $-67:-27$ & $-67:-29$ & $-67:-31$ & $-67:-33$ & $-67:-37$ & $-67:-39$ & $-67:-45$ & $-67: 11$ & $-69:-15$ & $-69:-17$ & $-69:-29$ & $-69:-31$ & $-69:-33$ & $-69:-35$ & $-69:-39$ \\
\hline A_aberrans & 0 & 0 & 0 & 0 & 0 & 0 & 0 & 0 & 0 & 0 & 0 & 0 & 0 & 0 & 0 & 0 & 0 & 0 & 0 \\
\hline A_rubrithorax & 0 & 0 & 0 & 0 & 0 & 0 & 0 & 0 & 0 & 0 & 0 & 0 & 0 & 0 & 0 & 0 & 0 & 0 & 0 \\
\hline A_olivaceus & 0 & 0 & 0 & 0 & 0 & 0 & 0 & 0 & 0 & 0 & 0 & 0 & 0 & 0 & 0 & 0 & 0 & 0 & 0 \\
\hline A_unicolor & 0 & 0 & 0 & 0 & 0 & 0 & 0 & 1 & 0 & 0 & 0 & 0 & 0 & 0 & 0 & 0 & 0 & 0 & 0 \\
\hline B_bogotensis & 0 & 0 & 0 & 0 & 0 & 0 & 0 & 0 & 0 & 0 & 0 & 0 & 0 & 0 & 0 & 0 & 0 & 0 & 0 \\
\hline B_descampsi & 0 & 0 & 0 & 0 & 0 & 0 & 0 & 0 & 0 & 0 & 0 & 0 & 0 & 0 & 0 & 0 & 0 & 0 & 0 \\
\hline B_maquiritare & 0 & 1 & 0 & 0 & 0 & 0 & 0 & 0 & 0 & 0 & 0 & 1 & 0 & 0 & 0 & 0 & 0 & 0 & 0 \\
\hline B_peniana & 0 & 0 & 0 & 0 & 0 & 0 & 0 & 0 & 0 & 0 & 0 & 0 & 1 & 0 & 0 & 0 & 0 & 0 & 0 \\
\hline B_pseudopunctulata & 0 & 0 & 0 & 0 & 0 & 0 & 0 & 0 & 0 & 0 & 0 & 0 & 0 & 0 & 0 & 0 & 0 & 0 & 0 \\
\hline B_punctulata & 0 & 0 & 1 & 0 & 0 & 0 & 0 & 1 & 0 & 0 & 0 & 0 & 0 & 0 & 0 & 0 & 0 & 0 & 0 \\
\hline B_tarijensis & 0 & 0 & 0 & 0 & 0 & 0 & 0 & 0 & 0 & 0 & 0 & 0 & 0 & 0 & 0 & 0 & 0 & 0 & 0 \\
\hline B_acuticauda & 0 & 0 & 0 & 0 & 0 & 0 & 0 & 0 & 0 & 0 & 0 & 0 & 0 & 0 & 0 & 0 & 0 & 0 & 0 \\
\hline B_casanare & 0 & 0 & 0 & 0 & 0 & 0 & 0 & 0 & 0 & 0 & 0 & 0 & 0 & 0 & 0 & 0 & 0 & 0 & 0 \\
\hline B_nigrisoma & 0 & 0 & 0 & 0 & 0 & 0 & 0 & 0 & 0 & 0 & 0 & 0 & 0 & 0 & 0 & 0 & 0 & 0 & 0 \\
\hline B_pausifrons & 0 & 0 & 0 & 0 & 0 & 0 & 0 & 0 & 0 & 0 & 0 & 0 & 0 & 0 & 0 & 0 & 0 & 0 & 0 \\
\hline B_peruvianus & 0 & 0 & 0 & 0 & 0 & 0 & 0 & 0 & 0 & 0 & 0 & 0 & 0 & 0 & 0 & 0 & 0 & 0 & 0 \\
\hline B_rubripes & 0 & 0 & 0 & 0 & 0 & 0 & 0 & 0 & 0 & 0 & 0 & 0 & 0 & 0 & 0 & 0 & 0 & 0 & 0 \\
\hline B_aberrans & 0 & 0 & 1 & 0 & 0 & 0 & 0 & 0 & 0 & 0 & 0 & 0 & 0 & 0 & 0 & 0 & 0 & 0 & 0 \\
\hline B_acutifrons & 0 & 0 & 0 & 1 & 0 & 0 & 0 & 0 & 0 & 0 & 0 & 0 & 0 & 0 & 0 & 0 & 0 & 0 & 0 \\
\hline B_badius & 0 & 0 & 0 & 0 & 0 & 0 & 0 & 0 & 0 & 0 & 0 & 0 & 0 & 0 & 0 & 0 & 0 & 0 & 0 \\
\hline B jujuyensis & 0 & 0 & 0 & 0 & 0 & 0 & 0 & 0 & 0 & 0 & 0 & 0 & 0 & 0 & 0 & 0 & 0 & 0 & 0 \\
\hline B_noroestensis & 0 & 0 & 0 & 0 & 0 & 0 & 0 & 0 & 0 & 0 & 0 & 0 & 0 & 0 & 0 & 0 & 0 & 0 & 0 \\
\hline C_bordoni & 0 & 0 & 0 & 0 & 0 & 0 & 0 & 0 & 0 & 0 & 0 & 0 & 0 & 0 & 0 & 0 & 0 & 0 & 0 \\
\hline C_carrikeri & 0 & 0 & 0 & 0 & 0 & 0 & 0 & 0 & 0 & 0 & 0 & 0 & 0 & 0 & 0 & 0 & 0 & 0 & 0 \\
\hline C_digitifera & 0 & 0 & 0 & 0 & 0 & 0 & 0 & 0 & 0 & 0 & 0 & 0 & 0 & 0 & 0 & 0 & 0 & 0 & 0 \\
\hline C fernandezi & 0 & 0 & 0 & 0 & 0 & 0 & 0 & 0 & 0 & 0 & 0 & 0 & 0 & 0 & 0 & 0 & 0 & 0 & 0 \\
\hline C furcata & 0 & 0 & 0 & 0 & 0 & 0 & 0 & 0 & 0 & 0 & 0 & 0 & 0 & 0 & 0 & 0 & 0 & 0 & 0 \\
\hline C_meridensis & 0 & 0 & 0 & 0 & 0 & 0 & 0 & 0 & 0 & 0 & 0 & 0 & 0 & 0 & 0 & 0 & 0 & 0 & 0 \\
\hline C_sturmi & 0 & 0 & 0 & 0 & 0 & 0 & 0 & 0 & 0 & 0 & 0 & 0 & 0 & 0 & 0 & 0 & 0 & 0 & 0 \\
\hline C_attenuatus & 0 & 0 & 0 & 0 & 0 & 0 & 0 & 0 & 0 & 0 & 0 & 0 & 0 & 0 & 0 & 0 & 0 & 0 & 0 \\
\hline C_bolivianus & 0 & 0 & 0 & 0 & 0 & 0 & 0 & 0 & 0 & 0 & 0 & 0 & 0 & 0 & 0 & 0 & 0 & 0 & 0 \\
\hline C_borellii & 0 & 0 & 0 & 0 & 0 & 0 & 0 & 0 & 0 & 0 & 0 & 0 & 0 & 0 & 0 & 0 & 0 & 0 & 0 \\
\hline C_brunneus & 0 & 0 & 0 & 0 & 0 & 0 & 0 & 0 & 0 & 0 & 0 & 0 & 0 & 0 & 0 & 0 & 0 & 0 & 0 \\
\hline C_chiquitensis & 0 & 0 & 0 & 0 & 0 & 0 & 0 & 0 & 0 & 0 & 0 & 0 & 0 & 0 & 0 & 0 & 0 & 0 & 0 \\
\hline C_spatulus & 0 & 0 & 0 & 0 & 0 & 0 & 0 & 0 & 0 & 0 & 0 & 0 & 0 & 0 & 0 & 0 & 0 & 0 & 0 \\
\hline C_vittatus & 0 & 0 & 0 & 0 & 0 & 0 & 0 & 0 & 0 & 0 & 0 & 0 & 0 & 0 & 0 & 0 & 0 & 0 & 0 \\
\hline C_submontana & 0 & 0 & 0 & 0 & 0 & 0 & 0 & 0 & 0 & 0 & 0 & 0 & 0 & 0 & 0 & 0 & 0 & 0 & 0 \\
\hline C_brevipennis & 0 & 0 & 0 & 0 & 0 & 0 & 0 & 0 & 0 & 0 & 0 & 0 & 0 & 0 & 0 & 0 & 0 & 0 & 0 \\
\hline C_collis & 0 & 0 & 1 & 0 & 0 & 0 & 0 & 0 & 0 & 0 & 0 & 0 & 0 & 0 & 0 & 0 & 0 & 0 & 0 \\
\hline C_saltensis & 0 & 0 & 0 & 0 & 0 & 0 & 0 & 0 & 0 & 0 & 0 & 0 & 0 & 0 & 0 & 0 & 0 & 0 & 0 \\
\hline D_corupa & 0 & 0 & 0 & 0 & 0 & 0 & 0 & 0 & 0 & 0 & 0 & 0 & 0 & 0 & 0 & 0 & 0 & 0 & 0 \\
\hline D_lilloanus & 0 & 0 & 0 & 0 & 0 & 0 & 0 & 0 & 0 & 0 & 0 & 0 & 0 & 0 & 0 & 0 & 0 & 0 & 0 \\
\hline D_montanus & 0 & 0 & 0 & 0 & 0 & 0 & 0 & 0 & 0 & 0 & 0 & 0 & 0 & 0 & 0 & 0 & 0 & 0 & 0 \\
\hline D_schrottkyi & 0 & 0 & 0 & 0 & 0 & 0 & 0 & 0 & 0 & 0 & 0 & 0 & 0 & 0 & 0 & 0 & 0 & 0 & 0 \\
\hline D_alejomesai & 0 & 0 & 0 & 0 & 0 & 0 & 0 & 0 & 1 & 1 & 0 & 0 & 0 & 0 & 0 & 0 & 0 & 0 & 0 \\
\hline D_conspersus & 0 & 0 & 0 & 0 & 0 & 0 & 0 & 0 & 0 & 0 & 0 & 0 & 0 & 0 & 0 & 0 & 0 & 0 & 0 \\
\hline D_democraticus & 0 & 0 & 0 & 0 & 0 & 0 & 0 & 0 & 0 & 0 & 0 & 0 & 0 & 0 & 0 & 0 & 0 & 0 & 0 \\
\hline D_elongatus & 0 & 0 & 0 & 0 & 0 & 0 & 0 & 0 & 0 & 0 & 0 & 0 & 0 & 0 & 0 & 0 & 1 & 0 & 0 \\
\hline D_exilis & 0 & 0 & 0 & 0 & 0 & 0 & 0 & 0 & 0 & 0 & 0 & 0 & 0 & 0 & 0 & 0 & 0 & 0 & 0 \\
\hline Dfuscus & 0 & 0 & 0 & 0 & 0 & 0 & 0 & 0 & 0 & 0 & 0 & 0 & 0 & 0 & 0 & 0 & 0 & 0 & 0 \\
\hline D_intermedius & 0 & 0 & 0 & 0 & 0 & 0 & 0 & 0 & 0 & 0 & 0 & 0 & 0 & 0 & 0 & 0 & 0 & 0 & 0 \\
\hline D_maculipennis & 0 & 0 & 0 & 0 & 0 & 0 & 0 & 0 & 0 & 0 & 0 & 0 & 0 & 0 & 0 & 0 & 0 & 0 & 1 \\
\hline D_mantiqueirae & 0 & 0 & 0 & 0 & 0 & 0 & 0 & 0 & 0 & 0 & 0 & 0 & 0 & 0 & 0 & 0 & 0 & 0 & 0 \\
\hline D_misionensis & 0 & 0 & 0 & 0 & 0 & 0 & 0 & 0 & 0 & 0 & 0 & 0 & 0 & 0 & 0 & 0 & 0 & 0 & 0 \\
\hline D_obscurus & 0 & 0 & 0 & 0 & 0 & 0 & 0 & 0 & 0 & 0 & 0 & 0 & 0 & 0 & 0 & 0 & 0 & 0 & 0 \\
\hline D_paraelongatus & 0 & 0 & 0 & 0 & 0 & 0 & 0 & 0 & 0 & 0 & 0 & 0 & 0 & 0 & 0 & 0 & 0 & 0 & 0 \\
\hline D_patruelis & 0 & 0 & 0 & 0 & 0 & 0 & 0 & 0 & 0 & 0 & 0 & 0 & 0 & 0 & 0 & 0 & 0 & 0 & 0 \\
\hline D_porteri & 0 & 0 & 0 & 0 & 0 & 0 & 0 & 0 & 0 & 0 & 0 & 0 & 0 & 0 & 0 & 0 & 0 & 0 & 0 \\
\hline D_pratensis & 1 & 0 & 0 & 0 & 0 & 1 & 1 & 0 & 0 & 0 & 1 & 0 & 0 & 0 & 0 & 0 & 1 & 0 & 0 \\
\hline D_robustulus & 0 & 0 & 0 & 0 & 0 & 0 & 0 & 0 & 0 & 0 & 0 & 0 & 0 & 0 & 0 & 0 & 0 & 0 & 0 \\
\hline D_schulzi & 0 & 0 & 0 & 0 & 0 & 0 & 0 & 0 & 0 & 0 & 0 & 0 & 0 & 0 & 0 & 0 & 0 & 0 & 0 \\
\hline D_silveiraguidoi & 0 & 0 & 0 & 0 & 0 & 0 & 0 & 0 & 0 & 0 & 0 & 0 & 0 & 0 & 0 & 0 & 0 & 0 & 0 \\
\hline D_vittatus & 1 & 0 & 0 & 0 & 1 & 1 & 1 & 0 & 1 & 1 & 1 & 0 & 0 & 0 & 1 & 1 & 1 & 1 & 0 \\
\hline D_vittigerum & 0 & 0 & 0 & 0 & 0 & 0 & 0 & 0 & 0 & 0 & 0 & 0 & 0 & 0 & 0 & 0 & 0 & 0 & 0 \\
\hline D_amoena & 0 & 0 & 0 & 0 & 0 & 0 & 0 & 0 & 0 & 0 & 0 & 0 & 0 & 0 & 0 & 0 & 0 & 0 & 0 \\
\hline D fraterna & 0 & 0 & 0 & 0 & 0 & 0 & 0 & 0 & 0 & 0 & 0 & 0 & 0 & 0 & 0 & 0 & 0 & 0 & 0 \\
\hline E_brevicerci & 0 & 0 & 0 & 0 & 0 & 0 & 0 & 0 & 0 & 0 & 0 & 0 & 0 & 0 & 0 & 0 & 0 & 0 & 0 \\
\hline E_bugresensis & 0 & 0 & 0 & 0 & 0 & 0 & 0 & 0 & 0 & 0 & 0 & 0 & 0 & 0 & 0 & 0 & 0 & 0 & 0 \\
\hline E_carbonelli & 0 & 0 & 0 & 0 & 0 & 0 & 0 & 0 & 0 & 0 & 0 & 0 & 0 & 0 & 0 & 0 & 0 & 0 & 0 \\
\hline E_concavus & 0 & 0 & 0 & 0 & 0 & 0 & 0 & 0 & 0 & 0 & 0 & 0 & 0 & 0 & 0 & 0 & 0 & 0 & 0 \\
\hline Efemoratus & 0 & 0 & 0 & 0 & 0 & 0 & 0 & 0 & 0 & 0 & 0 & 0 & 0 & 0 & 0 & 0 & 0 & 0 & 0 \\
\hline E_latus & 0 & 0 & 0 & 0 & 0 & 0 & 0 & 0 & 0 & 0 & 0 & 0 & 0 & 0 & 0 & 0 & 0 & 0 & 0 \\
\hline E_minor & 0 & 0 & 0 & 0 & 0 & 0 & 0 & 0 & 0 & 0 & 0 & 0 & 0 & 0 & 0 & 0 & 0 & 0 & 0 \\
\hline E_monnei & 0 & 0 & 0 & 0 & 0 & 0 & 0 & 0 & 0 & 0 & 0 & 0 & 0 & 0 & 0 & 0 & 0 & 0 & 0 \\
\hline E_procerus & 0 & 0 & 0 & 0 & 0 & 0 & 0 & 0 & 0 & 0 & 0 & 0 & 0 & 0 & 0 & 0 & 0 & 0 & 0 \\
\hline E_raphaelandrearum & 0 & 0 & 0 & 0 & 0 & 0 & 0 & 0 & 0 & 0 & 0 & 0 & 0 & 0 & 0 & 0 & 0 & 0 & 0 \\
\hline Erobustus & 0 & 0 & 0 & 0 & 0 & 0 & 0 & 0 & 0 & 0 & 0 & 0 & 0 & 0 & 0 & 0 & 0 & 0 & 0 \\
\hline Esimilraphael & 0 & 0 & 0 & 0 & 0 & 0 & 0 & 0 & 0 & 0 & 0 & 0 & 0 & 0 & 0 & 0 & 0 & 0 & 0 \\
\hline
\end{tabular}


Tabla Suplementaria 5 Continuación:

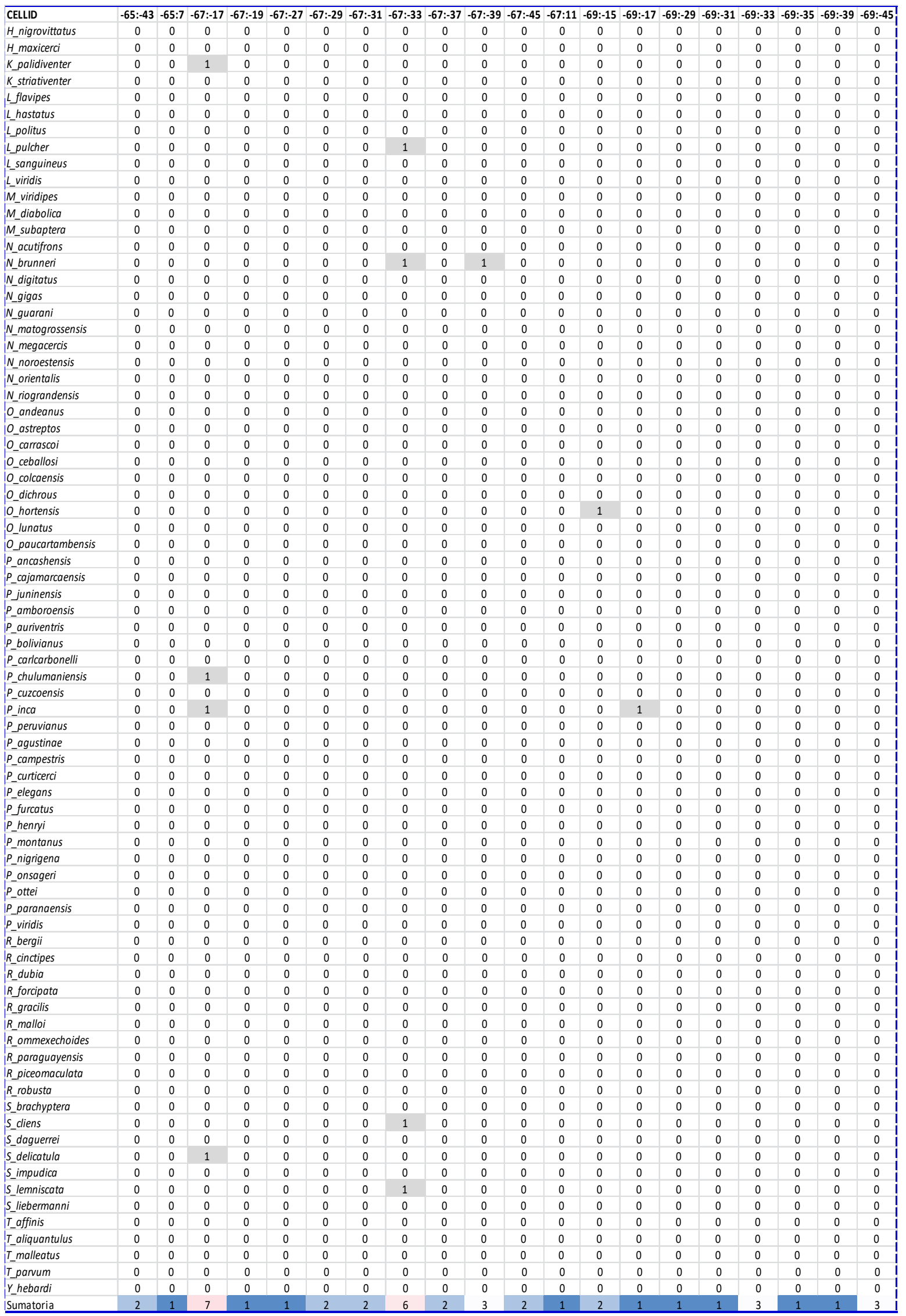


Tabla Suplementaria 5 Continuación:

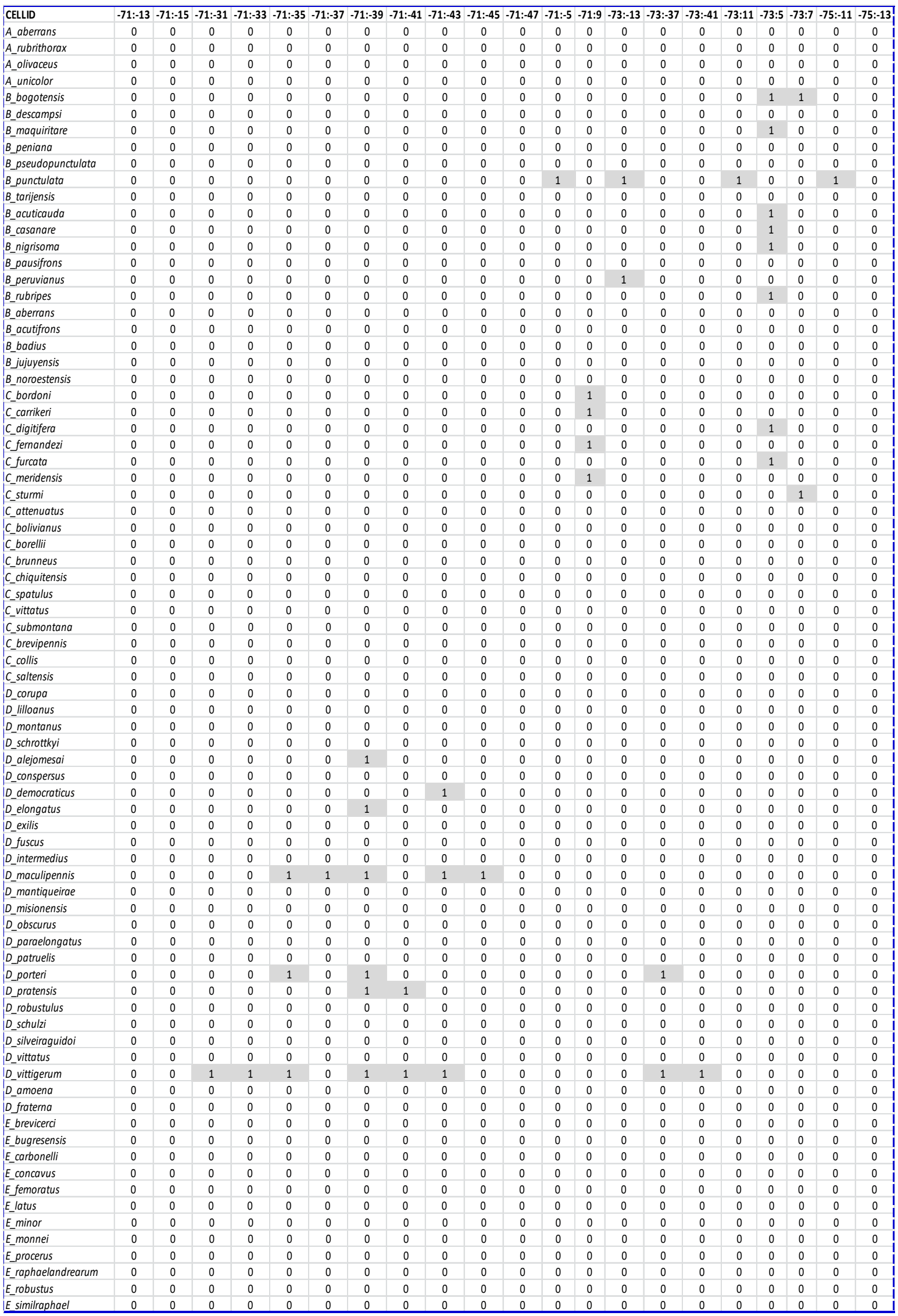


Tabla Suplementaria 5 Continuación:

\begin{tabular}{|c|c|c|c|c|c|c|c|c|c|c|c|c|c|c|c|c|c|c|c|}
\hline CELLID & $-71:-13$ & $-71:-15$ & $-71:-31$ & $-71:-33$ & $-71:-35$ & $-71:-37$ & $\mid-71:-39$ & $-71:-41$ & $-71:-43$ & $-71:-45$ & $-71:-47$ & $-71:-5$ & $\mid-71: 9$ & $-73:-13$ & $-73:-37$ & $-73:-41$ & $-73: 11$ & $-73: 5$ & $-73: 7$ \\
\hline H_nigrovittatus & 0 & 0 & 0 & 0 & 0 & 0 & 0 & 0 & 0 & 0 & 0 & 0 & 0 & 0 & 0 & 0 & 0 & 0 & 0 \\
\hline H_maxicerci & 0 & 0 & 0 & 0 & 0 & 0 & 0 & 0 & 0 & 0 & 0 & 0 & 0 & 0 & 0 & 0 & 0 & 0 & 0 \\
\hline K_palidiventer & 0 & 0 & 0 & 0 & 0 & 0 & 0 & 0 & 0 & 0 & 0 & 0 & 0 & 0 & 0 & 0 & 0 & 0 & 0 \\
\hline K_striativenter & 0 & 0 & 0 & 0 & 0 & 0 & 0 & 0 & 0 & 0 & 0 & 0 & 0 & 0 & 0 & 0 & 0 & 0 & 0 \\
\hline Lflavipes & 0 & 0 & 0 & 0 & 0 & 0 & 0 & 0 & 0 & 0 & 0 & 0 & 0 & 0 & 0 & 0 & 0 & 0 & 0 \\
\hline L_hastatus & 0 & 0 & 0 & 0 & 0 & 0 & 0 & 0 & 0 & 0 & 0 & 0 & 0 & 0 & 0 & 0 & 0 & 0 & 0 \\
\hline L_politus & 0 & 0 & 0 & 0 & 0 & 0 & 0 & 0 & 0 & 0 & 0 & 0 & 0 & 0 & 0 & 0 & 0 & 0 & 0 \\
\hline L_pulcher & 0 & 0 & 0 & 0 & 0 & 0 & 0 & 0 & 0 & 0 & 0 & 0 & 0 & 0 & 0 & 0 & 0 & 0 & 0 \\
\hline L_sanguineus & 0 & 0 & 0 & 0 & 0 & 0 & 0 & 0 & 0 & 0 & 0 & 0 & 0 & 0 & 0 & 0 & 0 & 0 & 0 \\
\hline L_viridis & 0 & 0 & 0 & 0 & 0 & 0 & 0 & 0 & 0 & 0 & 0 & 0 & 0 & 0 & 0 & 0 & 0 & 0 & 0 \\
\hline M_viridipes & 0 & 0 & 0 & 0 & 0 & 0 & 0 & 0 & 0 & 0 & 0 & 0 & 0 & 0 & 0 & 0 & 0 & 0 & 0 \\
\hline M_diabolica & 0 & 0 & 0 & 0 & 0 & 0 & 0 & 0 & 0 & 0 & 0 & 0 & 1 & 0 & 0 & 0 & 0 & 0 & 0 \\
\hline M_subaptera & 0 & 0 & 0 & 0 & 0 & 0 & 0 & 0 & 0 & 0 & 0 & 0 & 1 & 0 & 0 & 0 & 0 & 0 & 0 \\
\hline N_acutifrons & 0 & 0 & 0 & 0 & 0 & 0 & 0 & 0 & 0 & 0 & 0 & 0 & 0 & 0 & 0 & 0 & 0 & 0 & 0 \\
\hline N_brunneri & 0 & 0 & 0 & 0 & 0 & 0 & 0 & 0 & 0 & 0 & 0 & 0 & 0 & 0 & 0 & 0 & 0 & 0 & 0 \\
\hline N_digitatus & 0 & 0 & 0 & 0 & 0 & 0 & 0 & 0 & 0 & 0 & 0 & 0 & 0 & 0 & 0 & 0 & 0 & 0 & 0 \\
\hline N_gigas & 0 & 0 & 0 & 0 & 0 & 0 & 0 & 0 & 0 & 0 & 0 & 0 & 0 & 0 & 0 & 0 & 0 & 0 & 0 \\
\hline N_guarani & 0 & 0 & 0 & 0 & 0 & 0 & 0 & 0 & 0 & 0 & 0 & 0 & 0 & 0 & 0 & 0 & 0 & 0 & 0 \\
\hline N_matogrossensis & 0 & 0 & 0 & 0 & 0 & 0 & 0 & 0 & 0 & 0 & 0 & 0 & 0 & 0 & 0 & 0 & 0 & 0 & 0 \\
\hline N_megacercis & 0 & 0 & 0 & 0 & 0 & 0 & 0 & 0 & 0 & 0 & 0 & 0 & 0 & 0 & 0 & 0 & 0 & 0 & 0 \\
\hline N_noroestensis & 0 & 0 & 0 & 0 & 0 & 0 & 0 & 0 & 0 & 0 & 0 & 0 & 0 & 0 & 0 & 0 & 0 & 0 & 0 \\
\hline N_orientalis & 0 & 0 & 0 & 0 & 0 & 0 & 0 & 0 & 0 & 0 & 0 & 0 & 0 & 0 & 0 & 0 & 0 & 0 & 0 \\
\hline N_riograndensis & 0 & 0 & 0 & 0 & 0 & 0 & 0 & 0 & 0 & 0 & 0 & 0 & 0 & 0 & 0 & 0 & 0 & 0 & 0 \\
\hline O_andeanus & 1 & 0 & 0 & 0 & 0 & 0 & 0 & 0 & 0 & 0 & 0 & 0 & 0 & 1 & 0 & 0 & 0 & 0 & 0 \\
\hline O_astreptos & 0 & 0 & 0 & 0 & 0 & 0 & 0 & 0 & 0 & 0 & 0 & 0 & 0 & 1 & 0 & 0 & 0 & 0 & 0 \\
\hline O_carrascoi & 0 & 0 & 0 & 0 & 0 & 0 & 0 & 0 & 0 & 0 & 0 & 0 & 0 & 1 & 0 & 0 & 0 & 0 & 0 \\
\hline O_ceballosi & 0 & 0 & 0 & 0 & 0 & 0 & 0 & 0 & 0 & 0 & 0 & 0 & 0 & 1 & 0 & 0 & 0 & 0 & 0 \\
\hline O_colcaensis & 0 & 1 & 0 & 0 & 0 & 0 & 0 & 0 & 0 & 0 & 0 & 0 & 0 & 0 & 0 & 0 & 0 & 0 & 0 \\
\hline O_dichrous & 0 & 0 & 0 & 0 & 0 & 0 & 0 & 0 & 0 & 0 & 0 & 0 & 0 & 1 & 0 & 0 & 0 & 0 & 0 \\
\hline O_hortensis & 0 & 1 & 0 & 0 & 0 & 0 & 0 & 0 & 0 & 0 & 0 & 0 & 0 & 0 & 0 & 0 & 0 & 0 & 0 \\
\hline O_lunatus & 0 & 0 & 0 & 0 & 0 & 0 & 0 & 0 & 0 & 0 & 0 & 0 & 0 & 1 & 0 & 0 & 0 & 0 & 0 \\
\hline O_paucartambensis & 1 & 0 & 0 & 0 & 0 & 0 & 0 & 0 & 0 & 0 & 0 & 0 & 0 & 0 & 0 & 0 & 0 & 0 & 0 \\
\hline P_ancashensis & 0 & 0 & 0 & 0 & 0 & 0 & 0 & 0 & 0 & 0 & 0 & 0 & 0 & 0 & 0 & 0 & 0 & 0 & 0 \\
\hline P_cajamarcaensis & 0 & 0 & 0 & 0 & 0 & 0 & 0 & 0 & 0 & 0 & 0 & 0 & 0 & 0 & 0 & 0 & 0 & 0 & 0 \\
\hline$P$ juninensis & 0 & 0 & 0 & 0 & 0 & 0 & 0 & 0 & 0 & 0 & 0 & 0 & 0 & 0 & 0 & 0 & 0 & 0 & 0 \\
\hline P_amboroensis & 0 & 0 & 0 & 0 & 0 & 0 & 0 & 0 & 0 & 0 & 0 & 0 & 0 & 0 & 0 & 0 & 0 & 0 & 0 \\
\hline P_auriventris & 0 & 0 & 0 & 0 & 0 & 0 & 0 & 0 & 0 & 0 & 0 & 0 & 0 & 1 & 0 & 0 & 0 & 0 & 0 \\
\hline P_bolivianus & 0 & 0 & 0 & 0 & 0 & 0 & 0 & 0 & 0 & 0 & 0 & 0 & 0 & 0 & 0 & 0 & 0 & 0 & 0 \\
\hline P_carlcarbonelli & 0 & 0 & 0 & 0 & 0 & 0 & 0 & 0 & 0 & 0 & 0 & 0 & 0 & 1 & 0 & 0 & 0 & 0 & 0 \\
\hline P_chulumaniensis & 0 & 0 & 0 & 0 & 0 & 0 & 0 & 0 & 0 & 0 & 0 & 0 & 0 & 0 & 0 & 0 & 0 & 0 & 0 \\
\hline P_cuzcoensis & 1 & 0 & 0 & 0 & 0 & 0 & 0 & 0 & 0 & 0 & 0 & 0 & 0 & 1 & 0 & 0 & 0 & 0 & 0 \\
\hline P_inca & 1 & 0 & 0 & 0 & 0 & 0 & 0 & 0 & 0 & 0 & 0 & 0 & 0 & 1 & 0 & 0 & 0 & 0 & 0 \\
\hline P_peruvianus & 0 & 0 & 0 & 0 & 0 & 0 & 0 & 0 & 0 & 0 & 0 & 0 & 0 & 0 & 0 & 0 & 0 & 0 & 0 \\
\hline P_agustinae & 0 & 0 & 0 & 0 & 0 & 0 & 0 & 0 & 0 & 0 & 0 & 0 & 0 & 0 & 0 & 0 & 0 & 0 & 0 \\
\hline P_campestris & 0 & 0 & 0 & 0 & 0 & 0 & 0 & 0 & 0 & 0 & 0 & 0 & 0 & 0 & 0 & 0 & 0 & 0 & 0 \\
\hline P_curticerci & 0 & 0 & 0 & 0 & 0 & 0 & 0 & 0 & 0 & 0 & 0 & 0 & 0 & 0 & 0 & 0 & 0 & 0 & 0 \\
\hline P_elegans & 0 & 0 & 0 & 0 & 0 & 0 & 0 & 0 & 0 & 0 & 0 & 0 & 0 & 0 & 0 & 0 & 0 & 0 & 0 \\
\hline$P$ furcatus & 0 & 0 & 0 & 0 & 0 & 0 & 0 & 0 & 0 & 0 & 0 & 0 & 0 & 0 & 0 & 0 & 0 & 0 & 0 \\
\hline P_henryi & 0 & 0 & 0 & 0 & 0 & 0 & 0 & 0 & 0 & 0 & 0 & 0 & 0 & 0 & 0 & 0 & 0 & 0 & 0 \\
\hline P_montanus & 0 & 0 & 0 & 0 & 0 & 0 & 0 & 0 & 0 & 0 & 0 & 0 & 0 & 0 & 0 & 0 & 0 & 0 & 0 \\
\hline P_nigrigena & 0 & 0 & 0 & 0 & 0 & 0 & 0 & 0 & 0 & 0 & 0 & 0 & 0 & 0 & 0 & 0 & 0 & 0 & 0 \\
\hline P_onsageri & 0 & 0 & 0 & 0 & 0 & 0 & 0 & 0 & 0 & 0 & 0 & 0 & 0 & 0 & 0 & 0 & 0 & 0 & 0 \\
\hline P_ottei & 0 & 0 & 0 & 0 & 0 & 0 & 0 & 0 & 0 & 0 & 0 & 0 & 0 & 0 & 0 & 0 & 0 & 0 & 0 \\
\hline P_paranaensis & 0 & 0 & 0 & 0 & 0 & 0 & 0 & 0 & 0 & 0 & 0 & 0 & 0 & 0 & 0 & 0 & 0 & 0 & 0 \\
\hline P_viridis & 0 & 0 & 0 & 0 & 0 & 0 & 0 & 0 & 0 & 0 & 0 & 0 & 0 & 0 & 0 & 0 & 0 & 0 & 0 \\
\hline R_bergii & 0 & 0 & 0 & 0 & 0 & 0 & 0 & 0 & 0 & 0 & 1 & 0 & 0 & 0 & 0 & 0 & 0 & 0 & 0 \\
\hline$R_{-}$cinctipes & 0 & 0 & 0 & 0 & 0 & 0 & 0 & 0 & 0 & 0 & 0 & 0 & 0 & 0 & 0 & 0 & 0 & 0 & 0 \\
\hline R_dubia & 0 & 0 & 0 & 0 & 0 & 0 & 0 & 0 & 0 & 0 & 0 & 0 & 0 & 0 & 0 & 0 & 0 & 0 & 0 \\
\hline$R$ forcipata & 0 & 0 & 0 & 0 & 0 & 0 & 0 & 0 & 0 & 0 & 0 & 0 & 0 & 0 & 0 & 0 & 0 & 0 & 0 \\
\hline R_gracilis & 0 & 0 & 0 & 0 & 0 & 0 & 0 & 0 & 0 & 0 & 0 & 0 & 0 & 0 & 0 & 0 & 0 & 0 & 0 \\
\hline R_malloi & 0 & 0 & 0 & 0 & 0 & 0 & 1 & 0 & 0 & 0 & 0 & 0 & 0 & 0 & 0 & 0 & 0 & 0 & 0 \\
\hline R_ommexechoides & 0 & 0 & 0 & 0 & 0 & 0 & 0 & 0 & 0 & 0 & 0 & 0 & 0 & 0 & 0 & 0 & 0 & 0 & 0 \\
\hline R_paraguayensis & 0 & 0 & 0 & 0 & 0 & 0 & 0 & 0 & 0 & 0 & 0 & 0 & 0 & 0 & 0 & 0 & 0 & 0 & 0 \\
\hline R_piceomaculata & 0 & 0 & 0 & 0 & 0 & 0 & 0 & 0 & 0 & 0 & 0 & 0 & 0 & 0 & 0 & 0 & 0 & 0 & 0 \\
\hline R_robusta & 0 & 0 & 0 & 0 & 0 & 0 & 0 & 0 & 0 & 0 & 0 & 0 & 0 & 0 & 0 & 0 & 0 & 0 & 0 \\
\hline S_brachyptera & 0 & 0 & 0 & 0 & 0 & 0 & 0 & 0 & 0 & 0 & 0 & 0 & 0 & 0 & 0 & 0 & 0 & 0 & 0 \\
\hline S_cliens & 0 & 0 & 0 & 0 & 0 & 0 & 0 & 0 & 0 & 0 & 0 & 0 & 0 & 0 & 0 & 0 & 0 & 0 & 0 \\
\hline S_daguerrei & 0 & 0 & 0 & 0 & 0 & 0 & 0 & 0 & 0 & 0 & 0 & 0 & 0 & 0 & 0 & 0 & 0 & 0 & 0 \\
\hline S_delicatula & 0 & 0 & 0 & 0 & 0 & 0 & 0 & 0 & 0 & 0 & 0 & 0 & 0 & 0 & 0 & 0 & 0 & 0 & 0 \\
\hline S_impudica & 0 & 0 & 0 & 0 & 0 & 0 & 0 & 0 & 0 & 0 & 0 & 0 & 0 & 0 & 0 & 0 & 0 & 0 & 0 \\
\hline S_lemniscata & 0 & 0 & 0 & 0 & 0 & 0 & 1 & 1 & 0 & 0 & 0 & 0 & 0 & 0 & 0 & 0 & 0 & 0 & 0 \\
\hline S_liebermanni & 0 & 0 & 0 & 0 & 0 & 0 & 0 & 0 & 0 & 0 & 0 & 0 & 0 & 0 & 0 & 0 & 0 & 0 & 0 \\
\hline T_affinis & 0 & 0 & 0 & 0 & 0 & 0 & 0 & 0 & 0 & 0 & 0 & 0 & 1 & 0 & 0 & 0 & 0 & 0 & 1 \\
\hline T_aliquantulus & 0 & 0 & 0 & 0 & 0 & 0 & 0 & 0 & 0 & 0 & 0 & 0 & 1 & 0 & 0 & 0 & 0 & 0 & 0 \\
\hline T_malleatus & 0 & 0 & 0 & 0 & 0 & 0 & 0 & 0 & 0 & 0 & 0 & 0 & 1 & 0 & 0 & 0 & 0 & 0 & 0 \\
\hline T_parvum & 0 & 0 & 0 & 0 & 0 & 0 & 0 & 0 & 0 & 0 & 0 & 0 & 1 & 0 & 0 & 0 & 0 & 0 & 0 \\
\hline Y_hebardi & 0 & 0 & 0 & 0 & 0 & 0 & 0 & 0 & 0 & 0 & 0 & 0 & 0 & 0 & 0 & 0 & 0 & 0 & 0 \\
\hline Sumatoria & 4 & 2 & 1 & 1 & 3 & 1 & 8 & 3 & 3 & 1 & 1 & 1 & 10 & 12 & 2 & 1 & 1 & 8 & 3 \\
\hline
\end{tabular}


Tabla Suplementaria 5 Continuación:

\begin{tabular}{|c|c|c|c|c|c|c|c|c|c|c|c|c|c|}
\hline CELLID & $-75: 11$ & $-75: 5$ & $-75: 7$ & $-75: 9$ & $-77:-11$ & $-77:-9$ & $-77: 1$ & $-77: 3$ & $-79:-1$ & $-79:-5$ & $-79:-7$ & $-81:-1$ & Sumatoria \\
\hline A_aberrans & 0 & 0 & 0 & 0 & 0 & 0 & 0 & 0 & 0 & 0 & 0 & 0 & 3 \\
\hline A_rubrithorax & 0 & 0 & 0 & 0 & 0 & 0 & 0 & 0 & 0 & 0 & 0 & 0 & 1 \\
\hline A_olivaceus & 0 & 0 & 0 & 0 & 0 & 0 & 0 & 0 & 0 & 0 & 0 & 0 & 12 \\
\hline A_unicolor & 0 & 0 & 0 & 0 & 0 & 0 & 0 & 0 & 0 & 0 & 0 & 0 & 20 \\
\hline B_bogotensis & 1 & 1 & 1 & 0 & 0 & 0 & 1 & 1 & 0 & 0 & 0 & 0 & 7 \\
\hline B_descampsi & 0 & 0 & 0 & 1 & 0 & 0 & 1 & 1 & 0 & 0 & 0 & 0 & 3 \\
\hline B_maquiritare & 0 & 0 & 0 & 0 & 0 & 0 & 0 & 0 & 0 & 0 & 0 & 0 & 6 \\
\hline B_peniana & 0 & 0 & 0 & 0 & 0 & 0 & 0 & 0 & 0 & 0 & 0 & 0 & 1 \\
\hline B_pseudopunctulata & 0 & 0 & 0 & 0 & 0 & 0 & 0 & 0 & 0 & 0 & 0 & 0 & 20 \\
\hline B_punctulata & 0 & 0 & 0 & 0 & 0 & 0 & 0 & 0 & 1 & 1 & 0 & 0 & 36 \\
\hline B_tarijensis & 0 & 0 & 0 & 0 & 0 & 0 & 0 & 0 & 0 & 0 & 0 & 0 & 1 \\
\hline B_acuticauda & 0 & 1 & 0 & 0 & 0 & 0 & 0 & 0 & 0 & 0 & 0 & 0 & 2 \\
\hline B_casanare & 0 & 0 & 0 & 0 & 0 & 0 & 0 & 0 & 0 & 0 & 0 & 0 & 1 \\
\hline B_nigrisoma & 0 & 0 & 0 & 0 & 0 & 0 & 0 & 0 & 0 & 0 & 0 & 0 & 1 \\
\hline B_pausifrons & 0 & 1 & 1 & 0 & 0 & 0 & 0 & 0 & 0 & 0 & 0 & 0 & 2 \\
\hline B_peruvianus & 0 & 0 & 0 & 0 & 0 & 0 & 0 & 0 & 0 & 0 & 0 & 0 & 1 \\
\hline B_rubripes & 0 & 1 & 0 & 0 & 0 & 0 & 0 & 0 & 0 & 0 & 0 & 0 & 2 \\
\hline B_aberrans & 0 & 0 & 0 & 0 & 0 & 0 & 0 & 0 & 0 & 0 & 0 & 0 & 2 \\
\hline B_acutifrons & 0 & 0 & 0 & 0 & 0 & 0 & 0 & 0 & 0 & 0 & 0 & 0 & 2 \\
\hline B_badius & 0 & 0 & 0 & 0 & 0 & 0 & 0 & 0 & 0 & 0 & 0 & 0 & 1 \\
\hline B jujuyensis & 0 & 0 & 0 & 0 & 0 & 0 & 0 & 0 & 0 & 0 & 0 & 0 & 1 \\
\hline B_noroestensis & 0 & 0 & 0 & 0 & 0 & 0 & 0 & 0 & 0 & 0 & 0 & 0 & 1 \\
\hline C_bordoni & 0 & 0 & 0 & 0 & 0 & 0 & 0 & 0 & 0 & 0 & 0 & 0 & 1 \\
\hline C_carrikeri & 0 & 0 & 0 & 0 & 0 & 0 & 0 & 0 & 0 & 0 & 0 & 0 & 1 \\
\hline C_digitifera & 0 & 0 & 0 & 0 & 0 & 0 & 0 & 0 & 0 & 0 & 0 & 0 & 1 \\
\hline C fernandezi & 0 & 0 & 0 & 0 & 0 & 0 & 0 & 0 & 0 & 0 & 0 & 0 & 1 \\
\hline C furcata & 0 & 0 & 0 & 0 & 0 & 0 & 0 & 0 & 0 & 0 & 0 & 0 & 1 \\
\hline C_meridensis & 0 & 0 & 0 & 0 & 0 & 0 & 0 & 0 & 0 & 0 & 0 & 0 & 1 \\
\hline C_sturmi & 0 & 0 & 0 & 0 & 0 & 0 & 0 & 0 & 0 & 0 & 0 & 0 & 1 \\
\hline C_attenuatus & 0 & 0 & 0 & 0 & 0 & 0 & 0 & 0 & 0 & 0 & 0 & 0 & 2 \\
\hline C_bolivianus & 0 & 0 & 0 & 0 & 0 & 0 & 0 & 0 & 0 & 0 & 0 & 0 & 4 \\
\hline C_borellii & 0 & 0 & 0 & 0 & 0 & 0 & 0 & 0 & 0 & 0 & 0 & 0 & 7 \\
\hline C_brunneus & 0 & 0 & 0 & 0 & 0 & 0 & 0 & 0 & 0 & 0 & 0 & 0 & 2 \\
\hline C_chiquitensis & 0 & 0 & 0 & 0 & 0 & 0 & 0 & 0 & 0 & 0 & 0 & 0 & 1 \\
\hline C_spatulus & 0 & 0 & 0 & 0 & 0 & 0 & 0 & 0 & 0 & 0 & 0 & 0 & 4 \\
\hline C_vittatus & 0 & 0 & 0 & 0 & 0 & 0 & 0 & 0 & 0 & 0 & 0 & 0 & 2 \\
\hline C_submontana & 0 & 1 & 0 & 0 & 0 & 0 & 0 & 0 & 0 & 0 & 0 & 0 & 1 \\
\hline C_brevipennis & 0 & 0 & 0 & 0 & 0 & 0 & 0 & 0 & 0 & 0 & 0 & 0 & 1 \\
\hline C_collis & 0 & 0 & 0 & 0 & 0 & 0 & 0 & 0 & 0 & 0 & 0 & 0 & 1 \\
\hline C_saltensis & 0 & 0 & 0 & 0 & 0 & 0 & 0 & 0 & 0 & 0 & 0 & 0 & 1 \\
\hline D_corupa & 0 & 0 & 0 & 0 & 0 & 0 & 0 & 0 & 0 & 0 & 0 & 0 & 4 \\
\hline D_lilloanus & 0 & 0 & 0 & 0 & 0 & 0 & 0 & 0 & 0 & 0 & 0 & 0 & 6 \\
\hline D_montanus & 0 & 0 & 0 & 0 & 0 & 0 & 0 & 0 & 0 & 0 & 0 & 0 & 2 \\
\hline D_schrottkyi & 0 & 0 & 0 & 0 & 0 & 0 & 0 & 0 & 0 & 0 & 0 & 0 & 4 \\
\hline D_alejomesai & 0 & 0 & 0 & 0 & 0 & 0 & 0 & 0 & 0 & 0 & 0 & 0 & 4 \\
\hline D_conspersus & 0 & 0 & 0 & 0 & 0 & 0 & 0 & 0 & 0 & 0 & 0 & 0 & 13 \\
\hline D_democraticus & 0 & 0 & 0 & 0 & 0 & 0 & 0 & 0 & 0 & 0 & 0 & 0 & 1 \\
\hline D_elongatus & 0 & 0 & 0 & 0 & 0 & 0 & 0 & 0 & 0 & 0 & 0 & 0 & 18 \\
\hline D_exilis & 0 & 0 & 0 & 0 & 0 & 0 & 0 & 0 & 0 & 0 & 0 & 0 & 4 \\
\hline D_fuscus & 0 & 0 & 0 & 0 & 0 & 0 & 0 & 0 & 0 & 0 & 0 & 0 & 4 \\
\hline D_intermedius & 0 & 0 & 0 & 0 & 0 & 0 & 0 & 0 & 0 & 0 & 0 & 0 & 3 \\
\hline D_maculipennis & 0 & 0 & 0 & 0 & 0 & 0 & 0 & 0 & 0 & 0 & 0 & 0 & 14 \\
\hline D_mantiqueirae & 0 & 0 & 0 & 0 & 0 & 0 & 0 & 0 & 0 & 0 & 0 & 0 & 1 \\
\hline D_misionensis & 0 & 0 & 0 & 0 & 0 & 0 & 0 & 0 & 0 & 0 & 0 & 0 & 3 \\
\hline D_obscurus & 0 & 0 & 0 & 0 & 0 & 0 & 0 & 0 & 0 & 0 & 0 & 0 & 11 \\
\hline D_paraelongatus & 0 & 0 & 0 & 0 & 0 & 0 & 0 & 0 & 0 & 0 & 0 & 0 & 1 \\
\hline D_patruelis & 0 & 0 & 0 & 0 & 0 & 0 & 0 & 0 & 0 & 0 & 0 & 0 & 6 \\
\hline D_porteri & 0 & 0 & 0 & 0 & 0 & 0 & 0 & 0 & 0 & 0 & 0 & 0 & 3 \\
\hline D_pratensis & 0 & 0 & 0 & 0 & 0 & 0 & 0 & 0 & 0 & 0 & 0 & 0 & 30 \\
\hline D_robustulus & 0 & 0 & 0 & 0 & 0 & 0 & 0 & 0 & 0 & 0 & 0 & 0 & 5 \\
\hline D_schulzi & 0 & 0 & 0 & 0 & 0 & 0 & 0 & 0 & 0 & 0 & 0 & 0 & 6 \\
\hline D_silveiraguidoi & 0 & 0 & 0 & 0 & 0 & 0 & 0 & 0 & 0 & 0 & 0 & 0 & 3 \\
\hline D_vittatus & 0 & 0 & 0 & 0 & 0 & 0 & 0 & 0 & 0 & 0 & 0 & 0 & 32 \\
\hline D_vittigerum & 0 & 0 & 0 & 0 & 0 & 0 & 0 & 0 & 0 & 0 & 0 & 0 & 9 \\
\hline D_amoena & 0 & 0 & 0 & 0 & 0 & 0 & 0 & 0 & 0 & 0 & 0 & 0 & 3 \\
\hline D fraterna & 0 & 0 & 0 & 0 & 0 & 0 & 0 & 0 & 0 & 0 & 0 & 0 & 4 \\
\hline E_brevicerci & 0 & 0 & 0 & 0 & 0 & 0 & 0 & 0 & 0 & 0 & 0 & 0 & 2 \\
\hline E_bugresensis & 0 & 0 & 0 & 0 & 0 & 0 & 0 & 0 & 0 & 0 & 0 & 0 & 1 \\
\hline E_carbonelli & 0 & 0 & 0 & 0 & 0 & 0 & 0 & 0 & 0 & 0 & 0 & 0 & 4 \\
\hline E_concavus & 0 & 0 & 0 & 0 & 0 & 0 & 0 & 0 & 0 & 0 & 0 & 0 & 1 \\
\hline Effemoratus & 0 & 0 & 0 & 0 & 0 & 0 & 0 & 0 & 0 & 0 & 0 & 0 & 2 \\
\hline E_latus & 0 & 0 & 0 & 0 & 0 & 0 & 0 & 0 & 0 & 0 & 0 & 0 & 1 \\
\hline E_minor & 0 & 0 & 0 & 0 & 0 & 0 & 0 & 0 & 0 & 0 & 0 & 0 & 1 \\
\hline E_monnei & 0 & 0 & 0 & 0 & 0 & 0 & 0 & 0 & 0 & 0 & 0 & 0 & 2 \\
\hline E_procerus & 0 & 0 & 0 & 0 & 0 & 0 & 0 & 0 & 0 & 0 & 0 & 0 & 1 \\
\hline E_raphaelandrearum & 0 & 0 & 0 & 0 & 0 & 0 & 0 & 0 & 0 & 0 & 0 & 0 & 1 \\
\hline E_robustus & 0 & 0 & 0 & 0 & 0 & 0 & 0 & 0 & 0 & 0 & 0 & 0 & 3 \\
\hline E_similraphael & 0 & 0 & 0 & 0 & 0 & 0 & 0 & 0 & 0 & 0 & 0 & 0 & 1 \\
\hline
\end{tabular}


Tabla Suplementaria 5 Continuación:

\begin{tabular}{|c|c|c|c|c|c|c|c|c|c|c|c|c|c|}
\hline CELLID & $-75: 11$ & $-75: 5$ & $-75: 7$ & $-75: 9$ & $-77:-11$ & $-77:-9$ & $-77: 1$ & $-77: 3$ & $-79:-1$ & -79:-5 & $-79:-7$ & $-81:-1$ & Sumatoria \\
\hline H_nigrovittatus & 0 & 0 & 0 & 0 & 0 & 0 & 0 & 0 & 0 & 0 & 0 & 1 & 1 \\
\hline H_maxicerci & 0 & 0 & 0 & 0 & 1 & 1 & 0 & 0 & 0 & 0 & 0 & 0 & 2 \\
\hline K_palidiventer & 0 & 0 & 0 & 0 & 0 & 0 & 0 & 0 & 0 & 0 & 0 & 0 & 2 \\
\hline K_striativenter & 0 & 0 & 0 & 0 & 0 & 0 & 0 & 0 & 0 & 0 & 0 & 0 & 1 \\
\hline L flavipes & 0 & 0 & 0 & 0 & 0 & 0 & 0 & 0 & 0 & 0 & 0 & 0 & 10 \\
\hline L_hastatus & 0 & 0 & 0 & 0 & 0 & 0 & 0 & 0 & 0 & 0 & 0 & 0 & 1 \\
\hline L_politus & 0 & 0 & 0 & 0 & 0 & 0 & 0 & 0 & 0 & 0 & 0 & 0 & 3 \\
\hline L_pulcher & 0 & 0 & 0 & 0 & 0 & 0 & 0 & 0 & 0 & 0 & 0 & 0 & 31 \\
\hline L_sanguineus & 0 & 0 & 0 & 0 & 0 & 0 & 0 & 0 & 0 & 0 & 0 & 0 & 8 \\
\hline L_viridis & 0 & 0 & 0 & 0 & 0 & 0 & 0 & 0 & 0 & 0 & 0 & 0 & 9 \\
\hline M_viridipes & 0 & 0 & 0 & 0 & 0 & 0 & 0 & 0 & 0 & 0 & 0 & 0 & 1 \\
\hline M_diabolica & 0 & 0 & 0 & 0 & 0 & 0 & 0 & 0 & 0 & 0 & 0 & 0 & 1 \\
\hline M_subaptera & 0 & 0 & 0 & 0 & 0 & 0 & 0 & 0 & 0 & 0 & 0 & 0 & 1 \\
\hline N_acutifrons & 0 & 0 & 0 & 0 & 0 & 0 & 0 & 0 & 0 & 0 & 0 & 0 & 2 \\
\hline$N$ brunneri & 0 & 0 & 0 & 0 & 0 & 0 & 0 & 0 & 0 & 0 & 0 & 0 & 16 \\
\hline$N$ digitatus & 0 & 0 & 0 & 0 & 0 & 0 & 0 & 0 & 0 & 0 & 0 & 0 & 1 \\
\hline$N$ _gigas & 0 & 0 & 0 & 0 & 0 & 0 & 0 & 0 & 0 & 0 & 0 & 0 & 2 \\
\hline$N \_$guarani & 0 & 0 & 0 & 0 & 0 & 0 & 0 & 0 & 0 & 0 & 0 & 0 & 2 \\
\hline N_matogrossensis & 0 & 0 & 0 & 0 & 0 & 0 & 0 & 0 & 0 & 0 & 0 & 0 & 1 \\
\hline N_megacercis & 0 & 0 & 0 & 0 & 0 & 0 & 0 & 0 & 0 & 0 & 0 & 0 & 2 \\
\hline$N_{-}$noroestensis & 0 & 0 & 0 & 0 & 0 & 0 & 0 & 0 & 0 & 0 & 0 & 0 & 5 \\
\hline N_orientalis & 0 & 0 & 0 & 0 & 0 & 0 & 0 & 0 & 0 & 0 & 0 & 0 & 9 \\
\hline N_riograndensis & 0 & 0 & 0 & 0 & 0 & 0 & 0 & 0 & 0 & 0 & 0 & 0 & 3 \\
\hline O_andeanus & 0 & 0 & 0 & 0 & 0 & 0 & 0 & 0 & 0 & 0 & 0 & 0 & 2 \\
\hline O_astreptos & 0 & 0 & 0 & 0 & 0 & 0 & 0 & 0 & 0 & 0 & 0 & 0 & 1 \\
\hline O_carrascoi & 0 & 0 & 0 & 0 & 0 & 0 & 0 & 0 & 0 & 0 & 0 & 0 & 1 \\
\hline O_ceballosi & 0 & 0 & 0 & 0 & 0 & 0 & 0 & 0 & 0 & 0 & 0 & 0 & 3 \\
\hline O_colcaensis & 0 & 0 & 0 & 0 & 0 & 0 & 0 & 0 & 0 & 0 & 0 & 0 & 1 \\
\hline O_dichrous & 0 & 0 & 0 & 0 & 0 & 0 & 0 & 0 & 0 & 0 & 0 & 0 & 1 \\
\hline O_hortensis & 0 & 0 & 0 & 0 & 0 & 0 & 0 & 0 & 0 & 0 & 0 & 0 & 2 \\
\hline O_lunatus & 0 & 0 & 0 & 0 & 0 & 0 & 0 & 0 & 0 & 0 & 0 & 0 & 1 \\
\hline O_paucartambensis & 0 & 0 & 0 & 0 & 0 & 0 & 0 & 0 & 0 & 0 & 0 & 0 & 1 \\
\hline P_ancashensis & 0 & 0 & 0 & 0 & 1 & 0 & 0 & 0 & 0 & 0 & 0 & 0 & 1 \\
\hline P_cajamarcaensis & 0 & 0 & 0 & 0 & 0 & 0 & 0 & 0 & 0 & 0 & 1 & 0 & 1 \\
\hline P_juninensis & 0 & 0 & 0 & 0 & 0 & 0 & 0 & 0 & 0 & 0 & 0 & 0 & 1 \\
\hline P_amboroensis & 0 & 0 & 0 & 0 & 0 & 0 & 0 & 0 & 0 & 0 & 0 & 0 & 1 \\
\hline$P \_$auriventris & 0 & 0 & 0 & 0 & 0 & 0 & 0 & 0 & 0 & 0 & 0 & 0 & 1 \\
\hline P_bolivianus & 0 & 0 & 0 & 0 & 0 & 0 & 0 & 0 & 0 & 0 & 0 & 0 & 2 \\
\hline P_carlcarbonelli & 0 & 0 & 0 & 0 & 0 & 0 & 0 & 0 & 0 & 0 & 0 & 0 & 1 \\
\hline P_chulumaniensis & 0 & 0 & 0 & 0 & 0 & 0 & 0 & 0 & 0 & 0 & 0 & 0 & 1 \\
\hline P_cuzcoensis & 0 & 0 & 0 & 0 & 0 & 0 & 0 & 0 & 0 & 0 & 0 & 0 & 2 \\
\hline$P_{-}$inca & 0 & 0 & 0 & 0 & 0 & 0 & 0 & 0 & 0 & 0 & 0 & 0 & 7 \\
\hline P_peruvianus & 0 & 0 & 0 & 0 & 1 & 0 & 0 & 0 & 0 & 0 & 0 & 0 & 2 \\
\hline P_agustinae & 0 & 0 & 0 & 0 & 0 & 0 & 0 & 0 & 0 & 0 & 0 & 0 & 1 \\
\hline P_campestris & 0 & 0 & 0 & 0 & 0 & 0 & 0 & 0 & 0 & 0 & 0 & 0 & 2 \\
\hline P_curticerci & 0 & 0 & 0 & 0 & 0 & 0 & 0 & 0 & 0 & 0 & 0 & 0 & 2 \\
\hline P_elegans & 0 & 0 & 0 & 0 & 0 & 0 & 0 & 0 & 0 & 0 & 0 & 0 & 2 \\
\hline$P$ furcatus & 0 & 0 & 0 & 0 & 0 & 0 & 0 & 0 & 0 & 0 & 0 & 0 & 1 \\
\hline P_henryi & 0 & 0 & 0 & 0 & 0 & 0 & 0 & 0 & 0 & 0 & 0 & 0 & 3 \\
\hline P_montanus & 0 & 0 & 0 & 0 & 0 & 0 & 0 & 0 & 0 & 0 & 0 & 0 & 1 \\
\hline P_nigrigena & 0 & 0 & 0 & 0 & 0 & 0 & 0 & 0 & 0 & 0 & 0 & 0 & 3 \\
\hline P_onsageri & 0 & 0 & 0 & 0 & 0 & 0 & 0 & 0 & 0 & 0 & 0 & 0 & 1 \\
\hline P_ottei & 0 & 0 & 0 & 0 & 0 & 0 & 0 & 0 & 0 & 0 & 0 & 0 & 5 \\
\hline P_paranaensis & 0 & 0 & 0 & 0 & 0 & 0 & 0 & 0 & 0 & 0 & 0 & 0 & 1 \\
\hline$P \_$viridis & 0 & 0 & 0 & 0 & 0 & 0 & 0 & 0 & 0 & 0 & 0 & 0 & 2 \\
\hline$R \_$bergii & 0 & 0 & 0 & 0 & 0 & 0 & 0 & 0 & 0 & 0 & 0 & 0 & 42 \\
\hline$R \_$cinctipes & 0 & 0 & 0 & 0 & 0 & 0 & 0 & 0 & 0 & 0 & 0 & 0 & 3 \\
\hline$R \_d u b i a$ & 0 & 0 & 0 & 0 & 0 & 0 & 0 & 0 & 0 & 0 & 0 & 0 & 3 \\
\hline$R$ forcipata & 0 & 0 & 0 & 0 & 0 & 0 & 0 & 0 & 0 & 0 & 0 & 0 & 17 \\
\hline$R \_$gracilis & 0 & 0 & 0 & 0 & 0 & 0 & 0 & 0 & 0 & 0 & 0 & 0 & 1 \\
\hline R_malloi & 0 & 0 & 0 & 0 & 0 & 0 & 0 & 0 & 0 & 0 & 0 & 0 & 6 \\
\hline R_ommexechoides & 0 & 0 & 0 & 0 & 0 & 0 & 0 & 0 & 0 & 0 & 0 & 0 & 1 \\
\hline R_paraguayensis & 0 & 0 & 0 & 0 & 0 & 0 & 0 & 0 & 0 & 0 & 0 & 0 & 5 \\
\hline R_piceomaculata & 0 & 0 & 0 & 0 & 0 & 0 & 0 & 0 & 0 & 0 & 0 & 0 & 1 \\
\hline$R \_$robusta & 0 & 0 & 0 & 0 & 0 & 0 & 0 & 0 & 0 & 0 & 0 & 0 & 5 \\
\hline S_brachyptera & 0 & 0 & 0 & 0 & 0 & 0 & 0 & 0 & 0 & 0 & 0 & 0 & 5 \\
\hline S_cliens & 0 & 0 & 0 & 0 & 0 & 0 & 0 & 0 & 0 & 0 & 0 & 0 & 33 \\
\hline S_daguerrei & 0 & 0 & 0 & 0 & 0 & 0 & 0 & 0 & 0 & 0 & 0 & 0 & 8 \\
\hline$S$ delicatula & 0 & 0 & 0 & 0 & 0 & 0 & 0 & 0 & 0 & 0 & 0 & 0 & 2 \\
\hline S_impudica & 0 & 0 & 0 & 0 & 0 & 0 & 0 & 0 & 0 & 0 & 0 & 0 & 24 \\
\hline S_lemniscata & 0 & 0 & 0 & 0 & 0 & 0 & 0 & 0 & 0 & 0 & 0 & 0 & 33 \\
\hline S_liebermanni & 0 & 0 & 0 & 0 & 0 & 0 & 0 & 0 & 0 & 0 & 0 & 0 & 11 \\
\hline T_affinis & 0 & 0 & 0 & 0 & 0 & 0 & 0 & 0 & 0 & 0 & 0 & 0 & 2 \\
\hline T_aliquantulus & 0 & 0 & 0 & 0 & 0 & 0 & 0 & 0 & 0 & 0 & 0 & 0 & 1 \\
\hline T_malleatus & 0 & 0 & 0 & 0 & 0 & 0 & 0 & 0 & 0 & 0 & 0 & 0 & 1 \\
\hline T_parvum & 0 & 0 & 0 & 0 & 0 & 0 & 0 & 0 & 0 & 0 & 0 & 0 & 1 \\
\hline$Y_{\text {_h hebardi }}$ & 0 & 0 & 0 & 0 & 0 & 0 & 0 & 0 & 0 & 0 & 0 & 0 & 1 \\
\hline Sumatoria & 1 & 5 & 2 & 1 & 3 & 1 & 2 & 2 & 1 & 1 & 1 & 1 & \\
\hline
\end{tabular}


Tabla Suplementaria 6: PAM Géneros:

\begin{tabular}{|c|c|c|c|c|c|c|c|c|c|c|c|c|c|c|c|c|c|c|c|c|c|c|c|c|c|c|c|c|c|c|}
\hline & $-74: 11$ & & 0:11 & $-68: 11$ & $-66: 11$ & 64. & 2 & $78: 9$ & & & & 70:9 & $-68: 9$ & $-66: 9$ & $-64: 9$ & $-62:=$ & & & $2: 1$ & $66: 1$ & $64: 1$ & $-62:$ & /b:5 & /4: & 72:5 & $-68: 5$ & $-66: 5-$ & $-64: 5$ & -78 & $-76: 3$ \\
\hline Atrachelacris & 0 & 0 & 0 & 0 & 0 & 0 & 0 & 0 & 0 & 0 & 0 & 0 & 0 & 0 & 0 & 0 & 0 & 0 & 0 & 0 & 0 & 0 & 0 & 0 & 0 & 0 & 0 & 0 & 0 & 0 \\
\hline Timotes & 0 & 0 & 1 & 1 & 0 & 0 & 0 & 0 & 0 & 1 & 1 & 1 & 0 & 0 & 0 & 0 & 0 & 1 & 1 & 0 & 0 & 0 & 0 & 0 & 0 & 0 & 0 & 0 & 0 & 0 \\
\hline Scotussa & 0 & 0 & 0 & 0 & 0 & 0 & 0 & 0 & 0 & 0 & 0 & 0 & 0 & 0 & 0 & 0 & 0 & 0 & 0 & 0 & 0 & 0 & 0 & 0 & 0 & 0 & 0 & 0 & 0 & 0 \\
\hline Ronderosia & 0 & 0 & 0 & 0 & 0 & 0 & 0 & 0 & 0 & 0 & 0 & 0 & 0 & 0 & 0 & 0 & 0 & 0 & 0 & 0 & 0 & 0 & 0 & 0 & 0 & 0 & 0 & 0 & 0 & 0 \\
\hline Pseudoscopas & 0 & 0 & 0 & 0 & 0 & 0 & 0 & 0 & 0 & 0 & 0 & 0 & 0 & 0 & 0 & 0 & 0 & 0 & 0 & 0 & 0 & 0 & 0 & 0 & 0 & 0 & 0 & 0 & 0 & 0 \\
\hline Ponderacris & 0 & 0 & 0 & 0 & 0 & 0 & 0 & 0 & 0 & 0 & 0 & 0 & 0 & 0 & 0 & 0 & 0 & 0 & 0 & 0 & 0 & 0 & 0 & 0 & 0 & 0 & 0 & 0 & 0 & 0 \\
\hline Pediella & 0 & 0 & 0 & 0 & 0 & 0 & 0 & 0 & 0 & 0 & 0 & 0 & 0 & 0 & 0 & 0 & 0 & 0 & 0 & 0 & 0 & 0 & 0 & 0 & 0 & 0 & 0 & 0 & 0 & 0 \\
\hline Orotettix & 0 & 0 & 0 & 0 & 0 & 0 & 0 & 0 & 0 & 0 & 0 & 0 & 0 & 0 & 0 & 0 & 0 & 0 & 0 & 0 & 0 & 0 & 0 & 0 & 0 & 0 & 0 & 0 & 0 & 0 \\
\hline Neopedies & 0 & 0 & 0 & 0 & 0 & 0 & 0 & 0 & 0 & 0 & 0 & 0 & 0 & 0 & 0 & 0 & 0 & 0 & 0 & 0 & 0 & 0 & 0 & 0 & 0 & 0 & 0 & 0 & 0 & 0 \\
\hline Leiotettix & 0 & 0 & 0 & 0 & 0 & 0 & 0 & 0 & 0 & 0 & 0 & 0 & 0 & 0 & 0 & 0 & 0 & 0 & 0 & 0 & 0 & 0 & 0 & 0 & 0 & 0 & 0 & 0 & 0 & 0 \\
\hline Keyopsis & 0 & 0 & 0 & 0 & 0 & 0 & 0 & 0 & 0 & 0 & 0 & 0 & 0 & 0 & 0 & 0 & 0 & 0 & 0 & 0 & 0 & 0 & 0 & 0 & 0 & 0 & 0 & 0 & 0 & 0 \\
\hline Huaylasacris & 0 & 0 & 0 & 0 & 0 & 0 & 0 & 0 & 0 & 0 & 0 & 0 & 0 & 0 & 0 & 0 & 0 & 0 & 0 & 0 & 0 & 0 & 0 & 0 & 0 & 0 & 0 & 0 & 0 & 0 \\
\hline Eurotettix & 0 & 0 & 0 & 0 & 0 & 0 & 0 & 0 & 0 & 0 & 0 & 0 & 0 & 0 & 0 & 0 & 0 & 0 & 0 & 0 & 0 & 0 & 0 & 0 & 0 & 0 & 0 & 0 & 0 & 0 \\
\hline Digamacris & 0 & 0 & 0 & 0 & 0 & 0 & 0 & 0 & 0 & 0 & 0 & 0 & 0 & 0 & 0 & 0 & 0 & 0 & 0 & 0 & 0 & 0 & 0 & 0 & 0 & 0 & 0 & 0 & 0 & 0 \\
\hline Dichroplus & 0 & 0 & 0 & 0 & 0 & 0 & 0 & 0 & 0 & 0 & 0 & 0 & 0 & 0 & 0 & 0 & 0 & 0 & 0 & 0 & 0 & 0 & 0 & 0 & 0 & 0 & 0 & 0 & 0 & 0 \\
\hline Dichromatos & 0 & 0 & 0 & 0 & 0 & 0 & 0 & 0 & 0 & 0 & 0 & 0 & 0 & 0 & 0 & 0 & 0 & 0 & 0 & 0 & 0 & 0 & 0 & 0 & 0 & 0 & 0 & 0 & 0 & 0 \\
\hline Chlorus & 0 & 0 & 0 & 0 & 0 & 0 & 0 & 0 & 0 & 0 & 0 & 0 & 0 & 0 & 0 & 0 & 0 & 0 & 0 & 0 & 0 & 0 & 0 & 0 & 0 & 0 & 0 & 0 & 0 & 0 \\
\hline Chibchacris & 0 & 0 & 0 & 0 & 0 & 0 & 0 & 0 & 0 & 1 & 1 & 1 & 0 & 0 & 0 & 0 & 0 & 1 & 1 & 0 & 0 & 0 & 1 & 1 & 1 & 0 & 0 & 0 & 0 & 1 \\
\hline Boliviacris & 0 & 0 & 0 & 0 & 0 & 0 & 0 & 0 & 0 & 0 & 0 & 0 & 0 & 0 & 0 & 0 & 0 & 0 & 0 & 0 & 0 & 0 & 0 & 0 & 0 & 0 & 0 & 0 & 0 & 0 \\
\hline Bogotacris & 0 & 1 & 0 & 0 & 0 & 0 & 0 & 0 & 0 & 1 & 1 & 0 & 0 & 0 & 0 & 0 & 1 & 1 & 1 & 0 & 0 & 0 & 1 & 1 & 1 & 0 & 0 & 0 & 1 & 1 \\
\hline Baeacris & 1 & 1 & 1 & 1 & 1 & 1 & 1 & 1 & 1 & 1 & 1 & 1 & 1 & 1 & 1 & 1 & 1 & 1 & 1 & 1 & 1 & 1 & 1 & 1 & 1 & 1 & 1 & 1 & 1 & 1 \\
\hline Sumatoria & 1 & 2 & 2 & 2 & 1 & 1 & 1 & 1 & 1 & 4 & 4 & 3 & 1 & 1 & 1 & 1 & 2 & 4 & 4 & 1 & 1 & 1 & 3 & 3 & 3 & 1 & 1 & 1 & 2 & 3 \\
\hline
\end{tabular}

\begin{tabular}{|c|c|c|c|c|c|c|c|c|c|c|c|c|c|c|c|c|c|c|c|c|c|c|c|c|c|c|c|c|c|c|}
\hline & $-74: 3$ & $-72: 3$ & $-80: 1$ & $-78: 1$ & $-76: 1$ & $-74: 1$ & $-72: 1$ & $80:-1$ & $78:-1$ & 80:-3 & $78:-3$ & 80:-5 & 80:-7 & $78:-7$ & $76:-7$ & 78:- -9 & 76:- -9 & 74:- & 48:-9 & 8:-1 & $6:-1$ & 4:-1 & $2:-1$ & $0:-1$ & $2:-1$ & $0:-1$ & 2:-1] & $0:-11$ & 8:-11 & 16:-11 \\
\hline Atrachelacris & 0 & 0 & 0 & 0 & 0 & 0 & 0 & 0 & 0 & 0 & 0 & 0 & 0 & 0 & 0 & 0 & 0 & 0 & 0 & 0 & 0 & 0 & 0 & 0 & 0 & 0 & 0 & 0 & 0 & 0 \\
\hline Timotes & 0 & 0 & 0 & 0 & 0 & 0 & 0 & 0 & 0 & 0 & 0 & 0 & 0 & 0 & 0 & 0 & 0 & 0 & 0 & 0 & 0 & 0 & 0 & 0 & 0 & 0 & 0 & 0 & 0 & 0 \\
\hline Scotussa & 0 & 0 & 0 & 0 & 0 & 0 & 0 & 0 & 0 & 0 & 0 & 0 & 0 & 0 & 0 & 0 & 0 & 0 & 0 & 0 & 0 & 0 & 0 & 0 & 0 & 0 & 0 & 0 & 0 & 0 \\
\hline Ronderosia & 0 & 0 & 0 & 0 & 0 & 0 & 0 & 0 & 0 & 0 & 0 & 0 & 0 & 0 & 0 & 0 & 0 & 0 & 0 & 0 & 0 & 0 & 0 & 0 & 0 & 0 & 0 & 0 & 0 & 0 \\
\hline Pseudoscopas & 0 & 0 & 0 & 0 & 0 & 0 & 0 & 0 & 0 & 0 & 0 & 0 & 0 & 0 & 0 & 0 & 0 & 0 & 0 & 0 & 0 & 0 & 0 & 0 & 0 & 0 & 0 & 0 & 0 & 0 \\
\hline Ponderacris & 0 & 0 & 0 & 0 & 0 & 0 & 0 & 0 & 0 & 0 & 0 & 0 & 0 & 0 & 1 & 1 & 1 & 1 & 0 & 1 & 1 & 1 & 1 & 1 & 0 & 0 & 0 & 0 & 0 & 0 \\
\hline Pediella & 0 & 0 & 0 & 0 & 0 & 0 & 0 & 0 & 0 & 0 & 0 & 0 & 0 & 0 & 0 & 1 & 1 & 0 & 0 & 1 & 1 & 0 & 0 & 0 & 0 & 0 & 0 & 0 & 0 & 0 \\
\hline Orotettix & 0 & 0 & 0 & 0 & 0 & 0 & 0 & 0 & 0 & 0 & 0 & 0 & 0 & 0 & 0 & 1 & 1 & 0 & 0 & 1 & 1 & 1 & 0 & 0 & 0 & 0 & 0 & 0 & 0 & 0 \\
\hline Neopedies & 0 & 0 & 0 & 0 & 0 & 0 & 0 & 0 & 0 & 0 & 0 & 0 & 0 & 0 & 0 & 0 & 0 & 0 & 0 & 0 & 0 & 0 & 0 & 0 & 0 & 0 & 0 & 0 & 0 & 0 \\
\hline Leiotettix & 0 & 0 & 0 & 0 & 0 & 0 & 0 & 0 & 0 & 0 & 0 & 0 & 0 & 0 & 0 & 0 & 0 & 0 & 0 & 0 & 0 & 0 & 0 & 0 & 0 & 0 & 0 & 0 & 0 & 0 \\
\hline Keyopsis & 0 & 0 & 0 & 0 & 0 & 0 & 0 & 0 & 0 & 0 & 0 & 0 & 0 & 0 & 0 & 0 & 0 & 0 & 0 & 0 & 0 & 0 & 0 & 0 & 0 & 0 & 0 & 0 & 0 & 0 \\
\hline Huaylasacris & 0 & 0 & 0 & 0 & 0 & 0 & 0 & 0 & 0 & 0 & 0 & 0 & 0 & 1 & 0 & 1 & 0 & 0 & 0 & 1 & 1 & 0 & 0 & 0 & 0 & 0 & 0 & 0 & 0 & 0 \\
\hline Eurotettix & 0 & 0 & 0 & 0 & 0 & 0 & 0 & 0 & 0 & 0 & 0 & 0 & 0 & 0 & 0 & 0 & 0 & 0 & 1 & 0 & 0 & 0 & 0 & 0 & 0 & 0 & 1 & 1 & 1 & 1 \\
\hline Digamacris & 0 & 0 & 0 & 0 & 0 & 0 & 0 & 0 & 0 & 0 & 0 & 0 & 0 & 0 & 0 & 0 & 0 & 0 & 0 & 0 & 0 & 0 & 0 & 0 & 0 & 0 & 0 & 0 & 0 & 0 \\
\hline Dichroplus & 0 & 0 & 0 & 0 & 0 & 0 & 0 & 0 & 0 & 0 & 0 & 0 & 0 & 0 & 0 & 0 & 0 & 0 & 0 & 0 & 0 & 0 & 0 & 0 & 0 & 0 & 0 & 0 & 0 & 0 \\
\hline Dichromatos & 0 & 0 & 0 & 0 & 0 & 0 & 0 & 0 & 0 & 0 & 0 & 0 & 0 & 0 & 0 & 0 & 0 & 0 & 0 & 0 & 0 & 0 & 0 & 0 & 0 & 0 & 0 & 0 & 0 & 0 \\
\hline Chlorus & 0 & 0 & 0 & 0 & 0 & 0 & 0 & 0 & 0 & 0 & 0 & 0 & 0 & 0 & 0 & 0 & 0 & 0 & 0 & 0 & 0 & 0 & 0 & 0 & 1 & 1 & 0 & 0 & 0 & 0 \\
\hline Chibchacris & 1 & 0 & 0 & 0 & 0 & 0 & 0 & 0 & 0 & 0 & 0 & 0 & 0 & 0 & 0 & 0 & 0 & 0 & 0 & 0 & 0 & 0 & 0 & 0 & 0 & 0 & 0 & 0 & 0 & 0 \\
\hline Boliviacris & 0 & 0 & 0 & 0 & 0 & 0 & 0 & 0 & 0 & 0 & 0 & 0 & 0 & 0 & 0 & 0 & 0 & 0 & 0 & 0 & 0 & 0 & 0 & 0 & 0 & 0 & 0 & 0 & 0 & 0 \\
\hline Bogotacris & 1 & 0 & 0 & 1 & 1 & 0 & 0 & 0 & 0 & 0 & 0 & 0 & 0 & 0 & 0 & 0 & 1 & 0 & 0 & 0 & 1 & 0 & 0 & 0 & 0 & 0 & 0 & 0 & 0 & 0 \\
\hline Baeacris & 1 & 1 & 1 & 1 & 1 & 1 & 1 & 1 & 1 & 1 & 1 & 1 & 1 & 1 & 0 & 1 & 1 & 0 & 0 & 1 & 1 & 1 & 0 & 0 & 0 & 0 & 0 & 0 & 0 & 0 \\
\hline Sumatoria & 3 & 1 & 1 & 2 & 2 & 1 & 1 & 1 & 1 & 1 & 1 & 1 & 1 & 2 & 1 & 5 & 5 & 1 & 1 & 5 & 6 & 3 & 1 & 1 & 1 & 1 & 1 & 1 & 1 & 1 \\
\hline
\end{tabular}

\begin{tabular}{|c|c|c|c|c|c|c|c|c|c|c|c|c|c|c|c|c|c|c|c|c|c|c|c|c|c|}
\hline & $-40:-11$ & $-38:-11$ & $-76:-13$ & $-74:-13$ & $-72:-13$ & $-70:-13$ & $-68:-13$ & $-66:-13$ & $-64:-13$ & $-62:-13$ & $-60:-13$ & $-58:-13$ & $-56:-13$ & $-54:-13$ & $-52:-13$ & $-50:-13$ & $-48:-13$ & $-46:-13$ & $-42:-13$ & $-40:-13$ & $-38:-13$ & $-76:-15$ & $-74:-15$ & $-72:-15$ & $-70:-15$ \\
\hline Atrachelacris & 0 & 0 & 0 & 0 & 0 & 0 & 0 & 0 & 0 & 0 & 0 & 0 & 0 & 0 & 0 & 0 & 0 & 0 & 0 & 0 & 0 & 0 & 0 & 0 & 0 \\
\hline Timotes & 0 & 0 & 0 & 0 & 0 & 0 & 0 & 0 & 0 & 0 & 0 & 0 & 0 & 0 & 0 & 0 & 0 & 0 & 0 & 0 & 0 & 0 & 0 & 0 & 0 \\
\hline Scotussa & 0 & 0 & 0 & 0 & 0 & 0 & 0 & 0 & 0 & 0 & 0 & 0 & 0 & 0 & 0 & 0 & 0 & 0 & 0 & 0 & 0 & 0 & 0 & 0 & 0 \\
\hline Ronderosia & 1 & 1 & 0 & 0 & 0 & 0 & 0 & 0 & 0 & 0 & 0 & 0 & 0 & 0 & 0 & 0 & 0 & 0 & 0 & 1 & 0 & 0 & 0 & 0 & 0 \\
\hline Pseudoscopas & 0 & 0 & 0 & 0 & 0 & 0 & 0 & 0 & 0 & 0 & 0 & 0 & 0 & 0 & 0 & 0 & 0 & 0 & 0 & 0 & 0 & 0 & 0 & 0 & 0 \\
\hline Ponderacris & 0 & 0 & 1 & 1 & 1 & 1 & 1 & 0 & 0 & 0 & 0 & 0 & 0 & 0 & 0 & 0 & 0 & 0 & 0 & 0 & 0 & 0 & 1 & 1 & 1 \\
\hline Pediella & 0 & 0 & 0 & 1 & 0 & 0 & 0 & 0 & 0 & 0 & 0 & 0 & 0 & 0 & 0 & 0 & 0 & 0 & 0 & 0 & 0 & 0 & 0 & 0 & 0 \\
\hline Orotettix & 0 & 0 & 1 & 1 & 1 & 1 & 0 & 0 & 0 & 0 & 0 & 0 & 0 & 0 & 0 & 0 & 0 & 0 & 0 & 0 & 0 & 0 & 1 & 1 & 1 \\
\hline Neopedies & 0 & 0 & 0 & 0 & 0 & 0 & 0 & 0 & 0 & 0 & 0 & 0 & 0 & 0 & 0 & 0 & 0 & 0 & 0 & 0 & 0 & 0 & 0 & 0 & 0 \\
\hline Leiotettix & 0 & 0 & 0 & 0 & 0 & 0 & 1 & 0 & 0 & 0 & 0 & 0 & 0 & 0 & 0 & 0 & 0 & 0 & 0 & 0 & 0 & 0 & 0 & 0 & 0 \\
\hline Keyopsis & 0 & 0 & 0 & 0 & 0 & 0 & 0 & 0 & 0 & 0 & 0 & 0 & 0 & 0 & 0 & 0 & 0 & 0 & 0 & 0 & 0 & 0 & 0 & 0 & 0 \\
\hline Huaylasacris & 0 & 0 & 1 & 1 & 0 & 0 & 0 & 0 & 0 & 0 & 0 & 0 & 0 & 0 & 0 & 0 & 0 & 0 & 0 & 0 & 0 & 0 & 1 & 0 & 0 \\
\hline Eurotettix & 0 & 0 & 0 & 0 & 0 & 0 & 0 & 0 & 0 & 1 & 1 & 1 & 1 & 1 & 1 & 1 & 1 & 1 & 0 & 0 & 0 & 0 & 0 & 0 & 0 \\
\hline Digamacris & 1 & 1 & 0 & 0 & 0 & 0 & 0 & 0 & 0 & 0 & 0 & 0 & 0 & 0 & 0 & 0 & 0 & 0 & 0 & 1 & 1 & 0 & 0 & 0 & 0 \\
\hline Dichroplus & 0 & 0 & 0 & 0 & 0 & 0 & 0 & 0 & 0 & 0 & 0 & 0 & 0 & 0 & 0 & 0 & 0 & 0 & 0 & 0 & 0 & 0 & 0 & 0 & 0 \\
\hline Dichromatos & 0 & 0 & 0 & 0 & 0 & 0 & 0 & 0 & 0 & 0 & 0 & 0 & 0 & 0 & 0 & 0 & 0 & 0 & 0 & 0 & 0 & 0 & 0 & 0 & 0 \\
\hline Chlorus & 0 & 0 & 0 & 0 & 0 & 0 & 0 & 1 & 1 & 1 & 1 & 1 & 1 & 0 & 0 & 0 & 0 & 0 & 0 & 0 & 0 & 0 & 0 & 0 & 0 \\
\hline Chibchacris & 0 & 0 & 0 & 0 & 0 & 0 & 0 & 0 & 0 & 0 & 0 & 0 & 0 & 0 & 0 & 0 & 0 & 0 & 0 & 0 & 0 & 0 & 0 & 0 & 0 \\
\hline Boliviacris & 0 & 0 & 0 & 0 & 0 & 0 & 0 & 0 & 0 & 0 & 0 & 0 & 0 & 0 & 0 & 0 & 0 & 0 & 0 & 0 & 0 & 0 & 0 & 0 & 0 \\
\hline Bogotacris & 0 & 0 & 1 & 1 & 1 & 1 & 0 & 0 & 0 & 0 & 0 & 0 & 0 & 0 & 0 & 0 & 0 & 0 & 0 & 0 & 0 & 0 & 1 & 1 & 1 \\
\hline Baeacris & 1 & 1 & 1 & 1 & 1 & 1 & 1 & 0 & 0 & 0 & 0 & 0 & 0 & 0 & 0 & 0 & 0 & 0 & 1 & 1 & 1 & 1 & 1 & 1 & \\
\hline
\end{tabular}


Tabla Suplementaria 6 Continuación:

\begin{tabular}{|c|c|c|c|c|c|c|c|c|c|c|c|c|c|c|c|c|c|c|c|c|c|c|c|c|c|}
\hline & $-68:-15$ & $-66:-15$ & $-64:-15$ & $-62:-15$ & $-60:-15$ & $-58:-15$ & $-56:-15$ & $-54:-15$ & $-52:-15$ & $-50:-15$ & $5-48:-15$ & $5-46:-15$ & $5-44:-15$ & $-42:-15$ & $-40:-15$ & $5-38:-15$ & $-70:-17$ & $-68:-17$ & $-66:-17$ & - $64:-17$ & $-62:-17$ & $-60:-17$ & $-58:-17$ & $-56:-17$ & $-54:-17$ \\
\hline Atrachelacris & 0 & 0 & 0 & 0 & 0 & 0 & 0 & 0 & 0 & 0 & 0 & 0 & 1 & 1 & 1 & 0 & 0 & 0 & 0 & 1 & 0 & 0 & 0 & 0 & 0 \\
\hline Timotes & 0 & 0 & 0 & 0 & 0 & 0 & 0 & 0 & 0 & 0 & 0 & 0 & 0 & 0 & 0 & 0 & 0 & 0 & 0 & 0 & 0 & 0 & 0 & 0 & 0 \\
\hline Scotussa & 0 & 0 & 0 & 0 & 0 & 0 & 0 & 0 & 0 & 0 & 0 & 0 & 0 & 0 & 0 & 0 & 0 & 0 & 0 & 0 & 0 & 0 & 0 & 0 & 0 \\
\hline Ronderosia & 0 & 0 & 0 & 0 & 0 & 0 & 1 & 1 & 1 & 0 & 1 & 1 & 1 & 1 & 1 & 0 & 0 & 0 & 0 & 1 & 1 & 1 & 1 & 1 & 1 \\
\hline Pseudoscopas & 0 & 0 & 0 & 0 & 0 & 0 & 0 & 0 & 0 & 0 & 0 & 0 & 0 & 0 & 0 & 0 & 0 & 0 & 0 & 0 & 0 & 0 & 0 & 0 & 0 \\
\hline Ponderacris & 1 & 1 & 0 & 0 & 0 & 0 & 0 & 0 & 0 & 0 & 0 & 0 & 0 & 0 & 0 & 0 & 0 & 1 & 1 & 1 & 0 & 0 & 0 & 0 & 0 \\
\hline Pediella & 0 & 0 & 0 & 0 & 0 & 0 & 0 & 0 & 0 & 0 & 0 & 0 & 0 & 0 & 0 & 0 & 0 & 0 & 0 & 0 & 0 & 0 & 0 & 0 & 0 \\
\hline Orotettix & 1 & 0 & 0 & 0 & 0 & 0 & 0 & 0 & 0 & 0 & 0 & 0 & 0 & 0 & 0 & 0 & 1 & 1 & 1 & 0 & 0 & 0 & 0 & 0 & 0 \\
\hline Neopedies & 0 & 0 & 0 & 0 & 0 & 0 & 0 & 0 & 0 & 0 & 0 & 0 & 0 & 0 & 0 & 0 & 0 & 0 & 0 & 0 & 0 & 0 & 0 & 0 & 0 \\
\hline Leiotettix & 1 & 1 & 0 & 0 & 0 & 0 & 0 & 0 & 0 & 0 & 0 & 0 & 0 & 0 & 0 & 0 & 0 & 1 & 1 & 1 & 0 & 0 & 1 & 0 & 1 \\
\hline Keyopsis & 0 & 0 & 0 & 0 & 0 & 0 & 0 & 0 & 0 & 0 & 0 & 0 & 0 & 0 & 0 & 0 & 0 & 1 & 1 & 1 & 0 & 0 & 0 & 0 & 0 \\
\hline Huaylasacris & 0 & 0 & 0 & 0 & 0 & 0 & 0 & 0 & 0 & 0 & 0 & 0 & 0 & 0 & 0 & 0 & 0 & 0 & 0 & 0 & 0 & 0 & 0 & 0 & 0 \\
\hline Eurotettix & 0 & 0 & 0 & 0 & 1 & 1 & 1 & 1 & 1 & 1 & 1 & 1 & 0 & 0 & 1 & 0 & 0 & 0 & 0 & 0 & 0 & 1 & 1 & 1 & 1 \\
\hline Digamacris & 0 & 0 & 0 & 0 & 0 & 0 & 0 & 0 & 0 & 0 & 0 & 0 & 0 & 1 & 1 & 0 & 0 & 0 & 0 & 0 & 0 & 0 & 0 & 0 & 0 \\
\hline Dichroplus & 0 & 0 & 0 & 0 & 0 & 0 & 0 & 0 & 0 & 0 & 0 & 0 & 0 & 0 & 0 & 0 & 0 & 0 & 0 & 0 & 0 & 0 & 0 & 0 & 0 \\
\hline Dichromatos & 0 & 0 & 0 & 0 & 0 & 0 & 0 & 0 & 0 & 0 & 0 & 0 & 0 & 0 & 0 & 0 & 0 & 0 & 0 & 0 & 0 & 0 & 0 & 0 & 0 \\
\hline Chlorus & 1 & 1 & 1 & 1 & 1 & 1 & 1 & 0 & 0 & 0 & 0 & 0 & 0 & 0 & 0 & 0 & 0 & 1 & 1 & 1 & 1 & 1 & 1 & 1 & 0 \\
\hline Chibchacris & 0 & 0 & 0 & 0 & 0 & 0 & 0 & 0 & 0 & 0 & 0 & 0 & 0 & 0 & 0 & 0 & 0 & 0 & 0 & 0 & 0 & 0 & 0 & 0 & 0 \\
\hline Boliviacris & 0 & 0 & 0 & 0 & 0 & 0 & 0 & 0 & 0 & 0 & 0 & 0 & 0 & 0 & 0 & 0 & 0 & 1 & 1 & 1 & 1 & 1 & 1 & 0 & 0 \\
\hline Bogotacris & 0 & 0 & 0 & 0 & 0 & 0 & 0 & 0 & 0 & 0 & 0 & 0 & 0 & 0 & 0 & 0 & 0 & 0 & 0 & 0 & 0 & 0 & 0 & 0 & 0 \\
\hline Baeacris & 1 & 1 & 0 & 0 & 0 & 0 & 0 & 0 & 0 & 1 & 1 & 0 & 1 & 1 & 1 & 1 & 0 & 1 & 1 & 1 & 1 & 0 & 0 & 0 & 0 \\
\hline Sumatoria & 5 & 4 & 1 & 1 & 2 & 2 & 3 & 2 & 2 & 2 & 3 & 2 & 3 & 4 & 5 & 1 & 1 & 7 & 7 & 8 & 4 & 4 & 5 & 3 & 3 \\
\hline
\end{tabular}

\begin{tabular}{|c|c|c|c|c|c|c|c|c|c|c|c|c|c|c|c|c|c|c|c|c|c|c|c|c|c|}
\hline & $-52:-17$ & $-50:-17$ & $-48:-17$ & $-46:-17$ & $-44:-17$ & $-42:-17$ & $-40:-17$ & $-38:-17$ & $-68:-19$ & $-66:-19$ & $-64:-19$ & $-62:-19$ & - $-60:-19$ & 9 -58:-19 & $-56:-19$ & $-54:-19$ & $-52:-19$ & $-50:-19$ & $-48:-19$ & - $46:-19$ & $-44:-19$ & $-42:-19$ & $-40:-19$ & $-68:-21$ & $-66:-21$ \\
\hline Atrachelacris & 0 & 0 & 0 & 1 & 1 & 1 & 1 & 0 & 0 & 0 & 1 & 0 & 0 & 0 & 1 & 1 & 1 & 1 & 0 & 1 & 1 & 1 & 0 & 0 & 1 \\
\hline Timotes & 0 & 0 & 0 & 0 & 0 & 0 & 0 & 0 & 0 & 0 & 0 & 0 & 0 & 0 & 0 & 0 & 0 & 0 & 0 & 0 & 0 & 0 & 0 & 0 & 0 \\
\hline Scotussa & 0 & 0 & 0 & 0 & 0 & 0 & 0 & 0 & 0 & 0 & 0 & 0 & 0 & 0 & 0 & 0 & 0 & 0 & 0 & 0 & 0 & 0 & 0 & 0 & 0 \\
\hline Ronderosia & 1 & 1 & 1 & 1 & 1 & 1 & 1 & 0 & 0 & 1 & 1 & 1 & 0 & 1 & 1 & 1 & 1 & 1 & 1 & 1 & 1 & 1 & 1 & 0 & 1 \\
\hline Pseudoscopas & 0 & 0 & 0 & 0 & 0 & 0 & 0 & 0 & 0 & 0 & 0 & 0 & 0 & 0 & 0 & 0 & 0 & 0 & 0 & 0 & 0 & 0 & 0 & 0 & 0 \\
\hline Ponderacris & 0 & 0 & 0 & 0 & 0 & 0 & 0 & 0 & 0 & 1 & 1 & 0 & 0 & 0 & 0 & 0 & 0 & 0 & 0 & 0 & 0 & 0 & 0 & 0 & 0 \\
\hline Pediella & 0 & 0 & 0 & 0 & 0 & 0 & 0 & 0 & 0 & 0 & 0 & 0 & 0 & 0 & 0 & 0 & 0 & 0 & 0 & 0 & 0 & 0 & 0 & 0 & 0 \\
\hline Orotettix & 0 & 0 & 0 & 0 & 0 & 0 & 0 & 0 & 0 & 0 & 0 & 0 & 0 & 0 & 0 & 0 & 0 & 0 & 0 & 0 & 0 & 0 & 0 & 0 & 0 \\
\hline Neopedies & 0 & 0 & 0 & 0 & 0 & 0 & 0 & 0 & 0 & 0 & 0 & 0 & 0 & 0 & 0 & 0 & 0 & 0 & 0 & 0 & 0 & 0 & 0 & 0 & 0 \\
\hline Leiotettix & 1 & 1 & 1 & 1 & 1 & 1 & 1 & 0 & 0 & 0 & 1 & 0 & 0 & 1 & 1 & 1 & 1 & 1 & 1 & 1 & 1 & 1 & 0 & 0 & 0 \\
\hline Keyopsis & 0 & 0 & 0 & 0 & 0 & 0 & 0 & 0 & 0 & 0 & 0 & 0 & 0 & 0 & 0 & 0 & 0 & 0 & 0 & 0 & 0 & 0 & 0 & 0 & 0 \\
\hline Huaylasacris & 0 & 0 & 0 & 0 & 0 & 0 & 0 & 0 & 0 & 0 & 0 & 0 & 0 & 0 & 0 & 0 & 0 & 0 & 0 & 0 & 0 & 0 & 0 & 0 & 0 \\
\hline Eurotettix & 1 & 1 & 1 & 1 & 0 & 1 & 1 & 0 & 0 & 0 & 0 & 0 & 0 & 1 & 1 & 1 & 1 & 1 & 1 & 1 & 1 & 1 & 0 & 0 & 0 \\
\hline Digamacris & 0 & 0 & 0 & 0 & 0 & 1 & 1 & 0 & 0 & 0 & 0 & 0 & 0 & 0 & 0 & 0 & 0 & 0 & 0 & 0 & 0 & 1 & 1 & 0 & 0 \\
\hline Dichroplus & 0 & 0 & 0 & 0 & 0 & 0 & 0 & 0 & 0 & 0 & 0 & 0 & 0 & 0 & 0 & 0 & 0 & 0 & 0 & 0 & 0 & 0 & 0 & 0 & 0 \\
\hline Dichromatos & 0 & 0 & 0 & 0 & 0 & 0 & 0 & 0 & 0 & 0 & 0 & 0 & 0 & 0 & 0 & 0 & 0 & 0 & 0 & 0 & 0 & 0 & 0 & 0 & 0 \\
\hline Chlorus & 1 & 1 & 1 & 0 & 0 & 0 & 0 & 0 & 0 & 1 & 1 & 1 & 1 & 1 & 1 & 0 & 1 & 1 & 1 & 0 & 0 & 0 & 0 & 0 & 0 \\
\hline Chibchacris & 0 & 0 & 0 & 0 & 0 & 0 & 0 & 0 & 0 & 0 & 0 & 0 & 0 & 0 & 0 & 0 & 0 & 0 & 0 & 0 & 0 & 0 & 0 & 0 & 0 \\
\hline Boliviacris & 0 & 0 & 0 & 0 & 0 & 0 & 0 & 0 & 1 & 1 & 1 & 1 & 1 & 1 & 0 & 0 & 0 & 0 & 0 & 0 & 0 & 0 & 0 & 1 & 1 \\
\hline Bogotacris & 0 & 0 & 0 & 0 & 0 & 0 & 0 & 0 & 0 & 0 & 0 & 0 & 0 & 0 & 0 & 0 & 0 & 0 & 0 & 0 & 0 & 0 & 0 & 0 & 0 \\
\hline Baeacris & 1 & 1 & 1 & 0 & 1 & 1 & 1 & 1 & 0 & 1 & 1 & 0 & 1 & 1 & 0 & 0 & 1 & 1 & 1 & 1 & 1 & 1 & 1 & 0 & 1 \\
\hline Sumatoria & 5 & 5 & 5 & 4 & 4 & 6 & 6 & 1 & 1 & 5 & 7 & 3 & 3 & 6 & 5 & 4 & 6 & 6 & 5 & 5 & 5 & 6 & 3 & 1 & 4 \\
\hline
\end{tabular}

\begin{tabular}{|c|c|c|c|c|c|c|c|c|c|c|c|c|c|c|c|c|c|c|c|c|c|c|c|c|c|}
\hline & $-64:-21$ & $-62:-21$ & $-60:-21$ & $-58:-21$ & $-56:-21$ & $-54:-21$ & $-52:-21$ & $-50:-21$ & $-48:-21$ & $-46:-21$ & $-44:-21$ & $1-42:-21$ & $-40:-21$ & $-68:-23$ & $-66:-23$ & $-64:-23$ & $-62:-23$ & $-60:-23-$ & $-58:-23-$ & $-56:-23$ & $-54:-23$ & $-52:-23$ & $-50:-23$ & $-48:-23$ & $-46:-23$ \\
\hline Atrachelacris & 1 & 0 & 0 & 1 & 1 & 1 & 1 & 1 & 1 & 1 & 1 & 1 & 0 & 0 & 1 & 1 & 0 & 1 & 1 & 1 & 1 & 1 & 1 & 1 & 1 \\
\hline Timotes & 0 & 0 & 0 & 0 & 0 & 0 & 0 & 0 & 0 & 0 & 0 & 0 & 0 & 0 & 0 & 0 & 0 & 0 & 0 & 0 & 0 & 0 & 0 & 0 & 0 \\
\hline Scotussa & 0 & 0 & 0 & 1 & 1 & 1 & 0 & 0 & 0 & 0 & 0 & 0 & 0 & 0 & 0 & 0 & 0 & 1 & 1 & 1 & 1 & 1 & 1 & 0 & 1 \\
\hline Ronderosia & 1 & 0 & 1 & 1 & 1 & 1 & 1 & 1 & 1 & 1 & 1 & 1 & 1 & 0 & 1 & 1 & 1 & 1 & 1 & 1 & 1 & 1 & 1 & 1 & 1 \\
\hline Pseudoscopas & 0 & 0 & 0 & 0 & 0 & 0 & 0 & 0 & 0 & 0 & 0 & 0 & 0 & 0 & 0 & 0 & 0 & 0 & 0 & 1 & 1 & 1 & 1 & 0 & 0 \\
\hline Ponderacris & 0 & 0 & 0 & 0 & 0 & 0 & 0 & 0 & 0 & 0 & 0 & 0 & 0 & 0 & 0 & 0 & 0 & 0 & 0 & 0 & 0 & 0 & 0 & 0 & 0 \\
\hline Pediella & 0 & 0 & 0 & 0 & 0 & 0 & 0 & 0 & 0 & 0 & 0 & 0 & 0 & 0 & 0 & 0 & 0 & 0 & 0 & 0 & 0 & 0 & 0 & 0 & 0 \\
\hline Orotettix & 0 & 0 & 0 & 0 & 0 & 0 & 0 & 0 & 0 & 0 & 0 & 0 & 0 & 0 & 0 & 0 & 0 & 0 & 0 & 0 & 0 & 0 & 0 & 0 & 0 \\
\hline Neopedies & 0 & 0 & 0 & 1 & 1 & 0 & 0 & 0 & 0 & 0 & 0 & 0 & 0 & 0 & 0 & 0 & 0 & 1 & 1 & 1 & 1 & 1 & 0 & 0 & 0 \\
\hline Leiotettix & 0 & 0 & 0 & 1 & 1 & 1 & 1 & 1 & 1 & 1 & 1 & 1 & 0 & 0 & 0 & 1 & 0 & 1 & 1 & 1 & 1 & 1 & 1 & 1 & 1 \\
\hline Keyopsis & 0 & 0 & 0 & 0 & 0 & 0 & 0 & 0 & 0 & 0 & 0 & 0 & 0 & 0 & 0 & 0 & 0 & 0 & 0 & 0 & 0 & 0 & 0 & 0 & 0 \\
\hline Huaylasacris & 0 & 0 & 0 & 0 & 0 & 0 & 0 & 0 & 0 & 0 & 0 & 0 & 0 & 0 & 0 & 0 & 0 & 0 & 0 & 0 & 0 & 0 & 0 & 0 & 0 \\
\hline Eurotettix & 0 & 0 & 0 & 1 & 1 & 1 & 1 & 1 & 1 & 1 & 1 & 0 & 0 & 0 & 0 & 0 & 0 & 0 & 1 & 1 & 1 & 1 & 1 & 1 & 1 \\
\hline Digamacris & 0 & 0 & 0 & 0 & 0 & 0 & 0 & 0 & 1 & 1 & 1 & 1 & 1 & 0 & 0 & 0 & 0 & 0 & 0 & 0 & 0 & 0 & 0 & 1 & 1 \\
\hline Dichroplus & 0 & 0 & 0 & 0 & 0 & 0 & 0 & 0 & 0 & 0 & 0 & 0 & 0 & 0 & 1 & 1 & 1 & 1 & 1 & 1 & 1 & 1 & 0 & 0 & 0 \\
\hline Dichromatos & 0 & 0 & 0 & 0 & 0 & 0 & 0 & 0 & 0 & 0 & 0 & 1 & 0 & 0 & 0 & 0 & 0 & 0 & 0 & 1 & 1 & 1 & 1 & 1 & 1 \\
\hline Chlorus & 1 & 1 & 1 & 1 & 1 & 1 & 1 & 1 & 1 & 0 & 0 & 0 & 0 & 0 & 0 & 1 & 1 & 1 & 1 & 1 & 1 & 1 & 1 & 1 & 0 \\
\hline Chibchacris & 0 & 0 & 0 & 0 & 0 & 0 & 0 & 0 & 0 & 0 & 0 & 0 & 0 & 0 & 0 & 0 & 0 & 0 & 0 & 0 & 0 & 0 & 0 & 0 & 0 \\
\hline Boliviacris & 1 & 1 & 1 & 1 & 0 & 0 & 0 & 0 & 0 & 0 & 0 & 0 & 0 & 1 & 1 & 1 & 1 & 1 & 1 & 0 & 0 & 0 & 0 & 0 & 0 \\
\hline Bogotacris & 0 & 0 & 0 & 0 & 0 & 0 & 0 & 0 & 0 & 0 & 0 & 0 & 0 & 0 & 0 & 0 & 0 & 0 & 0 & 0 & 0 & 0 & 0 & 0 & 0 \\
\hline Baeacris & 1 & 1 & 1 & 1 & 1 & 1 & 1 & 1 & 1 & 1 & 1 & 1 & 1 & 0 & 1 & 1 & 1 & 1 & 1 & 1 & 1 & 1 & 1 & 1 & 1 \\
\hline Sumatoria & 5 & 3 & 4 & 9 & 8 & 7 & 6 & 6 & 7 & 6 & 6 & 6 & 3 & 1 & 5 & 7 & 5 & 9 & 10 & 11 & 11 & 11 & 9 & 8 & 8 \\
\hline
\end{tabular}


Tabla Suplementaria 6 Continuación:

\begin{tabular}{|c|c|c|c|c|c|c|c|c|c|c|c|c|c|c|c|c|c|c|c|c|c|c|c|c|c|}
\hline & $-44:-23$ & $-42:-23$ & $-40:-23$ & $-70:-25$ & $-68:-25$ & $-66:-25$ & $-64:-25$ & $-62:-25$ & $5-60:-25$ & $5-58:-25$ & $-56:-25$ & $-54:-25$ & $5-52:-25$ & $-50:-25$ & $-48:-25$ & $5-68:-27$ & -66:-27 & -64:-27 & $-62:-27$ & $-60:-27$ & 7 -58:-27 & - $-56:-27$ & $-54:-27$ & $-52:-27$ & $-50:-27$ \\
\hline Atrachelacris & 0 & 0 & 0 & 0 & 0 & 1 & 1 & 1 & 1 & 1 & 1 & 1 & 1 & 0 & 1 & 1 & 1 & 1 & 1 & 1 & 1 & 1 & 1 & 1 & 0 \\
\hline Timotes & 0 & 0 & 0 & 0 & 0 & 0 & 0 & 0 & 0 & 0 & 0 & 0 & 0 & 0 & 0 & 0 & 0 & 0 & 0 & 0 & 0 & 0 & 0 & 0 & 0 \\
\hline Scotussa & 1 & 1 & 0 & 0 & 0 & 0 & 1 & 1 & 1 & 1 & 1 & 1 & 1 & 1 & 1 & 0 & 1 & 1 & 1 & 1 & 1 & 1 & 1 & 1 & 1 \\
\hline Ronderosia & 1 & 1 & 0 & 0 & 0 & 1 & 1 & 1 & 1 & 1 & 1 & 1 & 1 & 1 & 1 & 1 & 1 & 1 & 1 & 1 & 1 & 1 & 1 & 1 & 1 \\
\hline Pseudoscopas & 0 & 0 & 0 & 0 & 0 & 0 & 0 & 0 & 0 & 1 & 1 & 1 & 1 & 1 & 1 & 0 & 0 & 0 & 0 & 0 & 1 & 1 & 1 & 1 & 1 \\
\hline Ponderacris & 0 & 0 & 0 & 0 & 0 & 0 & 0 & 0 & 0 & 0 & 0 & 0 & 0 & 0 & 0 & 0 & 0 & 0 & 0 & 0 & 0 & 0 & 0 & 0 & 0 \\
\hline Pediella & 0 & 0 & 0 & 0 & 0 & 0 & 0 & 0 & 0 & 0 & 0 & 0 & 0 & 0 & 0 & 0 & 0 & 0 & 0 & 0 & 0 & 0 & 0 & 0 & 0 \\
\hline Orotettix & 0 & 0 & 0 & 0 & 0 & 0 & 0 & 0 & 0 & 0 & 0 & 0 & 0 & 0 & 0 & 0 & 0 & 0 & 0 & 0 & 0 & 0 & 0 & 0 & 0 \\
\hline Neopedies & 0 & 0 & 0 & 0 & 0 & 0 & 1 & 1 & 1 & 1 & 1 & 1 & 1 & 0 & 0 & 1 & 1 & 1 & 1 & 1 & 1 & 1 & 1 & 1 & 0 \\
\hline Leiotettix & 1 & 1 & 0 & 0 & 0 & 0 & 0 & 1 & 1 & 1 & 1 & 1 & 1 & 1 & 1 & 0 & 0 & 0 & 1 & 1 & 1 & 1 & 1 & 1 & 1 \\
\hline Keyopsis & 0 & 0 & 0 & 0 & 0 & 0 & 0 & 0 & 0 & 0 & 0 & 0 & 0 & 0 & 0 & 0 & 0 & 0 & 0 & 0 & 0 & 0 & 0 & 0 & 0 \\
\hline Huaylasacris & 0 & 0 & 0 & 0 & 0 & 0 & 0 & 0 & 0 & 0 & 0 & 0 & 0 & 0 & 0 & 0 & 0 & 0 & 0 & 0 & 0 & 0 & 0 & 0 & 0 \\
\hline Eurotettix & 0 & 0 & 0 & 0 & 0 & 0 & 0 & 0 & 0 & 1 & 1 & 0 & 0 & 0 & 0 & 0 & 0 & 0 & 0 & 0 & 1 & 1 & 0 & 0 & 0 \\
\hline Digamacris & 1 & 1 & 0 & 0 & 0 & 0 & 0 & 0 & 0 & 0 & 0 & 0 & 0 & 0 & 1 & 0 & 0 & 0 & 0 & 0 & 0 & 0 & 0 & 0 & 0 \\
\hline Dichroplus & 0 & 0 & 0 & 1 & 0 & 1 & 1 & 1 & 1 & 1 & 1 & 1 & 1 & 0 & 0 & 1 & 1 & 1 & 1 & 1 & 1 & 1 & 1 & 1 & 0 \\
\hline Dichromatos & 1 & 1 & 0 & 0 & 0 & 0 & 0 & 0 & 0 & 1 & 1 & 1 & 1 & 1 & 1 & 0 & 0 & 0 & 0 & 0 & 1 & 1 & 1 & 1 & 1 \\
\hline Chlorus & 0 & 0 & 0 & 0 & 0 & 0 & 0 & 1 & 1 & 1 & 1 & 1 & 1 & 1 & 1 & 0 & 0 & 0 & 0 & 1 & 1 & 1 & 1 & 1 & 0 \\
\hline Chibchacris & 0 & 0 & 0 & 0 & 0 & 0 & 0 & 0 & 0 & 0 & 0 & 0 & 0 & 0 & 0 & 0 & 0 & 0 & 0 & 0 & 0 & 0 & 0 & 0 & 0 \\
\hline Boliviacris & 0 & 0 & 0 & 0 & 1 & 1 & 1 & 1 & 1 & 0 & 0 & 0 & 0 & 0 & 0 & 1 & 1 & 1 & 1 & 0 & 0 & 0 & 0 & 0 & 0 \\
\hline Bogotacris & 0 & 0 & 0 & 0 & 0 & 0 & 0 & 0 & 0 & 0 & 0 & 0 & 0 & 0 & 0 & 0 & 0 & 0 & 0 & 0 & 0 & 0 & 0 & 0 & 0 \\
\hline Baeacris & 1 & 1 & 1 & 0 & 0 & 1 & 1 & 1 & 1 & 1 & 1 & 1 & 1 & 1 & 1 & 1 & 1 & 1 & 1 & 1 & 1 & 1 & 1 & 1 & 1 \\
\hline Sumatoria & 6 & 6 & 1 & 1 & 1 & 5 & 7 & 9 & 9 & 11 & 11 & 10 & 10 & 7 & 9 & 6 & 7 & 7 & 8 & 8 & 11 & 11 & 10 & 10 & 6 \\
\hline
\end{tabular}

\begin{tabular}{|c|c|c|c|c|c|c|c|c|c|c|c|c|c|c|c|c|c|c|c|c|c|c|c|c|c|}
\hline & $-48:-27$ & $-68:-29$ & $-66:-29$ & $-64:-29$ & $-62:-29$ & $-60:-29$ & $-58:-29$ & $-56:-29$ & $-54:-29$ & $-52:-29$ & $-50:-29$ & $-48:-29$ & $-70:-31$ & $-68:-31$ & $-66:-31$ & $-64:-31$ & $-62:-31$ & $-60:-31$ & $-58:-31$ & $-56:-31$ & $-54:-31$ & $-52:-31$ & $-50:-31$ & $-70:-33$ & $-68:-33$ \\
\hline Atrachelacris & 0 & 1 & 1 & 1 & 1 & 1 & 1 & 1 & 1 & 1 & 1 & 0 & 1 & 1 & 1 & 1 & 1 & 1 & 1 & 1 & 1 & 1 & 1 & 1 & 1 \\
\hline Timotes & 0 & 0 & 0 & 0 & 0 & 0 & 0 & 0 & 0 & 0 & 0 & 0 & 0 & 0 & 0 & 0 & 0 & 0 & 0 & 0 & 0 & 0 & 0 & 0 & 0 \\
\hline Scotussa & 1 & 1 & 1 & 1 & 1 & 1 & 1 & 1 & 1 & 1 & 1 & 1 & 0 & 0 & 1 & 1 & 1 & 1 & 1 & 1 & 1 & 1 & 1 & 1 & 1 \\
\hline Ronderosia & 1 & 1 & 1 & 1 & 1 & 1 & 1 & 1 & 1 & 1 & 1 & 1 & 1 & 1 & 1 & 1 & 1 & 1 & 1 & 1 & 1 & 1 & 1 & 1 & 1 \\
\hline Pseudoscopas & 1 & 0 & 0 & 0 & 0 & 0 & 1 & 1 & 1 & 1 & 1 & 1 & 0 & 0 & 0 & 0 & 0 & 0 & 1 & 1 & 1 & 1 & 1 & 0 & 0 \\
\hline Ponderacris & 0 & 0 & 0 & 0 & 0 & 0 & 0 & 0 & 0 & 0 & 0 & 0 & 0 & 0 & 0 & 0 & 0 & 0 & 0 & 0 & 0 & 0 & 0 & 0 & 0 \\
\hline Pediella & 0 & 0 & 0 & 0 & 0 & 0 & 0 & 0 & 0 & 0 & 0 & 0 & 0 & 0 & 0 & 0 & 0 & 0 & 0 & 0 & 0 & 0 & 0 & 0 & 0 \\
\hline Orotettix & 0 & 0 & 0 & 0 & 0 & 0 & 0 & 0 & 0 & 0 & 0 & 0 & 0 & 0 & 0 & 0 & 0 & 0 & 0 & 0 & 0 & 0 & 0 & 0 & 0 \\
\hline Neopedies & 1 & 1 & 1 & 1 & 1 & 1 & 1 & 1 & 1 & 1 & 1 & 1 & 0 & 1 & 1 & 1 & 1 & 1 & 1 & 1 & 1 & 1 & 1 & 1 & 1 \\
\hline Leiotettix & 1 & 0 & 0 & 0 & 1 & 1 & 1 & 1 & 1 & 1 & 1 & 1 & 0 & 0 & 0 & 0 & 1 & 1 & 1 & 1 & 1 & 1 & 1 & 0 & 0 \\
\hline Keyopsis & 0 & 0 & 0 & 0 & 0 & 0 & 0 & 0 & 0 & 0 & 0 & 0 & 0 & 0 & 0 & 0 & 0 & 0 & 0 & 0 & 0 & 0 & 0 & 0 & 0 \\
\hline Huaylasacris & 0 & 0 & 0 & 0 & 0 & 0 & 0 & 0 & 0 & 0 & 0 & 0 & 0 & 0 & 0 & 0 & 0 & 0 & 0 & 0 & 0 & 0 & 0 & 0 & 0 \\
\hline Eurotettix & 0 & 0 & 0 & 0 & 0 & 0 & 0 & 0 & 0 & 0 & 0 & 0 & 0 & 0 & 0 & 0 & 0 & 0 & 0 & 0 & 0 & 0 & 0 & 0 & 0 \\
\hline Digamacris & 0 & 0 & 0 & 0 & 0 & 0 & 0 & 0 & 0 & 0 & 0 & 0 & 0 & 0 & 0 & 0 & 0 & 0 & 0 & 0 & 0 & 0 & 0 & 0 & 0 \\
\hline Dichroplus & 1 & 1 & 1 & 1 & 1 & 1 & 1 & 1 & 1 & 1 & 1 & 1 & 1 & 1 & 1 & 1 & 1 & 1 & 1 & 1 & 1 & 1 & 1 & 1 & 1 \\
\hline Dichromatos & 1 & 0 & 0 & 0 & 0 & 0 & 1 & 1 & 1 & 1 & 1 & 1 & 0 & 0 & 0 & 0 & 0 & 0 & 1 & 1 & 1 & 1 & 1 & 0 & 0 \\
\hline Chlorus & 0 & 0 & 0 & 0 & 0 & 0 & 1 & 1 & 1 & 1 & 0 & 0 & 0 & 0 & 0 & 0 & 0 & 0 & 0 & 0 & 0 & 0 & 0 & 0 & 0 \\
\hline Chibchacris & 0 & 0 & 0 & 0 & 0 & 0 & 0 & 0 & 0 & 0 & 0 & 0 & 0 & 0 & 0 & 0 & 0 & 0 & 0 & 0 & 0 & 0 & 0 & 0 & 0 \\
\hline Boliviacris & 0 & 1 & 1 & 1 & 1 & 0 & 0 & 0 & 0 & 0 & 0 & 0 & 0 & 1 & 1 & 1 & 1 & 0 & 0 & 0 & 0 & 0 & 0 & 0 & 1 \\
\hline Bogotacris & 0 & 0 & 0 & 0 & 0 & 0 & 0 & 0 & 0 & 0 & 0 & 0 & 0 & 0 & 0 & 0 & 0 & 0 & 0 & 0 & 0 & 0 & 0 & 0 & 0 \\
\hline Baeacris & 1 & 1 & 1 & 1 & 1 & 1 & 1 & 1 & 1 & 1 & 1 & 1 & 1 & 1 & 1 & 1 & 1 & 1 & 1 & 1 & 1 & 1 & 1 & 1 & 1 \\
\hline Sumatoria & 8 & 7 & 7 & 7 & 8 & 7 & 10 & 10 & 10 & 10 & 9 & 8 & 4 & 6 & 7 & 7 & 8 & 7 & 9 & 9 & 9 & 9 & 9 & 6 & 7 \\
\hline
\end{tabular}

\begin{tabular}{|c|c|c|c|c|c|c|c|c|c|c|c|c|c|c|c|c|c|c|c|c|c|c|c|c|c|}
\hline & $-66:-33$ & $-64:-33$ & $-62:-33$ & $-60:-33$ & $-58:-33$ & $-56:-33$ & $-54:-33-$ & $-52:-33$ & $-72:-35$ & $-70:-35$ & $-68:-35$ & $-66:-35$ & $-64:-35$ & $-62:-35$ & $-60:-35$ & $-58:-35$ & $-56:-35-$ & $-54:-35-$ & $-70:-37-$ & $-68:-37$ & $-66:-37$ & $-64:-37$ & $-62:-37$ & $-60:-37$ & $-58:-37$ \\
\hline Atrachelacris & 1 & 1 & 1 & 1 & 1 & 1 & 1 & 1 & 0 & 1 & 1 & 1 & 1 & 1 & 1 & 1 & 1 & 1 & 1 & 1 & 1 & 1 & 1 & 1 & 1 \\
\hline Timotes & 0 & 0 & 0 & 0 & 0 & 0 & 0 & 0 & 0 & 0 & 0 & 0 & 0 & 0 & 0 & 0 & 0 & 0 & 0 & 0 & 0 & 0 & 0 & 0 & 0 \\
\hline Scotussa & 1 & 1 & 1 & 1 & 1 & 1 & 1 & 1 & 0 & 1 & 1 & 1 & 1 & 1 & 1 & 1 & 1 & 1 & 1 & 1 & 1 & 1 & 1 & 1 & 1 \\
\hline Ronderosia & 1 & 1 & 1 & 1 & 1 & 1 & 1 & 1 & 0 & 1 & 1 & 1 & 1 & 1 & 1 & 1 & 1 & 1 & 1 & 1 & 1 & 1 & 1 & 1 & 1 \\
\hline Pseudoscopas & 0 & 0 & 0 & 0 & 1 & 1 & 1 & 1 & 0 & 0 & 0 & 0 & 0 & 0 & 0 & 1 & 1 & 0 & 0 & 0 & 0 & 0 & 0 & 0 & 0 \\
\hline Ponderacris & 0 & 0 & 0 & 0 & 0 & 0 & 0 & 0 & 0 & 0 & 0 & 0 & 0 & 0 & 0 & 0 & 0 & 0 & 0 & 0 & 0 & 0 & 0 & 0 & 0 \\
\hline Pediella & 0 & 0 & 0 & 0 & 0 & 0 & 0 & 0 & 0 & 0 & 0 & 0 & 0 & 0 & 0 & 0 & 0 & 0 & 0 & 0 & 0 & 0 & 0 & 0 & 0 \\
\hline Orotettix & 0 & 0 & 0 & 0 & 0 & 0 & 0 & 0 & 0 & 0 & 0 & 0 & 0 & 0 & 0 & 0 & 0 & 0 & 0 & 0 & 0 & 0 & 0 & 0 & 0 \\
\hline Neopedies & 1 & 1 & 1 & 1 & 1 & 1 & 1 & 1 & 0 & 1 & 1 & 1 & 1 & 1 & 1 & 1 & 1 & 1 & 1 & 1 & 1 & 1 & 1 & 1 & 1 \\
\hline Leiotettix & 0 & 0 & 0 & 1 & 1 & 1 & 1 & 1 & 0 & 0 & 0 & 0 & 0 & 0 & 1 & 1 & 1 & 1 & 0 & 0 & 0 & 0 & 0 & 0 & 0 \\
\hline Keyopsis & 0 & 0 & 0 & 0 & 0 & 0 & 0 & 0 & 0 & 0 & 0 & 0 & 0 & 0 & 0 & 0 & 0 & 0 & 0 & 0 & 0 & 0 & 0 & 0 & 0 \\
\hline Huaylasacris & 0 & 0 & 0 & 0 & 0 & 0 & 0 & 0 & 0 & 0 & 0 & 0 & 0 & 0 & 0 & 0 & 0 & 0 & 0 & 0 & 0 & 0 & 0 & 0 & 0 \\
\hline Eurotettix & 0 & 0 & 0 & 0 & 0 & 0 & 0 & 0 & 0 & 0 & 0 & 0 & 0 & 0 & 0 & 0 & 0 & 0 & 0 & 0 & 0 & 0 & 0 & 0 & 0 \\
\hline Digamacris & 0 & 0 & 0 & 0 & 0 & 0 & 0 & 0 & 0 & 0 & 0 & 0 & 0 & 0 & 0 & 0 & 0 & 0 & 0 & 0 & 0 & 0 & 0 & 0 & 0 \\
\hline Dichroplus & 1 & 1 & 1 & 1 & 1 & 1 & 1 & 1 & 1 & 1 & 1 & 1 & 1 & 1 & 1 & 1 & 1 & 1 & 1 & 1 & 1 & 1 & 1 & 1 & 1 \\
\hline Dichromatos & 0 & 0 & 0 & 0 & 0 & 0 & 1 & 1 & 0 & 0 & 0 & 0 & 0 & 0 & 0 & 0 & 0 & 0 & 0 & 0 & 0 & 0 & 0 & 0 & 0 \\
\hline Chlorus & 0 & 0 & 0 & 0 & 0 & 0 & 0 & 0 & 0 & 0 & 0 & 0 & 0 & 0 & 0 & 0 & 0 & 0 & 0 & 0 & 0 & 0 & 0 & 0 & 0 \\
\hline Chibchacris & 0 & 0 & 0 & 0 & 0 & 0 & 0 & 0 & 0 & 0 & 0 & 0 & 0 & 0 & 0 & 0 & 0 & 0 & 0 & 0 & 0 & 0 & 0 & 0 & 0 \\
\hline Boliviacris & 1 & 1 & 0 & 0 & 0 & 0 & 0 & 0 & 0 & 0 & 0 & 1 & 0 & 0 & 0 & 0 & 0 & 0 & 0 & 0 & 0 & 0 & 0 & 0 & 0 \\
\hline Bogotacris & 0 & 0 & 0 & 0 & 0 & 0 & 0 & 0 & 0 & 0 & 0 & 0 & 0 & 0 & 0 & 0 & 0 & 0 & 0 & 0 & 0 & 0 & 0 & 0 & 0 \\
\hline Baeacris & 1 & 1 & 1 & 1 & 1 & 1 & 1 & 1 & 0 & 1 & 1 & 1 & 1 & 1 & 1 & 1 & 1 & 1 & 1 & 1 & 1 & 1 & 1 & 1 & 1 \\
\hline Sumatoria & 7 & 7 & 6 & 7 & 8 & 8 & 9 & 9 & 1 & 6 & 6 & 7 & 6 & 6 & 7 & 8 & 8 & 7 & 6 & 6 & 6 & 6 & 6 & 6 & 6 \\
\hline
\end{tabular}


Tabla Suplementaria 6 Continuación:

\begin{tabular}{|c|c|c|c|c|c|c|c|c|c|c|c|c|c|c|c|c|c|c|c|c|c|c|c|c|}
\hline & $-56:-37$ & $-74:-39$ & $-72:-39$ & $-70:-39$ & $-68:-39$ & $-66:-39$ & $-64:-39$ & $-62:-39$ & $-60:-39$ & $-58:-39$ & $-72:-41$ & $-70:-41$ & 1 -68:-41 & - $-66:-41$ & $1-64:-41$ & $1-62:-41$ & $1-72:-43$ & $-70:-43$ & $-68:-43$ & $-66:-43$ & $-64:-43$ & $-68:-45$ & $-66:-45$ & 5 Sumatoria \\
\hline Atrachelacris & 1 & 0 & 0 & 1 & 1 & 1 & 1 & 1 & 1 & 1 & 0 & 1 & 1 & 1 & 1 & 1 & 0 & 0 & 0 & 1 & 1 & 0 & 0 & 24 \\
\hline Timotes & 0 & 0 & 0 & 0 & 0 & 0 & 0 & 0 & 0 & 0 & 0 & 0 & 0 & 0 & 0 & 0 & 0 & 0 & 0 & 0 & 0 & 0 & 0 & 0 \\
\hline Scotussa & 1 & 0 & 0 & 1 & 1 & 1 & 1 & 1 & 1 & 1 & 0 & 1 & 1 & 1 & 1 & 1 & 0 & 0 & 0 & 1 & 0 & 0 & 1 & 24 \\
\hline Ronderosia & 1 & 0 & 0 & 1 & 1 & 1 & 1 & 1 & 1 & 1 & 0 & 1 & 1 & 1 & 1 & 1 & 0 & 0 & 0 & 1 & 1 & 0 & 0 & 24 \\
\hline Pseudoscopas & 0 & 0 & 0 & 0 & 0 & 0 & 0 & 0 & 0 & 0 & 0 & 0 & 0 & 0 & 0 & 0 & 0 & 0 & 0 & 0 & 0 & 0 & 0 & 6 \\
\hline Ponderacris & 0 & 0 & 0 & 0 & 0 & 0 & 0 & 0 & 0 & 0 & 0 & 0 & 0 & 0 & 0 & 0 & 0 & 0 & 0 & 0 & 0 & 0 & 0 & 0 \\
\hline Pediella & 0 & 0 & 0 & 0 & 0 & 0 & 0 & 0 & 0 & 0 & 0 & 0 & 0 & 0 & 0 & 0 & 0 & 0 & 0 & 0 & 0 & 0 & 0 & 0 \\
\hline Orotettix & 0 & 0 & 0 & 0 & 0 & 0 & 0 & 0 & 0 & 0 & 0 & 0 & 0 & 0 & 0 & 0 & 0 & 0 & 0 & 0 & 0 & 0 & 0 & 0 \\
\hline Neopedies & 1 & 0 & 0 & 1 & 1 & 1 & 1 & 1 & 1 & 1 & 0 & 0 & 1 & 1 & 1 & 1 & 0 & 0 & 0 & 1 & 1 & 0 & 0 & 24 \\
\hline Leiotettix & 1 & 0 & 0 & 0 & 0 & 0 & 0 & 0 & 0 & 0 & 0 & 0 & 0 & 0 & 0 & 0 & 0 & 0 & 0 & 0 & 0 & 0 & 0 & 9 \\
\hline Keyopsis & 0 & 0 & 0 & 0 & 0 & 0 & 0 & 0 & 0 & 0 & 0 & 0 & 0 & 0 & 0 & 0 & 0 & 0 & 0 & 0 & 0 & 0 & 0 & 0 \\
\hline Huaylasacris & 0 & 0 & 0 & 0 & 0 & 0 & 0 & 0 & 0 & 0 & 0 & 0 & 0 & 0 & 0 & 0 & 0 & 0 & 0 & 0 & 0 & 0 & 0 & 0 \\
\hline Eurotettix & 0 & 0 & 0 & 0 & 0 & 0 & 0 & 0 & 0 & 0 & 0 & 0 & 0 & 0 & 0 & 0 & 0 & 0 & 0 & 0 & 0 & 0 & 0 & 0 \\
\hline Digamacris & 0 & 0 & 0 & 0 & 0 & 0 & 0 & 0 & 0 & 0 & 0 & 0 & 0 & 0 & 0 & 0 & 0 & 0 & 0 & 0 & 0 & 0 & 1 & 0 \\
\hline Dichroplus & 1 & 1 & 1 & 1 & 1 & 1 & 1 & 1 & 1 & 1 & 1 & 1 & 1 & 1 & 1 & 1 & 1 & 1 & 1 & 1 & 1 & 1 & 0 & 25 \\
\hline Dichromatos & 0 & 0 & 0 & 0 & 0 & 0 & 0 & 0 & 0 & 0 & 0 & 0 & 0 & 0 & 0 & 0 & 0 & 0 & 0 & 0 & 0 & 0 & 0 & 2 \\
\hline Chlorus & 0 & 0 & 0 & 0 & 0 & 0 & 0 & 0 & 0 & 0 & 0 & 0 & 0 & 0 & 0 & 0 & 0 & 0 & 0 & 0 & 0 & 0 & 0 & 0 \\
\hline Chibchacris & 0 & 0 & 0 & 0 & 0 & 0 & 0 & 0 & 0 & 0 & 0 & 0 & 0 & 0 & 0 & 0 & 0 & 0 & 0 & 0 & 0 & 0 & 0 & 0 \\
\hline Boliviacris & 0 & 0 & 0 & 0 & 0 & 0 & 0 & 0 & 0 & 0 & 0 & 0 & 0 & 0 & 0 & 0 & 0 & 0 & 0 & 0 & 0 & 0 & 0 & 3 \\
\hline Bogotacris & 0 & 0 & 0 & 0 & 0 & 0 & 0 & 0 & 0 & 0 & 0 & 0 & 0 & 0 & 0 & 0 & 0 & 0 & 0 & 0 & 0 & 0 & 1 & 0 \\
\hline Baeacris & 1 & 0 & 0 & 1 & 1 & 1 & 1 & 1 & 1 & 1 & 0 & 1 & 1 & 1 & 1 & 1 & 0 & 0 & 1 & 1 & 1 & 1 & 3 & 24 \\
\hline Sumatoria & 7 & 1 & 1 & 6 & 6 & 6 & 6 & 6 & 6 & 6 & 1 & 5 & 6 & 6 & 6 & 6 & 1 & 1 & 2 & 6 & 5 & 2 & 6 & \\
\hline
\end{tabular}

